\title{
Scientific Knowledge Transfer within the Limits of Research, Integration, and Utilization: Cases of Nature Conservation in \\ Vietnam, Germany, Indonesia, Japan, and Sweden
}

\author{
Dissertation \\ Submitted in partial fulfillment of requirements for the degree of $\mathrm{Ph} . \mathrm{D}$. \\ Faculty of Forest Sciences and Forest Ecology \\ Georg-August-Universität Göttingen
}

Submitted by

Do Thi Huong

Born in Dien Bien, Vietnam, February 19 ${ }^{\text {th }}, 1984$

Göttingen, 2018 
$1^{\text {st }}$ reviewer: Prof. Dr. Max Krott

$2^{\text {nd }}$ reviewer: Prof. Dr. Michael Böcher

Date of oral exam (Disputation): 22.11.2018 
Chair Group of Forest and Nature Conservation Policy

Faculty of Forest Sciences and Forest Ecology

Georg-August-Universität Göttingen

Germany

This doctoral research is conducted through the working group "Research Policy and Knowledge Transfer" at the Chair Group of Forest and Nature Conservation Policy, Georg-August-Universität Göttingen, Germany.

Supervision:

1. Prof. Dr. Max Krott

2. Prof. Dr. Michael Böcher

The research presented in this dissertation was funded by the Vietnamese Government Fund (911 Scholarship) and the German Academic Exchange Service (DAAD). 
Dedicated to my family and my country 


\section{Declaration of originality and certificate of authorship}

I, Do Thi Huong, hereby declare that I am the sole author of this dissertation entitled: "Scientific Knowledge Transfer within the Limits of Research, Integration, and Utilization: Cases of Nature Conservation in Vietnam, Germany, Indonesia, Japan, and Sweden". All reference and data used in this dissertation have been appropriately acknowledged.

I furthermore declare that this work has not been submitted elsewhere in any form as part of another dissertation procedure.

Göttingen, 9. 2018

\section{Do Thi Huong}


“Once we accept our limits, we go beyond them".

\section{Albert Einstein}

"Rừng là vàng nếu ta biết bảo vệ thì rừng rất quý" (in Vietnamese)

(Forests are gold, if we know to protect and develop them well, they will be very precious)

Ho Chi Minh 


\section{Acknowledgments}

During the past four years, many people and organizations in both Germany and Vietnam have contributed in different ways to my thesis. Without their assistance, advice, constructive criticism, collaborations and support, this thesis would not have been possible.

I would firstly like to express my since thanks to Prof. Max Krott for his outstanding guidance, great support, and enthusiastic encouragement from the start to the accomplishment of this thesis. He shows me the way of critical thinking and objective assessing in seeing different problems and gives me confidence and trust in doing research. I really appreciate his work and value his assistance beyond expression.

My special thank goes to my second supervisor Prof. Michael Böcher. His extensive knowledge and expertise on scientific knowledge transfer and RIU model were reflected by his critical comments in my papers and thesis. Without his helpful suggestions, patience, and invaluable advice, the articles contained in the thesis would not have been what it has now become.

Many thanks could be also given to Dr. Nataly Juerges for her prompt comments, critical suggestions, and great cooperation. I am particularly thankful to Prof. Andreas Schuldt who agreed to act as the co - referee and a member of the examination committee. I would like to thank Lukas for sharing his experience and thoughts in science and giving me his helpful suggestions. I also thank Christiane and Heike for supportive administration and Jens for his technical support.

I would also like to thank my colleagues of the working group - Scientific knowledge transfer and research policy: Janina (Germany), Kenji (Japan) and Budi (Indonesia). At the time I joined this research group, they were experienced already doing research in the group. They created an active and supportive working group. They shared with me a lot of their ideas and encouragement. I am also grateful to the other $\mathrm{PhD}$ students in the Chair Group of Forest and Nature Conservation Policy, George-August University of Göttingen such as Ameni (Tunisia), Saifur (Bangladesh), Sarah (Argentina), Alif (Indonesia), Agung (Indonesia), Bach (Vietnam), Pradip (Bangladesh), Max (Germany), Minette (Cameroon), Symphorien (Cameroon), Faisal (Bangladesh), Carolina (Brazil), Manjola (Albania), Yue (China). Thanks to them for sharing happy lunch breaks, walking and talking with me. We had a great time together in Göttingen.

I would like to sincerely thank the Vietnamese Government Fund (911 Scholarship) and the German Academic Exchange Service (DAAD) for providing me a four - year 
scholarship to undertake the doctoral study. I would also thank the Göttingen Graduate School of Social Sciences (GGG) for providing a small grant on my fieldwork and Universitätsbund Göttingen for offering me financial support to present my research at an international conference on Sustainable Development in Rome, Italy.

I would also like to sincerely thank my colleagues from College of Land Management and Rural Development and Silviculture Faculty, Vietnam National University of Forestry for their continuous encouragement and support during the time of my Ph.D study. I very much thank and acknowledge their support.

This thesis is developed from invaluable information, experiences and support of many individuals and organizations. I would like to express my gratitude to the experts, researchers, and officials involved in the study, particularly those from FFI Vietnam, LLINC project, Institute of Anthropology, Research Institute on Geology and Mineral Resources, Pu Luong Nature Reserve, Ngo Son Ngo Luong Nature Reserve, Cuc Phuong National Park, Institute of Ecology and Biological Resources, Forest Inventory and Planning Institute, National University of Hanoi, College of Land Management and Rural Development - Vietnam National University of Forestry, Center for Plant Conservation, CITES Vietnam, IUCN Vietnam, PanNature, Biodiversity Conservation Agency (MONRE), Department of Nature Conservation (MARD), Forest Protection Department (MARD), Vietnam Primate Conservation Program, for providing valuable data. I am particularly grateful to Mr. Nguyen Ba Ngai (MARD), Mr. Nguyen Ngoc Quang (FFI), Mr. Tran The Lien (MARD), Mr. Tran Tan Van (VIGMR), Mr. Tilo Nadler (CPNP), Mr. Dang Huy Huynh (IEBR), Mr. Le Xuan Canh (IEBR), Mr. Dang Tat The (IEBR), Mr. Vu Van Dung (FIPI), Mr. Nguyen Van Doan (CITES Vietnam), Mr. Nguyen Quang (UN-Habitat Programme), Mrs. Nguyen Thi Thu Thuy (VCF), Mr. Do Ngoc Duong (Pu Luong Nature Reserve), Mrs. Le Thi Lien (Pu Luong Nature Reserve) for their great support in my fieldwork. I owe a debt of gratitude to local people in PLNR and NSNLNR who gave their time to participate in interviews, provide much practical information and share their knowledge, experiences, and opinions with me.

I am particularly thankful to all Vietnamese students and their families in Göttingen and Dresden for sharing happy minutes as well as hard moments with me for the last four years. I appreciate their friendships.

Finally, words might not be sufficient to express my since thanks to my parents, my parents in law, my sister and my brother in law. They always believe in me and provide loving support for my advanced studies. Special thanks to them for taking care of my son when I and my husband was doing Ph.D. in Germany for our first two years. 
Without their support and encouragement, this thesis could not be completed. I owe special thanks to my husband and my little son, who always are by my side in the highs and lows of my research, as well as my life. My son became stronger and more independent when he accompanied me and my husband during our Ph.D. period. I know that by no means would I be able to express my gratitude to them. To all of them, I dedicate this thesis.

I thank you all!

Göttingen, 9. 2018 


\section{Summary}

There is a strong scholarly consensus that scientific expertise plays an important role in addressing complex and uncertain issues in environmental governance. It is expected that when scientific ideas are put into practice, they should significantly contribute to the improvement of environmental solutions and a better science should lead to a better policy. However, such a perspective is rare in practice. There have been many efforts to explain the transfer of scientific knowledge from various perspectives. In this dissertation, we use a novel theoretical model of scientific knowledge transfer (RIU model) to explore limits of scientific knowledge transfer in cases of nature conservation in Vietnam, Germany, Indonesia, Japan, and Sweden with a great focus on three factors: Research, Integration, and Utilization.

This dissertation consists of my own four constitutive publications and a literature review of publications based on the RIU model from Germany, Indonesia, Japan, and Sweden. The dissertation focuses on three research questions:

\section{What are the limits of scientific knowledge transfer?}

\section{Which factors determine the limits for scientific knowledge transfer according} to RIU model?

\section{Are these factors independent of each other?}

The RIU model served as a theoretical foundation for this dissertation. The RIU model predominantly follows the idea that policies are the result of co-production between scientific arguments and political reasoning. In the RIU model, knowledge transfer process is defined as a connection of three spheres: Research (R), Integration (I), and Utilization (U), each of which follows an individual logic. With the differentiation between research, integration, and utilization, typical activities of scientific knowledge transfer, based on different rationalities, can be analyzed and explained. Nevertheless, there is still the question of whether the factors limiting research, integration, and utilization depend on each other or they are independent of each other. This means whether a high amount of scientific statements causes much utilization always or they are independent of each other. The basic assumption of the RIU model is that the factors of research, integration, and utilization are independent of each other in limiting the transfer of knowledge. We take this assumption and formulate a leading hypothesis of our synthesis dissertation: The factors of research, integration, and utilization determine independently from each other the transfer of scientific knowledge. 
This dissertation was conducted using a meta-analysis of 15 publications based on the RIU model in five countries including Vietnam, Germany, Indonesia, Japan, and Sweden. The independence of research, integration, and utilization could be tested through direct hypotheses and indirect hypotheses in all 15 cases. The primary analysis of this dissertation consists of my own four constitutive articles that relied principally on two sources of data: document analysis and semi-structured expert interviews. During the last four years, I have conducted two field studies in Vietnam between October 2015 and February 2016, and between May and August 2017. I used the triangulation method (data, methodology, and investigator) for increasing study credibility. Qualitative content analysis and stakeholder analysis were also conducted to analyze all collected documents and role of actors with the aim of testing the hypotheses in particular cases studies in Vietnam.

The results show that, first, there are five hypotheses that directly support the independence from each other of research, integration and utilization activities in the RIU model. These hypotheses have been examined in the comparative studies on forest policy development between Japan and Sweden, case studies of the German Federal Agency for Nature Conservation, and case studies of fishery management in Indonesia. All five hypotheses are supported by empirical evidence of the case studies. Second, independence of research, integration, and utilization is tested indirectly. The truth table formulates eight combinations of research, integration, and utilization. Out of these, five are supported by empirical evidence of cases in Vietnam, Germany, Indonesia, Japan, and Sweden. These results indicate that the research, integration, and utilization are independent of each other in our cases. One important consequence of independence is that a big amount of research does not necessarily lead to effective integration or utilization and vice versa.

Third, by applying the RIU model, the limiting factors of knowledge transfer could be identified within research, integration, and utilization. The RIU model is a useful tool to particularly indicate these limitations and give recommendations to improve research or/and integration or/and utilization in an effort to enhance science - based policy support.

Fourth, since the factors of research, integration, and utilization determine independently from each other the transfer of scientific knowledge, we emphasize the importance of checking all three factor to assess the transfer of scientific knowledge in practice.

To conclude, the dissertation presents three strategic options for the Vietnam National University of Forestry (the VNUF) from the perspective of scientific knowledge 
transfer. One option is linking theory - based teaching with consulting experience for project learning at the VNUF. We suggest that the consulting experience of scientists at the VNUF could be integrated into the university teaching, which will help to improve the practical aspect of the university teaching. However, only consulting knowledge which is explicitly based on scientific statements can contribute to the improvement of the university teaching. By using the RIU model, the scientists can check scientific statements within consulting projects and select consulting work that is based on scientific statements for the university teaching.

Another option is to strengthen scientific research by national institutions. It shows that the results and science - based solutions produced by the national research organizations are well accepted by the powerful Vietnamese stakeholders. The deficit is only that they have narrow scientific limitations. Thus, strengthening the national research organizations would be a promising way to improve scientific support of policy in Vietnam.

An additional option is to improve integration to optimize scientific knowledge transfer of international conservation projects in Vietnam. Based on our analysis, we suggest that the task of integration should be conducted by a Vietnamese research institution since Vietnamese scientists have good knowledge of Vietnam political context and they are able to make good communications with national actors.

My own articles along, with a brief description, are provided below:

Article 1: Do Thi, H., Krott, M., \& Böcher, M. (2017). The success of scientific support for biodiversity conservation policy: The case of Ngoc Son Ngo Luong nature reserve in Vietnam. Journal for Nature Conservation, 38, 3-10.

Based on the case study on the establishment of a biodiversity corridor (NSNL NR), this article shows the successes and failures of scientific support for Vietnam's biodiversity conservation policy. High-quality scientific solutions of the Limestone Landscape: Improving Negotiation for Conservation Project were not utilized by stakeholders due to those solutions' weak integration. Weak research conducted by the Forest Inventory and Planning Institute of Vietnam was transferred through professional integration, which thereby achieved some successes in utilization. The article suggests three options to strengthen scientific support of policy: (1) need for professional integration, (2) improvement of the local scientific basis, and (3) need for improved communication between research and practice.

Article 2: Do Thi, H., Krott, M., Böcher, M., \& Juerges, N. (2018). Toward successful implementation of conservation research: A case study from Vietnam. Ambio, 47(5), 608-621. 
This article analyzes three conservation strategies employed in the $\mathrm{Pu}$ Luong Cuc Phuong Conservation Area by applying the Research-Integration-Utilization (RIU) model of scientific knowledge transfer. It reveals weaknesses in scientific knowledge transfer arising from low-quality research and poor integration strategies. The recommendations are given to improve research and integration in an effort to enhance science - based policy support.

Article 3: Do Thi, H., Krott, M., Juerges N. \& Böcher, M. (2018) Red lists in conservation science - policy interfaces: A case study from Vietnam. Biological Conservation, 226, 101-110.

This article explores science - policy interface in the development and use of the Vietnamese Red Data Book 2007 by applying the Research - Integration - Utilization (RIU) model of scientific knowledge transfer. It shows the scientific weaknesses of the Vietnamese Red Data Book 2007, which arise from the limited availability of updated data on rare and threatened species in Vietnam and unknown factors influencing them. Despite the existing limitations, the science-based policy advice of the Vietnamese Red

Data Book 2007 has achieved certain political influence due to successful integration. It reveals that good and actor-relevant communication could help to win powerful allies in conservation policy formulation, which contributes to a successful transfer of scientific knowledge.

Article 4: Do Thi, H., Juerges N., Krott, M. \& Böcher, M. (2018) Can Landscape planning solve scale mismatches in environmental governance? Under revision in Environment and Planning E.

This article examines an internationally funded project in Vietnam (the ECOLIME project) that failed in its endeavor to establish landscape planning at the scale of an ecologically valuable karst landscape. It shows that the implementation of landscape planning in the $\mathrm{Pu}$-Luong Cuc Phuong area was not successful to solve scale mismatches in environmental governance because of weak integration resulting from a lack of both a link to the Vietnamese political process and support from powerful Vietnamese actors. The establishment of a landscape-planning group with the support of an internationally funded project (the ECOLIME project) was not a sufficient means to create links to the political process and win powerful allies. The recommendations are given to make scientific research relevant to science - based policy support, including (1) the need for a link to the existing political process and (2) the need to gain the sustainable support of powerful allies. 


\section{List of abbreviations}

BfN

CITES

CPNP

ECOLIME

FFI

FIPI

ICDP

IUCN

LLINC Project

MARD

MONRE

NFP

NSNL NR

PCD

PL NR

PLCP

REDD+

SACDP

SLT

SLU

UNEP

VNUF
German Federal Agency for Nature Conservation (Bundesamt für Naturschutz)

Convention on International Trade in Endangered Species of Wild Fauna and Flora

Cuc Phuong National Park

$\mathrm{Pu}$ Luong Cuc Phuong Limestone Landscape Conservation Project

Fauna and Flora International

Forest Inventory and Planning Institute

Integrated Conservation and Development Project

International Union for Conservation of Nature

Limestone Landscape: Improving Negotiation for

Conservation Project

Ministry of Agriculture and Rural Development

Ministry of Natural Resource and Environment

National Forest Program

Ngoc Son Ngo Luong Nature Reserve

Participatory Curriculum Development

$\mathrm{Pu}$ Luong Nature Reserve

$\mathrm{Pu}$ Luong - Cuc Phuong conservation area

Reducing Emissions from Deforestation and Forest

Degradation

Segara Anakan Conservation and Development Project

Social Learning Theory

Swedish University of Agricultural Sciences (Sveriges Lantbruksuniversitet)

United Nations Environment Program

Vietnam National University of Forestry 


\section{List of Publications and author's contributions}

Do Thi, H., Krott, M., \& Böcher, M. (2017). The success of scientific support for biodiversity conservation policy: The case of Ngoc Son Ngo Luong nature reserve in Vietnam. Journal for Nature Conservation, 38, 3-10.

Do Thi Huong as the first and main author of this publication applied theory, hypothesis and methodology to the case as well as produced the findings. Krott and Böcher developed the general theory, hypothesis, and methodology.

Do Thi, H., Krott, M., Böcher, M., \& Juerges, N. (2018). Toward successful implementation of conservation research: A case study from Vietnam. Ambio, 47(5), 608-621.

Do Thi Huong, as the first and main author of this publication, applied theory, hypothesis and methodology to the case and produced the findings regarding the implementation of conservation strategies in Pu Luong Cuc Phuong conservation area. Krott and Böcher developed the general theory, hypothesis, and methodology. Juerges extended the ideas and edited the final draft.

Do Thi, H., Krott, M., Juerges N. \& Böcher, M. (2018) Red lists in conservation science - policy interfaces: A case study from Vietnam. Biological Conservation, 226, 101-110.

Do Thi Huong as the first and main author of this publication applied theory, hypothesis and methodology to the case as well as produced the findings. Krott and Böcher developed the general theory, hypothesis, and methodology. Juerges contributed to science - policy interface in biodiversity conservation and edited language.

Do Thi, H., Juerges N., Krott, M. \& Böcher, M. (2018) Can Landscape planning solve scale mismatches in environmental governance? Under revision in Environment and Planning $E$

Do Thi Huong as the first and main author of this publication applied theory, hypothesis and methodology to the case as well as produced the findings. Juerges, Krott, and Böcher developed the general theory, hypothesis, and methodology, and edited language. 


\section{Table of contents}

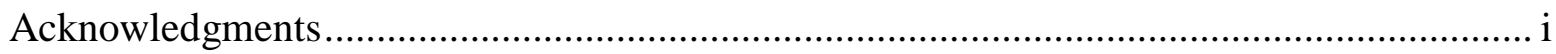

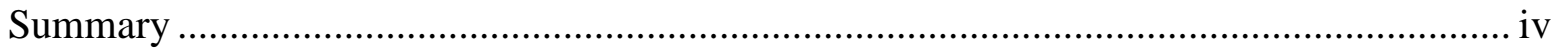

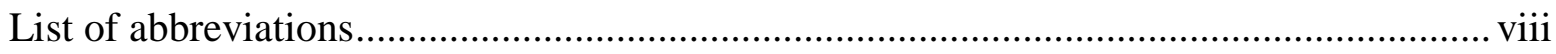

List of publications and author's contributions................................................................ ix

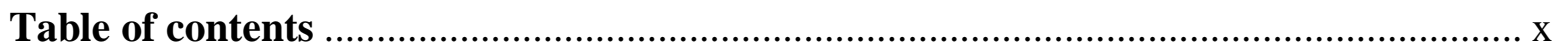

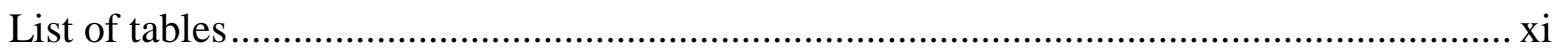

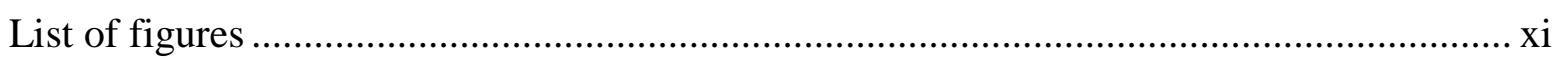

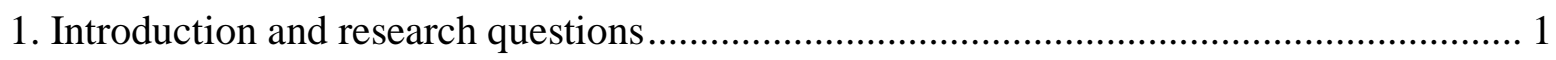

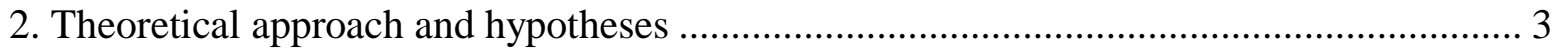

2.1. Description of riu model and main hypothesis: ............................................................ 3

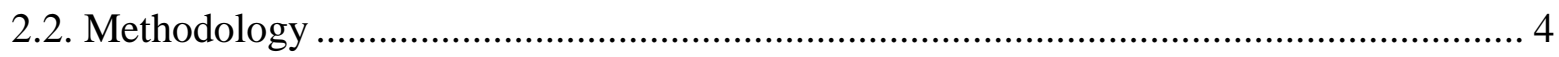

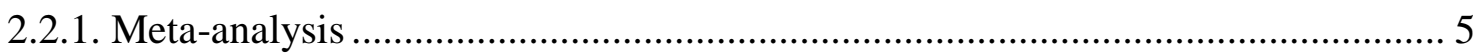

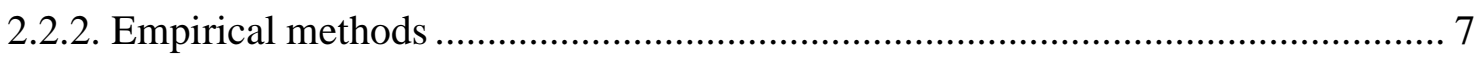

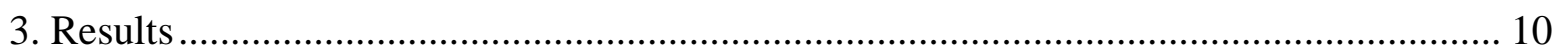

3.1. Direct hypotheses about the independence of factors of the riu model ....................... 11

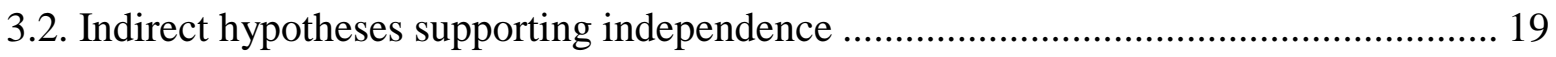

4. Strategic options for stakeholders: the vietnam national university of forestry ............... 33

4.1. Linking theory - based teaching with consulting experience for project-learning ........ 33

4.2. Need for improvement of national scientific basis ................................................. 36

4.3. Optimizing conservation projects by vietnam - based professional integration ............ 38

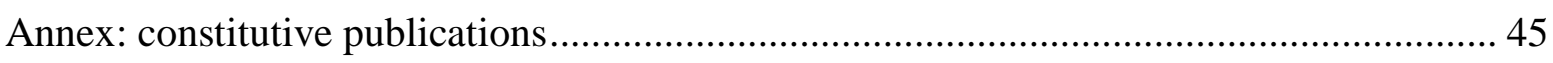

Curriculum vitae 


\section{List of tables}

Table 1. The number of hypotheses and publications used in the dissertation ..................... 6

Table 2. The number of collected documents and interviewees in the dissertation............... 7

Table 3. The application of triangulation method........................................................ 9

Table 4. Direct hypotheses for the independence of RIU's factors ................................... 13

Table 5. Comparative empirical evidence for independence of factors determined

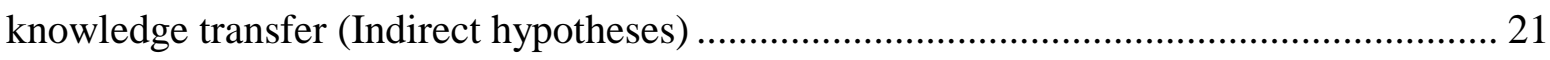

Table 6. The number of research projects implemented by the VNUF in 2016 .................. 34

\section{List of figures}

Figure 1. The RIU model of scientific knowledge transfer (Böcher and Krott 2016) ............ 3

Figure 2. Independently influence of R, I, U on scientific knowledge transfer .................... 4

Figure 3: Model for using consulting knowledge in university teaching........................... 37 


\section{Introduction and research questions}

There is increasing recognition of the importance of scientific expertise and scientific knowledge transfer in the environmental governance of global policy issues (e.g., biodiversity conservation and climate change) (Miller, 2009; Biermann and Pattberg, 2012; Pregernig and Böcher, 2012; Pregernig, 2014). Since global environmental problems are becoming more and more complex (Wood et al., 2000; Saterson et al., 2004), policymakers and practitioners increasingly rely on science-based solutions to address them (Perrings et al., 2011; Young et al., 2014; Nesshöver et al., 2016; Juntti et al., 2009). It is expected that when scientific ideas are put into practice, they should significantly contribute to the improvement of environmental solutions (Böcher and Krott, 2016; Böcher, 2016; Heim and Böcher, 2016a; Cortner et al., 1999). However, although the transfer of scientific knowledge into practice has paid attention of scientists and policymakers, the perspective is that better science should lead to better policy is rare in practice (Böcher and Krott, 2016). It is showed that not everything that is scientifically produced becomes politically relevant and not every political demand can be solved by scientific research (Böcher and Krott, 2010; Böcher, 2016). In addition, it also seems that a "linear" scientific knowledge transfer from science to political practice is not possible because of the different underlying rationalities of science ("finding the truth") and politics ("finding the power") (Krott, 2012, Böcher and Krott, 2014). Thus, there is an increasing concern to better understand how the transfer of scientific knowledge works in practice and what the limits of scientific knowledge transfer are?

Given this gap, numerous studies have attempted to explain the transfer of scientific knowledge from many different perspectives. Among these, using theoretical models of scientific knowledge transfer to explore the interaction between science and policy could be a fruitful approach. In this dissertation, we used a new model of scientific knowledge transfer (Research - Integration - Utilization model) as a theoretical framework. The RIU model was first developed by Böcher and Krott (2016), focusing on three key factors of successful scientific knowledge transfer: Research, Integration, and Utilization. The RIU model presents a professional approach to the identification of key factors involved in knowledge transfer within the spectrum of existing institutions and activities (Böcher and Krott, 2016). By applying the RIU model of scientific knowledge transfer, it becomes possible to identify and analyze three important interconnected steps for the transfer of scientific knowledge: research, integration, and utilization (Böcher, 2016; Nagasaka et al., 2016b). Nevertheless, the 
main question regarding scientific knowledge transfer, according to the RIU model, is whether and how the transfer of scientific knowledge happens within the limits of three factors: Research, Integration, and Utilization. This is the starting point of this dissertation since the RIU model claims that scientific knowledge transfer can be possible even without changing the underlying rationality of power - oriented politics (Böcher and Krott, 2014; Heim and Böcher, 2016a; Stevanov et al., 2013), and a lack of scientific expertise in available scientific findings does not necessarily mean that political actors cannot draw conclusions for their political products (Böcher and Krott, 2016).

This dissertation aims to analyze the limits of research, integration and utilization and their influence on scientific knowledge transfer in case studies from Vietnam, Germany, Indonesia, Japan, and Sweden.

In doing so, this dissertation poses the following research questions:

\section{What are the limits of scientific knowledge transfer?}

2. Which factors determine the limits for scientific knowledge transfer according to RIU model?

\section{Are these factors independent of each other?}

These questions will be addressed in a cumulative Ph.D. dissertation consisting of 4 peer-reviewed publications and a literature review based on the RIU model. According to the RIU model, the main elements of the transfer of scientific knowledge can be defined. In the RIU model, the transfer of scientific knowledge happens if scientific statements are used by actors to perform specific acts changing practice. The transfer starts with statements by scientists. The scientists produce statements but do not act in practice. In an informational process, the scientific statements get the attention of actors in practice. The actors become active and "act" based on the scientific knowledge changing the practice in order to solve their problems. It is important that acting is the final phase of knowledge transfer. Without acts, we do not consider that a transfer of knowledge is achieved. Acts could be multiple activities, e.g. planting or cutting a tree, formulating a law restricting forest use, subsidizing users or changing technology.

Another key element of the analysis is research. It is defined as a process that produces a specific form of knowledge by using scientifically accepted principles, methods and standards (Böcher and Krott, 2016). Research produces scientific statements describing and explaining the world. It aims to produce more and more statements, which are rich in content and theoretically based and empirical sound. In this dissertation, we look at the specific statements, which are relevant for a specific topic, 
which later is turned into an action. Additionally, we estimate how many scientific statements were made. If there is a lower number, we take this as an indicator for the little amount of scientific knowledge. Vice versa if there is a higher amount of scientific statements, we peak of a high amount of scientific knowledge. This definition enables us to identify scientific knowledge and to quantify it roughly into groups of more and less scientific knowledge.

\section{Theoretical approach and hypotheses}

\subsection{Description of RIU model and main hypothesis:}

The RIU model differs from classical linear models of scientific knowledge transfer, in which policy-making simply follows scientific evidence (Durant, 2015; Hulme, 2009). The RIU model predominantly follows the idea that policies are the result of co-production between scientific arguments and political reasoning. In the RIU model, knowledge transfer process is defined as a connection of three spheres: Research $(\mathrm{R})$, Integration (I) and Utilization (U), each of which follows an individual logic (Böcher and Krott, 2014; 2016) (Figure 1).

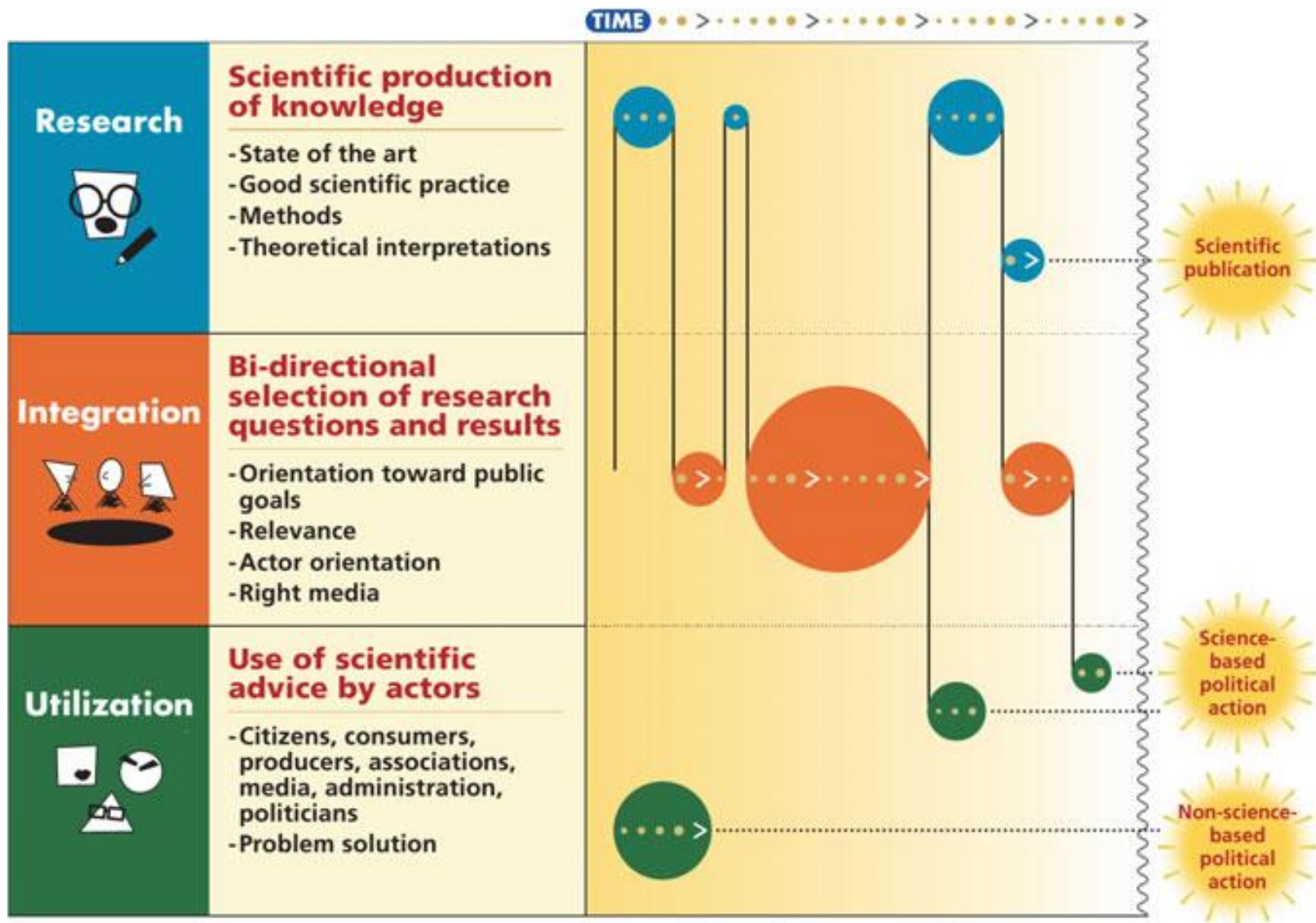

Figure 1. The RIU model of scientific knowledge transfer (Böcher and Krott 2016) 
In the RIU model, scientific results are formulated by scientists using scientific methods and standards from the research sphere (Stevanov et al., 2013; Böcher and Krott, 2014; 2016). Then, scientific results are led to the integration sphere for the selection of scientific knowledge. In integration, stakeholders select research results, which are relevant to solve practical problems using criteria based on practical demands (Böcher and Krott, 2014; 2016). On the contrary, practical demands for scientific solutions are interpreted to formulate scientific research questions addressing those practical questions (Böcher and Krott, 2016).

The RIU model emphasizes an important bi-directional, non-linear process of switching between research and integration activities to create scientific policy advisory products (Böcher and Krott, 2016; Böcher, 2016). Integration leads to utilization of scientific results by political and practical stakeholders in practice. With the differentiation between research, integration, and utilization, typical activities of scientific knowledge transfer, based on different rationalities, can be analyzed and explained (Böcher, 2016). Accordingly, based on these theoretical arguments, we formulated the hypothesis:

The factors of research, integration, and utilization set limits for the transfer of scientific knowledge.

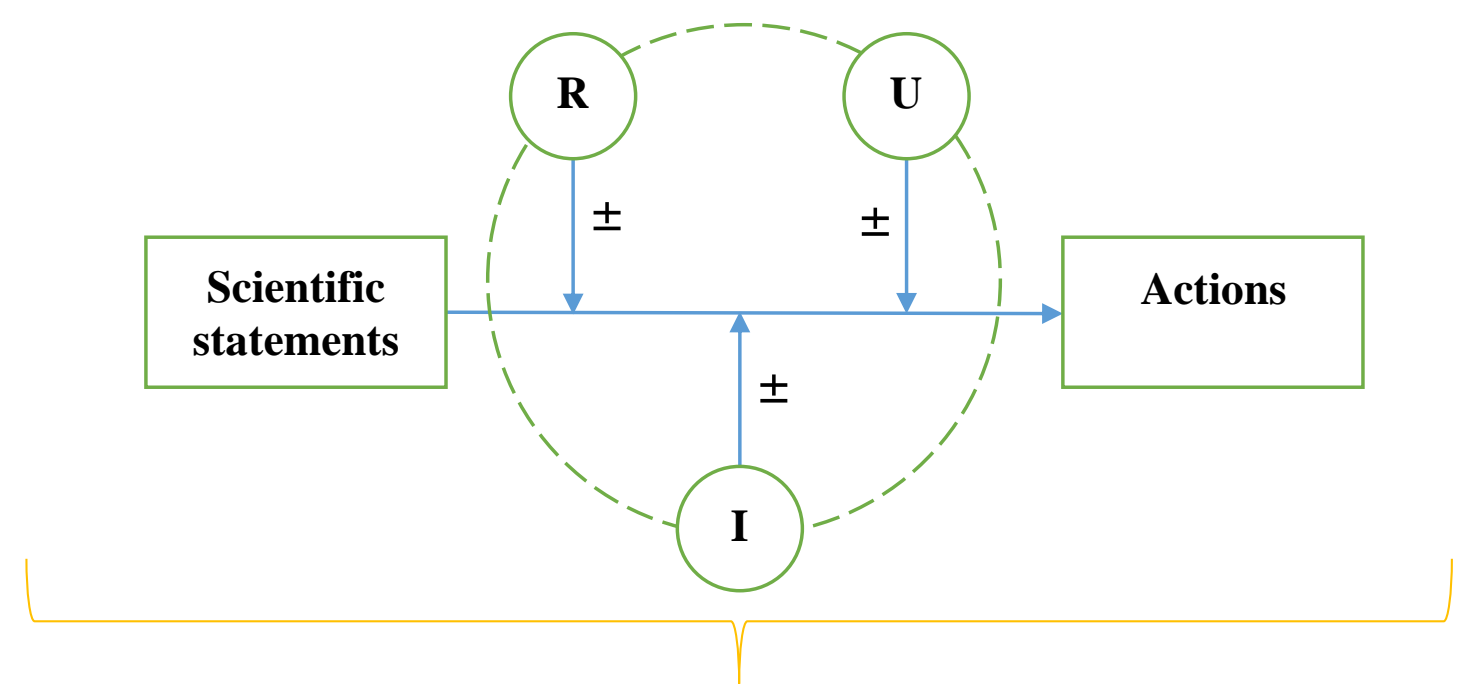

Scientific knowledge transfer

Notes:

$\mathrm{R}$ : Research I: Integration $\mathrm{U}$ : Utilization

Figure 2. Independently influence of R, I, U on scientific knowledge transfer 
Knowledge transfer links research with utilization. Nevertheless, there is still the question of whether the factors limiting research, integration, and utilization depend on each other or whether they are independent of each other. This means whether a high amount of scientific statements causes much utilization always or high amount of science and factors of integration are independent. For the latter one, we should expect cases in which professional integration happens combined with little scientific knowledge. Finally, even utilization can be expected in both cases little and much scientific knowledge. The basic assumption of RIU is that the factors of research, integration, and utilization are independent of each other in limiting the transfer of knowledge (Böcher and Krott, 2016).

We take this assumption as leading hypothesis of our synthesis dissertation and formulate: The factors of research, integration, and utilization determine independently from each other the transfer of scientific knowledge.

Figure 2 illustrates the hypothesis in regards to the independent influence of R, I, U on scientific knowledge transfer. A transfer of scientific knowledge is achieved when scientific statements are used by political/practical actors to make actions in reality. During this process, the elements of research, integration, and utilization determine the transfer of knowledge and these elements could be plus (bigger amount) or minus (less amount). In this dissertation, we focus on testing the independence of three factors (Research, Integration, and Utilization) in empirical case studies.

\subsection{Methodology}

This chapter presents the method of meta-analysis to analyze and summarize 15 publications based on the RIU model. In addition, our empirical methods are also given including data collection for primary analysis and primary data analysis.

\subsubsection{Meta-analysis}

Meta-analysis is defined as the quantitative review and synthesis of the results of related and independent studies (Normand, 1999; Bailar, 1997). It is claimed that meta-analysis may be applied even when the number of studies is small and there is substantial variation in the specific issues studied, the research methods applied, the source and nature of the study subjects, and other factors that may have an important bearing on the findings (Bailar, 1997). In order to test the leading hypothesis on the independence of the factors in the RIU model, we used the method of meta-analysis to analyze 15 publications based on the RIU model in five countries including Vietnam, Germany, Indonesia, Japan, and Sweden. We figured out that the 
independence of research, integration, and utilization could be tested through direct hypotheses and indirect hypotheses in all 15 cases in the five countries. A direct hypothesis means that a publication makes a direct scientific statement whether the factors are independent. We found five direct scientific statements in the publications applying the RIU model.

Indirect hypothesis means that multiple combinations of research, integration, and utilization exist and the cases provide empirical evidence for such combinations. This can be checked by a truth table (Caramani, 2009). Based on the published cases we evaluated the factors by + (more) and - (less) and check the empirical support for a truth table consisting of all eight options of the combination. In this dissertation, plus or minus of the factors (Research, Integration, and Utilization) is defined as follows:

Research: (+): More scientific statements about problems and solutions

(-): Less scientific statements about problems and solutions

Integration: (+): More scientific statements about future actions

$(-)$ : Less scientific statements about future actions

Utilization: (+): More actions

$(-)$ : Less actions

In this dissertation, we have conducted a literature review of the publications based on the RIU model, which have been implemented in Vietnam, Germany, Indonesia, Japan, and Sweden. All hypotheses of the publications, based on the RIU model, from these five countries, have been compiled to test the independence of the RIU's factors (Table 1).

Table 1. The number of hypotheses and publications used in the dissertation

\begin{tabular}{|c|l|r|r|l|}
\hline No & Countries & $\begin{array}{r}\text { Number of } \\
\text { hypotheses }\end{array}$ & $\begin{array}{c}\text { Number of } \\
\text { publications }\end{array}$ & \multicolumn{1}{|c|}{ Source of data } \\
\hline 1 & $\begin{array}{l}\text { Japan and } \\
\text { Sweden }\end{array}$ & 5 & 3 & $\begin{array}{l}\text { Nagasaka et al., 2016a; 2016b; } \\
2016 \mathrm{c}\end{array}$ \\
\hline 2 & Germany & 3 & 4 & $\begin{array}{l}\text { Heim et al., 2016a; 2016b; } \\
2017 ; 2018\end{array}$ \\
\hline 3 & Indonesia & 5 & 4 & $\begin{array}{l}\text { Dharmawan et al., 2016; } \\
2017 \mathrm{a} ; 2017 \mathrm{~b} ; 2017 \mathrm{c}\end{array}$ \\
\hline 4 & Vietnam & 5 & $\begin{array}{l}\text { Do Thi et al., 2017; 2018a; } \\
2018 \mathrm{~b} ; 2018 \mathrm{c}\end{array}$ \\
\hline & Total & $\mathbf{1 8}$ & $\mathbf{1 5}$ & \\
\hline
\end{tabular}




\subsubsection{Empirical methods}

\section{2. 2. 1. Data collection for primary analysis}

The primary analysis of this dissertation consists of my own four constitutive articles that relied principally on two sources of data: document analysis and semi-structured expert interviews. During the last four years, I have conducted two field studies in Vietnam between October 2015 and February 2016, and between May and August 2017.

The documents have been collected from many different sources including FFI library, Forest Protection Department, Department for Nature Conservation, national research institutions, IUCN Vietnam, CITES Vietnam, the CPNP, PLNR, and NSNLNR libraries. In total, I have collected 128 different documents related mainly to the ECOLIME project, LLINC project, FIPI project and the red listing project of Vietnam such as project proposals, project completion reports, technical reports, progress reports, publications, unpublished reports, scientific articles, books, and policy documents (Table 2). The purpose of the extensive document analysis was to better understand the project activities, biodiversity conservation strategies, landscapeplanning activities and the establishment of Vietnamese Red Data Book 2007.

I have conducted 87 semi-structured interviews to various stakeholders involved in the ECOLIME project, LLINC project, FIPI project and Vietnamese red listing project 2007 such as researchers, governmental staffs, project staffs, forest rangers, and community representatives (Table 2). The interview questions focused on the project activities and their effects, the establishment of Vietnamese Red Data Book 2007, and the existing laws on biodiversity conservation and endangered species protection in Vietnam. The interviews, lasting between 1 and $2 \mathrm{~h}$, were conducted in Vietnamese. The results of the interviews were used to analyze and clarify the hypotheses of the articles.

Table 2. The number of collected documents and interviewees in the dissertation

\begin{tabular}{|c|r|r|l|}
\hline Articles & $\begin{array}{c}\text { Secondary } \\
\text { documents (project } \\
\text { report, laws, } \\
\text { publications, etc) }\end{array}$ & $\begin{array}{c}\text { Semi-structured } \\
\text { interviews } \\
\text { (number of } \\
\text { interviewees) }\end{array}$ & Sources \\
\hline 1 & 40 & 16 & Do Thi et al., 2017 \\
\hline 2 & 30 & 24 & Do Thi et al., 2018a \\
\hline 3 & 28 & 25 & Do Thi et al., 2018b \\
\hline 4 & 30 & 22 & Do Thi et al., 2018c \\
\hline Sum & $\mathbf{1 2 8}$ & $\mathbf{8 7}$ & \\
\hline
\end{tabular}




\subsubsection{Primary data analysis}

The primary data analysis in this dissertation aims at understanding the transfer of scientific knowledge in specific cases of Vietnam.

\section{+ Triangulation method}

Triangulation can be defined as the use of multiple methodological approaches, theoretical perspectives, data sources, investigators and analysis methods in studying the same phenomenon for increasing study credibility (Hilton, 2003; Hussein, 2015; Weyers et al., 2014). It is based on a general consent that the reliability and validity of any study would be improved if the researcher uses several different types of sources that provide more insight in the same phenomenon and then cross-check the result against that of another procedure (Babbie and Mouton, 2001; De Vos, 2005; Monette et al., 2002; Patton, 2002; Silverman, 2000). It has also been argued that the deficiencies and bias of any one method can be overcome by combining methods and thus capitalizing on their individual strengths (Blaikie, 1991; Babbie, 2004).

In qualitative social research, triangulation generally involves using multiple methods (e.g. interviews, observations) (Archibald, 2016) or diverse analytic perspectives (e.g., Patton, 2002) to explore complementary information or synthesize divergent views with the aim of overcoming strengths, weaknesses, and associated biases of a particular approach (Bergman, 2008).

There are many types of triangulation (Denzin, 1978; Hussein, 2015; Weyers et al., 2014). Our analyses use mainly three types of triangulation: data triangulation; methodological triangulation, and investigator triangulation (Table 3). All data from the interviews and document analyses were interpreted following the triangulation method (Hussein, 2015) to identify reliable information and data. Then, we analyzed the collected data according to the main criteria of the RIU model of scientific knowledge transfer.

\section{+ Qualitative content analysis}

The qualitative content analysis is defined as "an approach of empirical, methodological controlled analysis of texts within their context of communication, following content analytical rules and step by step models, without rash quantification" (Mayring, 2000). One of the strengths of qualitative content analysis is that it is strictly controlled methodologically and that the material is analyzed stepby-step (Kohlbacher, 2006). It is claimed that qualitative content analysis can have its strong ability to deal with complexity since it tries to synthesize openness which is claimed by the qualitative research paradigm and theory - guided investigation which is demanded by the hypothetical - deductive paradigm (Kohlbacher, 2006). By using 
a rule-based and methodologically controlled approach, the qualitative content analysis can deal with the complexity and gradually reduce it (Kohlbacher, 2006).

It is also believed that the connection to the concrete subject of analysis is a very important point for qualitative content analysis (Mayring, 2003). This shows that the procedures of content analysis cannot be fixed but have to be adapted depending on the subject and its context (Kohlbacher, 2006). Since the qualitative content analysis applies a systematic, theory-guided approach to text analysis using a category system, it preserves the advantages of quantitative content analysis and concurrently uses a more qualitative text interpretation (Mayring, 2000). Thus, it is also argued that qualitative content analysis could prove to be a useful tool for analyzing data material in case study research (Kohlbacher, 2006). In this dissertation, a qualitative content analysis was conducted to analyze all of the documents and interviews for the purpose of testing the hypotheses in particular case studies in Vietnam, which are presented in the four peer-reviewed publications.

Table 3. The application of triangulation method

\begin{tabular}{|c|c|c|c|}
\hline No & $\begin{array}{c}\text { Types of } \\
\text { triangulation }\end{array}$ & Description & Detailed application \\
\hline 1 & $\begin{array}{l}\text { Data } \\
\text { triangulation }\end{array}$ & $\begin{array}{l}\text { Use of multiple data sources } \\
\text { in the same study for } \\
\text { validation purposes (Denzin, } \\
\text { 1978; Hussein, 2015). }\end{array}$ & $\begin{array}{l}\text { Types of documents: } \\
\text { 1/ Project documents } \\
\text { 2/ Interview results (field-notes) } \\
\text { 3/ Related publications } \\
\text { 4/ Policy documents } \\
\text { Variety of interviewees: } \\
\text { Researchers; Policymakers; } \\
\text { Local authorities; Forest } \\
\text { rangers, and Local people }\end{array}$ \\
\hline 2 & $\begin{array}{l}\text { Methodological } \\
\text { triangulation }\end{array}$ & $\begin{array}{l}\text { Use of more than two } \\
\text { methods in studying the same } \\
\text { phenomenon } \\
\text { investigation } \\
\text { 1986). }\end{array}$ & $\begin{array}{l}\text { 1/ Document analysis } \\
\text { 2/ Semi-structured interview } \\
\text { 3/ Observation }\end{array}$ \\
\hline 3 & $\begin{array}{l}\text { Investigator } \\
\text { triangulation }\end{array}$ & $\begin{array}{l}\text { Use of more than two } \\
\text { researchers in any of the } \\
\text { research stages in the same } \\
\text { study (Hussein, 2015) }\end{array}$ & $\begin{array}{l}\text { Case studies of other three } \\
\text { researchers in } 4 \text { countries } \\
\text { (Germany, Indonesia, Japan and } \\
\text { Sweden) have been used in a } \\
\text { meta-analysis study. }\end{array}$ \\
\hline
\end{tabular}




\section{+ Stakeholder analysis}

We used stakeholder analysis, as described by Schmeer (1999), to identify the main stakeholders in the biodiversity conservation strategies in $\mathrm{Pu}$ Luong Cuc Phuong conservation area (Do Thi et al., 2017; 2018a), investigate the role of main actors in the Vietnamese planning system as well as their potential links and interests in landscape planning (Do Thi et al., 2018c), explore powerful actors in the development and use of Vietnamese Red Data Book (Do Thi et al., 2018b). The stakeholder analysis helped to identify the actors that should be involved and to shed light on the possible roles of different actors, as well as some of the opportunities and risks associated with involving these actors (Hermans, 2008). We also employed eight steps for stakeholder analysis by Schmeer (1999) (1) planning the process; (2) selecting and defining policy; (3) identifying key stakeholders; (4) adapting the tools; (5) collecting and recording the information; (6) filling in the stakeholder table; (7) analyzing the stakeholder table; and (8) using the information.

In addition, the collected data were analyzed to assess the power of the stakeholders within the political system in Vietnam as being either high (+) or low (-), based on an analysis of power that considered three aspects: (1) legal decision-making right, (2) informal decision power, and (3) the main budget.

\section{Results}

According to the RIU model, three factors of scientific knowledge transfer: Research, Integration, and Utilization were analytically understood as independent variables, leading to an active use of science - based information by different political and practical actors (Böcher and Krott, 2016, pp32). The RIU model also claims that the factors (Research, Integration, Utilization) can be derived which help researchers, research funding institutions, and integrators to steer their research process with regard to practical implication (Böcher and Krott, 2016, pp52). In this dissertation, first, the independence of the RIU's factors will be tested through reviewing the publications that applied the RIU model and synthesizing empirical data of the cases in the five countries (Vietnam, Germany, Indonesia, Japan, and Sweden). Second, we searched and analyzed all three factors of research, integration, and utilization to reveal their limits for the transfer of scientific knowledge in our case studies. Based on the results of the literature review, there are some hypotheses related to the independence of the RIU's factors in our investigated case studies. We divided these hypotheses into two main categories: direct and indirect hypotheses. 


\subsection{Direct hypotheses about the independence of factors of the RIU model}

There are five hypotheses that directly support for the independence of research, integration and utilization activities in the RIU model (Table 4). These hypotheses have been examined in the comparative studies on forest policy development between Japan and Sweden, case studies of the German Federal Agency for Nature Conservation, and case studies of fishery management in Indonesia. The author herself did not find any direct hypothesis for the independence in the case studies of Vietnam.

Direct hypothesis 1:The researcher can be scientist, integrator or policy entrepreneur for policymaking (Nagasaka et al., 2016c).

There has been previous research dealing with the issue on the role of researchers in policy and politics. Pielke (2007) has described four ideal roles of researchers, namely "pure scientist", "science arbiter", "Issue advocate" and "honest broker of policy alternatives" (Pielke, 2007). Each of these four idealized roles of scientists in policy and politics has its place in responding to the increasing demands for scientists to be active in politics and policy. It has emphasized that scientists have choices about if, how and when they decide to become actively engaged in policy and politics (Pielke, 2007). Since scientists could select what role they would play in scientific knowledge transfer, the independence of research, integration, and utilization is supported by the concepts of Pielke.

The RIU model assumes multiple roles for scientists in scientific knowledge transfer, highlights the important role of integrators and analyses the necessity of having powerful political actors as allies who are crucial for the realization of science - based policy advice (Böcher and Krott, 2016, Nagasaka et al., 2016a). The RIU model implies that a researcher does not always have to play exclusively the role of scientists who satisfy the standards of research. Rather, a researcher may also play a role in integration, or even utilization (Böcher and Krott, 2016). Each of these roles relies on different activities and standards. Nagasaka et al. (2016a) have clarified the roles of researchers in the forest policy development process in Japan and Sweden based on RIU model. A comparative case study between forest policy reform program of Japan and national forest program of Sweden was conducted to reveal the roles of researchers in the forest policy development process. The results show that researchers played important roles as both scientists and integrators in Japan (Nagasaka et al., 2016a).

The Japanese researchers were asked to engage in, and give science-based advice on the six proposals regarding Japanese forestry reform and the Revitalization Planplaying the roles of scientists (Nagasaka et al., 2016a). These researchers specialized in various areas, including environmental economics, forest economics, forest 
engineering, and forest policy analysis (Nagasaka et al., 2016a). It shows that the activities of the researchers meet the criteria of the RIU model as "scientists" (Nagasaka et al., 2016a). In addition, the researchers played an important role in contributing science-based policy advice during alternative specification phases and scrutinized the policy processes of the Revitalization Plan after implementation (Nagasaka et al., 2016a). Scientists involved in the policy process of the Revitalization Plan also fulfilled the criteria of the research category in the RIU model (Nagasaka et al., 2016a).

Nagasaka et al. (2016a) indicate that the researchers also played the role of an integrator in the policy process of the Revitalization Plan. Five university researchers were assigned as chairpersons of the subcommittees for discussing five detailed alternative strategies (Nagasaka et al., 2016a). They worked together with the administrative officers in the Forestry Agency to select related scientific knowledge based in compliance with public goals and the policy process (Nagasaka et al., 2016a). In Sweden, researchers played only the role of scientist (Nagasaka et al., 2016a). The role of researchers has been examined in the establishment of the Swedish national forest program (NFP). The Swedish University of Agricultural Sciences (Sveriges lantbruksuniversitet in Swedish: SLU) was assigned the task of conducting a second pre-study on the NFP with support from a research program "Future Forests" (Nagasaka et al., 2016a). About forty forest-related researchers have been involved in the research program, mainly from the SLU, Umeå University, and the Forestry Research Institute of Sweden (Nagasaka et al., 2016a). The Future Forests aims at providing scientifically robust knowledge to enable greater and sustainable provision of ecosystem services from forests, which face climate change, energy transition, and altered markets for forest goods and services (Nagasaka et al., 2016a). Based on previous research, the Future Forests proposed the organizational structure for the policy process of the Swedish NFP and the 'Structural decision-making model' in the alternative specification phase (Nagasaka et al., 2016a). As a result, researchers in Future Forests worked as scientists, contributing to Swedish NFP policymaking. However, no researcher in Future Forests was observed to play the role of an integrator in the establishment of the NFP (Nagasaka et al., 2016a). The power alliance between any researcher and a certain powerful political actor was not found in the establishment process (Nagasaka et al., 2016a). 
Table 4. Direct hypotheses for the independence of RIU's factors

\begin{tabular}{|c|c|c|c|c|c|}
\hline No & Direct hypothesis & Case studies & Countries & Status & Sources \\
\hline 1 & $\begin{array}{l}\text { The researcher can be scientist, integrator or } \\
\text { policy entrepreneur for policymaking. }\end{array}$ & $\begin{array}{l}\text { Forest policy development of Japan } \\
\text { and Sweden }\end{array}$ & $\begin{array}{l}\text { Japan and } \\
\text { Sweden }\end{array}$ & $\sqrt{ }$ & $\begin{array}{l}\text { Nagasaka et } \\
\text { al., 2016a }\end{array}$ \\
\hline 2 & $\begin{array}{l}\text { The different roles in the science - based policy } \\
\text { advice processes of departmental research } \\
\text { organization can be clearly distinguished, even if } \\
\text { the actor stays the same and the roles change over } \\
\text { the time. }\end{array}$ & $\begin{array}{l}\text { Case studies on CITES, national } \\
\text { floodplain protection, and World } \\
\text { Heritage beech forests }\end{array}$ & Germany & $\sqrt{ }$ & $\begin{array}{l}\text { Heim at al., } \\
2016 a ; 2016 b ; \\
2018\end{array}$ \\
\hline 3 & $\begin{array}{l}\text { Integration can flexibly define (political or } \\
\text { practical) solutions according to different } \\
\text { interests and needs of actors using scientific } \\
\text { results in different contexts. }\end{array}$ & $\begin{array}{l}\text { Case studies on CITES, national } \\
\text { floodplain protection, and World } \\
\text { Heritage beech forests }\end{array}$ & Germany & $\sqrt{ }$ & $\begin{array}{l}\text { Heim et al., } \\
2016 \mathrm{a} ; 2016 \mathrm{~b} ; \\
2018\end{array}$ \\
\hline 4 & $\begin{array}{l}\text { Powerful actors are able to implement their } \\
\text { preferred solutions and to neglect win - win } \\
\text { solutions. }\end{array}$ & Fishery management of Indonesia & Indonesia & $\sqrt{ }$ & $\begin{array}{l}\text { Dharmawan et } \\
\text { al., } 2017 \text { a }\end{array}$ \\
\hline 5 & $\begin{array}{l}\text { Strong actors will fail by selected scientific - } \\
\text { based solutions if they assume their power } \\
\text { wrong. }\end{array}$ & $\begin{array}{l}\text { Mangrove conservation plan of } \\
\text { Indonesia }\end{array}$ & Indonesia & $\sqrt{ }$ & $\begin{array}{l}\text { Dharmawan et } \\
\text { al., } 2016\end{array}$ \\
\hline
\end{tabular}

Notes: $\sqrt{ }$ : proved

?: No information 
Additionally, the case study shows that no researchers working as policy entrepreneurs were observed in either country. These results indicate that the RIU model may be used as a powerful analytical tool for observing and identifying the multiple roles of researcher within scientific knowledge transfer of forest policy processes (Nagasaka et al., 2016a). These results contribute the empirical evidence to hypothesis 1 that shows that scientists can play different roles in the activities of research, integration, and utilization of scientific knowledge transfer.

Direct hypothesis 2: The different roles in the science - based policy advice processes of departmental research organization can be clearly distinguished, even if the actor stays the same and the roles change over the time (Heim et al., 2017).

Heim et al. (2017) show that the departmental research organization (e.g. BfN) can play various roles throughout a policy advice process. In the three different thematic case studies on CITES, national floodplain protection, and World Heritage beech forests, it was found that the BfN switches RIU roles constantly (Heim et al., 2017). By drawing the production line in the case of CITES, Heim et al. (2016a) have visualized the changing roles of the BfN.

First, the policy advice process started in the integration sphere when BfN officials recognized many difficulties in determining the age and origin of traded Elephant ivory specimens to list the species under CITES Appendix I in 1990 (Heim et al., 2016a). Nevertheless, it was not until 2009 when the BfN played as integrator, detecting political support for research on ivory determination within the BMUB (Heim et al., 2016a). Then the BfN acted as researcher again to initiate the research project "Determination of Age and Geographical Origin of African Elephant Ivory" in 2010 (Heim et al., 2016a). Consequently, the BfN took the role of integrator when it gathered support for the analysis of ivory samples via political channels as well as call for support from hunting associations, museums, zoos and NGOs (Heim et al., 2016a). As a result, the analysis of seized samples using BfN methodologies has been conducted since 2013 and the BfN contributed to the publication "Guidelines on Methods and Procedures for Ivory Sampling and Laboratory Analysis" prepared by the United Nation Office on Drugs and Crime (Heim et al., 2016a). Thus, the role of the BfN changes constantly among the activities of research, integration, and utilization.

In the case of national floodplain protection, the BfN's role according to the RIU model could be distinguished. The early 1990s, the BfN officials played as the researchers to conduct different small - scale, regional studies on floodplains (Heim et 
al., 2016b). Then, the position of the BfN changed to the role of integrator when it decided to take a different strategic decision by focusing on national floodplain protection (Heim et al., 2016b). Several BfN research projects on national floodplain protection were launched since 2003 (Heim et al., 2016b). With the impact of the Elbe river flood 2002, the BfN developed an internal strategy and discussion paper on floodplain protection, which aimed to provide technical tools for the Federal Government to meet national and international obligations in the field of floodplain protection (Heim et al., 2016b). When another flood occurred in 2013 on the Elbe river, the BfN published its position paper on preventive flood protection (Heim et al., 2016b). Consequently, two major political programs have been passed by the German government, based on the BfN's recommendations, including the National Flood Protection Program and the federal states "Blue Ribbon" (Heim et al., 2016b). This shows that the BfN switched its roles over the time from conducting scientific research to integrating its scientific findings to be used within politics.

Another case of nomination and inscription of German beech forests as World Heritage indicates that the activities in the Research, Integration, and Utilization spheres happened continuously across governance levels, often simultaneously overlapping (Heim et al., 2018). First, taking on the role of the researchers, the BfN provided the conceptualization and the supervision to conduct five research projects related to the nomination and inscription process (Heim et al., 2018). These research results were to emphasize the importance of listing ancient national beech forests under the World Heritage Convention. Then the BfN played as integrators to facilitate the transfer of research findings, ultimately resulting in the inscription of the German component parts (Heim et al., 2018).

Interestingly, Heim et al. (2017) indicate that the initial starting point for the BfN's activities can emerge in all three spheres according to the RIU model. In the CITES ivory trade case, activities were first derived from the integration at the national and international levels to develop a new methodology for ivory age and origin determination (Heim et al., 2016a). Similarly, in the case of the nomination and inscription of German beech forests as World Heritage, the integration was the starting point when the IUCN and World Heritage Committee showed an imbalance between natural and cultural World Heritage properties (Heim et al., 2018). Concerning the national floodplain activities of the BfN, much research on floodplains had been conducted before a series of flood events in Germany occurred, which led to an increasing need for national floodplain protection (Heim et al., 2016b). 
Therefore, the three case studies of Germany show that the role of departmental research organization can be separated among the activities of research, integration, and utilization. This discrimination is the first important step in supporting for the independence of research, integration, and utilization activities.

Direct hypothesis 3: Integration can flexibly define (political or practical) solutions according to different interests and needs of actors using scientific results in different contexts (Heim et al., 2017).

The case of nomination and inscription of German beech forests as World Heritage reveal that scientific research would most likely not have supported inscription of the German component parts since the research has shown that German beech forests only reached a level of 3 out of 6 ( 1 being the most feasible) to be inscribed as World Heritage (Heim et al., 2018). The research for the nomination of German beech forests suggested that a transnational nomination would probably be more successful than a national one (Heim et al., 2018). The inscription of the German component parts was only possible due to integration activities such as finding allies in the federal states, IUCN, World Heritage Committee, and broadening the extension process first to a trilateral World Heritage site and ultimately to a finite European property (Heim et al., 2018). Thus, the BfN used different integration strategies to meet the needs and interests of the actors, which led to the use of scientific findings in the nomination and inscription of German beech forests as World Heritage (Heim et al., 2018).

The case study of floodplain protection demonstrates that the BfN's activities in the research sphere needed integration activities to actually be implemented in practice (Heim et al., 2016b). High - quality scientific research alone is not enough to place a topic on the political agenda (Heim et al., 2017). A number of external allies and events were necessary to push the topic forward (Heim et al., 2017). As an example, the flood events in Germany opened a political window of opportunity that helped the BfN to gain politically powerful allies in implementing science - based political solutions (Heim et al., 2016b).

The case of CITES also supports this hypothesis. It shows that the integration activities play a very important role in the implementation of a global environmental policy regime depends on science - based information like CITES (Heim et al., 2016a). Without the BfN's integration activities to find new allies that were able to help with the sampling of ivory, research activities would not have been possible (Heim et al., 2017). Implementation and enforcement of global environmental policy regime such 
as CITES can be tackled through demand-driven research and successful integration, leading to the utilization of research results by political actors (Heim et al., 2017).

These results provide evidence for the independence of the integration since the results have revealed that science - based solutions could be defined in integration according to different interests and needs of actors.

Direct hypothesis 4: Powerful actors are able to implement their preferred solutions and to neglect win - win solutions (Dharmawan et al., 2017c).

The win - win solution for the fishery management in the Segara Anakan Lagoon included the protection of the fisher community's interests and industrial activities as well as environmental conservation to save the lagoon and its environment (Dharmawan et al., 2017a). The research for Segara Anakan fisheries management plan tried to establish a win - win solution through a community - based management approach, relying on local knowledge to guarantee the relevance of a solution. Dharmawan et al. (2017a) observed that the concept of the win-win solution was expected to diminish the conflict among fishers, government and other actors in the industry.

The research recommended that allocating "apong" use to fishing areas near the ocean and adapting them to appropriate fishing gears would be a win-win solution for all actors (Dharmawan et al., 2017a). In this way, "apong" fishers could still use their nets, the silting rate from upstream could be decreased and ships could pass through the river (Dharmawan et al., 2017a). While the scientists assumed that the win - win solution was good for all actors, the district government did not implement it (Dharmawan et al., 2017a). The district government was interested in the old model and think that the implementation of the solution in a traditional way could solve the problem (Dharmawan et al., 2017a). In the end, the district government ignored the fishing zone concept suggested by the researchers and banned the use of "apongs" in the Segara Anakan waters, especially across the shipping lane (Dharmawan et al., 2017a). Although the formal regulation was established to ban the use of "apong" and require "apong" fishers to move out of the area, the fisher community objected to this regulation and continued using "apong" (Dharmawan et al., 2017a). Thus, the regulation was not enforced in practice. Dharmawan et al. (2017a) show that the zoning approach is very relevant and might provide a science - based win - win solution to the existing problem. However, the district government stayed with the traditional political approach and decided to implement a restrictive ban of apong that does not provide a win - win solution for all actors (Dharmawan et al., 2017a). 
The results provide empirical evidence for the independence of the utilization since the science based win- win solutions could be ignored by powerful allies and they could implement their preferred solutions instead.

Direct hypothesis 5: Strong actors will fail by selected scientific - based solutions if they assume their power wrong (Dharmawan et al., 2016).

The research of the SACDP (Segara Anakan Conservation and Development Project) recommended a diversion plan of Citanduy River that is expected to find a solution for the high levels of sedimentation, which shrink the river and lagoon (Dharmawan et al., 2016). Central and district government agreed to implement the river diversion plan as an important objective of the conservation project (Dharmawan et al., 2016). However, this diversion plan was facing tremendous protest from the grassroots communities. They argued that the diversion plan was only shifting problems from one place to another while the main problems were not solved such as deforestation and massive agricultural activities in the upstream area, the silting of the lagoon due to a high sedimentation rate, and illegal logging of mangrove forests (Dharmawan et al., 2016).

In spite of the strong rejection of grassroots, central and local governments continued the effort to use their power to implement the diversion plan (Dharmawan et al., 2016). The central government created a National Steering Committee to conduct a review study in order to support the plan (Dharmawan et al., 2016). However, the objection of grassroots could not be eradicated and even increased (Dharmawan et al., 2016). Finally, the central government decided to continue the SACDP without the Citanduy river diversion plan (Dharmawan et al., 2016). Thus, the expectation of the government to push the diversion plan through against the grassroots protest failed. Dharmawan et al. (2016) indicate that this failure mostly resulted from the wishes of ADB (the funder of the project) and the elite because these allies think that they can succeed in conducting the project without grassroots involvement. The results show that the powerful actors might fail in implementing science - based solution if they assume their power position wrong.

This indicates the independence of the utilization since science - based solution could be selected by powerful allies but their implementation still could fail if the allies assume their power position wrong. 


\subsection{Indirect hypotheses supporting independence}

The independence of the RIU's factors could also be tested through indirect hypotheses that need to be examined in particular case studies. All indirect hypotheses have been compiled from case studies of the RIU model. A truth table includes eight options for factors of the RIU model that were used in indirect hypotheses (Table 5). The indirect hypotheses were found in four countries (Sweden, Germany, Indonesia, and Vietnam). We observed that no indirect hypothesis was applied to cases of Japan.

\section{Indirect hypothesis 1: Research (+), Integration (+), Utilization (+)}

There are two cases supporting for this hypothesis. The first one is the case of the Swedish national forest program. It has been proved that science influenced the agenda - setting phase of the Swedish national forest program (Nagasaka et al., 2016a). In the establishment of the National Forest Program (NFP), the Swedish government officially mandated the Swedish Forest Agency to conduct a feasibility study for the establishment after receiving an interim report from the all party committee on Environmental Objectives (Nagasaka et al., 2016a). This committee was established to advise the government on strategies, policy instruments and measures to achieve the sixteen environmental quality objectives before 2020 (Nagasaka et al., 2016a). However, in order to foster the NFP through scientific research, the Swedish University of Agricultural Sciences (Sveriges lantbruksuniversitet in Swedish: SLU) was assigned the task of conducting second pre-studies on the NFP with support from a research program 'Future Forests' (Nagasaka et al., 2016a).

The research of the SLU and Future Forests provided science - based policy advice regarding the sustainable provision of ecosystem services from forests, organizational structure for the policy process and structural decision - making model for the group discussion (Nagasaka et al., 2016a). These scientific results had a certain influence on agenda - setting phase of the Swedish national forest program (Nagasaka et al., 2016a). Nagasaka et al. (2016a) show that the researchers of the SLU and Future Forest have fulfilled the criteria according to the RIU model to play as scientists in the establishment of the NFP. Therefore, the case of the NFP establishment supports the hypothesis that the option of a high amount of research, integration, and utilization exists.

The second one is three thematic case studies in Germany, which reveal that the institutional setting of departmental research institutions (i.e. BfN) allows for a high amount of research, integration, and utilization activities (Heim et al., 2017). This 
statement was supported by examining the quality criteria applied by the BfN according to the RIU model (Heim et al., 2017).

Böcher (2012) describes departmental research institutions as an institutionalized solution to address challenging problems at the interface between science and policy. As a department research institution, the BfN is tasked to provide science - based policy advice for the field of nature conservation in Germany and the BfN officials are trained to act in the different roles (Heim et al., 2017). Therefore, it is assumed that effective science - policy advice processes can be carried out by the BfN (Heim et al., 2017). The BfN's activities under CITES were analyzed using the case of ivory trade. The BfN had recognized many difficulties in the enforcement of CITES owing to a lack of methodologies to clearly determine the age and origin of traded ivory specimens (Heim et al., 2016a). To tackle these difficulties, the BfN initiated a research project to determine the age and origin of ivory in order to contribute to more effective CITES enforcement_(Heim et al., 2016a)._The BfN has also conducted different small - scale, regional studies on floodplains (Heim et al., 2016b) as well as the research related to the nomination and inscription process of national German beech forests under the World Heritage Convention (Heim et al., 2018). 
Table 5. Comparative empirical evidence for independence of factors determined knowledge transfer (Indirect hypotheses)

\begin{tabular}{|l|l|l|l|l|l|l|l|l|l|l|l|l|l|l|l|l|l|l|}
\hline \multirow{2}{*}{ No } & \multicolumn{2}{|l|}{ Options } & JS1 & JS2 & JS3 & JS4 & G1 & I1 & I2 & I3 & V1 & V2 & V3 & V4 & V5 & $\sum$ \\
\hline & R & I & U & & & & & & & & & & & & & \\
\hline 1 & + & + & + & $\sqrt{ } \sqrt{ }$ & $\sqrt{ } \sqrt{ } ?$ & $? \sqrt{ } \sqrt{ }$ & $\sqrt{ } \sqrt{ } ?$ & $\sqrt{ } \sqrt{ }$ & & & & & & & & & $\sqrt{ }$ \\
\hline 2 & + & + & - & & & & & & $\sqrt{ } ? \sqrt{ }$ & $\sqrt{ } ? \sqrt{ }$ & $\sqrt{ } \sqrt{ }$ & & & & & & $\sqrt{ }$ \\
\hline 3 & + & - & + & & & & & & & & & & & & & & $?$ \\
\hline 4 & + & - & - & & & & & & & & & $\sqrt{ } \sqrt{ }$ & & & & $\sqrt{ } \sqrt{ } ?$ & $\sqrt{ }$ \\
\hline 5 & - & + & + & & & & & & & & & & & $\sqrt{ } \sqrt{ }$ & & & $\sqrt{ }$ \\
\hline 6 & - & + & - & & & & & & & & & & $\sqrt{ } \sqrt{ }$ & & $\sqrt{ } \sqrt{ } ?$ & $\sqrt{ }$ \\
\hline 7 & - & - & + & & & & & & & & & & & & & \\
\hline 8 & - & - & - & & & & & & & & & & & & & & $?$ \\
\hline
\end{tabular}

Notes: $\sqrt{ }$ : Relevant

$?:$ No information
JS: Cases of Japan and Sweden

G: Case of Germany
I: Case of Indonesia

V: Case of Vietnam 
Notes:

\begin{tabular}{|l|l|l|l|}
\hline & & Bigger amount & Less amount \\
\hline $\mathbf{R}$ & $\begin{array}{l}\text { Scientific statements about } \\
\text { problems and solutions }\end{array}$ & + & - \\
\hline $\mathbf{I}$ & $\begin{array}{l}\text { Scientific Statements about } \\
\text { future actions }\end{array}$ & + & - \\
\hline $\mathbf{U}$ & Actions & + & - \\
\hline
\end{tabular}

The analysis of Heim et al. (2017) shows that the research of the BfN has conducted a high amount of research including the assessment of scientific data sources, cooperation with scientific institutions and individuals via various research projects and workshops following the good scientific practice.

Regarding integration activities, the BfN cooperated with the federal states and protected area administrations to find their alliance in gathering samples for ivory analysis (Heim et al., 2016a). The BfN made many efforts to find allies in different countries to support for the nomination and inscription of German beech forests as World Heritage. In addition, the BfN has demonstrated the scientific results by press coverage of BfN activities (Heim et al., 2017). In the sphere of Utilization, the BfN's activities led to the development of a new methodology on ivory age and origin determination (Heim et al., 2016a). The BfN largely contributed to the preparation of national flood protection programs and ultimately, via the BfN's engagement in the nomination and inscription of German beech forests (Heim et al., 2016b; 2018).

The case studies reveal that the $\mathrm{BfN}$, as department research organization, provided a high amount of research that was successfully integrated to be used in policy agenda by political actors.

\section{Indirect hypothesis 2: Research (+), Integration (+), Utilization (-)}

This hypothesis has been examined in the case of improving the management and rehabilitation of mangrove forest in Indonesia. Dharmawan et al. (2017b) show that the focus of research on Segara Anakan mangrove action plan is to improve the management and rehabilitation of the mangrove forests. A lot of research have been done but the research did not include the status of the mangroves i.e. location, ownership, and the change of land formation as a part of the research's concerns (Dharmawan et al., 2017b). Thus, the form of accreted lands that grow from the water 
was not mentioned in the scientific reports even though mangrove could also be observed in several parts of the land (Dharmawan et al., 2017b). The results of the research recommended the reforestation of the damaged mangrove area; however, the accreted land is not present in the scientific report (Dharmawan et al., 2017b). Thus, the scientific solution to the problem focused on improving mangrove forests and the entire area, and did not analyze the specific problem of accreted land (Dharmawan et al., 2017b). Dharmawan et al. (2017b) reveal that the scientific recommendation was not wrong but could not predict the problem on the conflicting use of accreted land. Regarding the activities of integration, it has been observed that the district government was a powerful ally supporting for the incorporation of the research results into a planning regulation. The district government intended to enlarge the regulation to cover the afforestation of accreted land and thus they were eager to use the scientific results for guidance and for legitimating their actions (Dharmawan et al., 2017b). However, the research results were relevant for the problem of damaged mangrove stands and they provided a sound scientific option for improving the stands while the problem concerning the use of accreted land is not discussed in the report (Dharmawan et al., 2017b).

In utilization, the district government had also an incorrect perception of its potential to solve this problem through regulations and strict implementation. The incorrect perception of the district government and the absence of scientific analysis of the specific problem concerning accreted land caused a failure in science - based policy advice (Dharmawan et al., 2017b). The district government used scientific advice on how to conduct mangrove management in order to legitimize the entire program, including the afforestation of accreted land, which was not part of the scientific analyses (Dharmawan et al., 2017b). This misuse of scientific advice for legitimating preferred policy later became the reason for the failure of this policy (Dharmawan et al., 2017b). The case of the mangrove action plan for the Segara Anaka Lagoon demonstrates a failure in scientific policy advice despite a high amount of research. The mangrove action plan was based on sound scientific research accompanied by effective integration but did not produce a solution to the problem of unsustainable management of mangrove forests (Dharmawan et al., 2017b). The illegal logging on accreted land was not stopped (Dharmawan et al., 2017b). Science did not change the district government's wishes to stop illegal use by issuing regulations on afforestation and the management of mangrove forests, including the accreted land. As a main ally of the mangrove action plan, the district government did not remain within the limited rationality of the scientific research and its recommendations but designed its own 
regulations to additionally address the issue of the conflicting use of the accreted land, resulting in its failure in practice (Dharmawan et al., 2017b).

The RIU model emphasizes that integration, as well as utilization, have the freedom to select scientific knowledge even though it is driven by political interests but this selection must be made from the existing research results (Böcher and Krott, 2016). In the case of the mangrove action plan, the actors (district government) decided to act beyond scientific results, thus science cannot be blamed for emerging political deficits (Dharmawan et al., 2017b). The limits of scientific knowledge, in this case, occur not because of deficits in transferring but they are caused by limited resource for research (Dharmawan et al., 2017b). It is supposed that the limits of scientific rationality are not an exception but they happen within any scientific advice (Dharmawan et al., $2017 \mathrm{~b}$ ). In the case of the management plan for mangrove forests, the district government ignored the limits of this plan and assumed that the plan will address the conflict on concreted land. Nevertheless, this conflict of ownership and access to land is outside the research topic and thus it could not be solved by science - based policy advice (Dharmawan et al., 2017b).

In short, the case of mangrove action plan shows that a big amount of research and professional integration might still fail in practice if the actors use the scientific results to solve the problem that is beyond the scope of the research. Thus, this hypothesis is supported.

\section{Indirect hypothesis 3: Research (+) Integration (-) Utilization (-)}

Do Thi et al. (2018a) show that scientific statements might fail to be used in practice owing to the limits of integration. This hypothesis has been supported by the case of LLINC project in the establishment of Ngo Son Ngo Luong Nature Reserve (Do Thi et al., 2017) and the case of biodiversity conservation strategy through efficient land use (Do Thi et al., 2018a).

Regarding the establishment of Ngoc Son Ngo Luong Nature Reserve, Do Thi et al. (2017) reveal that the LLINC project provided many scientific statements to the establishment process but its research was not used by political actors due to few integration activities. The research of the LLINC project was conducted by the researchers of the Institute of Anthropology and Leuven University, focusing on the socioeconomic characteristics of the Ngoc Son Ngo Luong region, land allocation, forest management, and the perceptions and expectations of stakeholders about the anticipated Nature Reserve. The research has suggested that the creation of the Nature 
Reserve to exclude the local people was possibly not a reasonable solution for the Ngoc Son Ngo Luong region (Do Thi et al., 2017). The LLINC project's results suggested that, apart from the option of establishing the Nature Reserve, other options under the existing legislation might be more effective (Do Thi et al., 2017). Based on international and national studies, and the particular context of Ngoc Son-Ngo Luong region, the research results suggested eight distinct options for the Ngoc Son Ngo Luong area (1) nature reserve (2) national park (3) species and habitat conservation area (4) cultural and historical environmental or landscape conservation area (5) UNESCO human and biosphere reserve (6) local or provincial forest reserve (7) allocated land-use certification of forest-land use (8) allocated forest-protection contracts (Do Thi et al., 2017). In the LLINCP research, the Vietnamese and Belgian researchers applied Social Learning Theory (SLT) to promote strategies for multiplestakeholder ecosystem management in the context of establishing the Nature Reserve (Do Thi et al., 2017). They aimed to attract all of the stakeholders' interests in the negotiating process, which was considered a social learning process. Regarding the Nature Reserve's boundaries, the LLINCP suggested to formulate the natural boundaries, which include almost the entire ecosystem of the region's limestone range from Pu Luong Nature Reserve to Cuc Phuong National Park (Do Thi et al., 2017). That option would have been relevant to biodiversity conservation. The research by LLINC project for the feasibility study of the Ngoc Son Ngo Luong region was conducted in compliance with sound scientific practices by the Vietnamese and Belgian scientists. That aspect of the study involved reviewing the legal framework for special-use forests in Vietnam and assessing international and national previous scientific research conducted in the Pu Luong Cuc Phuong region. SLT was applied as an interpretive framework for understanding the establishment process of the Nature Reserve. One important indicator of scientific research is the presentation of the research results to the scientific community and the publication of scientific papers (Do Thi et al., 2017). The LLINC project produced six published papers at the national level in Vietnamese social science journals, indicating the scientific activities of their studies. All of their methods and results were well documented in their reports on the LLINC project.

The research of LLINC project for establishing the Nature Reserve was oriented towards three public goals: nature conservation, improvement of local livelihoods, and involvement of local people. The LLINC project tried to engage local people and their interests in the establishment process through their research activities, and they expected the Hoa Binh provincial government to agree to establish a collaborative 
forest management model in the Pu Luong Cuc Phuong region. Based on its research results, the LLINC project claimed that the involvement of local people was necessary for conserving the Ngoc Son Ngo Luong region because their lives had greatly depended on forest resources for many generations.

The scientists of LLINC project argued on behalf of a collaborative forest management model with direct local participation, which they argued could reduce the anticipated tension among the three public goals. The communities that were expected to have an influence on the establishment of the Nature Reserve were invited to participate in the process. However, during a seminar in Hoa Binh on March 16, 2004, the interests of the local people were ignored by the powerful stakeholders (Do Thi et al., 2017). The notion of a collaborative forest management model based on the research results of LLINC project was not relevant to Vietnam's political process, which privileges the power of the state over the empowerment of local people. Therefore, the collaborative plan did not receive support from national allies.

It shows that the LLINC project tried to communicate with the local people through its research activities, interviews, meetings, and seminars. However, their communication was not successful because the information flow between the district and the community was disrupted. Therefore, the LLINC project was ineffective and the provincial government and local people did not understand the innovative messages about collaborative management and social learning disseminated by the LLINC project.

Consequently, the results of LLINC project were not applied by the provincial government or by the local people. The options proposed by the LLINC project were not seriously considered (Do Thi et al., 2017). The powerful actors at the provincial and district levels focused only on the conservation of forests regarding prohibited areas, which were defined in an exclusive way. The options to allocate forestland classified as protected forests under land use certificates (option 7 by LLINC project) or types of contracts (option 8 by LLINC project) were ignored by the powerful actors. In addition, the provincial government did not support the option of natural boundaries suggested by the LLINC project. Thus, although many research activities are conducted, they failed to influence politicians and had no effect on the local problems owing to a weak integration strategy (Do Thi et al., 2017).

This hypothesis has also been supported by the case of biodiversity conservation strategy through efficient land use in Pu Luong Cuc Phuong conservation area (Do Thi et al., 2018a)._Efficient land use became an important strategy for reducing the dependency of local people on natural resources and contributing to biodiversity 
conservation._Drawing upon research results, many land use measures were selected for implementation in the communities in and around the PLNR and NSNLNR. Of these, land use efficiency was best addressed through three main activities: (1) agroforestry cultivation, (2) irrigation development, and (3) delivery of improved cooking stoves (Do Thi et al., 2018a).

These initiatives for efficient land use (e.g., agroforestry cultivation, small irrigation development, and improved cooking stoves) were developed based on a 2002 ECOLIME project input study, which acquired both local and international information on ICDP approach. The research procedures followed proper scientific practices, and the results were clearly documented. The research reports became the foundation upon which the World Bank and FFI developed the biodiversity conservation strategies for PLCP area. The research was conducted in cooperation with the Limestone Landscape Improving Negotiation for Conservation project, which used a participatory approach to establish a biodiversity corridor between the PLNR and the CPNP. In addition, two baseline surveys, conducted by FFI in 2002, were consulted for efficient land use strategies in PLCP area. Based on such an accumulation of data, implementation of efficient land use activities for biodiversity conservation was clearly based on scientific research (Do Thi et al., 2018a).

Regarding the activities of integration, efficient land use was oriented toward two public goals: biodiversity conservation and poverty alleviation- both relevant to the Vietnamese government's poverty reduction policies and programs in rural areas. Although biodiversity conservation through efficient land use reflects a recent trend in community-based conservation and co-management in biodiversity conservation (Balint, 2006; Berkes, 2007), we found that its impact was limited and fragmented at the household level owing to the limited funding and duration of the project (FFI, 2006; 2009). Moreover, after the project's completion in 2009, few of the implemented efficient land use measures were continued by the local people (Do Thi et al., 2018a). In the RIU model, the ineffective utilization of this strategy was due to a lack of sustainable investment allies arising from the limits of integration. An analysis of the actors involved in the knowledge transfer process shows that the strategy did not garner strong support from powerful allies (e.g., provincial people's committees or provincial forest protection departments) such so that the activities could be implemented long-term at the study site (Do Thi et al., 2018a). Furthermore, the project itself was not a sustainable ally, as it operated for only a limited period of 8 years. These results support the hypothesis that many scientific statements might fail in practice owing to the limits of integration, as we conclude that despite its scientific 
basis, the strategy of efficient land use as a contributor to biodiversity conservation suffered limited implementation owing to the unsuccessful integration of efficient land use in practice.

\section{Indirect hypothesis 4: Research (-) Integration (+) Utilization (-)}

There are two cases supporting for this hypothesis. They are the case of Vietnamese Red Data Book (Do Thi et al., 2018b) and the case of FIPI project in the establishment of Ngoc Son Ngo Luong Nature Reserve (Do Thi et al., 2017). First, the case of Vietnamese Red Book states that_even if the research that provides less scientific statements, it can achieve political influence in case of successful integration. Do Thi et al. (2018b) reveal the little amount of scientific research that is done for the Vietnamese Red Data Book 2007, which are caused by a lack of data and scientific monitoring of rare and threatened species in Vietnam as well as unknown factors influencing them. In spite of these limitations, scientific recommendations of the Vietnamese Red Data Book 2007 have been selectively used by the policymakers in wildlife protection policy formulation of Vietnam. Do Thi et al. (2018b) explore the link between the Vietnamese Red Data Book 2007 and the lists of threatened species in five Vietnamese laws on protected species. It has been calculated that there were 856 species listed in the Vietnamese Red Data Book 2007, while 475 out of 856 species were listed in the five Vietnamese laws on protected species. Particularly, 19\% (164/856) of the species found in the Vietnamese Red Data Book made it into Decree 32 while $11 \%(94 / 856)$ of the species made it into Decree 160. In addition, the proportion of red - listed species that were also found in Circular 02/2006, Decision 82/2008, and Decision 140/2000, are 2.5\% (22/856), 21.8\% (187/856), and 0.9\% (8/856) respectively (Do Thi et al., 2018b). This has indicated that the Vietnamese Red Data Book 2007 has been selectively used by political actors. Therefore, there is a potential for science - based policy advice that is used by policymakers despite few scientific statements (Do Thi et al., 2018b).

Second is the case of FIPI project in the establishment of Ngoc Son Ngo Luong Nature Reserve. Together with the LLINC project, the FIPI was contracted by FFI (funder of ECOLIME project) to conduct the two aspects of the feasibility study of the Ngoc Son Ngo Luong region through the ECOLIME project. FIPI studied the characteristics of the flora and fauna, forest vegetation cover, and the status of land use in the Ngoc Son Ngo Luong region. FIPI assessed the extent of flora and fauna diversities, the valuable and rare species, and the importance of the ecological system (FIPI, 2004). However, 
it applied little clearly documented - research methods. Only a little amount of national and international scientific sources is cited (Do Thi et al., 2017). Little is published and no sound theory and data are applied (Do Thi et al., 2017).

The FIPI research focused on the public goal of biodiversity conservation, which was in accord with international stakeholders and the provincial government. The establishment of the Nature Reserve conformed to Vietnam's political processes, which strengthen the power of state agencies related to forest conservation. Thus, the FIPI research results gained support from national allies (Do Thi et al., 2017). During negotiations on the establishment of the Nature Reserve, Hoa Binh Provincial People's Committee and Hoa Binh Forest Protection Department always worked with the FIPI researchers to select solutions. Choosing to establish a nature reserve was a reasonable option for the Hoa Binh provincial government and somewhat expected by the local people because that option took Vietnam's traditional approach to forest conservation. Regarding the Nature Reserve's boundaries, FIPI scientists offered four options based on their research (Do Thi et al., 2017). However, during the selection process (integration), FIPI leaned toward using the administrative borders as the boundaries. This idea was consistent with Vietnam's political processes. That option could have created many advantages for protection and management; however, the option of using administrative boundaries did not meet the requirements of a biodiversity corridor because the Nature Reserve would not be physically adjacent to Cuc Phuong National Park (FIPI, 2004).

The FIPI researchers apparently communicated well with the provincial government, which had the most decision-making power for establishing the Nature Reserve. However, FIPI did not communicate with the local people because it knew that the local people were weak stakeholders with no power in the decision-making process. Therefore, the plan to establish the Nature Reserve used the administrative boundaries, including part of the Tan My community, to create the corridor between Pu Luong Nature Reserve and Cuc Phuong National Park, which was subsequently submitted to the Ministry of Agriculture and Rural Development for approval.

Although the research of FIPI project bases on few scientific statements, FIPI succeeded regarding political and practical utilization. As a result, Hoa Binh provincial People's Committee entered into decision No. 2714 (December 28, 2004) establishing the Nature Reserve based on FIPI's part in the feasibility study (Do Thi et al., 2017). The establishment of the Nature Reserve in this area meant that the forestland that had been allocated to local households was revoked and put under the government's protection. The Nature Reserve is in the special-use forest category of Vietnam's forest 
classification system. The Vietnamese special-use forest laws state that all exploited activities are forbidden, including hunting, logging, and collecting non-timber forest products. Upon the establishment of the Nature Reserve, the local people lost access to important survival resources. Due to the strong need of local people, there is a danger that the illegal uses of the forest resources will likely increase. To convince stakeholders of the feasibility of establishing the Nature Reserve, FIPI promised to develop a plan to support the local people. However, that plan was never implemented (Do Thi et al., 2017). In response, the local people resisted in many different ways (NSNL, 2006; 2007; 2008). They continued exploiting forest resources inside the nature reserve, which significantly increased because they no longer owned the forestland (Nguyen, 2014).

A lengthy period ensued between the establishment of the Nature Reserve in 2004 and the formation of its management board in 2006. During that gap, the Ngoc Son Ngo Luong region was not officially managed by any governmental agencies and serious exploitation of forest resources occurred (Do Thi et al., 2017). The slow and ineffectual implementation process and the illegal exploitation suggest that the Nature Reserve was established did not provide an appropriate local solution. The Hoa Binh provincial government fully adopted the FIPI results and, therefore, the recommended solution was not "good" governance because it ignored the local people. The effect of the Nature Reserve on the local people has been weak because their illegal exploitation still occurred after the establishment of the Nature Reserve.

Thus, these results indicate that although the research producing few scientific statements, it might achieve certain political and practical utilization in case of successful integration.

\section{Indirect hypothesis 5: Research (-) Integration (+) Utilization (-)}

This hypothesis has been examined by the case of the linkage strategy between biodiversity conservation and livelihood development in $\mathrm{Pu}$ Luong Cuc Phuong conservation area. Do Thi et al. (2018a) indicate that the research that provides few scientific statements, might fail to lead to practical application, even with integration efforts by powerful stakeholders.

Since the ECOLIME project is labeled as an Integrated Conservation and Development Project (ICDP), it attempted to link biodiversity conservation to livelihood development in most of its activities. The project expected to improve conservation efforts and reduce threats to biodiversity by integrating the development 
needs and aspirations of local communities with biodiversity conservation. Based on Salafsky and Wollenberg's conceptual framework (2000), Do Thi et al. (2018a) claim that the ECOLIME project employed a mixture of the three approaches (no linkage, indirect linkage, and direct linkage) to mitigate threats to biodiversity. The ECOLIME project, in partnership with the Limestone Landscape Improving Negotiation for Conservation project, supported the Hoa Binh provincial government in creating a biodiversity corridor between the PLNR and the CPNP (Do Thi et al., 2017). The creation of a new protected area (the NSNLNR) in 2004, which excluded local people from their land, could be characterized as a no linkage approach.

The ECOLIME project also provided substitute livelihoods to reduce activities that negatively affect biodiversity conservation (e.g., microfinancing, promotion of local products, cow/pig breeding) (Do Thi et al., 2018a). These created indirect linkages between biodiversity conservation and livelihood development; however, the goals of these activities were not easily achieved (Oates, 1995; Hughes and Flintan, 2001; Sunderland et al., 2007) because these approaches were not directly tied to conservation activities. Accordingly, the ECOLIME project and the PLNR enacted hundreds of informal agreements between the PLNR and local people, providing local people with small grants for livelihood development activities if they took on forest protection efforts (e.g., forest patrolling, watershed forest protection, or reporting violations) (Do Thi et al., 2018a). Unfortunately, the project only supported a small number of locals in targeted groups (FFI, 2006; 2009). Moreover, since these informal agreements were not legally binding, the local people were not committed to those efforts after the project ended, as no monitoring systems were created by the agreements (Do Thi et al., 2018a). In the PLCP area, violations triggered by neighboring villagers (e.g., poaching and illegal logging) were still observed (Do Thi et al., 2018a). The illegal exploitation and the ineffectiveness of the informal agreements suggest that this indirect linkage strategy did not provide an appropriate local solution for conservation in the study site (Do Thi et al., 2018a).

In addition, ecotourism is considered a direct linkage that creates dependent relationships between conservation and development. The idea of ecotourism was initiated within the framework of the ECOLIME project. Interview results have shown that some households could raise income from ecotourism, which is expected to provide a direct incentive to stop external threats to biodiversity (Do Thi et al., 2018a). It was observed that although ecotourism is prevalent in the area, poor people (the target group of the project) do not reap many benefits from it (Do Thi et al., 2018a). Since poor people lacked the skills and facilities with which to conduct ecotourism 
(e.g., homestays, transportation, and food services), they could not continue the ecotourism activities after the withdrawal of the project. Thus, direct linkage through ecotourism did not improve the livelihoods of the poor, who depend greatly on forest resources. The linkage strategies were directed toward two public goals, biodiversity conservation, and poverty alleviation, and were intertwined with the political process in Vietnam. However, although linkage strategies between conservation and development were integrated into the activities of the ECOLIME project, these strategies were not applicable in practice (Do Thi et al., 2018a).

Prior to the establishment of the ECOLIME project (2002), scientific research revealed that linkage between biodiversity conservation and livelihood development is a necessary but insufficient condition for conservation to take place, and high linkage by itself does not guarantee successful conservation (Salafsky and Wollenberg, 2000). However, despite the scientific literature claims that success through such linkages is elusive (Adams et al., 2004; Christensen, 2004), the ECOLIME project made many attempts to link livelihood development to biodiversity conservation through indirect and direct linkage approaches with the aim of achieving successful conservation in the PLCP area. However, these linkages were not efficiently maintained owing to weak monitoring of the nature reserve and a lack of strong allies investing in economic substitution for the long term. The analysis shows that although many integration efforts have been made by powerful actors, the research on the linkage between biodiversity conservation and livelihood development still failed in practical application due to the limits of the scientific statements within research.

In this dissertation, we have examined the independence of the factors of the RIU model that limit the transfer of scientific knowledge. The results of the literature review on RIU model and my own case studies show that empirical evidence of cases in Vietnam, Germany, Indonesia, Japan, and Sweden supports the hypothesis about the independence of research, integration, and utilization. Specifically, my own cases of nature conservation in Vietnam provide empirical evidence for three combinations of research, integration, and utilization. One important consequence of the independence is that a big amount of research does not necessarily lead to effective integration or utilization and vice versa. Thus, the factors of research, integration, and utilization determine independently from each other the transfer of scientific knowledge in our investigated cases. This supports our leading hypothesis in this dissertation.

In addition, our analysis demonstrates the usefulness of the RIU model. By applying the RIU model, the limiting factors of scientific knowledge transfer could be determined 
within research, integration, and utilization. Therefore, the RIU model becomes a useful tool to particularly indicate these limiting factors and give recommendations to improve research or integration or utilization in an effort to foster science - based policy support. Based on our research, we also emphasize the importance of checking all three factors (Research, Integration, and Utilization) to assess the transfer of scientific knowledge in practice.

However, further research is needed to investigate the existence of three combinations that we have not observed yet. We also suggest that further research should be implemented in various countries to examine the independence of research, integration, and utilization in scientific knowledge transfer within different contexts.

\section{Strategic options for stakeholders: The Vietnam National University of Forestry (the VNUF)}

The proof by this dissertation that research, integration, and utilization independently determine the transfer of scientific knowledge into practice opens up many options for improving knowledge transfer in practice. There is no need for an overall integrated solution that will be too difficult to achieve anyway. Small and independent steps within research or integration or utilization can strengthen the knowledge transfer sufficiently. Three options for Vietnam are suggested in the following chapter.

\subsection{Linking theory - based teaching with consulting experience for project- learning at the VNUF}

The Vietnam National University of Forestry (the VNUF) is one of the leading universities in the field of Forestry in Vietnam. Founded on 19 August 1964 according to decision 127/CP dated 19/08/1964 by the Prime Minister of Vietnam, the VNUF is committed to the values of quality of training, innovation, development, collaboration, and responsibility. As a multi-disciplinary university with 4 faculties and 5 research institutes, the VNUF covers a diverse spectrum of subjects in the field of forestry and rural development. Presently, the VNUF has been training 31 different majors, including Undergraduate (31 majors); Master (10 majors), and Doctor (6 majors) (VNUF, 2017). With around 11,000 students trained per year, the VNUF has significantly provided high-quality employees for the forestry and rural development sectors of Vietnam. Concerning scientific research, the VNUF is a center for research and development of applied science and technology and has partnerships with many universities, research institutions, national and international organizations. The VNUF 
has identified research focuses including Forest resources and environment management, Silviculture, Forest Ecology and Environment, Sustainable forest resources management, Forestry policy, Climate change and Wood technology (VNUF, 2017).

The VNUF always puts an important emphasis on the quality of teaching and studying. Of the 609 lecturers and researchers of VNUF, 80\% has Master and Doctor Degrees in different specialized majors (VNUF, 2017). They have participated in many important projects at national and international levels. According to statistics of the VNUF, in 2016 the VNUF has conducted 7 national research projects, 5 ministerial level projects, 2 provincial projects, 62 university-level projects with the total of fund is 634,228 euros (Table 6) (VNUF, 2017).

The VNUF has a system of laboratories, seeding garden and modern research centers to meet the requirements of the research and training. The VNUF has also established cooperation with more than 60 universities, organizations and research institutes in the world (VNUF, 2017). The VNUF is developing towards a leading center for counseling, training, and implementating of international cooperation in the forestry and forest - related projects in Vietnam.

Table 6 . The number of research projects implemented by the VNUF in 2016

\begin{tabular}{|l|l|r|r|}
\hline No & \multicolumn{1}{|c|}{ Research projects } & Number & \multicolumn{1}{|c|}{ Fund (Euros) } \\
\hline 1 & National research projects & 07 & 423,076 \\
\hline 2 & $\begin{array}{l}\text { Ministerial - level research } \\
\text { projects }\end{array}$ & 05 & 192,307 \\
\hline 3 & Provincial/City research projects & 02 & 11,538 \\
\hline 4 & University - level research projects & 62 & 7,307 \\
\hline 5 & Total & 76 & 634,228 \\
\hline
\end{tabular}

The quality of teaching and learning is always an important focus in the development vision of the VNUF (VNUF, 2017). The university has provided a good system of textbooks, libraries, laboratories and learning materials to its students and researchers. However, the fact is that the theoretical training is based on mainly theory and textbooks with the rigid curriculums could influence on the quality of training that leans towards basic theory and underestimate practical issues (VNUF, 2017). Thus, there is an increasing demand to improve practical part in university teaching at the VNUF. 
In 1996, a new approach of participatory curriculum development (PCD) has been applied at the VNUF with the initiation of the Social Forestry Support Program, funded by the Swiss government. A participatory curriculum development approach aims to develop a curriculum from the interchanges of experience and information between the various stakeholders in an education and training program (Taylor, 1998; 2000). The PCD approach has been tested extensively within a program of support for forestry education at the VNUF. Then, there has been a consensus among the Social Forestry Support Program that the PCD is a relevant and useful approach in the Vietnam context (Taylor, 2000). The application of new approaches like the PCD indicates that the VNUF may provide a good opportunity to apply other new approaches with aims of improving the quality of teaching and learning.

The fact is that scientists and lecturers of the VNUF have acted as consultants for some national and international projects (VNUF, 2017). Thus, they have cumulated practical experience through the projects in which they participated. If this consulting experience is integrated into teaching, it will help to improve the practical aspect of the university teaching. Therefore, we suggest conducting project learning that facilitates to learn the consulting knowledge from the consulting projects and integrate it into the university teaching.

However, there are growing debates that the consulting knowledge of practical projects does not always provide a good fit for the university teaching since consulting papers lack often a basis of the scientific statement. Often, the lecturers and researchers tend to teach the successful consulting projects. However, only consulting knowledge, which is explicitly linked to scientific statements can contribute to the improvement of the university teaching. We suggest discriminating four options of the consulting knowledge (Figure 3). The consulting projects can produce diverse products that depend on the objectives of the project. It is observed that a consulting project may put a focus on practical activities (option 4), which only conducts practical interventions without research and integration activities. The consulting project may also produce integration activities only (option 3), which looks for a good link to the political system and support from powerful allies through effective communications. Both options cannot make a link to university teaching since they are not based on scientific statements that are very important to academic teaching at universities.

In some other projects, both integration and utilization activities are implemented but they overlook the aspect of research or omit scientific statements (option 2). This case cannot also contribute to university teaching due to the absence of its scientific statements. In option 1, a consulting project can include three activities of research, 
integration, and utilization or it conducts integration and utilization based on scientific statements from other research. This option may provide a good link to university teaching because the project uses scientific statements as an important basis to implement integration and utilization activities. Thus, the products of the project in option 1 can be best used in university teaching.

Based on our analysis, we suggest that the RIU model can help scientists to look for empirical experience from consulting projects that are explicitly based on scientific statements as in option 1 to be integrated into the university teaching.

As an example, from 2016 to 2017, UNEP granted a project titled "Integrating knowledge on REDD+ for the master training program of the VNUF" to the VNUF (VNUF, 2017). Based on our results, we suggest applying the RIU model in implementing the project like this. Scientists of the VNUF who participated in the projects on REDD+ will be selected to formulate a project learning on REDD+. Then, scientists will apply the RIU models and its criteria to explore the activities of research, integration, and utilization within previous projects on REDD+ in which the scientists participated as consultants or technical advisers.

By using the criteria of the RIU model, the scientists can identify which part of consulting work is based on scientific statements complying with good scientific practice. Then, the scientists will choose consulting results that are based on scientific statements on REDD+ to be integrated into the master training program of the VNUF. Thus, the RIU model becomes a useful tool to select the consulting results that are based on scientific statements and integrate them into the university teaching. The selection of scientific statements within consulting works by scientists can significantly contribute to the development of practical - oriented teaching at the VNUF.

\subsection{Need for improvement of national scientific basis}

Our studies indicate that the results and solutions produced by the national research organizations are well accepted by the powerful stakeholders. The deficit is only that they have narrow scientific limitations. As an example, although both the red listing project and FIPI project for the establishment of Ngoc Son Ngo Luong Nature Reserve have scientific weaknesses, their scientific results were integrated into biodiversity conservation policy of Vietnam. These two projects were conducted by national research institutes of Vietnam. Thus, strengthening the national research organizations (e.g. the VNUF) would be a promising way to improve scientific support of the policy. 


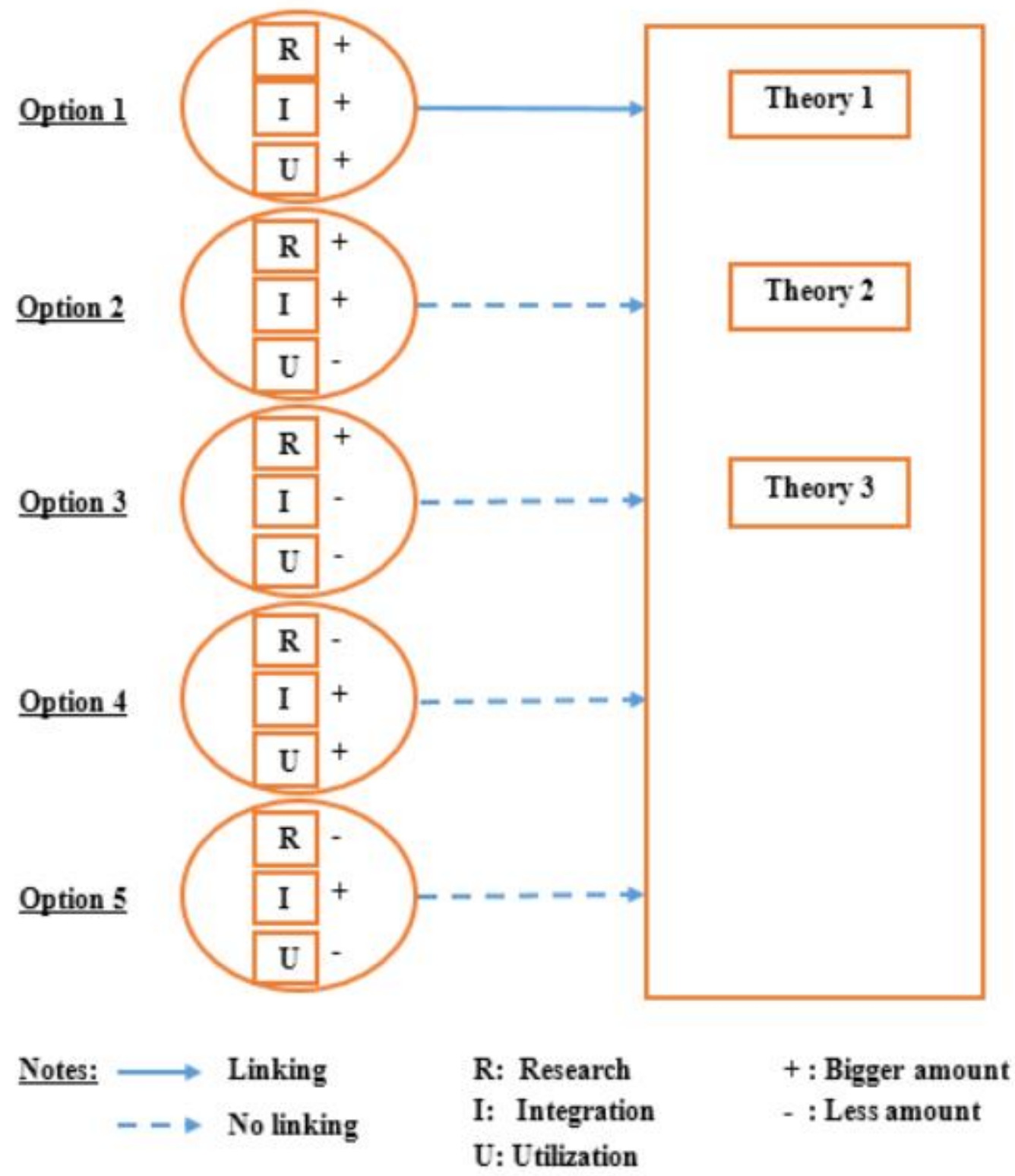

Figure 3: Model for using consulting knowledge in university teaching

A focus on improving national research through a series of small steps would likely foster the ability to support policy. Often the most innovative international project cannot provide this support because it is conducted on a too high level with too much focus on the scientific problems of the donor country, which are not the same as the problems of science in the target country. Thus, we would recommend that international donors should put a necessary emphasis on the improvement of national scientific basis in an effort to enhance science - based policy support in developing countries like 
Vietnam. As an example, the case of Vietnamese Red Data Book shows that the little amount of scientific statements is made by Vietnamese scientists in the establishment of Red Data Book due to a lack of updated data and scientific monitoring of rare and threatened species (Do Thi et al., 2018b). Thus, Vietnamese scientists need much stronger scientific statements to support the establishment of Vietnamese Red Data Book in the future. Such science might be improved by well-structured species monitoring surveys and an updated national system of biodiversity data, which help to avoid the subjective judgment and the potential bias of the assessment process (Do Thi et al., 2018b). Despite the limits of scientific statements, the research results for the red listing are selectively used by political actors. Therefore, the improvement of national scientific basis might be a promising step to enhance scientific support of policy in developing countries like Vietnam.

\subsection{Optimizing international conservation projects by Vietnam - based professional integration}

From a perspective of scientific knowledge transfer, lack of a professional integration is one significant challenge of international conservation projects in Vietnam (i.e. ECOLIME and LLINC projects). In Vietnam, no departmental agency that is responsible for the integration of international projects could be observed. Both the ECOLIME project and LLINC project have made many attempts to integrate their innovative messages into biodiversity conservation themselves. However, their efforts were not successful (Do Thi et al., 2017; 2018a). Based on our research results, we have shown that the improvement of integration is very essential to optimize scientific knowledge transfer of international conservation projects in Vietnam (Do Thi et al., 2017). Moreover, the task of integration should be conducted by Vietnamese research institutions (e.g. the VNUF) since they have good knowledge of Vietnam political context and they are able to make good communications with national actors. In line with this, we recommend two strategies to enhance the integration of international conservation projects in Vietnam (1) Integration should be implemented by Vietnam institutions (2) A new boundary organization should be established to conduct integration task for international projects. 


\section{References}

Adams, W.M., R. Aveling, D. Brockington, B. Dickson, J. Elliott, J. Hutton, D. Roe, B. Vira, et al. 2004. Biodiversity conservation and the eradication of poverty. Science 306 : 11461149.

Archibald, M. M. 2016. Investigator triangulation: A collaborative strategy with potential for mixed methods research. Journal of Mixed Methods Research, 10(3), 228-250.

Biermann, F., and P.H. Pattberg. 2012. Global environmental governance reconsidered. Cambridge, MA: MIT Press.

Babbie, E. \& Mouton, J. 2001. The practice of social research. Cape Town: Oxford University Press.

Babbie, E. 2004. The practice of social research. London: Thomson Wadsworth.

Bailar III, J. C. 1997. The promise and problems of meta-analysis.

Balint, P.J. 2006. Improving community-based conservation near protected areas: The importance of development variables. Environmental Management 38: 137-148.

Bergman, M. 2008. Advances in mixed methods research: Theories and applications. Thousand Oaks, CA: Sage.

Berkes, F. 2007. Community-based conservation in a globalized world. Proceedings of the National Academy of Sciences of the USA 104: 15188-15193.

Blaikie, N. W. 1991. A critique of the use of triangulation in social research. Quality and quantity, 25(2), 115-136.

Böcher, M. and Krott, M. 2010. Umsetzung des Konzepts einer modernen Ressortforschung im Geschäftsbereich des BMU (UBA-Texte Vol. 39/2010). Umweltbundesamt, Dessau Roßlau.

Böcher, M., and Krott, M. 2014. The RIU model as an analytical framework for scientific knowledge transfer: The case of the "decision support system forest" and climate change. Biodiversity and Conservation 23: 3641-3656.

Böcher, M., and Krott, M. 2016. Science makes the world go round: Successful scientific knowledge transfer for the environment. Basel: Springer.

Böcher, M. 2012. Wissenschaftsbasierte Politikberatung auf Abruf - zur Rolle der Ressortforschungseinrichtungen für Ministerien am Beispiel des BMU. der moderne Staat 5 (2), 459-480. 
Böcher, M. 2016. How does science-based policy advice matter in policymaking? The RIU model as a framework for analyzing and explaining processes of scientific knowledge transfer. Forest Policy and Economics, 68, 65-72.

Caramani, D. 2008. Introduction to the comparative method with Boolean algebra (Vol. 158). Sage publications.

Christensen, J. 2004. Win-win illusions. Conservation 5: 12-19.

Cortner, H. J., Wallace, M. G. and Moote, M. A. 1999. 'A Political Context Model for Bioregional Assessments'. In Johnson, K., Swanson, F., Herring, M. and Greene, S. (eds.). Bioregional Assessments: Science at the Crossroads of Management and Policy. Washington, DC: Island Press: $71-82$.

De Vos, A.S. 2005. Combined qualitative and quantitative approach. In: De Vos, A.S., Strydom, H., Fouché, C.B. \& Delport, C.S.L. Research at grass roots: for the social sciences and human service professions. Pretoria: Van Schaik Publishers: 357-366.

Denzin, N. K. 1978. The research act: A theoretical introduction to sociological methods. New York: McGraw-Hill.

Dharmawan, B., Böcher, M., \& Krott, M. 2016. The failure of the mangrove conservation plan in Indonesia: Weak research and an ignorance of grassroots politics. Ocean \& Coastal Management, 130, 250-259.

Dharmawan, B., Böcher, M., \& Krott, M. 2017a. Failure of science-based win-win solution in fishery management: Learnings from Segara Anakan Waters, Central Java, Indonesia. Ocean and Coastal Management, (141), 82-89.

Dharmawan, B., Böcher, M., \& Krott, M. 2017b. Endangered Mangroves in Segara Anakan, Indonesia: Effective and Failed Problem-Solving Policy Advice. Environmental management, 60(3), 409-421.

Dharmawan, B. 2017c. Science for sustainable use of a lagoon ecosystem: Example of knowledge transfer in Segara Anakan conservation project, Indonesia. Ph.D. dissertation. Goettingen University, Germany.

Do Thi, H., Krott, M., Böcher, M. 2017. The success of scientific support for biodiversity conservation policy: the case of Ngoc Son Ngo Luong nature reserve in Vietnam. J. Nat. Conserv. 38, 3-10

Do Thi, H., Krott, M., Böcher, M., Juerges, N. 2018a. Toward successful implementation of conservation research: a case study from Vietnam. Ambio 1-14.

Do, T.H., Krott, M., Juerges, N., Böcher, M. 2018b. Red lists in conservation science-policy interfaces: A case study from Vietnam. Biological Conservation. 226, 101-110. 
Do Thi, H., Juerges N., Krott, M. \& Böcher, M. 2018c. Can Landscape planning solve scale mismatches in environmental governance? Under revision in Environment and Planning E

Durant, D. 2015. The undead linear model of expertise. In: Heazle, M., Kane, J. (Eds.), Policy Legitimacy, Science and Political Authority: Knowledge and Action in Liberal Democracies. Routledge, Abingdon, New York, pp. 17-38.

FFI (Fauna and Flora International). 2006. Implementation completion report phase 1: Pu Luong - Cuc Phuong Limestone Landscape Conservation Project. Hanoi: Vietnam Country Program.

FFI (Fauna and Flora International). 2009. Implementation completion report phase 2: $\mathrm{Pu}$ Luong-Cuc Phuong Limestone Landscape Conservation Project. Hanoi: Vietnam Country Program.

FIPI (Forest Inventory and Planning Institute). 2004. The feasibility study for the establishment of Ngoc Son Ngo Luong Nature Reserve. Hanoi, Vietnam: FIPI Vietnam.

Heim, J., \& Böcher, M. 2016a. CITES and science: Using the RIU model to analyze institutionalized scientific policy advice in Germany for the case of ivory trade. Journal of International Wildlife Law \& Policy, 19(2), 159-175.

Heim, J., Böcher, M., \& Krott, M. 2016b. Alles im Fluss? Bundesweiter Auenschutz in Deutschland aus der Sicht des RIU Modells wissenschaftsbasierter Politikberatung. Zeitschrift für Umweltpolitik und Umweltrecht, 4, 348-377.

Heim. J. 2017. Assuring quality in science -based policy advice: The case of the German Federal Agency for Nature Conservation. PhD dissertation. Goettingen University, Germany.

Heim, J., Krott, M., \& Böcher, M. 2018. Nomination and inscription of the "Ancient Beech Forests of Germany" as natural World Heritage: multi-level governance between science and politics. International Environmental Agreements: Politics, Law and Economics, 1-19.

Hermans, L. 2008. Exploring the promise of actor analysis for environmental policy analysis: lessons from four cases in water resources management. Ecology and Society 13(1).

Hilton, A. 2003. Should qualitative and quantitative studies be triangulated? International Society of Nurses. Available: http://www.isncc.org/ news/triangle.htm. 
Hughes, R., and F. Flintan. 2001. Integrating conservation and development experience: A review and bibliography of the ICDP literature. London: International Institute for Environment and Development.

Hulme, M. 2009. Why we disagree about climate change: Understanding controversy, inaction and opportunity. Cambridge, UK: Cambridge University Press.

Hussein, A. 2015. The use of triangulation in social sciences research: Can qualitative and quantitative methods be combined? Journal of comparative social work, 4(1).

Juntti, M., Russel, D., \& Turnpenny, J. 2009. Evidence, politics and power in public policy for the environment. Environmental Science \& Policy, 12(3), 207-215.

Kohlbacher, F. 2006. The use of qualitative content analysis in case study research. In Forum Qualitative Sozialforschung/Forum: Qualitative Social Research (Vol. 7, No. 1, pp. 1-30). Institut für Qualitative Forschung.

Krott, M. 2012. Value and risks of the use of analytical theory in science for forest policy. Forest Policy and Economics 16: 35-42.

Mayring, P. 2000. Qualitative content analysis. Forum Qualitative Sozialforschung/Forum: Qualitative Social Research, 1(2), Art. 20. Available at: http://www.qualitativeresearch.net/fqs-texte/2-00/2-00mayring-e.htm.

Mayring, P. 2003. Qualitative Inhaltsanalyse, Grundlagen und Techniken (8th ed.). Weinheim: Beltz, UTB.

Miller, N. 2009. Environmental politics: Stakeholders, interests, and policymaking. New York: Routledge.

Mitchell, E. S. 1986. Multiple triangulation: A methodology for nursing science. . Advances in Nursing Science, 8(3), 18-26.

Monette, D.R., Sullivan, T.J. \& Dejong, C.R. 2002. Applied social research: tool for the human services. London: Harcourt College Publishers.

Nagasaka, K., Böcher, M., \& Krott, M. 2016a. Are forest researchers only scientists? Case studies on the roles of researchers in Japanese and Swedish forest policy processes. Forest Policy and Economics, 70, 147-154.

Nagasaka, K., Böcher, M., \& Krott, M. 2016b. Science-policy interaction: the case of the forest and forestry revitalization plan in Japan. Land Use Policy, 58, 145-151.

Nagasaka, K. 2016c. Roles of Forest Science in Practice: Cases from Japan and Sweden. Ph.D. dissertation. Goettingen University, Germany.

Nesshöver, C., M. Vandewalle, H. Wittmer, E.V. Balian, E. Carmen, I.R. Geijzendorffer, and S. Schindler. 2016. The Network of Knowledge approach: improving the science and 
society dialogue on biodiversity and ecosystem services in Europe. Biodiversity and Conservation 25: 1215-1233.

NSNL (Ngoc Son Ngo Luong Nature Reserve). 2006. Annual report of Ngoc Son Ngo Luong Nature Reserve management. Ngoc Son Ngo Luong Nature Reserve. Hoa Binh, Vietnam: Hoa Binh Forest Protection Department.

NSNL (Ngoc Son Ngo Luong Nature Reserve). 2007. Annual report of Ngoc Son Ngo Luong Nature Reserve management. Ngoc Son Ngo Luong Nature Reserve. Hoa Binh, Vietnam: Hoa Binh Forest Protection Department.

NSNL (Ngoc Son Ngo Luong Nature Reserve). 2008. Annual report of Ngoc Son Ngo Luong Nature Reserve management. Ngoc Son Ngo Luong Nature Reserve. Hoa Binh, Vietnam: Hoa Binh Forest Protection Department.

Nguyen, Q. N. 2014. Educative moments in participatory processes: The case of Ngoc Son Ngo Luong Nature Reserve, Hoa Binh, Vietnam. (Unpublished doctoral dissertation). The Catholic University of Leuven, Faculty of Psychology and Educational Science, Leuven, Belgium.

Normand, S. L. T. 1999. Meta-analysis: formulating, evaluating, combining, and reporting. Statistics in medicine, 18(3), 321-359).

Oates, J.F. 1995. The dangers of conservation by rural development - a case-study from the forests of Nigeria. Oryx 29: 115-122.

Patton, M.Q. 2002. Qualitative research and evaluation methods. London: SAGE.

Perrings, C., A. Duraiappah, A. Larigauderie, and H. Mooney. 2011. The biodiversity and ecosystem services science-policy interface. Science 331: 1139-1140.

Pielke, R., 2007. The Honest Broker: Making Sense of Science in Policy and Politics. Cambridge University Press, Cambridge.

Pregernig, M., and M. Böcher. 2012. Normative and analytical perspectives on the role of science and expertise in environmental governance. In Environmental governance: The challenge of legitimacy and effectiveness, ed. K. Hogl, E. Kvarda, R. Nordbeck, and M. Pregernig, 199-219. Cheltenham: Edward Elgar.

Pregernig, M. 2014. Framings of science-policy interactions and their discursive and institutional effects: Examples from conservation and environmental policy. Biodiversity and Conservation 23: 3615-3639.

Salafsky, N., and E. Wollenberg. 2000. Linking livelihoods and conservation: A conceptual framework and scale for assessing the integration of human needs and biodiversity. World Development 28: 1421-1438. 
Saterson, K.A., N.L. Christensen, R.B. Jackson, R.A. Kramer, S.L. Pimm, M.D. Smith, and J.B. Wiener. 2004. Disconnects in evaluating the relative effectiveness of conservation strategies. Conservation Biology 18: 597-599.

Schmeer, K. 1999. Stakeholder analysis guidelines. Policy Toolkit for Strengthening Health Sector Reform. Global Health Workforce Alliance: 1-43.

Silverman, D. 2000. Doing qualitative research: a practical handbook. London: SAGE Publications.

Stevanov, M., Böcher, M., Krott, M., Krajter, S., Vuletic, D., Orlovic, S. 2013. The Research, Integration and Utilization (RIU) model as analytical framework for the professionalization of departmental research organizations: case studies of publicly funded forest research institutes in Serbia and Croatia. Forest Policy Econ. 37, 20-28.

Sunderland, T.C.H., C. Ehringhaus, and B.M. Campbell. 2007. Conservation and development in tropical forest landscapes: a time to face the trade-offs? Environmental Conservation 34: 276-279.

Taylor, P. 1998. "Participatory Curriculum Development - Some Experiences from Vietnam and South Africa", in Training for Agricultural Development, 1996-98. Rome: FAO.

Taylor, P. 2000. New perspective, new curricula: A case study of participatory curriculum development in forestry education in Vietnam. In Forestry Education workshop, Vietnam.

VNUF. 2017. Annual report on training and scientific research. VNUF. Hanoi, Vietnam.

Weyers, M., Strydom, H., \& Huisamen, A. 2014. Triangulation in social work research: the theory and examples of its practical application. Social Work/Maatskaplike Werk, 44(2).

Wood, A., P. Stedman-Edwards, and J. Mang. 2000. The root causes of biodiversity loss. London: Earthscan.

Young, J.C., K.A. Waylen, S. Sarkki, S. Albon, I. Bainbridge, E. Balian, and D. McCracken. 2014. Improving the science-policy dialogue to meet the challenges of biodiversity conservation: Having conversations rather than talking at one-another. Biodiversity and Conservation 23: 387-404. 


\section{Annex: Constitutive publications}

Do Thi, H., Krott, M., \& Böcher, M. (2017) The success of scientific support for biodiversity conservation policy: The case of Ngoc Son Ngo Luong nature reserve in Vietnam. Journal for Nature Conservation, 38, 3-10.

Do Thi, H., Krott, M., Böcher, M., \& Juerges, N. (2018) Toward successful implementation of conservation research: A case study from Vietnam. Ambio, 47(5), 608-621.

Do Thi, H., Krott, M., Juerges N. \& Böcher, M. (2018) Red lists in conservation science - policy interfaces: A case study from Vietnam. Biological Conservation 226, $101-110$.

Do Thi, H., Juerges N., Krott, M. \& Böcher, M. (2018) Can Landscape planning solve scale mismatches in environmental governance? Under revision in Environment and Planning E 


\title{
The success of scientific support for biodiversity conservation policy: The case of Ngoc Son Ngo Luong nature reserve in Vietnam
}

\author{
Huong Do Thi ${ }^{\mathrm{a}, \mathrm{b}, *}$, Max Krott $^{\mathrm{a}}$, Michael Böcher ${ }^{\mathrm{c}}$ \\ a Georg-August-Universität Göttingen, Büsgenweg 3, 37077 Göttingen, Germany \\ ${ }^{\mathrm{b}}$ Vietnam National University of Forestry, Xuan Mai Town, Chuong My District, Hanoi, Viet Nam \\ c Otto von Guericke University Magdeburg, Chair of Political Science and Sustainable Development, Zschokkestr. 32, 39016 Magdeburg, Germany
}

\section{A R T I C L E I N F O}

\section{Article history:}

Received 19 October 2016

Received in revised form 15 May 2017

Accepted 15 May 2017

\section{Keywords:}

Scientific knowledge transfer

RIU model

Scientific support

Professional integration

Biodiversity conservation

Ngoc Son Ngo Luong nature reserve

\begin{abstract}
A B S T R A C T
The successful transfer of scientific knowledge is an increasingly important activity for addressing complex problems of biodiversity conservation. This study used the Research-Integration-Utilization model of scientific knowledge transfer to analyze the research, integration, and utilization activities in the establishment process of Ngoc Son Ngo Luong Nature Reserve in northern Vietnam. The results found successes and failures of scientific support for Vietnam's biodiversity conservation policy. High-quality scientific solutions of the Limestone Landscape: Improving Negotiation for Conservation Project were not utilized by stakeholders due to those solutions' weak integration. Weak research conducted by the Forest Inventory and Planning Institute of Vietnam was transferred through professional integration, which thereby achieved some successes in utilization. The results suggest three options to strengthen scientific support of policy: (1) need for professional integration, (2) improvement of the local scientific basis, and (3) need for improved communication between research and practice.
\end{abstract}

(c) 2017 Elsevier GmbH. All rights reserved.

\section{Introduction}

Many countries around the world have placed increasing policy importance on the conservation of biodiversity as part of their environmental governance (Van Straalen \& Altes, 2014; Wynberg, 2002; Zingerli, 2005). In Vietnam, the government has made many efforts to address its treatment and prevent loss of biodiversity, such as implementing relevant international treaties (e.g., Convention on Biological Diversity), developing national biodiversity conservation strategies, and creating protected areas in a national forest protection system. However, the issues of biodiversity conservation are complex and context-specific because the loss of biodiversity is a multi-dimensional issue related to numerous factors at the local, national, regional, and global levels (Indrawan, Garnett, Masala, \& Wirth, 2014; Managi, 2012; Zheng \& Cao, 2015). To tackle the

Abbreviations: FFI, fauna and flora international; Nature Reserve, Ngoc Son Ngo Luong nature reserve; LLINCP, limestone landscape: improving negotiation conservation project; Pu Luong Project, Pu Luong-Cuc Phuong limestone landscape conservation project; FIPI, forest inventory and planning institute of Vietnam; RIU, research-integration-utilization; SLT, social learning theory.

* Corresponding author at: Georg-August-Universität Göttingen, Büsgenweg 3, 37077 Göttingen, Germany.

E-mail addresses: dohuongnlkh@gmail.com (H. Do Thi), mkrott@gwdg.de (M. Krott), mboeche@gwdg.de (M. Böcher). complex problems of biodiversity loss and environmental change, policymakers and managers should call for scientific solutions. Although interest over the past few decades has been growing, and biodiversity conservation is presently ranked high in political agendas worldwide (Pullin \& Knight, 2001, 2009; Schindler et al., 2011), few studies have investigated the contributions of scientific research to the formation and implementation of biodiversity conservation policies.

Vietnam is an important biodiversity hotspot in Southeast Asia, and it has been a focus of concern among international conservation organizations, such as the World Wildlife Fund, Fauna and Flora International (FFI), International Union for Conservation of Nature, and Birdlife International, since the end of the 1990s. Through the efforts of the Vietnamese government, supported by the financial and technical support of international donors, a system of 164 protected areas was established to protect the country's remaining forest resources. The number of protected areas in Vietnam is predicted to increase in the coming years (MARD, 2014). Although the creation of protected areas remains an important aspect of any conservation plan (Adams \& Hutton 2007; Cernea \& Schmidt-Soltau, 2006), conservationists have begun to believe that they need to seek new conservation strategies as well as solve their limitations (Bruner et al., 2001;Bruner, Gullison, Rice, \& Da Fonseca, 2001; Salafsky \& Wollenberg, 2000). In this context, scientific research could be a good way to achieve long-term biodiversity conserva- 
tion goals and reduce conflicts in nature conservation (Githiru, Lens, Adriaensen, Mwang'ombe, \& Matthysen, 2011).

The Ngoc Son Ngo Luong region is in Hoa Binh province, northern Vietnam. Ngoc Son Ngo Luong is the central part of the Pu LuongCuc Phuong limestone range, which is, from the global perspective, an important example of a karst ecosystem. Moreover, it is the one remaining large area of lowland and limestone forest in northern Vietnam (FFI, 2002). This area supports the habitat of the endemic Delacour's Langur (Trachypithecus delacouri), which is one of the 25 most threatened primate species in the world (FFI, 2002). Because of the importance of protecting the entire Pu Luong-Cuc Phuong limestone range, the Hoa Binh provincial government established the Ngoc Son Ngo Luong Nature Reserve (Nature Reserve) through the support of the Limestone Landscape: Improving Negotiation for Conservation Project (LLINCP) and the Pu Luong-Cuc Phuong Limestone Landscape Conservation Project (Pu Luong Project) in the form of a feasibility study. The Nature Reserve is an important biodiversity corridor for the movement of fauna and flora between Pu Luong Nature Reserve and Cuc Phuong National Park (FFI, 2002).

The LLINCP was a joint research project of Vietnamese and Belgian scientists to develop a landscape and management plan for a biodiversity conservation area in the Ngoc Son Ngo Luong region (LLINCP, 2002). The Pu Luong Project was set up to protect this area and its endangered wildlife by delivering many activities designed to address current conservation issues in the $\mathrm{Pu}$ Luong-Cuc Phuong limestone region (FFI, 2002). To support the establishment of the Nature Reserve, the Pu Luong Project contracted with Forest Inventory and Planning Institute of Vietnam (FIPI) to conduct the feasibility study for the establishment process. Although LLINCP and FIPI contributed scientific support to the establishment of the Nature Reserve, their contributions differed with respect to scientific value and practical application.

This study used the Research-Integration-Utilization (RIU) model of scientific knowledge transfer to analyze the research, integration, and utilization activities during the establishment of the Nature Reserve. The analysis of scientific knowledge transfer in this case revealed the successes and failures of the scientific support for Vietnam's biodiversity conservation policy. This study analyzed the transfer of scientific results from national and international research efforts for the conservation of biodiversity regarding establishment concerns. The central research questions were as follows.

(1) What did scientific support contribute to the establishment of the Nature Reserve?

(2) How can the successes or failures of scientific support of the establishment of the Nature Reserve be explained?

The balance of this paper is structured as follows. First, the RIU analytical framework model is described, which is followed by an explanation of the research methods. Second, the empirical case study of the establishment of the Nature Reserve is elaborated to demonstrate the successes and failures of scientific support to the establishment process. Last, conclusions based on the results are presented to help design options to strengthen practical scientific policy support.

\section{Analytical framework: The RIU model of scientific knowledge transfer}

The RIU model was used to investigate the contributions of scientific support and its successes and failures regarding Vietnam's biodiversity conservation policy. The RIU model was developed by Böcher and Krott through their research projects involving scientific knowledge transfer for environmental and forest policy (Böcher \& Krott, 2016). Their work compiled interesting cases in which scientific knowledge was successfully transferred. Since then, the RIU model has been further developed and applied to cases of scientific knowledge transfer regarding the natural environment in Europe and at the international level (Böcher \& Krott 2016; Dharmawan, Böcher, \& Krott, 2016; Heim \& Böcher, 2016).

The RIU model differs from alternative models of scientific knowledge transfer, such as the linear, functional, and coproduction models (Böcher \& Krott, 2014). Under the linear model, scientific knowledge flows directly from science to application via political stakeholders. However, in reality, a linear scientific knowledge transfer is rare because it cannot directly function within the conflicting perspectives of science (seeking truth) and politics (seeking power) (Böcher \& Krott, 2014). The functional model also underscores the fundamental incompatibility between the scientific and political systems (Miller, 2009), revealing that the relevant actors use scientific results to serve their personal interests and ignore the epistemic core of the scientific results. This model clearly reflects the rationale of politics, but it underestimates the observable epistemic influence of scientific solutions on political and practical decisions (Böcher \& Krott, 2014). The co-production model of scientific knowledge transfer was put forth by Hulme (2009). It highlights the importance of the scientific and unscientific arguments that influence policymaking processes (Hulme, 2009). The co-production model can explain the relationship between science and policy in modern societies where policy decisions are based on scientific insights as well as on social and political factors (Böcher \& Krott, 2014). However, the co-production model lacks a clear way to analyze exactly what happens between practice and science in the co-production process and the part played by political power in the support or disregard of scientific results.

Under the RIU model, the scientific knowledge transfer process is understood as linkages among research, integration, and utilization (Böcher \& Krott, 2016). Research is understood as the production of a particular type of knowledge created using scientific principles, methods, and standards (Böcher \& Krott, 2016). Integration refers to the active bi-directional selection of research results relevant to the various stakeholders. In integration, research results are selected using criteria based on practical demand (Böcher \& Krott, 2014, 2016). Practical demands for scientific solutions also can guide questions for further research (Böcher \& Krott, 2014). The criteria applied to assess integration activities include orientation toward public goals, relevance to the political process, relevance to allies, and target-group oriented to intermediation through appropriate media. Utilization is the practical use of scientific knowledge by stakeholders. The potential products could be practical, and scientific utilization could take many forms, such as laws, decisions on implementation, or creation of political organizations (Böcher \& Krott, 2016). The criteria of the RIU model for assessing utilization comprise contributions to democracy, contributions to the rule of law, contributions to successful governance, appropriate solutions to problems, and participation in scientific discourse. In this study, the RIU model and its criteria were used to identify the contributions of scientific research support to the biodiversity conservation policy of Vietnam in the establishment of the Nature Reserve.

\section{Materials and methods}

\subsection{Study site}

The Nature Reserve is located in southwest Hoa Binh province in northern Vietnam (Fig. 1). It lies between $20^{\circ} 31^{\prime}$ and $20^{\circ} 30$ northern latitude and $105^{\circ} 15^{\prime}$ and $105^{\circ} 29^{\prime}$ eastern latitude (Birdlife International, 2009). The Nature Reserve comprises the central part of the Pu Luong-Cuc Phuong limestone range, which is a globally important karst ecosystem (FFI, 2002). 


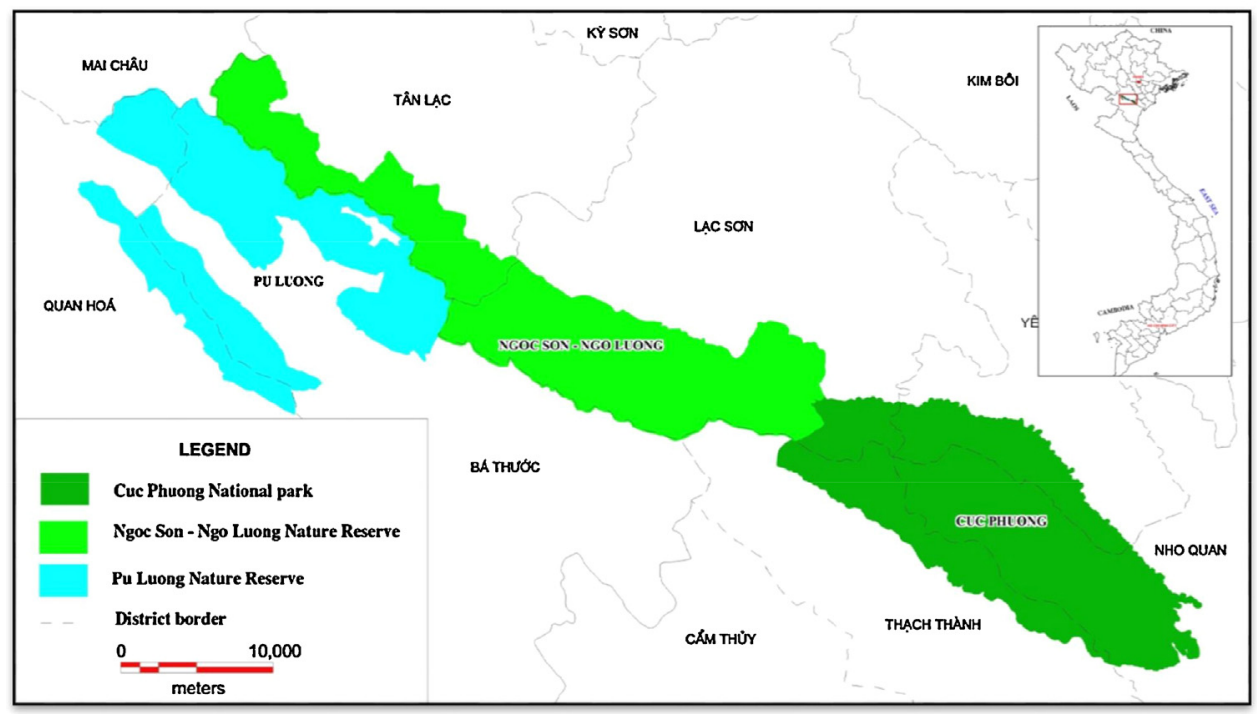

Fig. 1. Ngoc Son-Ngo Luong Nature Reserve in northern Vietnam (Map by Dinh Vu Xuan, 2016).

The Pu Luong-Cuc Phuong limestone range is home to many rare and endemic animals, notably the seriously endangered Delacour's Langur, which is one of Vietnam's important endemic species and a top priority in Vietnam's National Primate Action Plan (FFI, 2002). The Pu Luong-Cuc Phuong limestone range has been identified as a global center for plant biodiversity and includes examples of $18 \%$ of Vietnam's entire floral spectrum (FFI, 2002). The risks to biodiversity in this area have been identified as hunting, poaching, fuel wood collection, gold mining, limestone mining, and agricultural land encroachment (FFI, 2002). To conserve the entire limestone range, three protected areas were established in 1962, 1999, and 2004. These areas are Cuc Phuong National Park, which is the oldest national park in Vietnam, at the eastern end of the range, and $\mathrm{Pu}$ Luong Nature Reserve at the western end of the range. Then, the Nature Reserve (the object of this study) was established in 2004 as a biodiversity corridor between the two previously established protected areas.

The Nature Reserve comprises 19,254 ha, of which the strictly protected zone is 12,717 ha, the rehabilitation zone is 6526 ha, and the administrative zone is 11 ha (NSNL, 2009). The Nature Reserve is home to about 13,409 people, all of Muong ethnic background (NSNL, 2011). Before the Nature Reserve was established in 2004, forest resources, such as timber, non-timber forest products, wild animals, and medicinal plants were the major subsistence resources of the local communities (FFI, 2003). With the advent of the Nature Reserve, all activities that exploited the forest resources were forbidden, including hunting, logging, and gathering nontimber forest products (FFI, 2006). The local people, who lacked agricultural lands, had fewer resources after the forestland was designated for the Nature Reserve.

The establishment of the Nature Reserve was funded by the LLINCP and the Pu Luong Project through a feasibility study. The former is a research project of the Institute of Anthropology, the Research Institute on Geology and Mineral Resources in Hanoi, and the University of Leuven in Belgium. The latter is a joint conservation project of FFI and the Forest Protection Department of Vietnam's Ministry of Agriculture and Rural Development. Although it is an international conservation organization, FFI was not recognized by the Vietnamese government (Decision 08 in 2001) as an entity with legal status to conduct feasibility studies for protected areas in Vietnam (FFI, 2006). Thus, FFI contracted with FIPI to conduct the Nature Reserve's establishment process.

\subsection{Data collection and analysis}

This study is a qualitative case study of a single case using familiar research methods for data collection, such as interviews and surveys (Farquhar, 2012). Case study research is "an empirical inquiry that investigates a contemporary phenomenon in depth and within its real life context, especially when the boundaries between phenomenon and context are not clearly evident" (Yin, 1989). In this case, the scientific support of Vietnam's biodiversity conservation policy was explored via the establishment of the Nature Reserve. In addition, the qualitative content analysis focusing on language as the way to communicate through text (Neuman, 2005) was used to analyze documents.

First, all archival documents related to two projects were collected: the LLINCP and the Pu Luong Project. These archival data were crucial to understanding the projects' activities and their scientific and practical outcomes. The archival sources were mostly obtained from the libraries of the FFI, the Anthropology Institute, the Research Institute on Geology and Mineral Resources, the Pu Luong Nature Reserve, and the Nature Reserve. The documents comprised project proposals, completion reports, technical reports, progress reports, feasibility studies, consulting reports, publications, unpublished reports, scientific articles, books, decisions, and informative documents. All of the documentation was qualitatively analyzed using the RIU model of scientific knowledge transfer.

Second, semi-structured interviews were conducted to collect data on scientific research results, practical outcomes (application), and political outcomes. Sixteen interviews were conducted by a Vietnamese researcher to collect data from a variety of stakeholders in the establishment process of the Nature Reserve, such as researchers, governmental staff, forest rangers, and community representatives. Table 1 provides information on the identities and dates of the interviews. The selection of interviewees was based on their roles and extents of participation in the establishment of the Nature Reserve. Non-participants in the establishment process who were scientists with deep knowledge on forest ecology, biodiversity conservation, and social science were invited to participate in interviews. Interviewing non-participants allowed for objective assessment of the scientific quality of the research and its influence on Vietnam's biodiversity conservation policy. The interviews lasted between one and one-half to two hours and were conducted in Vietnamese. 
Table 1

List of interviewees.

\begin{tabular}{|c|c|c|}
\hline Interview & Affiliation & Date \\
\hline 1 & Senior researcher, Ethnology Institute & $12 / 03 / 2015$ \\
\hline 2 & Senior Researcher, Ethnology Institute & $12 / 04 / 2015$ \\
\hline 3 & $\begin{array}{l}\text { Senior Researcher, Institute of Geology } \\
\text { and Mineral Resources }\end{array}$ & $11 / 14 / 2015$ \\
\hline 4 & Senior Researcher, Ethnology Institute & $01 / 10 / 2016$ \\
\hline 5 & $\begin{array}{l}\text { Senior Researcher, Institute of Geology } \\
\text { and Mineral Resources }\end{array}$ & $11 / 15 / 2015$ \\
\hline 6 & $\begin{array}{l}\text { Senior Researcher, Forest Inventory } \\
\text { and Planning Institute (FIPI) }\end{array}$ & $12 / 22 / 2015$ \\
\hline 7 & Manager, FFI Vietnam (by email) & $10 / 2015$ \\
\hline 8 & $\begin{array}{l}\text { Manager of Pu Luong Project, FFI } \\
\text { Vietnam }\end{array}$ & $10 / 10 / 2015$ \\
\hline 9 & $\begin{array}{l}\text { Director of Nature Conservation } \\
\text { Department }\end{array}$ & $11 / 25 / 2015$ \\
\hline 10 & $\begin{array}{l}\text { Director of Hoa Binh Forest Protection } \\
\text { Department }\end{array}$ & $12 / 08 / 2015$ \\
\hline 11 & $\begin{array}{l}\text { Former director of Management Board } \\
\text { of Ngoc Son Ngo Luong Nature Reserve }\end{array}$ & $12 / 13 / 2015$ \\
\hline 12 & $\begin{array}{l}\text { Forest ranger of Ngo Son Ngo Luong } \\
\text { Nature Reserve }\end{array}$ & $12 / 15 / 2015$ \\
\hline 13 & $\begin{array}{l}\text { Forest ranger of Ngo Son Ngo Luong } \\
\text { Nature Reserve }\end{array}$ & $12 / 16 / 2015$ \\
\hline 14 & Local People of Ngoc Son Ngo Luong & $12 / 17 / 015$ \\
\hline 15 & Local People of Ngoc Son Ngo Luong & $12 / 18 / 2015$ \\
\hline 16 & Expert, Leuven University (by email) & $02 / 2016$ \\
\hline
\end{tabular}

Third, scientific publications of the LLINCP, the Pu Luong Project, and FIPI at the international and national levels were studied to assess whether researchers' policy advice was based on the current scientific research. Minutes of meetings and workshops on the establishment process were also used in the data analysis. There were two scientific research sources produced by the LLINCP and FIPI for formulating the Nature Reserve. The analysis of the research, integration, and utilization activities identified the contributions of the scientific support to Vietnam's biodiversity conservation policy.

\section{Results and discussion}

\subsection{Research projects for establishing the nature reserve}

The idea of establishing a protected area as a biodiversity corridor between Pu Luong Nature Reserve and Cuc Phuong National Park was initiated by the Hoa Binh provincial government in 2002 aiming to conserve the entire Pu Luong-Cuc Phuong limestone range. A feasibility study was conducted by the LLINCP and FIPI between August 2003 and March 2004 to support the Hoa Binh government's efforts. Under Vietnamese law, a feasibility study is one of two key documents that must be submitted for the decisionmaking process to designate a protected area (the other is an investment plan). The Nature Reserve's feasibility study focused on scientific research in four areas: (1) socioeconomic characteristics and analyses of people's perceptions and expectations, (2) geological characteristics, (3) flora and fauna, and (4) the land-use situation at the time.

The first research area was researched by the Institute of Anthropology and Leuven University, Belgium using the LLINCP, and the geological research was conducted by the Research Institute on Geology and Mineral Resources using the LLINCP. The FIPI researchers were responsible for research on flora and fauna and land uses through financial support of the Pu Luong Project. Thus, the four areas of the feasibility study were divided between the two projects and conducted by three organizations. There were three important concerns in the feasibility study related to the establishment process: (1) type of protected area, (2) external and internal boundaries, and (3) community participation in managing the protected area. The LLINCP and FIPI aimed to support a selec- tion of solutions relevant to the main three concerns through the application of their research results. The feasibility study was fully funded by the Flemish Interuniversity Council Belgium regarding the LLINCP's portion and Global Environmental Facility regarding the Pu Luong Project's portion.

The four research activities generally aimed to support the policy on biodiversity conservation. Under the RIU model of scientific knowledge transfer, the research projects needed to conduct research and perform integration to achieve utilization. The LLINCP and FIPI (funded by Pu Luong Project) produced different results (Table 2). Table 2 explains those results with respect to the RIU components of research, integration, and utilization.

\subsection{LLINCP scientific research for establishing the nature reserve}

The researchers of the Institute of Anthropology and Leuven University studied the socioeconomic characteristics of the Ngoc Son Ngo Luong region, land allocation, forest management, and the perceptions and expectations of stakeholders about the anticipated Nature Reserve. Final reports on their research activities were completed in 2004. The analysis of the political context and socioeconomic characteristics of the Ngoc Son Ngo Luong region found that collaborative forest management had existed in the area, ever since the forestland was allocated to the households with land-use certificates provided by the Hoa Binh Provincial People's Committee (LLINCP, 2004). Thus, the creation of the Nature Reserve to exclude the local people was possibly not a reasonable solution for the Ngoc Son Ngo Luong region (LLINCP, 2004). The LLINCP results suggested that, apart from the option of establishing the Nature Reserve, other options under the existing legislation might be more effective. Based on international and national studies, and the particular context of Ngoc Son-Ngo Luong region, the results suggested eight distinct options for the Ngoc Son Ngo Luong area as follows.

- nature reserve

- national park

- species and habitat conservation area

- cultural and historical environmental or landscape conservation area

- UNESCO human and biosphere reserve

- local or provincial forest reserve

- allocated land-use certification of forest-land use

- allocated forest-protection contracts

Based on the research of geological characteristics, the LLINCP produced three boundary options for the anticipated Nature Reserve, one natural and two administrative boundary plans, for the selection process (RIGMR, 2003).

In the LLINCP research, the Vietnamese and Belgian researchers applied SLT to promote strategies for multiple-stakeholder ecosystem management in the context of establishing the Nature Reserve (LLINCP, 2002). They aimed to attract all of the stakeholders' interests into the negotiating process, which was considered a social learning process. The research by LLINCP for the feasibility study of the Ngoc Son Ngo Luong region was conducted in compliance with sound scientific practices by the Vietnamese and Belgian scientists. That aspect of the study involved reviewing the legal framework for special-use forests in Vietnam and assessing international and national previous scientific research conducted in the Pu Luong-Cuc Phuong region.

SLT was applied as an interpretive framework for understanding the establishment process of the Nature Reserve. Social science research methods were used by LLINCP to collect and analyze field data, such as discourse analysis, interview data, and feedback meetings. The LLINCP research strengthened the orientation toward multiple-stakeholder ecosystem management via the Institution 
Table 2

Success or failure of scientific support of the conservation policy. ${ }^{\text {a }}$

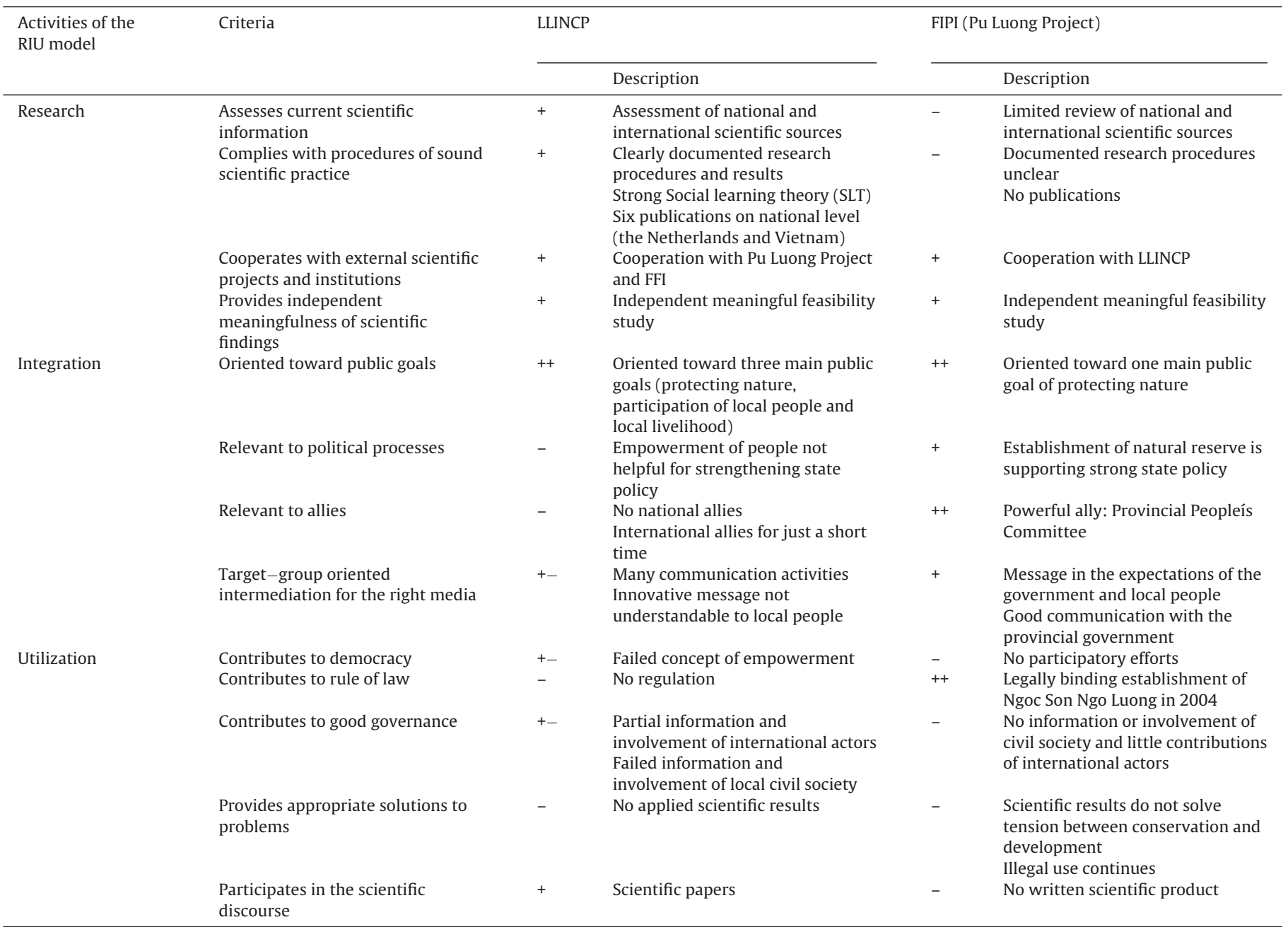

a Score on the fulfillment of the criteria from strong to weak:,,,,++++---- .

of Anthropology (LLINCP, 2007). The researchers of the Institute of Anthropology and Leuven University were integrated into the $\mathrm{Pu}$ Luong Project activities involving biodiversity conservation in the entire Pu Luong-Cuc Phuong limestone range. In August 2003, the LLINCP, the Pu Luong Project, and FIPI entered into an agreement to define the nature and extent of the relevant parties' involvement in the feasibility study. This was a cooperation between a research project (LLINCP) and an international non-governmental organization (FFI) working in the same region of Pu Luong-Cuc Phuong with the same research target of biodiversity conservation to avoid overlapping their research activities (Böcher \& Krott 2014, 2016).

One important indicator of the high quality of scientific research is the presentation of the research results to the scientific community and the publication of scientific papers (Böcher \& Krott, 2016). The LLINCP produced six published papers at the national level in Vietnamese social science journals, indicating the scientific quality of their studies. The key findings on the LLINCP mostly were presented in 2004 at the International Transdisciplinary Conference on Development and Conservation of Karst Regions (Batelaan et al., 2004). Some of the results related to social learning were included in a book, Social Learning: Towards a Sustainable World, published by Wageningen Academic Publisher in 2007. In this book, the researchers presented the main findings of their application of SLT in the context of biodiversity conservation in Ngoc Son Ngo
Luong (Wildemeersch, 2007). All of their methods and results were well documented in their reports on the LLINCP.

\subsection{FIPI scientific research for establishing the nature reserve}

FIPI was contracted by FFI to conduct the two aspects of the feasibility study of the Ngoc Son Ngo Luong region through the $\mathrm{Pu}$ Luong Project. FIPI studied the characteristics of the flora and fauna, forest vegetation cover, and the status of land use in the Ngoc Son Ngo Luong region. FIPI assessed the extent of flora and fauna diversities, the valuable and rare species, and the importance of the ecological system (FIPI, 2004). However, its research methods were not presented clearly in the documentation and the documents did not refer to national or international scientific sources. The results of the within study's literature search found that the FIPI results have not been published.

Under the RIU model, the FIPI research does not qualify as "good" science. However, the research on the LLINCP and FIPI both contributed to the feasibility study for the establishment of the Nature Reserve. The feasibility study results successfully provided options for decision-making in the establishment of the Nature Reserve. The LLINCP and FIPI scientists had distinct perspectives that led them to develop different options for the selection process on the conservation of the Ngoc Son Ngo Luong region, and the scientific quality of the two sources of research was quite different (Table 2 above). The 
LLINCP produced new, theory-based, and independently meaningful results, whereas the FIPI research was weak on theory and data, although it also produced an independently meaningful result.

\subsection{Integration in the establishment of the nature reserve}

Successful transfer of scientific knowledge depends on integration activities as defined above (Böcher \& Krott, 2014; Dharmawan, Böcher, \& Krott, 2016; Heim \& Böcher, 2016). This study analyzed the integration activities to determine whether the researchers selected their research questions and presented findings relevant to public goals, political processes, allies, and target groups oriented to intermediation.

\subsubsection{Integration of the LLINCP research}

The LLINCP research for establishing the Nature Reserve was oriented towards three public goals: nature conservation, improvement of local livelihoods, and involvement of local people. The LLINCP tried to engage local people and their interests in the establishment process through their research activities, and they expected the Hoa Binh provincial government to agree to establish a collaborative forest management model in the Pu Luong Cuc Phuong region. Based on its research results, the LLINCP claimed that involving local people was necessary for conserving the Ngoc Son Ngo Luong region because their lives had greatly depended on forest resources for many generations. The LLINCP scientists argued on behalf of a collaborative forest management model with direct local participation, which they argued could reduce the anticipated tension among the three public goals. The communities that were expected to have an influence on the establishment of the Nature Reserve were invited to participate in the process. However, during a seminar in Hoa Binh on March 16, 2004, the interests of the local people were ignored by the powerful stakeholders (Nguyen, 2009).

The notion of a collaborative forest management model based on the LLINCP research results was not relevant to Vietnam's political process, which privileges the power of the state over the empowerment of local people. Therefore, the collaborative plan did not receive support from national allies. FFI (FIPI's funder) supported the LLINCP research results, but, in this case, the FFI, which was an advisor and funder, was in the region for only a short time (four years). Thus, the FFI had little influence on the establishment process. Moreover, the local people expected to participate in conserving the area, but their power to effect participation was weak and the powerful stakeholders were unconcerned about their interests.

The LLINCP tried to communicate with the local people through its research activities, interviews, meetings, and seminars. However, their communication was not successful because the information flow between the district and the community was disrupted. Two of six concerned communities were not fully informed of the Hoa Binh province's plan to create the Nature Reserve on their land. The communication method was unilateral rather than multilateral (Wildemeersch, 2007). Therefore, the LLINCP was ineffective and the provincial government and local people did not understand the innovative messages about collaborative management and social learning disseminated by the LLINCP.

\subsubsection{Integration of the FIPI research}

The FIPI research focused on the public goal of biodiversity conservation, which was in accord with international stakeholders and the provincial government. The establishment of the Nature Reserve conformed to Vietnam's political processes, which strengthen the power of state agencies related to forest conservation. Thus, the FIPI research results gained support from national allies. During negotiations on the establishment of the Nature Reserve, Hoa Binh Provincial People's Committee and Hoa Binh For- est Protection Department always worked with the FIPI researchers to select solutions. Choosing to establish a nature reserve was a reasonable option for the Hoa Binh provincial government and somewhat expected by the local people because that option took Vietnam's traditional approach to forest conservation. Establishing protected areas to conserve nature had been implemented in many areas in Vietnam (Phuong \& Dung, 2001).

Regarding the Nature Reserve's boundaries, FIPI scientists offered four options based on their research. However, during the selection process (integration), FIPI leaned toward using the administrative borders as the boundaries. This idea was consistent with Vietnam's political processes. That option could have created many advantages for protection and management; however, the option of using administrative boundaries did not meet the requirements of a biodiversity corridor because the Nature Reserve would not be physically adjacent to Cuc Phuong National Park (FIPI, 2004). From the perspective of the geological research, the scientist at the Research Institute on Geology and Mineral Resources proposed the natural boundaries, which included almost all of the ecosystem of the region's limestone range from Pu Luong Nature Reserve to Cuc Phuong National Park. That option would have been relevant to biodiversity conservation. However, it also had many potential disadvantages for management because its boundaries were inside the confines of 16 administrative units (communities) (FIPI, 2004). Therefore, the provincial government did not support the option of natural boundaries. The natural boundaries were not reasonable to the provincial government or the local people.

The FIPI researchers apparently communicated well with the provincial government, which had the most decision-making power for establishing the Nature Reserve. However, FIPI did not communicate with the local people because it knew that the local people were weak stakeholders with no power in the decisionmaking process. Therefore, the plan to establish the Nature Reserve used the administrative boundaries, including part of the Tan My community, to create the corridor between Pu Luong Nature Reserve and Cuc Phuong National Park, which was subsequently submitted to the Ministry of Agriculture and Rural Development for approval. This final solution to the question of boundaries was the second option of Research Institute on Geology and Mineral Resources (LLINCP) and the fourth option of FIPI.

In conclusion, FIPI conducted a strong integration phase whereas the LLINCP had serious weaknesses in integration. Although both studies focused on the public goal of biodiversity conservation, the other public goal of the LLINCP (social learning) was not strong in Vietnam. The FIPI options were relevant regarding Vietnam's political processes and it engaged national allies. The LLINCP options were not consistent with political processes and it failed to obtain national allies. The FIPI scientists developed successful communication with powerful stakeholders, and the LLINCP efforts to communicate with the local people were not effective.

\subsection{Utilization in the establishment of the nature reserve}

Under the RIU model, utilization concerns the active use of research results by stakeholders in politics or application (Böcher \& Krott, 2014, 2016). The criteria used to assess the quality of utilization are (1) contributions to democracy, (2) contributions to the rule of law, (3) contributions to good governance, (4) appropriate solutions to problems, and (5) participation in the scientific discourse.

\subsubsection{Utilization of the LLINCP research}

The LLINCP results were not applied by the provincial government or by the local people. The options proposed by the LLINCP were not seriously considered (LLINCP, 2004). The powerful actors at the provincial and district levels focused only on the conserva- 
tion of forests regarding prohibited areas, which were defined in an exclusive way. The options to allocate forestland classified as protected forests under land-use certificates (LLINCP option 7) or types of contracts (LLINCP option 8) were ignored by the powerful actors.

However, the LLINCP was successful regarding scientific utilization because it applied SLT and a new approach of multi-stakeholder ecosystem management through the research conducted by the Institute of Anthropology. Six scientific papers were published at the national level, a book was published in the Netherlands, and presentations were given at the 2004 international conference on Conservation and Development of Karst Regions. With the support of the LLINCP, one doctoral student and one master's student successfully used SLT in the context of the establishment of the Nature Reserve in their theses.

\subsubsection{Utilization of the FIPI research}

The FIPI research results did not contribute to scientific utilization because there are no known publications or scientific discourses. However, FIPI succeeded regarding political and practical utilization. As a result, Hoa Binh provincial People's Committee entered into decision No. 2714 (December 28, 2004) establishing the Nature Reserve based on FIPI's part in the feasibility study. The establishment the Nature Reserve in this area meant that the forestland that had been allocated to local households was revoked and put under the government's protection. The Nature Reserve is in the special-use forest category of Vietnam's forest classification system. The Vietnamese special-use forest laws state that all exploited activities are forbidden, including hunting, logging, and collecting non-timber forest products. Upon the establishment of the Nature Reserve, the local people lost access to important survival resources. Due to the strong need of local people, there is a danger that the illegal uses of the forest resources will likely increase.

To convince stakeholders of the feasibility of establishing the Nature Reserve, FIPI promised to develop a plan to support the local people. However, that plan was never implemented. In response, the local people resisted in many different ways (NSNL, 2006, $2007,2008)$. They still continued exploiting forest resources inside the nature reserve, which significantly increased because they no longer owned the forestland (Nguyen, 2014).

A lengthy period ensued between the establishment of the Nature Reserve in 2004 and the formation of its management board in 2006. During that gap, the Ngoc Son Ngo Luong region was not officially managed by any governmental agencies and serious exploitation of forest resources occurred (stated in interviews 11, 12, and 13). The slow and ineffectual implementation process and the illegal exploitation suggest that the Nature Reserve as established did not provide an appropriate local solution.

In comparison, the LLINCP was successful in scientific utilization because it produced publications and scientific presentations. Its research also contributed to developing SLT, although it failed to influence politicians and had no effect on the local problems. The Hoa Binh provincial government fully adopted the FIPI results and, therefore, the recommended solution was not "good" governance because it ignored the local people. The effect of the Nature Reserve on the local people has been weak because their illegal exploitation still occurred after the establishment of the Nature Reserve.

\section{Conclusions}

Conclusions can be drawn from the results of the study regarding the applicability of the RIU model and the future of scientific support of biodiversity conservation policies.

\subsection{Specified analysis by RIU-model}

This study's results demonstrate that the RIU model identified the effectiveness of internationally-supported research by assessing the extent of the transfer of scientific knowledge to conserve and protect natural biodiversity. Two scientific projects, the LLINCP and the FIPI ( $\mathrm{Pu}$ Luong Project), embodied the activities of the three RIU dimensions: research, integration, and utilization. The two research projects significantly differed regarding their successful executions of these elements. The LLINCP was relatively strong in research but weak in integration. It had no impact on practice (utilization). On the other hand, FIPI was quite weak in research, but was professional in integration and achieved some measures of success solving the problems in practice.

Based on the RIU model, the reason that the LLINCP failed was not a case of weak science, but a wrong concept of integration. The LLINCP expected some agreements among stakeholders about involving the local people in biodiversity conservation. However, this expectation proved to be wrong because the powerful stakeholders did not act on the LLINCP's ideas and the local people could not support the LLINCP because they lacked the power to do so. After four years, the international financial support of the project vanished. LLINCP's only important utilization was in its dissemination of scientific results valuable to the researchers and their institutions.

The FIPI project was weak regarding research but it achieved successful integration. FIPI carefully selected its scientific results to present solutions that would likely garner support and be implemented by the government. The researchers' proposals were recognized in practice as the most important basis for establishing the Nature Reserve. Despite this success, FIPI's solutions caused serious problems regarding illegal uses of the Nature Reserve driven by the local people's need to survive.

\subsection{Professional integration}

Excellent scientific results and sound proposals would not have local impacts unless research was accompanied by professional integration. Increased science or higher quality science will not solve the problems of politicians' ignorance. However, integration can influence that situation. What is termed "good" integration means that research accounts for the political importance of public goals, interests, the various extents of power among relevant actors, and the specific political processes of the involved regions. Integration concerns aspects of policy beneath the formal level, but it does not demand scientific solutions that consider only the most powerful stakeholders. The realistic information on the actors, interests, and power resources revealed by integration provides numerous ways to link science with powerful actors (Böcher \& Krott, 2016). The RIU model stresses that integration means leaving the protected realm of pure science. Therefore, integration should not be mingled with research; it should be professionally conducted as a separate and distinct activity. Applied to the within case study, it means that the scientists would remain designing social learning and the integrators would show them where to successfully implement those ideas in the power-dominated political process.

\subsection{Improvement of the local scientific basis}

The results and solutions produced by the national research organizations are well accepted by the powerful stakeholders. The deficit is only that they are scientifically weak. Strengthening the national research organizations would be a promising way to improve scientific support of policy. The LLINCP in the within case study supported the national research organization in principle. However, its focus was on the innovative research of the interna- 
tional partners. A focus on strengthening national research through a series of small steps would likely improve the ability to support policy. Even the most innovative international project cannot provide this support because it is conducted on a too high level with too much focus on the scientific problems of the donor country, which are not the same as the problems of science in the target country.

\subsection{Improved communication between research and practice}

A comparison of the LLINCP and FIPI revealed a paradox in which there were significant communication activities by the LLINCP, but no meaningful transmission of the innovative message to local people and stakeholders. FIPI made scant effort to communicate, but its traditional concept was clearly understood by stakeholders and local people. This outcome suggests the challenges inherent to communicating innovative scientific ideas. Improving communication in practice is indispensable, but the RIU model reminds us that even perfect communication and understanding will not have the expected effect so long as professional integration has not yielded a realistic power strategy for gathering political support of the scientific solutions.

\section{Acknowledgements}

We greatly appreciate the financial support of the German Academic Exchange Service (DAAD) and the Vietnamese Government Fund (911 Scholarship). This research was supported by the Chair Group of Forest and Nature Conservation Policy, Georg-AugustUniversität Göttingen, Germany, and Vietnam National University of Forestry. We also thank FFI Vietnam, LLINCP, Institute of Anthropology, Research Institute on Geology and Mineral Resources, $\mathrm{Pu}$ Luong Nature Reserve, Ngo Son Ngo Luong Nature Reserve, and Cuc Phuong National Park for providing valuable data. We thank the anonymous referees for their helpful comments on the article.

\section{References}

Adams, W. M., \& Hutton, J. (2007). People, parks, and poverty: Political ecology and biodiversity conservation. Conservation Society, 5, 147-183.

Böcher, M., \& Krott, M. (2014). The RIU model as an analytical framework for scientific knowledge transfer: The case of the decision support system forest and climate change. Biodiversity and Conservation, 23, 3641-3656.

Böcher, M., \& Krott, M. (2016). Science makes the world go round: Successful scientific knowledge transfer for the environment. Switzerland: Springer.

Batelaan, O., Dusar, M., Masschelein, J., Van, T. T., Tam, V. T., \& Khien, N. X. (2004). Proceedings of international transdisciplinary conference on development and conservation of karst regions. Hanoi, Vietnam: Research Institute on Geology and Mineral Resources.

Birdlife International. (2009). Source book of existing protected areas in Vietnam. Birdlife International Vietnam program. Retrieved 12/10/2015, from http:// thiennhienviet.org.vn/sourcebook/source_book/frs_nw_fr2.html.

Bruner, A. G., Gullison, R. E., Rice, R. E., \& Da Fonseca, G. A. (2001). Effectiveness of parks in protecting tropical biodiversity. Science, 291, 125-128.

Cernea, M. M., \& Schmidt-Soltau, K. (2006). Poverty risks and national parks: Policy issues in conservation and resettlement. World Development, 34, 1808-1830.

Dharmawan, B., Böcher, M., \& Krott, M. (2016). The failure of the mangrove conservation plan in Indonesia: Weak research and an ignorance of grassroots politics. Ocean \& Coastal Management, 130, 250-259.

FFI (Fauna and Flora International). (2002). Detailed proposal for development of the Pu Luong-Cuc Phuong Limestone Landscape Conservation Project. Hanoi, Vietnam: Vietnam Country Program.

FFI (Fauna and Flora International). (2003). A survey of hunting status and collection of non-timber forest products in Pu Luong Nature Reserve and its surrounding forests. Hanoi, Vietnam: FFI Vietnam.

FFI (Fauna and Flora International). (2006). Final report of the Pu Luong - Cuc Phuong Limestone Landscape Conservation Project. Vietnam Country Program. Hanoi, Vietnam: FFI Vietnam.

FIPI (Forest Inventory and Planning Institute). (2004). The feasibility study for the establishment of Ngoc Son Ngo Luong Nature Reserve. Hanoi, Vietnam: FIPI Vietnam.

Farquhar, J. D. (2012). Case study research for business. London, England: Sage.

Githiru, M., Lens, L., Adriaensen, F., Mwang'ombe, J., \& Matthysen, E. (2011). Using science to guide conservation: From landscape modelling to increased connectivity in the Taita Hills, SE Kenya. Journal for Nature Conservation, 19 263-268.

Heim, J., \& Böcher, M. (2016). CITES and Science: Using the RIU Model to analyze institutionalized scientific policy advice in Germany for the case of ivory trade. Journal of International Wildlife Law E' Policy, 19, 159-175.

Hulme, M. (2009). Why we disagree about climate change: Understanding controversy, inaction, and opportunity. UK: Cambridge University Press.

Indrawan, M., Garnett, S. T., Masala, Y., \& Wirth, R. (2014). Compromising for conservation: A protocol for developing sustainable conservation plans in biologically rich and monetarily impoverished communities. Pac Conserv Biol, 20,3-7.

LLINCP (Limestone Landscape Improving Negotiation Conservation Project). (2002). Project proposal of limestone landscape: Improving Negotiation Conservation Project. Hanoi, Vietnam: Institute of Anthropology.

LLINCP (Limestone Landscape Improving Negotiation Conservation Project). (2004). A feasibility study for the establishment of the Ngoc Son Ngo Luong Nature Reserve: Socio-economic survey, analysis of perceptions and expectations. Hanoi, Vietnam: Institute of Anthropology.

LLINCP (Limestone Landscape Improving Negotiation Conservation Project). (2007). Final evaluation of limestone landscape: Improving Negotiation Conservation Project. Hanoi, Vietnam: Institute of Anthropology.

MARD (Ministry of Agriculture and Rural Development). (2014). Report on planning for special use forest to 2020. Hanoi, Vietnam: MARD.

Managi, S. (Ed.). (2012). The economics of biodiversity and ecosystem services. In. New York, NY: Routledge.

Miller, N. (2009). Environmental politics: Stakeholders, interests and policy making. New York, NY: Routledge.

NSNL (Ngoc Son Ngo Luong Nature Reserve). (2006). Annual report of Ngoc Son Ngo Luong Nature Reserve management. Ngoc Son Ngo Luong Nature Reserve. Hoa Binh, Vietnam: Hoa Binh Forest Protection Department.

NSNL (Ngoc Son Ngo Luong Nature Reserve). (2007). Annual report of Ngoc Son Ngo Luong Nature Reserve management. Ngoc Son Ngo Luong Nature Reserve. Hoa Binh, Vietnam: Hoa Binh Forest Protection Department.

NSNL (Ngoc Son Ngo Luong Nature Reserve). (2008). Annual report of Ngoc Son Ngo Luong Nature Reserve management. Ngoc Son Ngo Luong Nature Reserve. Hoa Binh, Vietnam: Hoa Binh Forest Protection Department.

NSNL (Ngoc Son Ngo Luong Nature Reserve). (2009). Annual report of Ngoc Son Ngo Luong Nature Reserve management. Ngoc Son Ngo Luong Nature Reserve. Hoa Binh, Vietnam: Hoa Binh Forest Protection Department.

NSNL (Ngoc Son Ngo Luong Nature Reserve). (2011). Annual report of Ngoc Son Ngo Luong Nature Reserve management. Ngoc Son Ngo Luong Nature Reserve. Hoa Binh, Vietnam: Hoa Binh Forest Protection Department.

Neuman, L. W. (2005). Social research methods: Qualitative and quantitative approaches. London, England: Allyn and Bacon.

Nguyen, H. H. (2009). The (non)sense of social research driven Development Intervention. A contribution to a contemporary debate by studying (re) framing and negotiation processes in the creation of nature reserve in NW Vietnam. (Unpublished doctoral dissertation). The Catholic University of Leuven, Faculty of Psychology and Educational Science, Leuven, Belgium

Nguyen, Q. N. (2014). Educative moments in participatory processes: The case of Ngoc Son Ngo Luong Nature Reserve, Hoa Binh, Vietnam. (Unpublished doctoral dissertation). The Catholic University of Leuven, Faculty of Psychology and Educational Science, Leuven, Belgium.

Phuong, N. N., \& Dung, V. V.(2001). Assessment of legal documents and policies relating to management of Special-Use Forest in Vietnam. Technical Report No 1: SPAM project. Hanoi, Vietnam: WWF Vietnam.

Pullin, A. S., \& Knight, T. M. (2001). Effectiveness in conservation practice: Pointers from medicine and public health. Conservation Biology, 15, 50-54.

Pullin, A. S., \& Knight, T. M. (2009). Doing more good than harm: Building an evidence base for conservation and environmental management. Biological Conservation, 142, 931-934

RIGMR (Research Institute on Geology and Mineral Resources). (2003). Geological characteristics of the Pu Luong Nature Reserve and surrounding areas. Hanoi, Vietnam: RIGMR.

Salafsky, N., \& Wollenberg, E. (2000). Linking livelihoods and conservation: A conceptual framework and scale for assessing the integration of human needs and biodiversity. World Development, 28, 1421-1438.

Schindler, S., Curado, N., Nikolov, S. C., Kret, E., Cárcamo, B., Catsadorakis, G., \& Kati, V. (2011). From research to implementation: Nature conservation in the Eastern Rhodopes Mountains (Greece and Bulgaria), European Green Belt. Journal for Nature Conservation, 19, 193-201.

Van Straalen, F. M., \& Altes, W. K. (2014). Compulsory purchase for biodiversity conservation in the Netherlands. Land Use Policy, 38, 223-232.

Wildemeersch, D. (2007). Social learning revisited: Lessons learned from North and South. In A. E. Wals (Ed.), Social learning: Towards a sustainable world (pp. 99-116). The Netherlands: Wageningen Academic Publishers.

Wynberg, R. (2002). A decade of biodiversity conservation and use in South Africa: Tracking progress from the Rio Earth Summit to the Johannesburg World Summit on Sustainable Development. South African Journal of Science, 98, 233-243.

Yin, R. K. (1989). Case study research: Design and methods. London, England: Sage.

Zheng, H., \& Cao, S. (2015). Threats to China's biodiversity by contradictions policy. Ambio, 44, 23-33

Zingerli, C. (2005). Colliding understandings of biodiversity conservation in Vietnam: Global claims, national interests, and local struggles. Society and Natural Resources, 18, 733-747. 


\title{
Toward successful implementation of conservation research: A case study from Vietnam
}

\author{
Huong Do Thi, Max Krott, Michael Böcher, Nataly Juerges
}

Received: 10 March 2017/Revised: 28 August 2017/Accepted: 27 November 2017/Published online: 20 December 2017

\begin{abstract}
A number of different approaches have been used to explain the successes and failures of biodiversity conservation strategies in developing countries. However, to date, little attention has been paid toward assessing the influence of knowledge transfer between science, policy, and conservation practices in the implementation of these strategies. Vietnam's Pu Luong Cuc Phuong Conservation Area is a globally important ecosystem, situated within a limestone landscape and inhabited by hundreds of local communities. Biodiversity conservation has become an important part of sustainable development in this area. This study analyzes three conservation strategies employed in the Pu Luong Cuc Phuong Conservation Area by applying the Research-Integration-Utilization (RIU) model of scientific knowledge transfer. Our analyses reveal weaknesses in scientific knowledge transfer arising from low-quality research and poor integration strategies. Based on our results, we developed recommendations to improve research and integration in an effort to enhance sciencebased policy support.
\end{abstract}

Keywords Biodiversity conservation - ICDP .

Poverty alleviation · Pu Luong Cuc Phuong · RIU model . Scientific knowledge transfer

\section{INTRODUCTION}

There is increasing recognition of the importance of scientific knowledge and science-based policy advice in the environmental governance of global policy issues (e.g.,

Electronic supplementary material The online version of this article (https://doi.org/10.1007/s13280-017-0999-2) contains supplementary material, which is available to authorized users. biodiversity conservation and climate change) (Miller 2009; Biermann and Pattberg 2012; Pregernig and Böcher 2012; Pregernig 2014). Given the complex causes of biodiversity loss and the challenges involved in successfully implementing conservation strategies (Wood et al. 2000; Saterson et al. 2004), policymakers increasingly rely on science-based solutions to address them (Perrings et al. 2011; Young et al. 2014; Nesshöver et al. 2016). In 2012, the newly established intergovernmental science-policy platform on biodiversity and ecosystem services (IPBES) emphasized strengthening scientific research and sciencepolicy interfaces for more effective biodiversity conservation (Chapason and van den Hove 2009). However, some of the problems with the conservation science-policy nexus may emanate from unreasonable expectations about how and how much science can contribute to wise decision-making in policy processes (Dietz and Stern 1998; Koetz et al. 2008, 2009). Thus, there is an urgent need to better understand the factors influencing the transfer of scientific knowledge to policy-making in conservation practice.

Studies show that the loss of biodiversity will continue at an alarming rate over the twenty-first century (Pereira et al. 2010). In response, conservationists and policymakers have promoted many conservation strategies to protect the remaining biodiversity (Salafsky and Wollenberg 2000; Saterson et al. 2004; Brooks et al. 2006). However, empirical evidence demonstrates that conservation strategies, especially in developing countries, which ignore livelihood concerns and development goals of local populations, are ineffective (Arnold 2002; McShane 2003; Barrett et al. 2005). Therefore, conservation strategies that attempt to reconcile the benefits of biodiversity conservation and local development (like the Integrated Conservation and Development Projects (ICDPs)) have been widely 
implemented since the 1980s (Wells and McShane 2004). Despite their promises to deliver positive outcomes for both biodiversity conservation and poverty alleviation, ICDPs have shown mixed results (Adams et al. 2004; Garnett et al. 2007; Brooks et al. 2012). The desire for win-win scenarios for conservation and development have rarely been fulfilled in practice (Christensen 2004; Wells and McShane 2004).

Recognizing the multiple perspectives of ICDP outcomes, a number of approaches have been developed to test hypotheses regarding ICDP successes and failures (Salafsky et al. 2001; Agrawal and Chhatre 2006; Brooks et al. 2006). Brooks et al. (2006) used four different groups of criteria to measure project outcomes (ecological, economic, attitudinal, and behavioral), while Winkler (2011) used a bioeconomic model of open-access habitat and wildlife exploitation to show that the breakdown of socially optimal levels of conservation could be the root of failure. From an institutionalist perspective, Brown (2002) argued that misconceptions about four key elements (community, participation, empowerment, and sustainability) contribute to the failure of ICDPs. Some economists have critiqued ICDP approaches as insufficient for creating real incentives for substantial conservation measures (Ferraro and Kiss 2002). For those engaging in a protection-oriented approach to conservation, ICDPs are too social, meaning that the ICDP contributes more to the public interests of human communities than to substantial biodiversity protection. For those undertaking community-based forest management, ICDPs represent a means to support the established governmental actors and outsiders of local communities (Lovett and Ockwell 2010). Despite these studies, there remains a surprising lack of empirically substantiated research that attempts to explain the failure of ICDPs by investigating potential problems with the underlying science-policy interface. That is our starting point, as we want to investigate the effectiveness of the science-policy interface and its role in biodiversity conservation and poverty alleviation reconciliation as important prerequisites for the success of ICDPs. Thus, our guiding research question is this: Can the successes and failures of biodiversity conservation strategies in ICDPs be explained by the relationship between scientific research and the policy-making process?

To better understand successes and failures of ICDPs in regard to using science-based information in policy-making, we apply a new model of scientific knowledge transfer, the Research-Integration-Utilization (RIU) model, as our analytic tool. The RIU model states that successful knowledge transfer at the science-policy interface requires a combination of research that is relevant to solving practical problems, and strategic integration between science, policies, and practice to allow long-term implementation of the suggested solutions. The RIU model was developed based on various research projects that addressed scientific knowledge transfer for environmental and forest policy in Germany (Böcher and Krott 2014, 2016; Böcher 2016; Heim and Böcher 2016) and Eastern Europe (Stevanov et al. 2013). It has also been applied to environmental study and policy interfaces at an international level (Nagasaka et al. 2016; Dharmawan et al. 2016, 2017; Do Thi et al. 2017). In this study, we applied the RIU model as an analytic framework to investigate three conservation strategies including efficient land use; link biodiversity conservation to poverty alleviation; and restricted use of natural resources, which were implemented in the $\mathrm{Pu}$ Luong Cuc Phuong Limestone Landscape Conservation Project (ECOLIME project) in Vietnam.

We begin by describing the RIU model that serves as our analytic framework and explaining the research methodology. We then elaborate on the empirical case study of the ECOLIME project to demonstrate the influence of knowledge transfer on the success of science-based policy support for three strategies that combine biodiversity conservation and poverty alleviation. Finally, based on the analytic results, we present conclusions regarding potential improvements for research and integration to enhance science-based policy support for conservation policy in Vietnam.

\section{THEORETICAL FRAMEWORK: THE RIU MODEL OF SCIENTIFIC KNOWLEDGE TRANSFER}

The RIU model differs from classical linear models of scientific knowledge transfer, in which "pure science" directly influences the politics by political stakeholders, and the policy-making process is considered to comprise rational problem-solving activities (Guston 2001; Hulme 2009; Beck 2011). However, such linear scientific knowledge transfer is rare because it cannot directly function within the different underlying rationalities of science (the search for truth) and politics (the search for power) (Krott 2012; Böcher and Krott 2014).

The RIU model assumes that policies are the results of co-production between scientific arguments and political reasoning. Thus, it differentiates between activities that are integral to co-production at the microlevel. In this model, scientific knowledge-transfer process is defined as the connection between three central activities: Research (R), Integration (I), and Utilization (U), each of which follows its own logic (Böcher and Krott 2014, 2016; Fig. 1).

Research is understood as the production of specific knowledge by using scientific methods and standards. In the RIU model, research that is used successfully for scientific knowledge transfer must be of high quality, meaning 


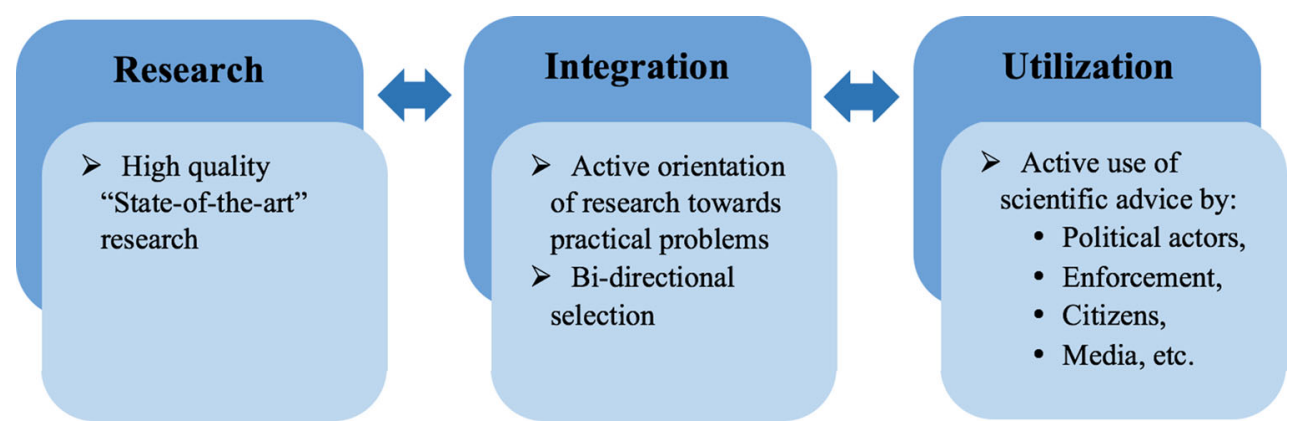

Fig. 1 The Research-Integration-Utilization (RIU) model of scientific knowledge transfer. Adapted from Böcher and Krott (2016) and Böcher (2016)

it must be based on scientifically accepted principles, methods, and standards, and include assessments of current scientific information, compliance with procedures of good scientific practice, cooperation with other scientific institutions and projects, independent meaningfulness of scientific knowledge) (Böcher and Krott 2014, 2016).

Integration is the interaction between scientific research and political or practical application. In the integration phase, stakeholders select research results appropriate for problem-solving based on their practical demands (Böcher and Krott 2014, 2016). During this selection process, practical and political reasoning drives the selection of scientific findings. Thus, integration is crucial, as it can selectively link the two spheres-science and (political) practice (Böcher and Krott 2014). Successful integration leads to practical utilization of scientific results. Utilization is the active use of science-based products by stakeholders. Weak integration means that little or no utilization of scientific results can be observed. The RIU model sets criteria for assessing integration as an orientation of research toward public goals, the applicability of scientific solutions to practical problems, the relevance to allies, and target group-oriented intermediation by means of the proper media. The RIU model also emphasizes the relationship between the criteria for successful knowledge transfer and the specific actors serving as important allies ("actors that support knowledge transfer from science into political practice by means of their power" (Böcher and Krott 2016)) for knowledge transfer.

This study uses the RIU model as its scientific framework to analyze three of the ECOLIME project's conservation strategies while considering the model's criteria for each aspect of scientific knowledge transfer-research, integration, and utilization (Table S1). Accordingly, we developed the following three hypotheses:

Hypothesis 1 Even if high-quality research has been conducted, it might not be applicable in practice because of weaknesses in the integration process.
Hypothesis 2 Low-quality research might fail to lead to practical application, even with integration efforts by powerful stakeholders.

Hypothesis 3 Results from high-quality research may be selected during integration, but if the selection is only oriented toward serving the interests of specific actors, important public goals will not be met.

According to the RIU model, robust research and professional integration are crucial for successful scientific knowledge transfer. The first two hypotheses are formulated to test two possible scientific knowledge-transfer scenarios: strong, but weakly integrated, science and weak, but strongly integrated, science. The RIU model suggests that neither scenario will result in successful scientific support in practice. Both hypotheses are relevant for analyzing our cases because in one case the scientists hoped that their robust research would lead to the implementation of practical solutions, while in another case, strong integration efforts were expected to be sufficient to generate a real impact.

Concerning RIU model, implementation of scientific knowledge transfer through strong integration changes the practice in different ways. Some solutions benefit the interests of specific powerful actors, while their effects fail to serve common public interests. We formulated the third hypothesis based on this possibility. These three hypotheses guide our analysis of the scientific knowledge transfer of three conservation strategies developed in the ECOLIME project.

\section{MATERIALS AND METHODS}

\section{Study site}

The Pu Luong Cuc Phuong (PLCP) limestone range is located in north-central Vietnam (FFI 2002a; Fig. 2). The limestone range covers approximately 170000 ha and encompasses the shared border areas of Thanh Hoa, Hoa 


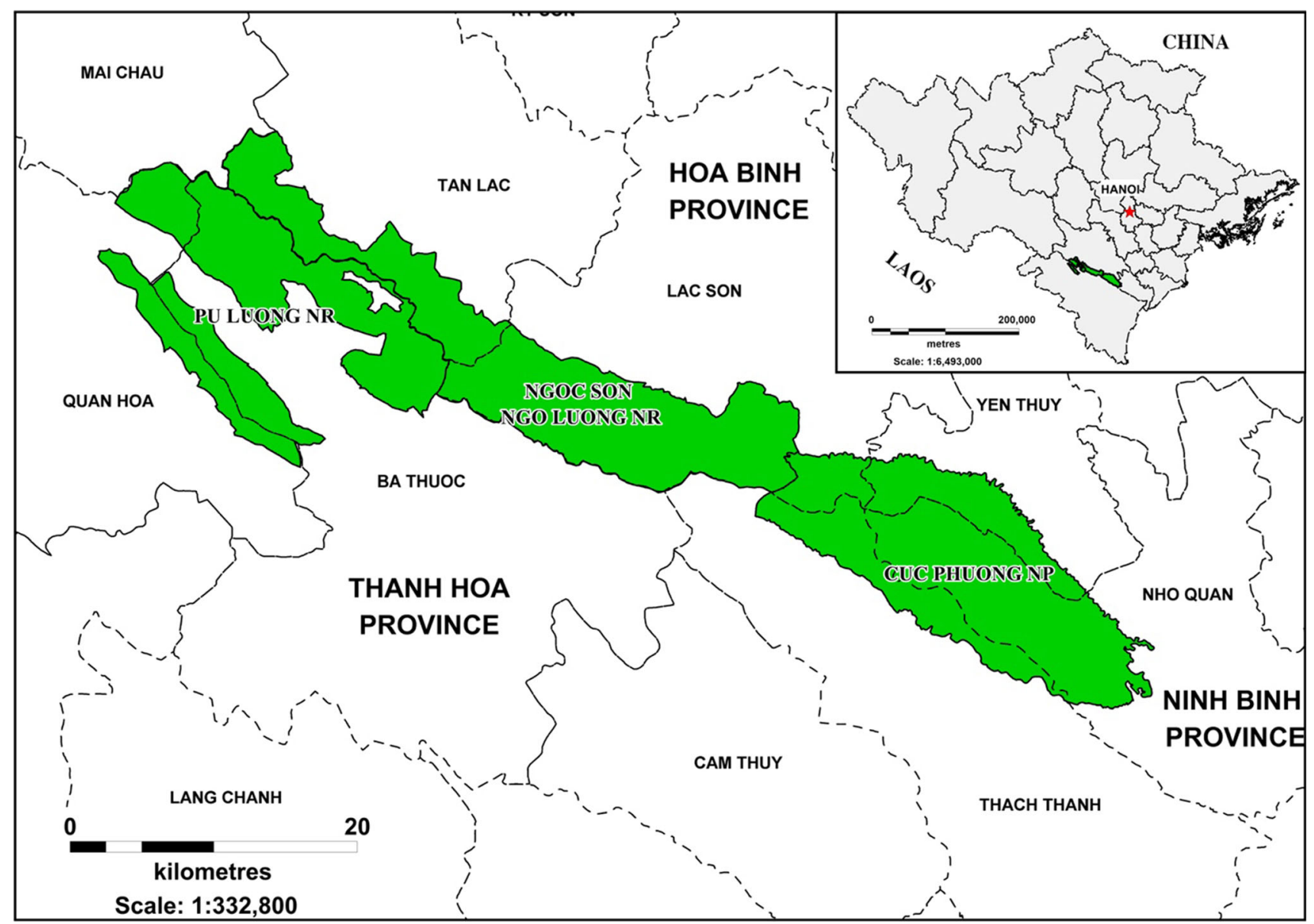

Fig. 2 Pu Luong Cuc Phuong Conservation Area, northern Vietnam. Map by Dinh Vu Xuan 2016

Binh, and Ninh Binh provinces (FFI 2002a). Owing to its altitude range, orientation, and large size, the PLCP range is recognized as a global karst ecosystem, supporting the largest remaining area of lowland limestone forest in northern Vietnam (FFI 2002a). PLCP forms part of the Annamese Lowlands Endemic Bird Area (Stattersfield et al. 1998) and includes a global center of plant diversity (WWF and IUCN 1994). It supports the last population of the endemic and critically endangered Delacour's langur (Trachypithecus delacouri), global population of which is believed to number less than 300 individuals (Nadler et al. 2003). To conserve this important limestone ecosystem, three protected areas were established in 1964, 1999, and 2004. These are the Cuc Phuong National Park (CPNP) at the eastern end of the range, the Pu Luong Nature Reserve (PLNR) at the western end of the range, and the Ngoc SonNgo Luong Nature Reserve (NSNLNR) in the center, forming a forest corridor between the CPNP and the PLNR.

A key feature of PLCP is the presence of hundreds of local communities who depend on agricultural cultivation and forest product exploitation (FFI 2002a). Threats endangering biodiversity in this area include hunting, poaching, fuelwood collection, gold mining, limestone quarrying, and agricultural land encroachment (FFI 2002a). A long tradition of hunting has reduced populations of larger mammals, like the Indochinese tiger, clouded leopard, Asiatic black bear, and serow, to critical levels (FFI 2002a). Although various hunting methods are practiced, the main threat is the use of homemade guns (FFI 2002a).

The ECOLIME project is labeled as an ICDP that aims to maintain the ecological integrity and cultural character of PLCP by addressing current conservation issues and building capacity for ecosystem management (FFI 2002a). The project was divided into two phases. Phase 1 (2002-2006), funded by the Global Environment Facility through the World Bank and the Spanish Agency for International Cooperation, focused on biodiversity research as well as law enforcement and protection. Phase 2 (2007-2009), funded by the Japan Social Development Fund, emphasized community livelihood development initiatives and raising awareness. Both phases were implemented by the Fauna \& Flora International (FFI) Vietnam Conservation Support Program in partnership 
with the Forest Protection Department of the Vietnamese Ministry of Agriculture and Rural Development. Technical assistance was also provided by the German Development Service (DED).

\section{Data collection and analysis}

\section{Data collection}

Empirically, this study is based on expert interviews and document analyses. We collected documents from many sources including the FFI library, central Forest Protection Department, and the CPNP, PLNR, and NSNLNR libraries. In total, 30 documents on the ECOLIME project were collected, including project proposals, project completion reports on Phases 1 and 2, technical reports, progress reports, publications, unpublished reports, scientific articles, books, and policy documents. The purpose of the extensive document analysis was to better understand the motivation for the implementation of biodiversity conservation strategies.

We conducted 24 semi-structured interviews between October 2015 and February 2016, and eight interviews between June and July 2017 (Table 1). Interviewees included various stakeholders involved in the ECOLIME project, such as researchers, governmental staff, project staff, forest rangers, and community representatives. The interview questions focused on introduced activities and outcomes of the three conservation strategies in the PLCP area. The interviews, lasting between one and $2 \mathrm{~h}$, were conducted in Vietnamese by a native researcher. The results of the interviews were used to analyze the effects and responses of conservation strategies.

\section{Data analysis}

All data from the interviews and document analysis were interpreted following the triangulation method (Hussein 2015) to identify reliable information and data. Then, the data were analyzed according to the main criteria of the RIU model of scientific knowledge transfer. In addition, a qualitative content analysis was conducted (Neuman 2005) to examine the viability of our hypotheses.

In this study, we also used Salafsky and Wollenberg's (2000) conceptual framework to analyze the linkage strategy between biodiversity conservation and livelihood development in the study site. In this conceptual framework, Salafsky and Wollenberg (2000) identified three different approaches to reconcile the demands of conservation and livelihood development: (1) no linkage, (2) indirect linkage, and (3) direct linkage. The no linkage approach claims to protect biodiversity by creating parks and protected areas that exclude livelihood activities. The
Table 1 List of interviewees

\begin{tabular}{|c|c|}
\hline Interview & Affiliation \\
\hline 1 & Manager, FFI Vietnam (by email) \\
\hline 2 & Manager of ECOLIME project \\
\hline 3 & Coordinator of ECOLIME project \\
\hline 4 & Senior researcher, National University of Hanoi \\
\hline 5 & Senior researcher, Center for Plant Conservation \\
\hline 6 & Researcher, Ethnology Institute \\
\hline 7 & Researcher, Ethnology Institute \\
\hline 8 & Researcher, Vietnam National University of Forestry \\
\hline 9 & Researcher, Vietnam National University of Forestry \\
\hline 10 & Researcher, Vietnamese Academic of Forest Sciences \\
\hline 11 & Researcher, FFI Vietnam \\
\hline 12 & Researcher, FFI Vietnam \\
\hline 13 & Director, PLNR \\
\hline 14 & Former Director, PLNR \\
\hline 15 & Former Director, NSNLNR \\
\hline 16 & Director of Nature Conservation Department \\
\hline 17 & Forest ranger, PLNR \\
\hline 18 & Forest ranger, PLNR \\
\hline 19 & Forest ranger, PLNR \\
\hline 20 & Forest ranger, NSNLNR \\
\hline 21 & Forest ranger, NSNLNR \\
\hline 22 & Forest ranger, NSNLNR \\
\hline 23 & Villager, PLNR \\
\hline 24 & Villager, PLNR \\
\hline 25 & Villager, PLNR \\
\hline 26 & Villager, PLNR \\
\hline 27 & Villager, PLNR \\
\hline 28 & Villager, PLNR \\
\hline 29 & Villager, PLNR \\
\hline 30 & Villager, NSNLNR \\
\hline 31 & Villager, NSNLNR \\
\hline 32 & Villager, NSNLNR \\
\hline
\end{tabular}

FFI Fauna and Flora International, ECOLIME Pu Luong Cuc Phuong Limestone Landscape Conservation Project, PLNR Pu Luong Nature Reserve, NSNLNR Ngoc Son Ngo Luong Nature Reserve

indirect linkage approach tries to link livelihoods to conservation activities by providing economic substitutions to local people. The direct linkage approach is based on making livelihood activities dependent on biodiversity, and thus directly linked to conservation goals.

\section{RESULTS}

In 2002, input research within the framework of the ECOLIME project was initially commissioned by the World Bank and FFI to provide scientific recommendations for building conservation strategies in the PLCP area. The 
research was implemented by a team of international and national researchers, as well as independent consultants. From the perspective of conservation, the research indicated that solutions to conservation problems in the PLCP area would have to involve development programs to reduce poverty, deflect forest use, subsidize the development of alternative economic activities, and find substitutes for forest resources (Apel et al. 2002). On this basis, the ECOLIME project endeavored to implement three main conservation strategies: (1) efficient land use, (2) link biodiversity conservation to poverty alleviation, and (3) restricted use of natural resources (Table 2). We employed the RIU model to analyze the scientific knowledge transfer and relationship between the quality of research and quality of integration in these three strategies. These strategies differed in terms of scientific bases, integration levels, and utilization in practice.

\section{High-quality research and weak integration}

We examined Hypothesis 1 (high-quality research might fail in practice owing to weak integration) by analyzing the strategy for conserving biodiversity through the case of efficient land use in the PLCP conservation area. The ECOLIME project believed that conservation

Table 2 Conservation strategies for Pu Luong Cuc Phuong conservation area

\begin{tabular}{|c|c|c|}
\hline Strategy & Description & Features \\
\hline Efficient land Use & $\begin{array}{l}\text { Agroforestry } \\
\text { cultivation } \\
\text { Irrigation } \\
\text { development } \\
\text { Improved cooking } \\
\text { stoves }\end{array}$ & $\begin{array}{l}\text { Science-based strategy } \\
\text { Lack of sustainable } \\
\text { allies for investment } \\
\text { Limited influence due to } \\
\text { lack of sustainable } \\
\text { investment }\end{array}$ \\
\hline $\begin{array}{l}\text { Linking nature } \\
\text { conservation } \\
\text { and poverty } \\
\text { alleviation }\end{array}$ & $\begin{array}{l}\text { Informal agreements } \\
\text { between local } \\
\text { people and nature } \\
\text { reserve }\end{array}$ & $\begin{array}{l}\text { Innovative, but partly } \\
\text { contradicts } \\
\text { international } \\
\text { scientific literature } \\
\text { No strong allies for } \\
\text { monitoring } \\
\text { Informal agreements did } \\
\text { not work in practice }\end{array}$ \\
\hline Restricted use & $\begin{array}{l}\text { Gun confiscation by } \\
\text { force }\end{array}$ & $\begin{array}{l}\text { Successfully reduced } \\
\text { the number of guns, } \\
\text { Support of strong } \\
\text { allies (government, } \\
\text { police, the nature } \\
\text { reserve) } \\
\text { Communication by } \\
\text { forced confiscation } \\
\text { Did not improve } \\
\text { livelihoods of local } \\
\text { people }\end{array}$ \\
\hline
\end{tabular}

improvements through efficient land use activities would increase agricultural land productivity, address food security concerns, and reduce threats to biodiversity. However, owing to the geological characteristics of the karst ecosystem, land resources for agricultural and forestry production in PLCP is limited (RIGMR 2003), and agricultural productivity is low (Apel et al. 2002; FFI 2002b). Irrigation structures are underdeveloped, resulting in most paddy fields yielding only one crop per year (FFI 2002b, c). Consequently, the livelihoods of communities in and around the two reserves (PLNR and NSNLNR) were at risk, with a considerable segment of the population facing food shortages for three to six months per year (Apel et al. 2002; FFI 2002b). Efficient land use became an important strategy for reducing the dependency of local people on natural resources and contributing to biodiversity conservation. Drawing upon research results, many land use measures were selected for implementation in the communities in and around the PLNR and NSNLNR. Of these, land use efficiency was best addressed through three main activities: (1) agroforestry cultivation, (2) irrigation development, and (3) delivery of improved cooking stoves. These activities were introduced to households in four communes around the PLNR and four communes in the NSNLNR (FFI 2006).

\section{Agroforestry cultivation}

Agroforestry can contribute to rural development by making the land more productive (Bene et al. 1977; Schroth et al. 2004; Lu 2006). The availability of useful tree species and other non-timber forest products in the agroforestry system can alleviate resource-use pressure on conservation areas (Bhagwat et al. 2008).

The ECOLIME project introduced numerous agroforestry activities to households (FFI 2006, 2009). Our results show that during the ECOLIME project, agroforestry activities that met the demands of local people were applied effectively by local farmers (interviews 17, 19, and 22). The introduction of new high-yield seeds (e.g., Maize LVN 10) and fast-growing trees (e.g., Acacia mangium) contributed to improved yields per hectare or increased numbers of crops per year. Mushroom plantations, beekeeping, and cow/pig husbandry were adopted by some households to develop new alternative sources for subsistence. The planting of fodder (e.g., VA-05 grass) helped reduce exploitation of natural fodder resources for cattle breeding (FFI 2005). An assessment of development activities in the NSNLNR by the ECOLIME project in 2005 showed that project-related agroforestry cultivation activities improved certain aspects of the local peoples' lives (FFI 2005). The project aimed at addressing food security and reducing pressure by local people on the forest 
resources by implementing efficient land use practices. However, investment in these practices was limited by time and finances; therefore, the contribution toward the improvement of livelihoods was limited (FFI 2005). Moreover, the sustainability of agroforestry activities presented an inextricable problem. After the withdrawal of the project, few households maintained the agroforestry measures in their cropping systems (interviews 18, 19, and 23). The reasons for this were diverse and complex, but most interviewees claimed that the lack of capital and cultivated land, disease, and limited markets were the main causes (interviews 17, 20, 22, and 23).

\section{Small irrigation development}

Lack of water for agriculture is a common problem in limestone areas (Liu et al. 2008). There is irregular water distribution in the PLCP area, i.e., there are areas with either too much or too little water for wetland agriculture (RIGMR 2003). An FFI survey in the NSNLNR in 2002, showed that shortage of water is the main reason farmers cultivate only a single crop (FFI 2002b); therefore, although more than $90 \%$ of the population in the area is involved in agriculture, they face rice shortages for an average of three months per year (FFI 2002b). A consultant for the ECOLIME project suggested that irrigation could help improve crop productivity and expand productive farmlands. Based on topography analysis, the consultant proposed that small gravity-based irrigation schemes were the most appropriate (FFI 2005). As a result, the project built 13 small irrigation systems that provided water to single-crop areas, allowing them to become double-crop areas (FFI 2009). The interview results revealed that rice production increased from 3.2 ton per ha to approximately 4.5 ton per ha after irrigation construction (interviews 19, $22,28,29)$. To date, 6 of the 13 irrigation systems are still in operation, while the others have been damaged or abandoned.

\section{Improved cooking stoves}

There are an estimated 585 million people who depend on traditional biomass as fuel, and by 2030, this number will increase to 632 million (IEA 2002; Kanagawa and Nakata 2007). In Vietnam, biomass is traditionally used in rural areas for cooking and heating (Tu et al., 2010; Schirmer 2014). In 2012, Vietnam's total biomass use accounted for $24 \%$ of the total energy consumed nationwide (Schirmer 2014), with fuelwood being the most used type of biomass, accounting for $65 \%$ of total biomass consumed (Quang Tuan and Huy Ngoc 2016).

Populations in PLCP have a long history of using fuelwood for cooking, animal husbandry, and homemade alcohol production. Fuelwood is taken mainly from natural forest areas, generating a substantial pressure on forest resources. Some assert that improved cooking stoves, if well adapted to local circumstances, can contribute to forest conservation and carbon emission reduction (Wallmo and Jacobson 1998; Dresen et al. 2014). As improved cooking stoves can reduce fuelwood demand for cooking by 40-50\% (Manibog 1984; Adrianzén 2013; Bensch and Peters 2015), the benefits are promising for developing countries, where alternative commercial fuels are costly or unavailable (Sesan 2012; Urmee and Gyamfi 2014).

The ECOLIME project provided improved cooking stoves to 12 households in two communes (Ngoc Son and $\mathrm{Tu}$ do) in the core zone of the NSNLNR (FFI 2009). We observed that only households that have a high demand for cooking, are involved in animal husbandry, and/or are involved in homemade alcohol production continue using improved cooking stoves in their houses (interviews 23, 26, $28,29)$. In addition, the use of improved cooking stoves in the area remains limited owing to certain difficulties. Specifically, improved cooking stoves are larger and heavier than traditional stoves, making them inappropriate for the local people's traditional stilt houses (interviews 18 and 22). Thus, the improved cooking stoves were constructed under the stilt houses, which made daily use inconvenient. Moreover, the improved cooking stoves could only be used efficiently with specific-sized pots, which often developed cracks after a short time (interviews 19 and 20).

These initiatives for efficient land use (e.g., agroforestry cultivation, small irrigation development, and improved cooking stoves) were developed based on a 2002 ECOLIME project input study, which acquired both local and international information on ICDP approaches. The research procedures followed proper scientific practices, and the results were clearly documented. However, the results had not been peer-reviewed. The research reports became the foundation upon which the World Bank and FFI developed the biodiversity conservation strategies for PLCP. The research was conducted in cooperation with the Limestone Landscape Improving Negotiation for Conservation project, which used a participatory approach to establish a biodiversity corridor between the PLNR and the CPNP. In addition, two baseline surveys, conducted by FFI in 2002, were consulted for efficient land use strategies in PLCP. Based on such an accumulation of data, implementation of efficient land use activities for biodiversity conservation was clearly based on scientific research.

In the PLCP area, efficient land use was oriented toward two public goals: biodiversity conservation and poverty alleviation-both relevant to the Vietnamese government's poverty reduction policies and programs in rural areas. 
Although biodiversity conservation through efficient land use reflects a recent trend in community-based conservation and co-management in biodiversity conservation (Balint 2006; Berkes 2007), we found that its impact was limited and fragmented at the household level owing to the limited funding and duration of the project (FFI 2006, 2009). Moreover, after the project's completion in 2009, few of the implemented efficient land use measures were continued by the local people (interviews 18, 20, and 23). In the RIU model, the ineffective utilization of this strategy was due to a lack of sustainable investment allies arising from weak integration. An analysis of the actors involved in the knowledge-transfer process, presented in Table S2, shows that the strategy did not garner strong support from powerful allies (e.g., provincial people's committees or provincial forest protection departments) such so that the activities could be implemented long-term at the study site. Furthermore, the project itself was not a sustainable ally, as it operated for only a short period (8 years). These results support Hypothesis 1 (high-quality research might fail in practice owing to weak integration), as we conclude that despite its scientific basis, the strategy of efficient land use as a contributor to biodiversity conservation suffered limited implementation owing to the unsuccessful integration of efficient land use in practice.

\section{Low-quality research and successful integration}

The linkage strategy of biodiversity conservation and livelihood development was analyzed to test Hypothesis 2 (low-quality research might fail to lead to practical application, even with integration efforts by powerful stakeholders). Since the ECOLIME project is labeled as an ICDP, it attempted to link biodiversity conservation to livelihood development in most of its activities. The project expected to improve conservation efforts and reduce threats to biodiversity by integrating the development needs and aspirations of local communities with biodiversity conservation. Based on Salafsky and Wollenberg's conceptual framework (2000), we claimed that the ECOLIME project employed a mixture of the three approaches (no linkage, indirect linkage, and direct linkage) to mitigate threats to biodiversity (Table 3 ). The ECOLIME project, in partnership with the Limestone Landscape Improving Negotiation for Conservation project, supported the Hoa Binh provincial government in creating a biodiversity corridor between the PLNR and the CPNP (Do Thi et al. 2017). The creation of a new protected area (the NSNLNR) in 2004, which excluded local people from their land, could be characterized as a no linkage approach.

The ECOLIME project also provided substitute livelihoods to reduce activities that negatively affect biodiversity conservation (e.g., microfinancing, promotion of local
Table 3 Strategies for linkage between biodiversity conservation and livelihood development

\begin{tabular}{clc}
\hline $\begin{array}{c}\text { Linkage } \\
\text { strategy }\end{array}$ & Activities & Features \\
\hline $\begin{array}{c}\text { No } \\
\text { linkage }\end{array}$ & $\begin{array}{c}\text { Creation of Ngoc Son Ngo } \\
\text { Luong Nature Reserve } \\
\text { Indirect } \\
\text { linkage } \\
\begin{array}{c}\text { Provided economic } \\
\text { substitution (e.g., } \\
\text { husbandry, cow bank, } \\
\text { small credit scheme, } \\
\text { agroforestry) }\end{array}\end{array}$ & $\begin{array}{c}\text { Exclude needs of local } \\
\text { people } \\
\text { Informal agreements } \\
\text { between local people and } \\
\text { Nature Reserve }\end{array}$ \\
$\begin{array}{c}\text { Direct } \\
\text { linkage }\end{array}$ & $\begin{array}{c}\text { Ecotourism } \\
\text { Informal agreements } \\
\text { between households and } \\
\text { Nature Reserve }\end{array}$ \\
\hline
\end{tabular}

products, cow/pig breeding) (interviews 15, 16, and 22). These created indirect linkages between biodiversity conservation and livelihood development; however, the goals of these activities were not easily achieved (Oates 1995; Hughes and Flintan 2001; Sunderland et al. 2007) because these approaches were not directly tied to conservation activities. Accordingly, the project and the PLNR enacted hundreds of informal agreements between the PLNR and local people, providing local people with small grants for livelihood development activities if they took on forest protection efforts (e.g., forest patrolling, watershed forest protection, or reporting violations) (interviews 5, 10, 13, 14, and 15). Unfortunately, the project only supported a small number of locals in targeted groups (FFI 2006, 2009). Moreover, since these informal agreements were not legally binding, the local people were not committed to those efforts after the project ended, as no monitoring systems were created by the agreements. In the PLCP area, violations triggered by neighboring villagers (e.g., poaching and illegal logging) were still observed (interviews 7, 9, and 11). The illegal exploitation and the ineffectiveness of the informal agreements suggest that this indirect linkage strategy did not provide an appropriate local solution for conservation in the study site.

Ecotourism is considered a direct linkage that creates dependent relationships between conservation and development. The idea of ecotourism was initiated within the framework of the ECOLIME project. Interview results have shown that some households could raise income from ecotourism, which is expected to provide a direct incentive to stop external threats to biodiversity. We observed that although ecotourism is prevalent in the area, poor people (the target group of the project) do not reap many benefits from it (interviews 15, 19, and 23). Since poor people lacked the skills and facilities with which to conduct ecotourism (e.g., homestays, transportation, and food services), they could not continue the ecotourism activities 
after the withdrawal of the project. Thus, direct linkage through ecotourism did not improve the livelihoods of the poor, who depend greatly on forest resources. The linkage strategies were directed toward two public goals, biodiversity conservation, and poverty alleviation, and were intertwined with the political process in Vietnam. However, although linkage strategies between conservation and development were integrated into the activities of the ECOLIME project, these strategies were not applicable in practice.

Prior to the establishment of the ECOLIME project (2002), scientific research revealed that linkage between biodiversity conservation and livelihood development is a necessary but insufficient condition for conservation to take place, and high linkage by itself does not guarantee successful conservation (Salafsky and Wollenberg 2000). However, despite the scientific claim that success through such linkages is elusive (Adams et al. 2004; Christensen 2004), the ECOLIME project made many attempts to link livelihood development to biodiversity conservation through indirect and direct linkage approaches with the aim of achieving successful conservation in the PLCP area.

However, these linkages were not efficiently maintained owing to weak monitoring of the nature reserve and a lack of strong allies investing in economic substitution for the long term. According to the RIU model, weak utilization of these linkage strategies could be explained by low-quality research that partially contradicted the international scientific literature. Thus, Hypothesis 2 is supported.

\section{Lack of orientation toward public goals in integration}

We analyzed the natural resource restriction strategy of gun confiscation in the PLCP conservation area to examine Hypothesis 3 (although high-quality research results may be selected during integration, if the selection orients toward serving specific actors' interests, important public goals will not be met). Restricting the use of natural resources is a traditional regulatory policy instrument used to solve nature-based social or economic conflicts (Krott 2005). Regulatory political interventions are based on legally binding regulations that can be implemented by force and the imposition of sanctions by the government (Krott 2005; Böcher 2012). The ECOLIME project claimed that the PLCP area needed a strategy to restrict the use of natural resources, related specifically to the one of the main threats to biodiversity conservation-hunting (both commercial hunting by outsiders and subsistence hunting by local people) (Apel et al. 2002). The ECOLIME project's research revealed that illegal hunting led to the decline of macaque, white-checked gibbon, and Delacour's langur populations (FFI 2003a). Moreover, hunting survey indicated that wildlife hunting and trade are ineffectively monitored and relatively uncontrollable (FFI 2003a).

Given the seriousness of the hunting threat to biodiversity in PLCP, a hunting survey was carried out in 2002, to provide science-based advice for establishing a gun confiscation program in the PLNR. The survey revealed that many people continued to hunt to fulfill food and market demands (FFI 2003a). Furthermore, a report by FFI in 2003 was consulted to provide alternatives for a gun control program in PLCP (FFI 2003b). These research efforts followed proper scientific practices, and the results were clearly documented. Accordingly, the research reports became the basis for establishing a gun confiscation program in the area.

This gun confiscation program was implemented in nine communes in and around the PLNR from 2006 to 2009, with the support of the Vietnamese police department, forest protection department, district government, and management board of the PLNR. The gun confiscation conformed to decision 08 of the Vietnamese government, which stated that hunting within special-use forests is illegal, and to the gun confiscation policy of the Vietnamese police department. In total, 1197 guns were confiscated and destroyed (PLNR 2010) (Table 4). Traps and crossbows were also confiscated. The interviews revealed that the numbers of guns kept locally declined significantly (interviews 19, 21, 28, 29). There was also a decrease in gunshots in the forest recorded by the nature reserve forest rangers and in the number of people bringing guns to the forest (interviews 17, 19, 21, 22).

The hunting confiscation program was based on scientific recommendations by researchers and experts from the ECOLIME project. In addition, evidence from Africa has shown that the efficacy of law enforcement remains a crucial determinant in the conservation of large mammals (Milner-Gulland and Leader-Williams 1992; Arcese et al. 1995). However, since hunting was a commercial activity that contributed to local livelihoods (FFI 2003a), gun confiscation restricted subsistence efforts by local people, making their lives more difficult. Moreover, there remained a strong cultural interest in hunting as well as the bearing of arms by men in Thai and Muong communities in PLCP (interviews 15, 18, and 21). In addition, because guns, traps, and crossbows could all be bought on the black market or made locally (interviews 14 and 19), it was difficult to completely eliminate them from the PLCP area.

Table 4 Guns confiscated in 2006-2009. Source: PLNR 2010

\begin{tabular}{llllll}
\hline Year & 2006 & 2007 & 2008 & 2009 & Total \\
\hline No. guns & 450 & 426 & 223 & 98 & 1197
\end{tabular}

PLNR Pu Luong Nature Reserve 
A similar gun confiscation program in the Ba Be National Park, Vietnam (part of another internationally funded ICDP), created conflict between forest rangers and local people (Zingerli 2005). In PLCP, the effectiveness of this gun confiscation program and whether guns would return to the PLCP area in a short time remain questionable.

Our results indicate that Hypothesis 3 is supported. The strategy of confiscating guns led to the exclusion of poor people with regard to their former practice of biodiversity management. Although enforcing the regulatory gun policy successfully reduced the number of guns and contributed to biodiversity conservation, it did not improve the livelihoods of the local people, which was an important goal of the ECOLIME project.

\section{DISCUSSION}

Previous studies have evaluated ICDPs by assessing social, economic, or political factors (Brown 2002; Ferraro and Kiss 2002; Brooks et al. 2006; Winkler 2011). Our contribution to the enhanced theoretical understanding of ICDPs is to analyze the underlying processes of scientific knowledge transfer to reveal why biodiversity conservation strategies succeed or fail in an internationally funded ICDP. The ICDP, developed by experts and implemented by the Vietnamese government, can be viewed as the result of a scientific knowledge transfer that we analyzed by empirically investigating the research, integration, and utilization elements of three conservation strategies based on the main criteria of the RIU model.

Our analysis shows that successful knowledge transfer that leads to implementation requires a combination of high-quality research and a good integration strategy. Because of the absence of this required combination, neither the biodiversity conservation strategy through efficient land use nor the linkage strategy between conservation and development were successfully implemented in practice. The restricted use strategy through the regulatory policy instrument of gun confiscation achieved certain successes with regard to the biodiversity conservation goal but ignored the livelihood development goal, which is an important factor in conservation strategies in developing countries. This emphasizes the importance of selecting appropriate research materials during scientific knowledge transfer, to orient the resulting policy toward common interests to meet public goals.

Previous studies also pointed out the need to improve the interfaces between science and policy to manage the continuing biodiversity loss (Watson 2005; Nesshöver et al. 2008, 2013; Young et al. 2014). Such studies have shown that scientists can contribute significantly to the application of science in policy development by providing high-quality policy-relevant data and by actively sharing the results of their work to policymakers (Scott et al. 2008). In this study, we take additional analytical steps to clarify that high-quality research can only forge successful knowledge transfer from science to practice when combined with a good integration strategy. The analysis of actors involved with developing the three biodiversity conservation strategies shows that the support of powerful allies is important in achieving successful integration. For the biodiversity conservation strategy through efficient land use, it is crucial to garner the support of provincial and district governments by integrating efficient land use activities into socioeconomic development plans to help to make these measures permanent. Concerning linkage strategies between biodiversity conservation and livelihood development, efforts should be made to establish legally binding agreements between conservation activities and livelihood support in order to improve the ability to monitor the strategies. Although the strategy on restricted use through gun confiscation was successful in regard to conservation, it should be combined with development activities to help achieve the public-interest goal in the ICDP (e.g., gun owners should be encouraged to hand in their guns and be supported in livelihood development activities as compensation). In addition, legally binding agreements to prevent local people from reusing the guns should be issued.

Much of the previous research has focused on either theoretical and practical issues of conservation and development or the science-policy interface. Our study uses a novel model of scientific knowledge transfer (the RIU model) to reveal the effectiveness of the science-policy interface and its role in biodiversity conservation and poverty alleviation reconciliation. Based on our results, we emphasize that excellent scientific results would not have practical impacts unless research was accompanied by professional integration and vice versa. Therefore, a focus on improving the quality of research and the quality of integration could help internationally funded projects such as the ECOLIME project to be more successful in practice.

\section{CONCLUSIONS}

In this study, we examined scientific knowledge-transfer processes involved in developing three conservation strategies in Vietnam by applying the RIU model of scientific knowledge transfer. Based on our analysis, we provide recommendations for improving the impact of conservation strategies in practice. Although Strategy 1 (undertaking efficient land use activities to contribute to biodiversity conservation) worked in practice, it lacked sustainable allies to fully integrate the strategy into a long- 
lasting practice. Thus, improvement of integration between science and practice is necessary to improve this strategy. Strategy 2 (emphasize linkage between biodiversity conservation and livelihood development) was found to be insufficient scientifically and inapplicable in practice because of low-quality research that contradicted scientific evidence. Thus, in the future, researchers should clarify the nature of the linkage and seek more sufficient solutions for linking biodiversity conservation and livelihood development goals. Strategy 3 (restricted use of natural resources through gun confiscation) was successful in terms of biodiversity conservation (i.e., the number of guns available to local people decreased). However, this strategy only served the interests of specific state actors (e.g., government agencies, police department, and actors from the nature reserve) and did not contribute to poverty alleviation, an important factor in conservation strategies in developing countries. Improvement of this strategy would require a greater focus on both biodiversity conservation and poverty alleviation goals.

Overall, the results demonstrated that conservation research can provide support for successful implementation of conservation strategies only when the data meet high scientific standards and achieve successful integration. Low-quality research and/or unsuccessful integration can result in failures of science-based policy support. Our study recommends improvements to both the research and integration processes of scientific knowledge transfer in order to successfully implement conservation research. Future research should examine the applicability of the RIU model for analyzing scientific knowledge-transfer cases and identify potential improvements in processes involving scientific knowledge transfer.

Acknowledgements We greatly appreciate the financial support of the German Academic Exchange Service (DAAD) and the Vietnamese Government Fund (911 Scholarship). This research was supported by the Chair Group of Forest and Nature Conservation Policy, George-August University of Göttingen, Germany, and Vietnam National University of Forestry. We thank all of the experts and officials involved in the study, particularly those from Fauna and Flora International Vietnam, PLNR, NSNLNR, and CPNP for providing valuable data. We owe a debt of gratitude to local people in PLNR and NSNLNR who gave their time to participate in interviews, provide much practical information and share their knowledge, experiences, and opinions with us. Finally, we would like to thank four anonymous referees for their very helpful comments on this article.

\section{REFERENCES}

Adams, W.M., R. Aveling, D. Brockington, B. Dickson, J. Elliott, J. Hutton, D. Roe, B. Vira, et al. 2004. Biodiversity conservation and the eradication of poverty. Science 306: 1146-1149.
Adrianzén, M.A. 2013. Improved cooking stoves and firewood consumption: Quasi-experimental evidence from the Northern Peruvian Andes. Ecological Economics 89: 135-143.

Agrawal, A., and A. Chhatre. 2006. Explaining success on the commons: Community forest governance in the Indian Himalaya. World Development 34: 149-166.

Apel, U., O.C. Maxwell, T.N. Nguyen, M. Nurse, R.K. Puri, and V.C. Trieu. 2002. Collaborative management and conservation: $A$ strategy for community based natural resource management of special use forest in Vietnam-Case studies from Pu Luong Nature Reserve. Cambridge, UK: Thanh Hoa Province. Fauna \& Flora International/World Bank.

Arcese, P., J. Hando, and K. Campbell. 1995. Historical and presentday anti-poaching efforts in Serengeti. In Serengeti II: Dynamics, management, and conservation of an ecosystem, ed. A.R.E. Sinclair, and P. Arcese, 506-533. Chicago: University of Chicago Press.

Arnold, M. 2002. Clarifying the links between forests and poverty reduction. The International Forestry Review 4: 231-233.

Balint, P.J. 2006. Improving community-based conservation near protected areas: The importance of development variables. Environmental Management 38: 137-148.

Barrett, C.B., D.R. Lee, and J.G. McPeak. 2005. Institutional arrangements for rural poverty reduction and resource conservation. World Development 33: 193-197.

Beck, S. 2011. Moving beyond the linear model of expertise? IPCC and the test of adaptation. Regional Environmental Change 11: 297-306.

Bene, J.G., H.W. Beall, and A. Coote. 1977. Trees, food and people: Land management in the tropics. Ottawa, Canada: International Development Research Center.

Bensch, G., and J. Peters. 2015. The intensive margin of technology adoption-Experimental evidence on improved cooking stoves in rural Senegal. Journal of health economics 42: 44-63.

Berkes, F. 2007. Community-based conservation in a globalized world. Proceedings of the National Academy of Sciences of the USA 104: 15188-15193.

Bhagwat, S.A., K.J. Willis, H.J.B. Birks, and R.J. Whittaker. 2008. Agroforestry: A refuge for tropical biodiversity? Trends in Ecology Evolution 23: 261-267.

Biermann, F., and P.H. Pattberg. 2012. Global environmental governance reconsidered. Cambridge, MA: MIT Press.

Böcher, M. 2012. A theoretical framework for explaining the choice of instruments in environmental policy. Forest Policy and Economics 16: 14-22.

Böcher, M. 2016. How does science-based policy advice matter in policy making? The RIU model as a framework for analyzing and explaining processes of scientific knowledge transfer. Forest Policy and Economics 68: 65-72.

Böcher, M., and M. Krott. 2014. The RIU model as an analytical framework for scientific knowledge transfer: The case of the "decision support system forest" and climate change. Biodiversity and Conservation 23: 3641-3656.

Böcher, M., and M. Krott. 2016. Science makes the world go round: Successful scientific knowledge transfer for the environment. Basel: Springer.

Brooks, J.S., M.A. Franzen, C.M. Holmes, M.N. Grote, and M.B. Mulder. 2006. Testing hypotheses for the success of different conservation strategies. Conservation Biology 20: 1528-1538.

Brooks, J.S., K.A. Waylen, and M.B. Mulder. 2012. How national context, project design, and local community characteristics influence success in community-based conservation projects. Proceedings of the National Academy of Sciences 109: 21265-21270.

Brown, K. 2002. Innovations for conservation and development. The Geographical Journal 168: 6-17. 
Chapason, L., and S. van den Hove. 2009. The debate on an intergovernmental science-policy platform on biodiversity and ecosystem services (IPBES): Exploring gaps and needs. Idées pour le débat 1 .

Christensen, J. 2004. Win-win illusions. Conservation 5: 12-19.

Dharmawan, B., M. Böcher, and M. Krott. 2016. The failure of the mangrove conservation plan in Indonesia: Weak research and an ignorance of grassroots politics. Ocean and Coastal Management 130: 250-259.

Dharmawan, B., M. Böcher, and M. Krott. 2017. Failure of sciencebased win-win solution in fishery management: Learnings from Segara Anakan Waters, Central Java, Indonesia. Ocean and Coastal Management 141: 82-89.

Dietz, T., and P.C. Stern. 1998. Science, values, and biodiversity. BioScience Policy Forum 48: 441-444.

Do Thi, H., M. Krott, and M. Böcher. 2017. The success of scientific support for biodiversity conservation policy: The case of Ngoc Son Ngo Luong Nature Reserve in Vietnam. Journal for Nature Conservation 38: 3-10.

Dresen, E., B. DeVries, M. Herold, L. Verchot, and R. Müller. 2014. Fuelwood savings and carbon emission reductions by the use of improved cooking stoves in an Afromontane Forest, Ethiopia. Land 3: 1137-1157.

Ferraro, P.J., and A. Kiss. 2002. Direct payments to conserve biodiversity. Science 298: 1718-1719.

FFI (Fauna and Flora International). 2002a. Detailed proposal for development of the Pu Luong-Cuc Phuong Limestone Landscape Conservation Project. Hanoi: Vietnam Country Program.

FFI (Fauna and Flora International). 2002b. Baseline survey report: Survey of communes in Mai Chau. FFI Vietnam, Hanoi: Tan Lac and Lac Son Districts of Hoa Binh Province.

FFI (Fauna and Flora International). 2002c. Preliminary village survey: Surveys of villager in Thanh Son, $\mathrm{Ha}$ Trung and Lung Cao Communes, Ba Thuoc District. FFI Vietnam, Hanoi: Thanh Hoa Province.

FFI (Fauna and Flora International). 2003a. A survey of hunting status and collection of non-timber forest products in Pu Luong Nature Reserve and its surrounding forests. Hanoi: FFI Vietnam.

FFI (Fauna and Flora International). 2003b. Options for gun control program. Discussion paper for presentation to hunting workshop. Hoa Binh, Vietnam.

FFI (Fauna and Flora International). 2005. Report on development initiatives in the buffer zone in Hoa Binh. Pu Luong Cuc Phuong limestone landscape conservation project. Hanoi: FFI Vietnam.

FFI (Fauna and Flora International). 2006. Implementation completion report phase 1: Pu Luong-Cuc Phuong Limestone Landscape Conservation Project. Hanoi: Vietnam Country Program.

FFI (Fauna and Flora International). 2009. Implementation completion report phase 2: Pu Luong-Cuc Phuong Limestone Landscape Conservation Project. Hanoi: Vietnam Country Program.

Garnett, S.T., J. Sayer, and J. du Toit. 2007. Improving the effectiveness of interventions to balance conservation and development: A conceptual framework. Ecology and Society 12: $2-21$.

Guston, D.H. 2001. Toward a "best practice" of constructing "serviceable truths". In Knowledge, power, and participation in environmental policy analysis, ed. M. Hisschemöller, R. Hoppe, W.N. Dunn, and J.R. Ravetz, 97-118. Policy Studies Review Annual No. 12. New Brunswick: Transaction Publishers.

Heim, J., and M. Böcher. 2016. CITES and science: Using the RIU model to analyze institutionalized scientific policy advice in Germany for the case of ivory trade. Journal of International Wildlife Law and Policy 19: 159-175.

Hughes, R., and F. Flintan. 2001. Integrating conservation and development experience: A review and bibliography of the ICDP literature. London: International Institute for Environment and Development.

Hulme, M. 2009. Why we disagree about climate change: Understanding controversy, inaction and opportunity. Cambridge, UK: Cambridge University Press.

Hussein, A. 2015. The use of triangulation in social sciences research: Can qualitative and quantitative methods be combined? Journal of Comparative Social Work 4: 1-12.

IEA (International Energy Agency). 2002. Energy and poverty. World energy outlook. Paris: International Energy Agency.

Kanagawa, M., and T. Nakata. 2007. Analysis of the energy access improvement and its socio-economic impacts in rural areas of developing countries. Ecological Economics 62: 319-329.

Koetz, T., P. Bridgewater, S. van den Hove, and B. Siebenhüner. 2008. The role of the subsidiary body of scientific, technical and technological advice to the convention on biological diversity as science-policy interface. Environmental Science \& Policy 11: 505-516.

Koetz, T., P. Bridgewater, C. Miller, R. Norgaard, and R.A. Pielke. 2009. Science-policy interfaces for more effective governance of biodiversity and ecosystem services: Institutional mismatches, shifting paradigms, obstructions, and opportunities. Concept note for IPBES. Retrieved 17 July 2017, from http://sciencepolicy. colorado.edu/admin/publication_files/resource-2783-2009.40.pdf.

Krott, M. 2005. Forest policy analysis. Dordrecht: Springer.

Krott, M. 2012. Value and risks of the use of analytical theory in science for forest policy. Forest Policy and Economics 16: $35-42$.

Liu, Y., J. Wang, and X. Deng. 2008. Rocky land desertification and its driving forces in the karst areas of rural Guangxi, Southwest China. Journal of Mountain Science 5: 350-357.

Lovett, J.C., and D.G. Ockwell. 2010. A handbook of environmental management. Cheltenham: Edward Elgar Publishing.

Lu, J.B. 2006. Energy balance and economic benefits of two agroforestry systems in northern and southern China. Agriculture, Ecosystems Environment 116: 255-262.

Manibog, F.R. 1984. Improved cooking stoves in developing countries: Problems and opportunities. Annual Review of Energy 9: 199-227.

McShane, T.O. 2003. Protected areas and poverty. Policy Matters 12: $52-53$.

Miller, N. 2009. Environmental politics: Stakeholders, interests, and policymaking. New York: Routledge.

Milner-Gulland, E.J., and N. Leader-Williams. 1992. A model of incentives for the illegal exploitation of black rhinos and elephants: Poaching pays in Luangwa Valley, Zambia. Journal of Applied Ecology 29: 388-401.

Nadler, T., F. Momberg, N.X. Dang, and N. Lormee. 2003. Vietnam primate conservation status review 2002. Part II: Leaf monkeys, 145-164. Hanoi: Frankfurt Zoological Society and Fauna and Flora International.

Nagasaka, K., M. Böcher, and M. Krott. 2016. Science-policy interaction: The case of the forest and forestry revitalization plan in Japan. Land Use Policy 58: 145-151.

Nesshöver, C., R. Müssner, K. Henle, and I. Sousa Pinto. 2008. Linking biodiversity research and policy in Europe. Ambio 37: 138-141.

Nesshöver, C., J. Timaeus, H. Wittmer, A. Krieg, N. Geamana, S. van den Hove, J. Young, and A. Watt. 2013. Improving the sciencepolicy interface of biodiversity research projects. GAIA-Ecological Perspectives for Science and Society 22: 99-103.

Nesshöver, C., M. Vandewalle, H. Wittmer, E.V. Balian, E. Carmen, I.R. Geijzendorffer, and S. Schindler. 2016. The Network of Knowledge approach: improving the science and society dialogue on biodiversity and ecosystem services in Europe. Biodiversity and Conservation 25: 1215-1233. 
Neuman, W.L. 2005. Social research methods: Quantitative and qualitative approaches, 6th ed. London: Allyn and Bacon.

Oates, J.F. 1995. The dangers of conservation by rural developmenta case-study from the forests of Nigeria. Oryx 29: 115-122.

Pereira, H.M., P.W. Leadley, V. Proença, R. Alkemade, J.P. Scharlemann, J.F. Fernandez-Manjarrés, M.B. Araujo, P. Balvanera, et al. 2010. Scenarios for global biodiversity in the $21 \mathrm{st}$ century. Science 330: 1496-1501.

Perrings, C., A. Duraiappah, A. Larigauderie, and H. Mooney. 2011. The biodiversity and ecosystem services science-policy interface. Science 331: 1139-1140.

PLNR (Pu Luong Nature Reserve). 2010. Report on investment project for Pu Luong Nature Reserve 2006-2010. Pu Luong Nature Reserve.

Pregernig, M. 2014. Framings of science-policy interactions and their discursive and institutional effects: Examples from conservation and environmental policy. Biodiversity and Conservation 23: $3615-3639$.

Pregernig, M., and M. Böcher. 2012. Normative and analytical perspectives on the role of science and expertise in environmental governance. In Environmental governance: The challenge of legitimacy and effectiveness, ed. K. Hogl, E. Kvarda, R. Nordbeck, and M. Pregernig, 199-219. Cheltenham: Edward Elgar.

Quang Tuan, B., and H. Huy Ngoc. 2016. Exploitation and use of bioenergy during the Implementation of Vietnam's green growth strategy: Status and policy recommendations. Vietnam Social Sciences 2: 13-27.

RIGMR (Research Institute on Geology and Mineral Resources). 2003. Geological characteristics of the Pu Luong Nature Reserve and surrounding areas. Hanoi, Vietnam: RIGMR.

Salafsky, N., and E. Wollenberg. 2000. Linking livelihoods and conservation: A conceptual framework and scale for assessing the integration of human needs and biodiversity. World Development 28: 1421-1438.

Salafsky, N., H. Cauley, G. Balachander, B. Cordes, J. Parks, C. Margoluis, S. Bhatt, C. Encarnacion, et al. 2001. A systematic test of an enterprise strategy for community-based biodiversity conservation. Conservation Biology 15: 1585-1595.

Saterson, K.A., N.L. Christensen, R.B. Jackson, R.A. Kramer, S.L. Pimm, M.D. Smith, and J.B. Wiener. 2004. Disconnects in evaluating the relative effectiveness of conservation strategies. Conservation Biology 18: 597-599.

Schirmer, M. 2014. Biomass and waste as a renewable and sustainable energy source in Vietnam. Journal of Vietnamese Environment 6: 4-12.

Schroth, G., G.A.B. da Fonseca, C.A. Harvey, C. Gascon, H.L. Vasconcelos, and A.M.N. Izac (eds.). 2004. Agroforestry and biodiversity conservation in tropical landscapes. Washington, DC: Island Press.

Scott, J.M., J.L. Rachlow, and R.T. Lackey. 2008. The science-policy interface: What is an appropriate role for professional societies. AIBS Bulletin 58: 865-869.

Sesan, T. 2012. Navigating the limitations of energy poverty: Lessons from the promotion of improved cooking technologies in Kenya. Energy Policy 47: 202-210.

Stattersfield, A.J., M.J. Crosby, A.J. Long, and D.C. Wege. 1998. Endemic bird areas of the world: Priorities for biodiversity conservation. Cambridge, UK: BirdLife International.

Stevanov, M., M. Böcher, M. Krott, S. Krajter, D. Vuletic, and S. Orlovic. 2013. The research, integration and utilization (RIU) model as an analytical framework for the professionalization of departmental research organizations: Case studies of publicly funded forest research institutes in Serbia and Croatia. Forest Policy and Economics 37: 20-28.
Sunderland, T.C.H., C. Ehringhaus, and B.M. Campbell. 2007. Conservation and development in tropical forest landscapes: a time to face the trade-offs? Environmental Conservation 34: 276-279.

Tu, D.T., O. Saito, Y. Yamamoto, and A. Tokai. 2010. Scenarios for sustainable biomass use in the Mekong Delta, Vietnam. Journal of Sustainable Energy \& Environment 1: 137-148.

Urmee, T., and S. Gyamfi. 2014. A review of improved Cook stove technologies and programs. Renewable and Sustainable Energy Reviews 33: 625-635.

Wallmo, K., and S.K. Jacobson. 1998. A social and environmental evaluation of fuel-efficient cook-stoves and conservation in Uganda. Environmental Conservation 25: 99-108.

Watson, R.T. 2005. Turning science into policy: challenges and experiences from the science-policy interface. Philosophical Transactions of the Royal Society of London B: Biological Sciences 360: 471-477.

Wells, M.P., and T.O. McShane. 2004. Integrating protected area management with local needs and aspirations. Ambio 33: 513-519.

Winkler, R. 2011. Why do ICDPs fail? The relationship between agriculture, hunting and ecotourism in wildlife conservation. Resource and Energy Economics 33: 55-78.

Wood, A., P. Stedman-Edwards, and J. Mang. 2000. The root causes of biodiversity loss. London: Earthscan.

WWF, and IUCN. 1994. Centres of plant diversity: A guide and strategy for their conservation, vol. 3. Cambridge: IUCN Publications.

Young, J.C., K.A. Waylen, S. Sarkki, S. Albon, I. Bainbridge, E. Balian, and D. McCracken. 2014. Improving the science-policy dialogue to meet the challenges of biodiversity conservation: Having conversations rather than talking at one-another. Biodiversity and Conservation 23: 387-404.

Zingerli, C. 2005. Colliding understandings of biodiversity conservation in Vietnam: Global claims, national interests, and local struggles. Society and Natural Resources 18: 733-747.

\section{AUTHOR BIOGRAPHIES}

Huong Do Thi $(\bowtie)$ is a PhD student in the Department of Forest and Nature Conservation Policy at the George-August University of Göttingen, Germany. Her research is focused on knowledge transfer, biodiversity conservation policy and natural resource governance. Address: Chair Group of Forest and Nature Conservation Policy, George-August University of Göttingen, Büsgenweg 3, 37077 Göttingen, Germany.

Address: College of Land Management and Rural Development, Vietnam National University of Forestry, Xuan Mai town, Chuong My district, Hanoi, Vietnam.

e-mail: dohuongnlkh@gmail.com; huongdo.forestpolicy@gmail.com

Max Krott is a professor for forest policy and Chair in the Department of Forest and Nature Conservation Policy at the George-August University of Göttingen, Germany. He was teaching at several Universities in Europe and the US and has supervised $50 \mathrm{PhD}$ students. He was a member of the executive board of the International Union of Forest Research Organizations and is founding editor-inchief of the international Elsevier journal "Forest Policy and Economics." His main fields of research cover forest and nature conservation policy in Europe and research policy. He has published 25 books and more than 150 papers.

Address: Chair Group of Forest and Nature Conservation Policy, George-August University of Göttingen, Büsgenweg 3, 37077 Göttingen, Germany.

e-mail: mkrott@gwdg.de 
Michael Böcher is a professor for sustainability governance, environmental policy analysis, scientific knowledge transfer in the environmental sciences, and sustainable rural development. Since 2016 , he has been holding the Chair of political science and sustainable development at the Otto von Guericke University Magdeburg, Germany.

Address: Chair of Political Science and Sustainable Development, Otto von Guericke University Magdeburg, Zschokkestr. 32, 39016 Magdeburg, Germany.

e-mail: michael.boecher@ovgu.de
Nataly Juerges is a post doc researcher in the Department of Forest and Nature Conservation Policy at the Göttingen University, Germany. Her research is focused on knowledge transfer and natural resource governance.

Address: Chair Group of Forest and Nature Conservation Policy, George-August University of Göttingen, Büsgenweg 3, 37077 Göttingen, Germany.

e-mail: nataly.juerges@uni-goettingen.de 
Ambio

Electronic Supplementary Material

Title: Toward successful implementation of conservation research: A case study

from Vietnam

Authors: Huong Do Thi, Max Krott, Michael Böcher, Nataly Juerges. 
Table S1 Results of analysis of three biodiversity conservation strategies applying the RIU model

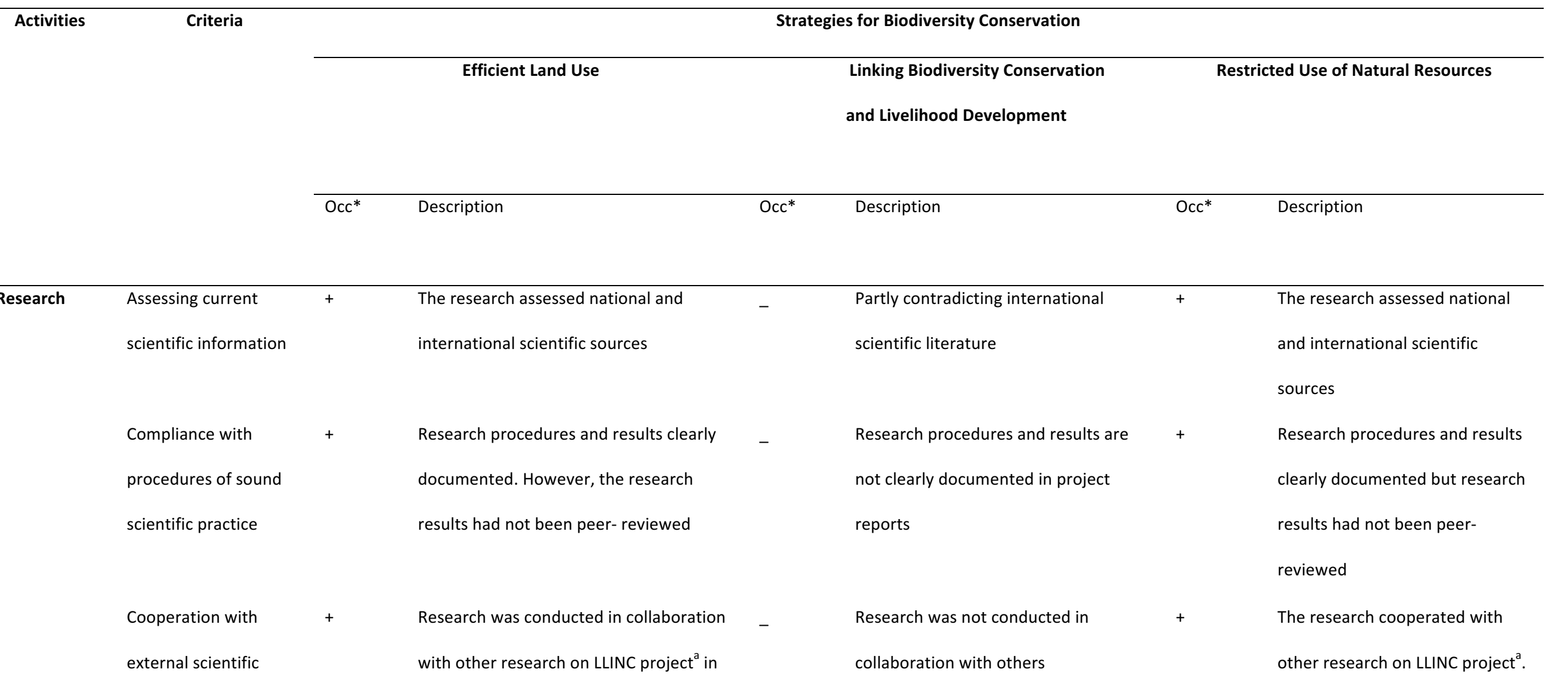

projects and

feasibility study for establishing the

institutions

NSNLRN 
Independent

meaningfulness of

scientific findings

Integration

Orientation towards

public goals

political processes

Relevance with regard

to allies

Target-group oriented

intermediation for the

appropriate media

Contribution to

democracy

local people

Participatory efforts
Research was directed toward two

main public goals (protecting

biodiversity, poverty alleviation)

Poverty alleviation is relevant to

political processes in Vietnam

No strong allies for sustainable

monitoring

International donors support for only a

short time

Many communication activities.

Informal agreements for linking

between the project and local people
Scientific recommendation from

research was not dependent on

other research projects

Research was orientated toward

biodiversity conservation goal,

but neglected livelihood

development goal of local people

Relevant to political control of

users

Strong allies: Forest protection

department, police department,

local authority, management

board of the nature reserves

Communication by forced

confiscation
Participatory efforts
No participation 


\begin{tabular}{|c|c|c|c|c|c|c|}
\hline Contribution to rule of & - & No regulation was established & - & Informal contracts for linking & + & Collection of guns by police \\
\hline \multicolumn{7}{|l|}{ law } \\
\hline Contribution to good & \pm & Partly information of local users and & \pm & Partly information of local users and & \pm & Partly information of local users \\
\hline \multirow[t]{2}{*}{ governance } & & involvement of international actors & & involvement of international actors & & and partial involvement of \\
\hline & & & & & & international actors \\
\hline Appropriate solutions & - & Limited contribution due to limited & - & Informal agreements for linking did not & + & 1197 guns were confiscated from \\
\hline \multirow[t]{2}{*}{ to problems } & & investment and small number of & & work due to weak monitoring & & local people, but did not help for \\
\hline & & participated households & & & & improving livelihoods \\
\hline Participation in the & - & No scientific papers & - & No scientific papers & - & No scientific papers \\
\hline scientific discourse & & & & & & \\
\hline
\end{tabular}

aLINC: The Limestone Landscape Improving Negotiation for Conservation project

Note: ${ }^{*}$ Occ. $=$ Occurrence $(-$ not given; \pm partly given; + given $)$.

Source: adapted from Böcher and $\operatorname{Krott}(2014,2016)$ 
Table S2 Actors involved in knowledge transfer process

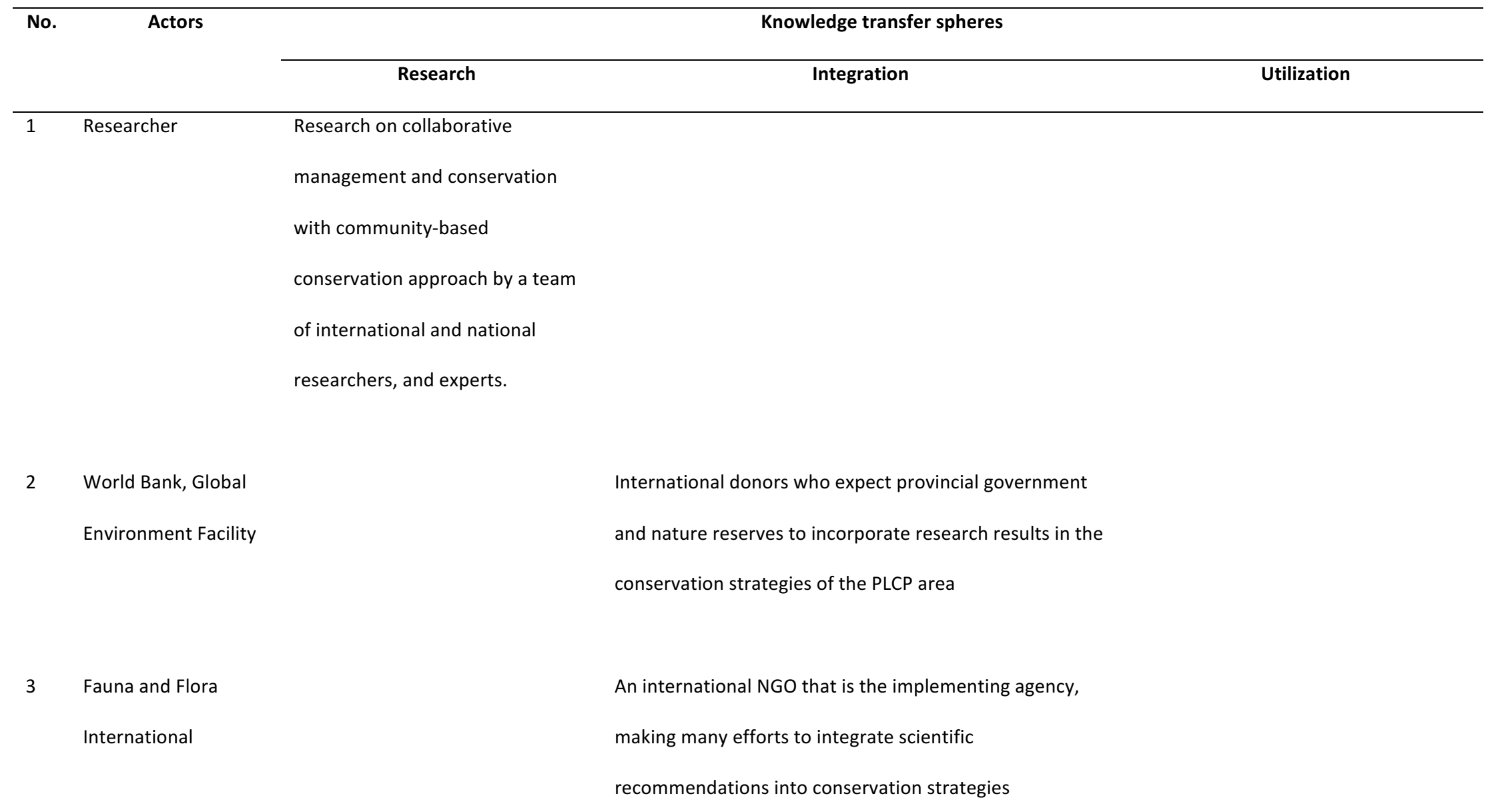


Central Forest

Protection

Department

Provincial

government

$\left(P P C s^{a}, P^{2} P D s^{b}\right)$

PLNR, NSNLNR

7
Government partner of the ECOLIME project that also

expect to incorporate scientific recommendations in

conservation strategies for the PLCP area

Powerful allies that did not sustainably support

conservation strategies in the PLCP area

Confiscated 1,197 guns from local

people, but did not help improve

livelihoods

Support for implementing efficient

land use activities and issuing informa

agreements to commit local people to

conservation activities

Supported through small grants to

implement efficient land use and

commit to conservation activities.

Note: aPPCs: Provincial people's committees

${ }^{\mathrm{b}}$ PFPDs: Provincial forest protection departments 


\title{
Red lists in conservation science-policy interfaces: A case study from Vietnam
}

\author{
Thi Huong Do ${ }^{\mathrm{a}, \mathrm{b}, *}$, Max Krott ${ }^{\mathrm{a}}$, Nataly Juerges ${ }^{\mathrm{a}}$, Michael Böcher ${ }^{\mathrm{c}}$ \\ ${ }^{\text {a } C h a i r ~ G r o u p ~ o f ~ F o r e s t ~ a n d ~ N a t u r e ~ C o n s e r v a t i o n ~ P o l i c y, ~ G e o r g e-A u g u s t ~ U n i v e r s i t y ~ o f ~ G o ̈ t t i n g e n, ~ B u ̈ s g e n w e g ~ 3, ~} 37077$ Göttingen, Germany \\ ${ }^{\mathrm{b}}$ College of Land Management and Rural Development, Vietnam National University of Forestry, Xuan Mai Town, Chuong My District, Hanoi, Viet Nam \\ ${ }^{\mathrm{c}}$ Chair of Political Science and Sustainable Development, Otto von Guericke University Magdeburg, Zschokkestr. 32, 39016 Magdeburg, Germany
}

\section{A R T I C L E I N F O}

\section{Keywords:}

Biodiversity conservation

Red lists

RIU model

Science-policy interface

Science-based policy advice

Vietnamese Red Data Book

\begin{abstract}
A B S T R A C T
Red lists of threatened species have been a powerful instrument to interact loss of biodiversity in many countries. However, there have been growing concerns over the scientific basis of red lists and the influence of red lists on conservation policy formulation. This article explores science-policy interface in the development and use of the Vietnamese Red Data Book 2007 by applying the Research - Integration - Utilization (RIU) model of scientific knowledge transfer. Our study has shown the scientific weaknesses of the Vietnamese Red Data Book 2007, which arise from limited availability of updated data on rare and threatened species in Vietnam and unknown factors influencing them. Despite the existing limitations, the science-based policy advice of the Vietnamese Red Data Book 2007 has achieved certain political influence due to successful integration. Our study also reveals that good and actor-relevant communication could help to win powerful allies in conservation policy formulation, which contributes to a successful transfer of scientific knowledge. Based on our results, we recommend that the improvement of the scientific basis of the red lists is essential to enhance science-based policy support in biodiversity conservation.
\end{abstract}

\section{Introduction}

Red lists of threatened species have been widely recognized as an increasingly powerful tool for conservation planning, management and policymaking in the field of biodiversity conservation (Cassini, 2011; Lamoreux et al., 2003; Mace et al., 2008; Rodrigues et al., 2006). The International Union for Conservation of Nature (IUCN) has been periodically assessing the global threat status of species and publishing the results in IUCN red lists of threatened species for more than five decades. However, given that the loss of species, as well as most conservation efforts, take place at the national scale, numerous countries have established national lists of threatened species, often based on IUCN red list criteria and guidelines at regional levels (Collen et al., 2013; Rossi et al., 2016; Zamin et al., 2010). Most national red lists are considered as an appropriate basis for setting conservation priorities, while in some countries red lists also have legal status (Keller and Bollmann, 2004). Although the red lists of threatened species have been considered as a valuable tool for conservation (Lamoreux et al., 2003; Rodrigues et al., 2006), the scientific basis of these lists has been debated (Cardoso et al., 2012; Collen et al., 2016; Hayward, 2009; Igor et al., 2017; Vignoli et al., 2017).
At the global level, there is an urgent call to improve the accuracy and scientific credibility of IUCN red list categories since the real risks of extinction for some species have been claimed to be exaggerated against these IUCN categories and criteria (Godfrey and Godley, 2008; Webb, 2008). It is also argued that using red lists as the only tool for setting resource allocation priorities and favoring threatened species over "data deficient" forms may lead researchers to "inflate" the lists (Pimenta et al., 2005). At national levels, red lists have been proved to be underestimated due to the deficit of information used in their assessment, for example, in the case of the red list of amphibians in Italy (Vignoli et al., 2017). In addition, a biased classification for some taxa was also found in an assessment of 135 rare or threatened vascular plant species from southeast Australia (Keith et al., 2000). Thus, there is an increasing need to better understand the scientific basis of red lists and the influence of science on the red listing.

An important role of red lists is to provide scientific policy advice which serves as an interface between science and politics, the so-called "science-policy interface" (Hulme, 2009) in the conservation of biodiversity. Scientific research and science-policy interface have become an increasingly important issue for addressing challenges of biodiversity conservation (Chapason and van den Hove, 2009; Koetz et al., 2012;

\footnotetext{
* Corresponding author at: George-August University of Göttingen, Büsgenweg 3, 37077 Göttingen, Germany.

E-mail addresses: dohuongnlkh@gmail.com, tdo1@gwdg.de (T.H. Do).
} 


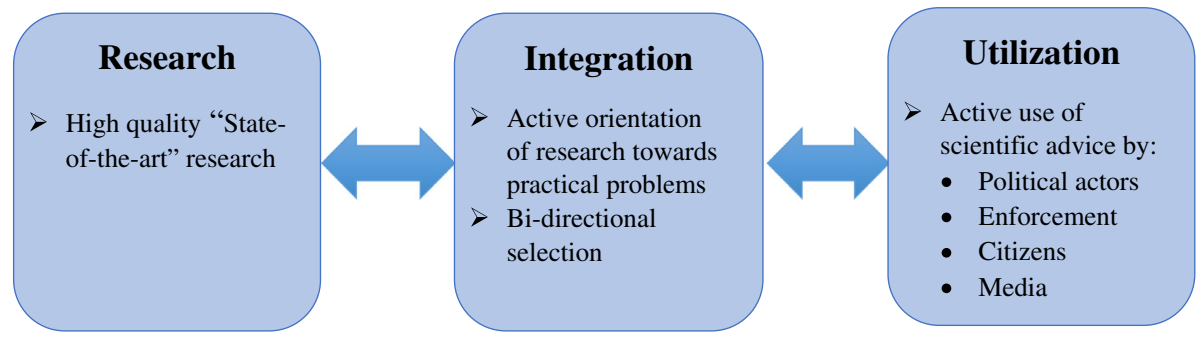

Fig. 1. The RIU model of scientific knowledge transfer.

(Adapted from Böcher and Krott (2016).)

Spierenburg, 2012; Young et al., 2014). Science is expected to provide scientific recommendations that will facilitate decision-making and a rational management of nature (Jørstad and Skogen, 2010). Some studies have shown that biodiversity conservation policies are most effective when based on current scientific knowledge and public verification (Babbitt, 1995; Eisner et al., 1995). Red listing is the process of assigning species to a category of threat representing their risk of extinction (Milner-Gulland et al., 2006). It is claimed that red lists function as a linkage between experts and policymakers where the reliability of red lists as a scientific assessment and the credibility of specific policy based on such scientific assessment are mutually strengthened (Gustafsson and Lidskog, 2013). However, while most studies about the topic of red lists had a natural science perspective (Eaton et al., 2005; Newton and Oldfield, 2008), few published studies have been carried out on the relationship between science and policy in red lists and its influence on conservation policy formulation within specific political context at the national level.

This paper presents findings from a study about the science-policy interface of Vietnamese Red Data Book 2007 by applying a new model of scientific knowledge transfer (RIU model). The RIU model was developed based on research that addressed scientific knowledge transfer for environmental and forest policy in Germany (Böcher and Krott, 2014; Böcher, 2016; Heim and Böcher, 2016) and Eastern Europe (Stevanov et al., 2013). It has also been applied to case studies of scientific knowledge transfer in other countries in Asia (Nagasaka et al., 2016; Dharmawan et al., 2016, 2017; Do Thi et al., 2017a, 2017b). The RIU model has been proved to be useful for analyzing dynamic interactions between science and policy (Nagasaka et al., 2016) and interconnected steps for science-based policy advice (Böcher, 2016). In this study, the RIU model is used as an analytical framework to demonstrate the activities of research, integration, and utilization of the Vietnamese Red Data Book 2007 to reveal its scientific basis and dynamic interactions between science and policy. Our guiding research questions are:

1/ What is the scientific basis of Vietnamese Red Data Book 2007?

2/ How was science-based policy advice of the red data book integrated into national conservation policymaking?

3/ Which role does the red data book play in the science-policy interface in Vietnamese conservation policy?

This paper begins by describing the RIU model that serves as our analytical framework and, subsequently, explains the research methods. Next, the paper elaborates on a case study of the Vietnamese Red Data Book 2007 to demonstrate the relationship between research, integration, and utilization. Finally, based on the research results, the paper presents conclusions regarding potential improvements for science-based policy advice of the Vietnamese Red Data Book to enhance biodiversity conservation in Vietnam.

\section{Theoretical framework: science-policy Interface in biodiversity conservation}

In the field of biodiversity conservation, people and institutions are becoming increasingly aware of the importance of scientific knowledge and knowledge transfer at the science-policy interface to address the challenge of biodiversity loss (Neßhöver et al., 2013; Spierenburg, 2012; Young et al., 2014). Often, a linear knowledge transfer process is expected, in which science provides knowledge and information about the impact of certain choices, and policy-makers use this information to design policies (Spierenburg, 2012). However, such linear scientific knowledge transfer is rare because it cannot directly function within different underlying rationalities of science (the search for truth) and politics (the search for power) (Böcher and Krott, 2014; Krott, 2012; Miller, 2009). Science-policy interfaces are expected to go beyond the linear model of scientific policy advice through creating space for the exchange and dialogue between 'policy' and 'knowledge' (Görg et al., 2016). However, there have been many challenges related to improving science-policy interactions in biodiversity conservation, which derive from the complexities of biodiversity, as well as from the policymaking process itself (Spierenburg, 2012).

To contribute to the literature about the science-policy interface in biodiversity conservation, we have applied a new model of scientific knowledge transfer (the RIU model) to analyze science-policy interactions of the Vietnamese Red Data Book 2007. The RIU model predominantly follows the idea that policies are the result of co-production between scientific arguments and political reasoning. In the RIU model, knowledge transfer process is defined as a connection of three spheres: Research (R), Integration (I), and Utilization (U), each of which follows an individual logic (Böcher and Krott, 2014, 2016) (Fig. 1).

In the RIU model, scientific results are formulated by scientists using scientific methods and standards from the research sphere (Stevanov et al., 2013; Böcher and Krott, 2014, 2016). Then, scientific results are led to the integration sphere for the selection of scientific knowledge. In integration, stakeholders select research results which are relevant to solve practical problems using criteria based on practical demands (Böcher and Krott, 2014, 2016). On the contrary, practical demands for scientific solutions are interpreted to formulate scientific research questions addressing those practical questions (Böcher and Krott, 2016). The RIU model emphasizes an important bi-directional, non-linear process of switching between research and integration activities to create scientific policy advisory products (Böcher and Krott, 2016; Böcher, 2016). Integration leads to utilization of scientific results by political and practical stakeholders in practice.

The RIU model also emphasizes the importance of quality of scientific expertise in successful knowledge transfer, which has been reflected in many previous studies (Lentsch and Weingart, 2011). Since the quality of scientific expertise is crucial for becoming credible among politicians and practitioners and since it supports the use of scientific knowledge in application contexts (Pregernig and Böcher, 2012), high quality research must be regarded as an important precondition for successful transfer of scientific knowledge from science to policymaking (Lentsch and Weingart, 2011). However, political actors follow their self-interests, which do not necessarily include the maximal, or even any, use of science (Braun and Benninghoff, 2003). The use of scientific expertise is by no means dependent only on scientific quality, but also on its usefulness for various political actors (Miller, 2009). In the 
political process, institutions, the power of different actors, the range of available policy instruments, as well as the underlying problem structure of a concrete policy, influence political decision-making (Böcher and Töller, 2015). In the policy process, not necessarily only the strongest, state-of-the-art scientific results become relevant for political actors; sometimes, science can fulfill certain functions for political actors (Boehmer-Christiansen, 1995) that must not necessarily need to be epistemological in a sense of scientific illumination or learning from science. Also, political actors always have to make decisions in situations of uncertainty or in situations in which certain external conditions are given, like in the case of a suddenly opening policy window for a certain policy issue, external shocks, a change in the government or available funding from external donors or national sources (Grossman, 2012; Kingdon and Thurber, 1984; Smith, 2017).

According to the RIU model, scientific results have to be linked to the interests of specific political actors in order to be able to expand into the political process (Böcher and Krott, 2016). The decisive link to the political actors is the specific policy issue relevant at given time, not the scientific content of the research results as such. Political actors are highly competent in linking scientific information to the political process to support their interests (Böcher and Krott, 2016). The main question regarding the science-policy interface is whether scientific knowledge transfer could happen if the scientific results are weak or if science is not able to diminish the level of uncertainty that political actors are confronted with? This is the starting point for our study since the RIU model states that a lack of scientific expertise or a lack of quality in available scientific findings does not necessarily mean that political actors cannot draw conclusions for their political products (Böcher and Krott, 2016). Here, the RIU model is well in line with current theories of the policy process. The question - if re-formulated in a normative manner - could be whether we can still speak of "scientific" knowledge transfer if the scientific basis of knowledge transfer is weak. Accordingly, based on these theoretical arguments, we formulated the first hypothesis:

Hypothesis 1. Even if science-based policy advice has a weak scientific basis, it can achieve political influence in case of successful integration.

The RIU model also highlights the importance of the specific actors serving as important allies for scientific knowledge transfer. Allies are identified as "all actors that support knowledge transfer from science into political practice by means of their powers" (Böcher and Krott, 2016). The connection between scientific knowledge and the concrete demands and interests of the actors is especially important, as it is also the link between scientific research results and the interest of actors in the political process (Böcher and Krott, 2014; Krott, 2012). As an additional aspect of scientific knowledge transfer, the RIU model highlights "target-group oriented intermediation" (Böcher and Krott, 2016: $\mathrm{p} 46$ ) as important in order to create and maintain the interest of policymakers in scientific results, within which effective communication would be an important strategy (Guldin, 2003). This argument conforms to the established studies on the science-policy interface and the question of how scientific knowledge can reach political actors as target groups, and vice versa, how practical and political demands of knowledge can lead to scientific research they deal with (Müller-Rommel, 1984; Renn, 2003). Many scientific or practical guidelines for scientific knowledge transfer often state that almost all that is crucial for knowledge transfer is communication (Moll and Zander, 2006; Richards and Den Hoed, 2018; Selin et al., 2018; Ugolini et al., 2015). For the RIU model, communication is an important subtask of the knowledge transfer. However, RIU argues that if the science-based information useful to the actors and their interests is well-communicated, they will use their resources to promote the use of scientific knowledge in their specific realm. This brings us to the assumption that good communication could help to win powerful allies in policymaking. We formulated the second hypothesis based on this assumption.
Hypothesis 2. Science-based policy advice wins powerful allies in policymaking due to good and actor-relevant communication.

These two hypotheses guide our analysis of the scientific basis and the relationship between science and policy of the Vietnamese Red Data Book 2007. Both hypotheses are relevant for our case of the Vietnamese Red Data Book because the red listing has been a controversial issue concerning its scientific accuracy (Webb, 2008; Godfrey and Godley, 2008) and uncertainty (Akçakaya et al., 2000; Newton, 2010), and political actors expected that red lists might provide a sufficient conservation tool in practice.

\section{Methodology}

\subsection{Introduction of the Vietnamese Red Data Book}

The issues concerning the establishment of the Vietnamese Red Data Book were first presented by Vietnamese scientists in the 1980 s. However, not until 1992 the first Vietnamese IUCN-based red data book of threatened animals was published. Then, the red data book of threatened plants was also published three years later, in 1996. In 2000, the red data book of threatened animals was re-published to meet the high demand for use by scientists and regulators. Vietnamese scientists followed IUCN categories and criteria, which are acknowledged as one of the most internationally accepted ways of developing red lists of threatened species (Miller et al., 2007; Brito et al., 2010). In comparison with other countries in Asia, Vietnam relatively early implemented IUCN's criteria in its establishment of the red data book.

The first edition of the Vietnamese Red Data Book is based on five categories and their criteria of IUCN in 1992 for developing red lists. However, in 1994 IUCN developed eight new categories and their criteria for classifying species at high risk of global extinction, which were developed to improve objectivity and transparency in assessing the conservation status of species and to enhance consistency and understanding among users (IUCN, 1994; Milner-Gulland et al., 2006).

In an attempt to encourage the establishment of red lists at national and regional levels, IUCN held a regional workshop to introduce the IUCN criteria 1994 and its application in 1999 in Sri Lanka. Vietnam is one of 15 countries that participated in the workshop. After the workshop, given the need of reviewing and revising Vietnamese Red Data Book in regard to new categories and criteria of IUCN (1994), a research project was proposed and implemented by Vietnam Academy of Science and Technology during the period from 2000 to 2003. As a result, the new Vietnamese Red Data Book compiled in 2004 and published in 2007 showed a new situation of the biodiversity of Vietnam after 15 years since the first red data book compilation in 1992 (Table 1).

Vietnamese scientists have published both the Vietnamese Red Data Book and the Vietnamese red list. The difference between the red list and the red data book is that the red data book includes more specific information on threatened species (i.e. identifying characteristics, biology, ecology, distribution, value) than the red list. In this article, "red list" and "red data book" are employed interchangeably for convenience, while "red listing" refers to the whole process associated with identifying threatened species according to standard assessment procedures.

Table 1

Historical development of the Vietnamese Red Data Book.

$\begin{array}{ll}1992 & \text { Vietnamese Red Data Book of threatened animals was first published } \\ 1996 & \text { Vietnamese Red Data Book of threatened plants was published } \\ 2000 & \text { Republication of Vietnamese Red Data Book of threatened animals } \\ 2004 & \begin{array}{l}\text { Research for revising and reassessing Vietnamese Red Data Book } \\ \text { following IUCN criteria 1994 was completed }\end{array} \\ 2007 & \begin{array}{l}\text { Vietnamese IUCN-based red data books of threatened animals and plants } \\ \text { were officially published }\end{array} \\ 2017 & \text { Research for revising Vietnamese Red Data Book } 2007 \text { is still ongoing }\end{array}$




\subsection{Data collection}

This study is based on expert interviews and policy document analyses. First, we collected all relevant documents from many research institutions and universities that participated in the establishment of the Vietnamese Red Data Book 2007, such as the Institute of Ecology and Biological Resources, Hanoi National University, Forest Inventory and Planning Institute, and Center for Plant Conservation. In total, we gathered 28 documents related to the establishment and use of the Vietnamese Red Data Book 2007, including project reports for red listing, published books, scientific articles, and regulatory documents. Second, we conducted 25 semi-structured interviews between May and August 2017. Appendix 1 provides information on the identities and dates of the interviews. Among interviewees, there were various stakeholders involved in the establishment and use of the red data book such as researchers, governmental officers, non-governmental organizations' staff (i.e. IUCN Vietnam). Interview questions focused on scientific research for the Vietnamese Red Data Book 2007, biodiversity monitoring activities, the red - listing process and wildlife protection laws of Vietnam. We also interviewed scientists and experts who did not directly participate in the establishment of the Vietnamese Red Data Book 2007. Interviewing non-participants in the establishment of the Vietnamese Red Data Book 2007 allowed for the objective assessment of scientific research in the red - listing process. The interviews lasted between 1 and $2 \mathrm{~h}$ and were conducted in Vietnamese by a native researcher.

\subsection{Data analysis}

All data from the interviews and document analyses were interpreted following the triangulation method (Hussein, 2015) to identify reliable information and data. Then, we analyzed the collected data according to the main criteria of the RIU model of scientific knowledge transfer (Appendix 2). In addition, a qualitative content analysis was conducted (Neuman, 2005) to examine the viability of our two hypotheses.

\section{Results}

\subsection{Weak research for establishing the Vietnamese Red Data Book 2007}

The assignment of establishing the Vietnamese Red Data Book based on the IUCN criteria 1994 was given to the Institute of Ecology and Biological Resources, the Vietnam Academy of Science and Technology in the frame of a government-funded research project. Its objective is to identify threat levels of animals and plants in Vietnam. The scientific research for the establishment was implemented in the period between 2000 and 2003.

Prior to initiating the research process, a workshop was held in Hai Phong, Vietnam, in 2000 by Asia Regional Biodiversity Program of IUCN to introduce new criteria of IUCN (1994) and discuss how to apply the IUCN criteria in the context of Vietnam. Many scientists from different Vietnamese research institutions participated in the workshop. In early 2001, species data sheets were delivered to experts and scientists to collect information on threatened plants and animals in Vietnam. The species data sheets were compiled by about 50 scientists, focusing on around 500 animals and 700 plants at threatened levels (VAST, 2003). Subsequently, discussions and workshops were organized within groups of experts to assess species data sheets according to IUCN criteria 1994 and identify categories for particular species. As a result, Vietnamese red lists of threatened animals and plants were created in 2002. Based on the established red list, Vietnamese Red Data Book was compiled in 2004 and published in 2007. In comparison to Vietnamese Red Data Book 1992, the establishment process of the red data book 2007 followed IUCN guidelines including three main steps: (1) making species data sheets (2) creating the red list (3) establishing the red data book.
The aim of making the Vietnamese Red Data Book 2007 is to reassess and update information on the distribution and the status of threatened species according to new criteria of IUCN (1994). It is expected that the established red data book can provide science-based policy advice for the protection and management of threatened species in Vietnam. With this in mind, it is pertinent to ask whether such red listing work should be based on scientific work or not. We used the RIU model's criteria to examine the activities of research, integration, and utilization in the red listing of the Vietnamese Red Data Book 2007 (Appendix 2).

Our research results, based on the RIU model, have shown that during red listing, current scientific information, i.e. national and international scientific sources, was well assessed. The scientific research for the establishment of the Vietnamese Red Data Book 2007 was mainly implemented by the Institute of Ecology and Biological Resources in cooperation with many Vietnamese research institutions. In addition, IUCN as an international ally of biodiversity conservation also supported the red listing of Vietnam through technical supports (i.e. training courses) (Interview 3, 18). Research for the red listing also cooperated with additional research from nationwide scientific institutions in regard to exchanging data and information. Sharing data and assistance is occasionally done to support mutual results and the aim for this cooperation is to detect knowledge gaps and help to avoid overlapping research (Böcher and Krott, 2014, 2016).

In this paper, we focus on a key question concerning the quality of the scientific basis used by Vietnamese scientists in the compilation of the Vietnamese Red Data Book 2007. In an attempt to answer this question it is necessary to examine the organization and work of the expert teams. A scientific advisory committee was created to compile the Vietnamese Red Data Book 2007. The scientific committee includes an editorial board and expert teams chosen for their knowledge and experience on various taxonomic groups (i.e. Primate, Bird, Reptile, Fish, and Invertebrates). The expert teams that compiled the red data book were created by putting together scientists from different universities and research institutes. It was expected that scientists would be independent in making the red data book. Our interviews showed that as part of the red - listing process, the search for scientists who were species specialists was undertaken by the team leaders themselves. The fact that the experts were identified in this way shows the direct influence of the team leaders on the composition of the groups and thus on the outcome of their work. One expert who participated in the red listing stated that the editorial board suggested the number of species listed in the red list and made a decision on selecting the groups of species before the assessment process officially began (Interview 2, 4). This probably would have indicated the triumph of only one or a few experts in the establishment process.

There were many difficulties in applying IUCN criteria to creating the Vietnamese Red Data Book 2007 (Interview 1, 2, 4, 7, 11). Vietnamese scientists followed IUCN assessment criteria which rely primarily on distribution data (i.e. criteria B and D2), estimations of population parameters (population size, reductions and decline rates; criteria A, C, and D1) and quantitative analyses (i.e. probability of extinction; criterion E) (IUCN, 1994). Although IUCN criteria 1994 are assessed as more quantitative in regard to population loss and the decline of range size (IUCN, 1994; Milner-Gulland et al., 2006), the red listing of the Vietnamese Red Data Book, according to these criteria, depends greatly on the experience of expert teams. The experts made the first decisions on whether a species was to be classified as "threatened" or "not threatened" and later placed all species into one of the eight specific categories provided by IUCN. Species are assigned to one of eight categories of threat based on whether they meet criteria linked to population trend, population size and structure, and geographic range (IUCN, 1994). Species listed as Critically Endangered, Endangered or Vulnerable are collectively described as Threatened (IUCN, 1994). The interview results indicated that the IUCN criteria set quite obviously influenced the outcomes of making the Vietnamese Red Data Book 2007 (Interview 1, 3, 4, 7). 
However, the assumption of a species belonging to a threat category would be different between the experts since the experts have different levels of experience. Although there were some discussions to compromise the classification of species, the ultimate decisions were in hand of the leaders of expert teams (Interview 2, 15). One of the experts who participated in the red listing stated that "the classification of plants in the Vietnamese Red Data Book 2007 lacked empirical evidence of plant samples. Identifying the threat levels of species depended greatly on the experience of experts which varies considerably among experts" (Interview 2). According to Amori et al. (2014), in most cases, the criteria are assessed by means of expert-driven approaches, and a species' true conservation status and risk of extinction may be evaluated incorrectly. To minimize this problem, it is claimed to update species' conservation status data with new evidence from field surveys (Vignoli et al., 2017). Therefore, since the expert opinion is included as part of the method in itself, generally, making red lists still needs sound and recent empirical monitoring data of species (Vignoli et al., 2017). This may derive from the general problem of the red lists that they demand a lot of facts about distribution and abundance of species for the results to be quantifiable and taken seriously (Jørstad and Skogen, 2010). This problem could only be solved with comprehensive monitoring of biodiversity and by a well-structured system of biodiversity data (Jørstad and Skogen, 2010). Thus, it is clear that scientists need to implement actual complete monitoring activities on the population, distribution and threat level of species before making a decision on its classification according to the IUCN criteria. However, in the process of making the Vietnamese Red Data Book 2007, there was a significant lack of species monitoring activities (VAST, 2003; Interview 2, 4, 22). Although Vietnamese scientists based the results of some surveys on some taxons that have been implemented before starting the red listing, the data is often fragmented and incomprehensive (Interview 2, 3, 7, 19), and rather outdated (Interview 2, 19, 25). In the frame of the research project for red - listing, there was a shortage of significant surveys implemented to ascertain empirical data for putting species into particular categories (VAST, 2003; Interviews 1, 2, 7). Although the research for the red listing was completed in 2004, these results were officially published only in the Vietnamese Red Data Book in 2007. Thus, the information in the Vietnamese red data book 2007 was already out of date for several points during printing (Interview 2, 22, 25). At the time of the compilation of the book, Vietnam did not have national biodiversity database system, which leads to fragmentation and backwardness of the existing biodiversity data (Interview 2, 19, 22). Almost all biodiversity data were obtained from personal sources or project documents, which have not been effectively documented (Interview 1, 3, 7). Studies have shown that Vietnam is still facing considerable challenges in attempting to conserve its rich and endemic biodiversity in which it has been found that species distributions remain poorly known (as evidenced by the high number of rediscoveries); population data are lacking for almost all organisms; and ecosystem-level interactions are practically unknown (Sterling and Hurley, 2005). Regarding the red - listing process, Jørstad and Skogen (2010) have shown that without having full knowledge of a problem, scientists will need to find ways to draw conclusions that do not fully comply with the rules of science itself. Lacking necessary information was stated by several informants as a significant challenge to the scientific method since it meant that scientists would have to make more or less well-founded assumptions (Jørstad and Skogen, 2010).

The interview results have shown that the establishment of the scientific knowledge for the Vietnamese red listing mainly includes personal knowledge, subjective judgment and literature review (Interviews 1, 2, 4, 7, 15). Due to the complex process of the distribution of species and influencing factors, it needs to be monitored empirically to come up with scientifically sound judgments. The assessment of the conservation status is only based on subjective judgment and lacks empirical data that could result in inconsistence and misclassifications (Regan et al., 2004). Based on our analysis, the shortage of updated empirical data about rare and threatened species is one of the remarkable limitations in the Vietnamese Red Data Book 2007.

Although the research procedures and results were documented, the research results for the red listing were not peer-reviewed before being published as a scientific book (VAST, 2003; Interview 2, 9). According to the RIU model, independent meaningfulness of scientific findings means that these scientific findings themselves offer a meaningful explanation of their descriptions and recommendations (Böcher and Krott, 2016). This means that for different research projects the result of a single research project is relevant independently. The classification of threatened species is based on IUCN criteria's system, which was designed to measure the symptoms of extinction risk by using five independent criteria relating to aspects of population loss and decline of range size. A species is assigned to a threat category if it meets the quantitative threshold for at least one criterion (Mace et al., 2008). For example, Delacour's langur (Trachypithecus delacouri) is classified as "Critically Endangered" in the Vietnamese Red Data Book 2007 because its status complies with two criteria: A1c,d C1 + 2a (MSTE, 2007a). It means that Vietnamese scientists predicted that Delacour's langur is facing an estimated reduction in population of at least $80 \%$ over the last 10 years or three generations, which was based on a decline in the area of occupancy, the extent of occurrence and/or quality of habitat, as well as the actual or potential levels of exploitation. Another criterion is that the population of Delacour's langur was estimated to number less than 250 mature individuals, and it was estimated that a continuing decline of at least $25 \%$ within three years or one generation due to a severe fragmentation will take place. Hence, the classification of Delacour's langur into "Critically Endangered" depends on the prediction about the reduction in population size and a decline in size of an already small population, mainly due to some factors such as overexploitation and severe fragmentation (MSTE, 2007a). However, the prediction about the threat status of species depends on doing other research as well (i.e. land use or climate change) (Akçakaya et al., 2006; Bomhard et al., 2005; Burgman, 2002). For example, it has been proven that future land use and climate change substantially affect the threat status of plant species of up to $29 \%$ of 227 Proteaceae taxa in Cape Floristic Region, South Africa (Bomhard et al., 2005). The consideration of future threats (i.e. land use change or climate change) is underutilized in current IUCN red list assessments (Burgman, 2002), which could derive from a lack of data or uncertainty about future threats (Bomhard et al., 2005). Thus, the research results on the threat level of species might not provide independent meaningfulness because it was also dependent on other studies. The dependent meaningfulness of the research results is also one of the drawbacks of the Vietnamese Red Data Book 2007.

In short, our research results have shown that there are scientific weaknesses of the Vietnamese Red Data Book 2007 arising from the limited availability of updated data about rare and threatened species in Vietnam and unknown factors influencing them.

\subsection{Successful integration by good and actor-relevant communication}

According to the RIU model, the research results lead to the sphere of integration that connects scientific knowledge and political activities (Böcher and Krott, 2014, 2016). Although the Vietnamese Red Data Book was officially published in 2007, the research results for red listing were completed in 2004. Thus, the results could get back to the sphere of integration since 2004. In this study, we examine how the research for the Vietnamese Red Data Book 2007 was integrated into wildlife protection policymaking of Vietnam. The establishment of the Vietnamese Red Data Book 2007 was directed toward two public goals: (1) contribution to the conservation of threatened species of Vietnam, and (2) compliance with international conventions on biodiversity that Vietnam signed (i.e. Convention on Biological Diversity). Linking scientific results with public goals is important for improving their relevance to political issues (Böcher and Krott, 2016). Research in the red listing aims to provide the list of threatened species and their categories 
Table 2

The number of protected species in the Vietnamese Red Data Book 2007 and current wildlife protection laws of Vietnam. (Source: Compiled by the authors.)

\begin{tabular}{|c|c|c|c|c|c|c|}
\hline \multirow[t]{2}{*}{ Categories } & \multirow[t]{2}{*}{ Red Data Book 2007} & \multicolumn{5}{|c|}{ Red listed species in Vietnamese wildlife protection laws } \\
\hline & & Decree 32 & Decree 160 & Circular 02/2006 & Decision $82 / 2008$ & Decision $140 / 2000$ \\
\hline \multicolumn{7}{|l|}{ Animals } \\
\hline EX & 4 & 1 & 1 & 0 & 0 & 0 \\
\hline EW & 5 & 1 & 0 & 1 & 4 & 0 \\
\hline $\mathrm{CR}$ & 48 & 22 & 22 & 4 & 16 & 2 \\
\hline EN & 113 & 46 & 36 & 6 & 45 & 4 \\
\hline VU & 189 & 38 & 19 & 11 & 108 & 2 \\
\hline LR & 17 & 7 & 0 & 0 & 0 & 0 \\
\hline DD & 31 & 7 & 2 & 0 & 1 & 0 \\
\hline \multicolumn{7}{|l|}{ Plants } \\
\hline EX & 0 & 0 & 0 & 0 & 0 & 0 \\
\hline EW & 1 & 0 & 0 & 0 & 0 & 0 \\
\hline $\mathrm{CR}$ & 45 & 10 & 8 & 0 & 1 & 0 \\
\hline EN & 189 & 17 & 4 & 0 & 6 & 0 \\
\hline VU & 210 & 15 & 2 & 0 & 6 & 0 \\
\hline LR & 4 & 0 & 0 & 0 & 0 & 0 \\
\hline $\mathrm{DD}$ & 0 & 0 & 0 & 0 & 0 & 0 \\
\hline Total & 856 & 164 & 94 & 22 & 187 & 8 \\
\hline
\end{tabular}

Notes:

$$
\begin{aligned}
& \text { EX: Extinct } \\
& \text { EW: Extinct in the Wild } \\
& \text { CR: Critically Endangered } \\
& \text { EN: Endangered }
\end{aligned}
$$
VU: Vulnerable
LR: Lower Risk
DD: Data Deficient

according to IUCN criteria of 1994, which helps to identify conservation priorities and to implement international commitments on biodiversity conservation of Vietnamese government.

The first law for protecting wildlife species was enacted by the Vietnamese government in 1963. Several laws were issued during the following years, increasing legislative protection of wildlife. In 1992 Decree 18 was issued, stipulating a list of endangered animals and plants along with the regulations for their management and protection. Since then, the list of endangered species has been revised and updated in the follow-up regulations and became a legislative tool for species conservation in Vietnam. Presently, there are five important laws related to the protection and management of endangered species in Vietnam (Appendix 3). In 2006, the Vietnamese government issued Decree 32 and the list of threatened species which are protected under the two levels. The latest Decree 160 was issued in 2013, delivering criteria to determine species and the regime of managing species under the list of endangered, precious and rare species prioritized protection. Besides these two decrees, there are Circulars and Decisions issued by Ministry of Agriculture and Rural Development (MARD), guiding the protection and management of some particular protected species. In this study, we explore the link between the Vietnamese Red Data Book 2007 and the lists of threatened species in the Vietnamese laws on protected species. It has been calculated that there were 856 species listed in the Vietnamese Red Data Book 2007, while 475 out of 856 species were listed in the Vietnamese laws on protected species. Particularly, 19\% (164/856) of the species found in the Vietnamese Red Data Book made it into Decree 32 while $11 \%(94 / 856)$ of the species made it into Decree 160. In addition, the proportion of red - listed species that were also found in Circular 02/2006, Decision 82/2008, and Decision 140/2000, are 2.5\% (22/856), 21.8\% (187/856), and $0.9 \%(8 / 856)$ respectively (Table 2$)$. This indicates that the Vietnamese Red Data Book 2007 has been selectively used by political actors.

Putting species into the binding regulations means that Vietnamese government needs the resources (i.e. funding, human resources) to protect them. The results of interview indicated that due to limitations of funding and human resources on protecting threatened species, the Vietnamese policymakers could only select some species which are conservation priorities for Vietnam, to put them into the regulations (Interview 3, 4, 10). In addition, some species that have the potential for developing local economics through breeding or trading were not included into the regulations to support the interest of agricultural development and poverty alleviation of the Vietnamese government (Interview 4, 9). For example, Cervus nippon is listed as EW and Aquilaria crassna is listed as EN in the Vietnamese Red Data Book 2007 (MSTE, 2007a, 2007b). However, both species are not found in the Vietnamese laws on protected species. The results of the interview stated that both Cervus nippon and Aquilaria crassna have high economic values and good potential for local economic development, so they have not been included into the Vietnamese laws on protected species to support for the interest of economic development (Interview 1, 4). One expert stated that MARD supports the farming of wildlife, as well as of threatened species for commercial purpose, which is why Decree 32 was revised in 2014 to support for this interest (Interview 25). However, the approval of the revised Decree 32 was postponed due to the establishment of a new Forestry Law in 2017.

According to the RIU model, successful knowledge transfer needs allies who are strong enough to support the use of scientific results (Böcher and Krott, 2014, 2016). We have analyzed actors involved in the establishment and use of the Vietnamese Red Data Book 2007 (Appendix 4). While the Ministry of Agriculture and Rural Development (MARD) is responsible for the establishment of Decree 32, Circular 02/ 2006, Decision 82/2008, and Decision 140/2000, Decree 160 was formulated by the Ministry of Natural Resource and Environment (MONRE). These five laws have been approved by the Vietnamese government to be legally binding regulations within the country. MARD and MONRE share highest responsibilities in threatened species protection in Vietnam. Since there has been no particular survey or study to support for the establishment of the five laws on protected species (Interview 13, 25), MARD and MONRE have a high interest in scientific recommendations of the Vietnamese Red Data Book 2007. Our research 
results have indicated that the Vietnamese Red Data Book 2007 won the support of MARD and MONRE which are two powerful actors for putting research findings into wildlife protection laws of Vietnam. It is also important to emphasize that one species that was labeled as critically endangered or endangered could stimulate political actions to abate threats (Possingham et al., 2002) and promote the flow of resources to the people, programs and organizations for species conservation (Webb, 2008). Our interview results have shown that MARD and MONRE clearly understood these and paid attention to species that are of interest to them.

The Vietnamese Red Data Book 2007 has been developed by scientific experts and could easily be communicated to policymakers. Since the red data book contains concise information on the name of the species, their distribution, status and structured sequences of categories, they are easy to be understood by political actors. The categories are familiar to both scientists and political actors. One expert stated that "it is not difficult for policymakers to understand that critically endangered is more serious than vulnerable" (Interview 3). Guldin (2003) has emphasized that scientific results need to be translated into words and proposals that are relevant and understandable to policymakers to make an effective communication from forest science to forest policy. The clear message is an advantage of the red data book which enables good communication from the field of science to the field of policy. Moreover, one of the effective strategies used by science communicators in practice is that the message should be direct and relevant to policymakers (Richards and Den Hoed, 2018). The information of the Vietnamese Red Data Book 2007 can meet specific needs of MARD and MONRE who are looking for policy-relevant information since such information serves their interests and priorities in the conservation of threatened species.

The use of the Vietnamese Red Data Book 2007 in policy formulation is also facilitated by the participation of scientists in the policymaking process. One expert stated that: "We (species experts) were requested to hand in species data sheets to MONRE for making Decree 160. We were also invited to expert teams organized by MONRE to identify species in Decree 160" (Interview 2). Most species proposed by scientists were considered in the discussions and many of them presented in the Vietnamese Red Data Book 2007 were put into Decree 32, Decree 160, Circular 02/2006, Decision 82/2008, and Decision 140/ 2000. Thus, scientific information of the Vietnamese Red Data Book 2007 has been selectively used in the establishment of these five laws since MARD and MONRE recognized political potential of the information and supported for their use. As stated in the RIU model, the use of the Vietnamese Red Data Book 2007 into policy formulation was attributed to the contribution of a successful integration deriving from good and actor-relevant communication. Such a good communication could help to win the support of powerful allies in integrating sciencebased policy advice into the policy formulation. It is also noted that the Vietnamese Red Data Book 2007 is not the only a scientific source for the policymaking. The policymakers also looked on IUCN red list and the list of CITES to select the species for listing in the Vietnamese laws on wildlife protection. However, the arguments by the national red data book were really essential.

\subsection{The impact of Vietnamese Red Data Book on conservation policy formulation}

The most important scientific recommendation of the Vietnamese Red Data Book 2007 is a list of endangered species and their categories based on IUCN criteria 1994. The scientific recommendations were integrated into the conservation policymaking by powerful allies (MARD, MONRE), which led to specific instruments for implementation of conservation policies.

With the establishment of the five laws on wildlife protection, the Vietnamese government claimed to halt the loss of species and improve the status of rare and endangered species. The policy instruments were well formulated, but they did not contribute to democracy since it only serves for elites (government, nature reserves). Local people and their ecological knowledge have not been effectively used in monitoring and surveying protected species in Vietnam (Interview 1, 4). It is believed that local ecological knowledge can serve as a useful and reliable complementary data source for wildlife monitoring and management (Anadón et al., 2009; Brook and McLachlan, 2008; Gilchrist et al., 2005). However, in the formulation of the Vietnamese Red Data Book 2007, local people were not invited to participate at any forms (e.g. providing information or monitoring) (Interview 3, 11, 12). This might cause some challenges in practical conservation efforts since local people are even not able to recognize that a species is listed in the red data book or the regulations (Interview 2, 4). There were some cases recorded that local people harvested or hunted some species without the knowledge that these species are listed under the highest level of protection in Decrees 32 and 160, and that the exploitation and use of all products derived from these species are forbidden (Interview 4, 9). According to the RIU model, the establishment of the Vietnamese Red Data Book 2007 contributes little to good governance owing to the lack of community participation.

The case of the Vietnamese Red Data Book 2007 is one of the very few cases where the Vietnamese scientists successfully convinced the policymakers to use their recommendations. This shows that science has the certain impact on the formulation of wildlife protection policy in Vietnam. However, with the same object of endangered species, there are the five regulations issued by two different ministries (MARD and MONRE) that compete with each other to enact the law on protected species, resulting in confusions for users (Interviews 1, 4, 11, 12, 25). There are 66 animals and 12 plants, presented concurrently in both Decree 32 and 160. However, 85 animals and 40 plants are listed in Decree 32, but not in Decree 160. On the contrary, 17 animals and 5 plants are presented in Decree 160 but are absent in from Decree 32. For example, Pavo muticus is listed in the Vietnamese Red Data Book as "Endangered" and presented in group IB of Decree 32. This species is absent in Decree 160. The experts we interviewed stated that "the inconsistencies between Decree 32 and Decree 160 on the lists of threatened species triggered confusions over implementing these decrees in practice" (Interview 1, 4, 11). In addition, the confusion even rises concerning several species which are cross -listed among other legal documents. Some aquatic and semi-aquatic species such as turtles and crocodiles are also listed in the Circular 02/2006 (amended by Circular $62 / 2008$ and Circular 02/2018) on aquatic species protection. As an example, Crocodylus siamensis was listed in the Vietnamese Red Data Book 2007 as "Critically Endangered". This species is found in the group IIB of the Decree 32 under the lower level of protection while it is also enumerated in the Circular $02 / 2006$ as a species banned from exploitation and in the Decision $82 / 2008$ as critically endangered aquatic species. These overlaps have caused many confusions for the management authorities responsible for supervising fishery and agricultural activities since they are not able to define which law should be applied (Nadler, 2014; Interview 4, 22, 25). Further complications could be found in the Decision $140 / 2000$ on the list of protected species which are predators of rats. In this decision, genera and families are also listed but overlooked any mention of species in these higher taxonomic levels. For example, Family Falconidae includes 11 species, however, these species were omitted from Decision 140/2000 when it listed Family Falconidae. This has made a significant challenge to practical conservation work since the enforcement authorities do not often know which species are included in a protected family (Interview $15,19,25)$.

Although the science-based policy advice of the Vietnamese Red Data Book 2007 has been incorporated in the formulation of the wildlife protection laws, further research is needed to assess the effectiveness of these laws in conserving the threatened species in Vietnam.

In conclusion, based on research results, we show that the Vietnamese Red Data Book 2007 has certain scientific weaknesses due 
to a lack of updated biodiversity data and unknown factors affecting them. However, the Vietnamese Red Data Book 2007 could achieve certain political influence as a result of successful integration. Thus, Hypothesis 1 is supported.

In addition, our analysis also revealed that the messages of the Vietnamese Red Data Book are understandable to policymakers and relevant to the interest of the powerful actors. These advantages of the Vietnamese Red Data Book 2007 help to make a good and actor-relevant communication that contributes to the alliance of the powerful actors and the use of science-based policy advice in conservation policy formulation. These results support Hypothesis 2 .

\section{Discussions}

Previous research has shown that when examining science and policy linkages, it is crucial to focus on both the content of scientific information and the processes by which that scientific information is produced and communicated (Selin et al., 2018). Our contribution is to examine the scientific basis of the Vietnamese Red Data Book 2007 and its impact on wildlife protection policymaking in Vietnam by using a new model of scientific knowledge transfer (the RIU model). Although the red lists have been widely accepted to be a powerful tool for conservation (Lamoreux et al., 2003; Rodrigues et al., 2006), there have been some disputes regarding the scientific basis and accuracy of the red lists both at the global level (Godfrey and Godley, 2008; Pimenta et al., 2005; Webb, 2008) and the national level (Keith et al., 2000; Vignoli et al., 2017). Our analysis has shown that the Vietnamese Red Data Book 2007 seems to be based on scientific research, but there still remain some scientific weaknesses due to limited availability of empirical biodiversity data in Vietnam and unknown factors influencing them. In spite of these limitations, scientific recommendations of the Vietnamese Red Data Book 2007 have been selectively used by the policymakers in the wildlife protection policy formulation of Vietnam. Therefore, there is a potential of science-based policy advice which is used by policymakers even if its scientific basis is weak or uncertain. However, from the perspective of scientific knowledge transfer, the case of the Vietnamese Red Data Book 2007 is not a good example of successful scientific knowledge transfer which needs a combination of high - quality research and professional integration (Böcher and Krott, 2016; Do Thi et al., 2017b). The case of the Vietnamese Red Data Book has shown an increasing responsibility of political actors in their selected actions in the issues which have scientific uncertainty, such as biodiversity conservation.

What our study also shares with previous studies is that the communication is crucial to creating, building and maintaining the interest of policymakers in scientific results (Guldin, 2003). Based on our research results, we revealed that science-based policy advice of the Vietnamese Red Data Book 2007 is linked to the interest of the powerful actors (MARD, MONRE) through a good and actor-relevant communication, which helps to win the support of the powerful allies. As a result, science-based policy advice of the Vietnamese Red Data Book has been selectively used in the conservation policy formulation. This demonstrates the importance of good communication in the successful transfer of scientific knowledge.

Previous studies have shown that the procedure of the red listing would need to be scientifically justified, politically acceptable and as benign as possible to the ongoing processes (Webb, 2008). In our case study, the Vietnamese Red Data Book 2007 was based on scientific research and then its scientific recommendations were incorporated into the policy formulation. However, Vietnamese scientists need much stronger scientific basis to support the establishment of red lists in Vietnam. Such science might be improved by well-structured species monitoring surveys and an updated national system of biodiversity data, which help to avoid the subjective judgment and the potential bias of the assessment process. In addition, available data also need to be complemented with some levels of standardized data collection
(Nourani et al., 2017). Lack of high-quality monitoring data is a problem which also causes considerable obstacles to the establishment of national red lists in some countries such as Iran (Nourani et al., 2017), and Bangladesh (Irfanullah, 2011). Establishing data collection schemes and optimizing the use of collected data would result in the more effective applicability of IUCN categories and criteria (Nourani et al., 2017).

It is claimed that updated, appropriate, standard assessment scheme is the key to prepare a red list (Irfanullah, 2011). Vietnamese scientists used the assessment system of IUCN proposed in 1994 (version 2.3) for establishing the Vietnamese Red Data Book 2007. However, since then many changes happened in the category system and IUCN criteria 2001 (version 3.1) is currently followed by many countries (Mace et al., 2008; Milner-Gulland et al., 2006). In addition, in 2003 IUCN published the guidelines on the application of the IUCN criteria at national and regional levels. Thus, the re-evaluation of threatened plants and animals of Vietnam is needed according to these guidelines. One expert we interviewed suggested that the Vietnamese Red Data Book should be reviewed at five-year intervals and that online red data book should replace the printed one (Interview 4). Establishing such online red data book may help different target groups easily access the information on threatened species of Vietnam. Based on research results, we also recommend that local ecological knowledge should be incorporated into the national red listing of Vietnam since local people have relevant practical knowledge about threatened species (Cano and Tellería, 2013). The locals could be involved in the red listing at some forms (i.e. providing information or supporting for species monitoring). This participation of local people can also help to improve their awareness about the importance of the threatened species' protection.

Much of the previous research has focused on natural science perspective of the red lists (Eaton et al., 2005; Newton and Oldfield, 2008). Our study uses a novel model of scientific knowledge transfer (the RIU model) to analyze science-policy interaction of the Vietnamese Red Data Book 2007. Based on our results, we emphasize the importance of a successful integration to enhance political influence of science-based policy support. In addition, searching and winning powerful allies of science-based policy advice should be an important focus for strategies of scientific knowledge transfer.

\section{Conclusions}

In this study, we examined the scientific basis and science - policy interaction of the Vietnamese Red Data Book 2007 by applying the RIU model of scientific knowledge transfer. Based on our analysis, we provide recommendations to enhance the science-based policy support in biodiversity conservation.

Regarding Hypothesis 1, our study has shown that there is a potential for scientific knowledge transfer from science into policy formulation even if its research is weak or uncertain. In these cases, political actors could well recognize political potential of the research results and they use their resources to promote the use of these research results. Concerning the Vietnamese Red Data Book 2007, the political actors could see political potential of the Vietnamese Red Data Book and use its scientific recommendations to support their interests in spite of its scientific weaknesses. However, the success of such red lists could not significantly contribute to science in the conservation of biodiversity. Thus, the improvement of the scientific basis of red lists will be essential to enhance science-based policy support.

Regarding Hypothesis 2, our study also revealed that good and actor-relevant communication plays an important role to achieve the support of powerful allies in the conservation policy formulation. The Vietnamese Red Data Book 2007 made a good communication through understandable and relevant information given to the policymakers. As a result, science-based policy advice of the Vietnamese Red Data Book is integrated into national regulations. Thus, up to now, the success of red lists focuses on integration only through good communication. We 
recommend that scientists should put a necessary stress on a good and relevant communication to increase the use of science-based policy advice in policy formulation.

There are scientific uncertainties in research fields like biodiversity conservation (Conroy et al., 2011; Keith et al., 2011; Pe'er et al., 2014). Thus, scientists need to promote different research strategies to tackle these challenges. Based on our research results, we suggest that the provision of weak or uncertain research could support for conducting further research tasks of scientists in the future. This is because scientists can link scientific research which is not connected in substance in order to achieve supporting coalitions for universities and research institutes in other research projects. This is similar to "pork barrel" projects which are used to construct supporting coalitions for legislative packages (Evans, 1994). We call this a "scientific pork barrel" in our study. In some cases, scientists could use "scientific pork barrel" to build up their supporting coalitions for future research through conducting weak or uncertain research at the present. This might be essential in research fields having scientific uncertainties (i.e. biodiversity conservation, climate change). In the case of the Vietnamese Red Data Book 2007, "scientific pork barrel" does not promote the scientific basis for wildlife protection policy of Vietnam, but it might contribute to the construction of supporting coalitions for further good research of Vietnamese scientists.

Based on the results of this study, we emphasize the importance of all three phases of the RIU model to make a successful transfer of scientific knowledge. Future research is needed to examine the effectiveness of threatened species protection policies which are based on Science-based policy advice by the red lists.

\section{Acknowledgements}

This research was supported by the Chair Group of Forest and Nature Conservation Policy of the George-August University of Göttingen, Germany and the Vietnam National University of Forestry. We would like to express our gratitude to the experts, researchers, and officials involved in the study, particularly those from the Institute of Ecology and Biological Resources, Forest Inventory and Planning Institute, National University of Hanoi, Center for Plant Conservation, CITES Vietnam, IUCN Vietnam, Biodiversity Conservation Agency (MONRE), Department of Nature Conservation (MARD), Forest Protection Department (MARD), Vietnam Primate Conservation Program, for providing valuable data. We would like to thank the Göttingen Graduate School of Social Sciences (GGG) for supporting our fieldwork. Finally, we would like to sincerely thank two anonymous referees for their very helpful comments on this article.

\section{Funding}

This research was funded by the Vietnamese Government Fund (911 Scholarship) and the German Academic Exchange Service (DAAD) (50015542). The fieldwork of this study was funded by the Göttingen Graduate School of Social Sciences (GGG) through Research Assistantships for international $\mathrm{PhD}$ students.

\section{Conflict of interest}

None declared.

\section{Appendix A. Supplementary data}

Supplementary data to this article can be found online at https:// doi.org/10.1016/j.biocon.2018.07.016.

\section{References}

Making consistent IUCN classifications under uncertainty. Conserv. Biol. 14 (4), 1001-1013.

Akçakaya, H.R., Butchart, S.H., Mace, G.M., Stuart, S.N., Hilton-Taylor, C., 2006. Use and misuse of the IUCN Red List Criteria in projecting climate change impacts on biodiversity. Glob. Chang. Biol. 12 (11), 2037-2043.

Amori, G., Gippoliti, S., Luiselli, L., 2014. A short review of the roles of climate and man in mammal extinctions during the Anthropocene. Rendiconti Lincei 25 (1), 95-99.

Anadón, J.D., Giménez, A., Ballestar, R., Pérez, I., 2009. Evaluation of local ecological knowledge as a method for collecting extensive data on animal abundance. Conserv. Biol. 23 (3), 617-625.

Babbitt, B., 1995. Science: opening the next chapter of conservation history. Science 267 (5206), 1954-1955.

Böcher, M., 2016. How does science-based policy advice matter in policy making? The RIU model as a framework for analyzing and explaining processes of scientific knowledge transfer. Forest Policy Econ. 68, 65-72.

Böcher, M., Krott, M., 2014. The RIU model as an analytical framework for scientific knowledge transfer: the case of the decision support system forest and climate change. Biodivers. Conserv. 23, 3641-3656.

Böcher, M., Krott, M., 2016. Science Makes the World Go Round: Successful Scientific Knowledge Transfer for the Environment. Springer, Basel, Switzerland.

Böcher, M., Töller, A., 2015. In: Inherent dynamics and chance as drivers in environmental policy? An approach to explaining environmental policy decisions. International Conference on Public Policy, Milan.

Boehmer-Christiansen, S., 1995. Reflections on scientific advice and EC transboundary pollution policy. Sci. Public Policy 22 (3), 195-203.

Bomhard, B., Richardson, D.M., Donaldson, J.S., Hughes, G.O., Midgley, G.F., Raimondo, D.C., Thuiller, W., 2005. Potential impacts of future land use and climate change on the Red List status of the Proteaceae in the Cape Floristic Region, South Africa. Glob. Chang. Biol. 11 (9), 1452-1468.

Braun, D., Benninghoff, M., 2003. Policy learning in Swiss research policy-the case of the National Centres of Competence in Research. Res. Policy 32 (10), 1849-1863.

Brito, D., Ambal, R.G., Brooks, T., De Silva, N., Foster, M., Hao, W., Rodríguez, J.V., 2010. How similar are national red lists and the IUCN Red List? Biol. Conserv. 143 (5), 1154-1158.

Brook, R.K., McLachlan, S.M., 2008. Trends and prospects for local knowledge in ecological and conservation research and monitoring. Biodivers. Conserv. 17 (14), 3501-3512.

Burgman, M.A., 2002. Are listed threatened plant species actually at risk? Aust. J. Bot. 50 (1), 1-13.

Cano, L.S., Tellería, J.L., 2013. Local ecological knowledge as a tool for assessing the status of threatened vertebrates: a case study in Vietnam. Oryx 47 (2), 177-183.

Cardoso, P., Borges, P.A., Triantis, K.A., Ferrández, M.A., Martín, J.L., 2012. The underrepresentation and misrepresentation of invertebrates in the IUCN Red List. Biol. Conserv. 149 (1), 147-148.

Cassini, M.H., 2011. Ranking threats using species distribution models in the IUCN Red List assessment process. Biodivers. Conserv. 20 (14), 3689-3692.

Chapason, L., van den Hove, S., 2009. The debate on an intergovernmental science-policy platform on biodiversity and ecosystem services (IPBES): exploring gaps and needs. Idées pour le débat(01).

Collen, B., Griffiths, J., Friedmann, Y., Rodriguez, J.P., Rojas-Suàrez, F., Baillie, J.E., 2013. Tracking change in national-level conservation status: national red lists. In: Collen, B., Pettorelli, N., Baillie, J.E., Durant, S.M. (Eds.), Biodiversity Monitoring and Conservation: Bridging the Gap Between Global Commitment and Local Action. John Wiley \& Sons, London, pp. 17-44.

Collen, B., Dulvy, N.K., Gaston, K.J., Gärdenfors, U., Keith, D.A., Punt, A.E., Butchart, S.H., 2016. Clarifying misconceptions of extinction risk assessment with the IUCN Red List. Biol. Lett. 12 (4), 20150843.

Conroy, M.J., Runge, M.C., Nichols, J.D., Stodola, K.W., Cooper, R.J., 2011. Conservation in the face of climate change: the roles of alternative models, monitoring, and adaptation in confronting and reducing uncertainty. Biol. Conserv. 144 (4), 1204-1213.

Dharmawan, B., Böcher, M., Krott, M., 2016. The failure of the mangrove conservation plan in Indonesia: weak research and an ignorance of grassroots politics. Ocean Coast. Manag. 130, 250-259.

Dharmawan, B., Böcher, M., Krott, M., 2017. Endangered mangroves in Segara Anakan, Indonesia: effective and failed problem-solving policy advice. Environ. Manag. 60 (3), 409-421.

Do Thi, H., Krott, M., Böcher, M., 2017a. The success of scientific support for biodiversity conservation policy: the case of Ngoc Son Ngo Luong nature reserve in Vietnam. J. Nat. Conserv. 38, 3-10.

Do Thi, H., Krott, M., Böcher, M., Juerges, N., 2017b. Toward successful implementation of conservation research: a case study from Vietnam. Ambio 1-14.

Eaton, M.A., Gregory, R.D., Noble, D.G., Robinson, J.A., Hughes, J., Procter, D., Gibbons, D.W., 2005. Regional IUCN red listing: the process as applied to birds in the United Kingdom. Conserv. Biol. 19 (5), 1557-1570.

Eisner, T., Lubchenco, J., Wilson, E.O., Wilcove, D.S., Bean, M.J., 1995. Building a scientifically sound policy for protecting endangered species. Science 269 (5228), 1231.

Evans, D., 1994. Policy and pork: the use of pork barrel projects to build policy coalitions in the House of Representatives. Am. J. Polit. Sci. 894-917.

Gilchrist, G., Mallory, M., Merkel, F., 2005. Can local ecological knowledge contribute to wildlife management? Case studies of migratory birds. Ecol. Soc. 10 (1).

Godfrey, M.H., Godley, B.J., 2008. Seeing past the red: flawed IUCN global listings for sea turtles. Endanger. Species Res. 6 (2), 155-159.

Görg, C., Wittmer, H., Carter, C., Turnhout, E., Vandewalle, M., Schindler, S., Lux, A., 2016. Governance options for science-policy interfaces on biodiversity and ecosystem services: comparing a network versus a platform approach. Biodivers. 
Conserv. 25 (7), 1235-1252.

Grossman, P.Z., 2012. The logic of deflective action: US energy shocks and the US policy process. J. Publ. Policy 32 (1), 33-51.

Guldin, R.W., 2003. Forest science and forest policy in the Americas: building bridges to a sustainable future. Forest Policy Econ. 5 (4), 329-337.

Gustafsson, K.M., Lidskog, R., 2013. Boundary work, hybrid practices, and portable representations: an analysis of global and national coproductions of red lists. Nat. Cult. 8 (1), 30-52.

Hayward, M.W., 2009. The need to rationalize and prioritize threatening processes used to determine threat status in the IUCN Red List. Conserv. Biol. 23 (6), 1568-1576.

Heim, J., Böcher, M., 2016. CITES and science: using the RIU model to analyze institutionalized scientific policy advice in Germany for the case of ivory trade. J. Int. Wildl. Law Policy 19, 159-175.

Hulme, M., 2009. Why We Disagree About Climate Change: Understanding Controversy, Inaction and Opportunity. Cambridge University Press, Cambridge.

Hussein, A., 2015. The use of triangulation in social sciences research: can qualitative and quantitative methods be combined? J. Comp. Soc. Work 4 (1), 1-12.

Igor, P., Anastasia, F., Elena, P., George, S., Kirill, G., Andrey, B., Ksenia, K., 2017. Effectiveness of "The IUCN red list of threatened species" application on a regional scale: current state of the "Red Data books" of Russia. Biol. Commun.(1).

Irfanullah, H.M., 2011. Conserving threatened plants of Bangladesh: miles to go before we start? Bangladesh J. Plant Taxon. 18 (1), 81-91.

IUCN, 1994. IUCN Red List Categories. IUCN-SSC.

Jørstad, E., Skogen, K., 2010. The Norwegian Red List between science and policy. Environ. Sci. Pol. 13 (2), 115-122.

Keith, D.A., Auld, T.D., Ooi, M.K., Mackenzie, B.D., 2000. Sensitivity analyses of decision rules in World Conservation Union (IUCN) Red List criteria using Australian plants. Biol. Conserv. 94 (3), 311-319.

Keith, D.A., Martin, T.G., McDonald-Madden, E., Walters, C., 2011. Uncertainty and adaptive management for biodiversity conservation. Biol. Conserv. 144 (4), 1175-1178.

Keller, V., Bollmann, K., 2004. From red lists to species of conservation concern. Conserv. Biol. 18 (6), 1636-1644.

Kingdon, J.W., Thurber, J.A., 1984. Agendas, Alternatives, and Public Policies. Little, Brown, Boston, pp. 165-169.

Koetz, T., Farrell, K.N., Bridgewater, P., 2012. Building better science-policy interfaces for international environmental governance: assessing potential within the Intergovernmental Platform for Biodiversity and Ecosystem Services. Int. Environ. Agreements 12 (1), 1-21.

Krott, M., 2012. Value and risks of the use of analytical theory in science for forest policy. Forest Policy Econ. 16, 35-42.

Lamoreux, J., Akçakaya, H.R., Bennun, L., Collar, N.J., Boitani, L., Brackett, D., Rylands, A.B., 2003. Value of the IUCN red list. Trends Ecol. Evol. 18 (5), 214-215.

Lentsch, J., Weingart, P., 2011. The Politics of Scientific Advice: Institutional Design for Quality Assurance. Cambridge University Press, Cambridge.

Mace, G.M., Collar, N.J., Gaston, K.J., Hilton-Taylor, C., Akçakaya, H.R., Leader-Williams, N., Stuart, S.N., 2008. Quantification of extinction risk: IUCN's system for classifying threatened species. Conserv. Biol. 22 (6), 1424-1442.

Miller, N., 2009. Environmental Politics. Stakeholders, Interests and Policy Making. Routledge, New York.

Miller, R.M., Rodríguez, J.P., Aniskowicz-Fowler, T., Bambaradeniya, C., Boles, R., Eaton, M.A., Pollock, C., 2007. National threatened species listing based on IUCN criteria and regional guidelines: current status and future perspectives. Conserv. Biol. 21 (3), 684-696.

Milner-Gulland, E.J., Kreuzberg-Mukhina, E., Grebot, B., Ling, S., Bykova, E., Abdusalamov, I., Stogova, L., 2006. Application of IUCN red listing criteria at the regional and national levels: a case study from Central Asia. Biodivers. Conserv. 15 (6), 1873-1886.

Moll, P., Zander, U., 2006. Managing the Interface. From Knowledge to Action in Global Change and Sustainability Science. Oekom, München.

MSTE (Ministry of Science, Technology and Environment), 2007a. Red Data Book of Vietnam. Volume 1 - Animals. Science and Techniques Publishing House, Hanoi.

MSTE (Ministry of Science, Technology and Environment), 2007b. Red Data Book of Vietnam. Volume 2 - Plant. Science and Techniques Publishing House, Hanoi.

Müller-Rommel, F., 1984. Sozialwissenschaftliche Politik-Beratung - Probleme und Perspektiven. Aus Politik und Zeitgeschichte 32 (B25-84), 26-39.

Nadler, T., 2014. Wildlife protection laws in Vietnam. In: Nadler, T., Brockman, D.K. (Eds.), Primates of Vietnam. Cuc Phuong National Park, EPRC, Vietnam, pp. 75-77.

Nagasaka, K., Böcher, M., Krott, M., 2016. Science-policy interaction: the case of the forest and forestry revitalisation plan in Japan. Land Use Policy 58, 145-151.
Neßhöver, C., Timaeus, J., Wittmer, H., Krieg, A., Geamana, N., van den Hove, S., Watt, A., 2013. Improving the science-policy interface of biodiversity research projects. GAIA 22 (2), 99-103.

Neuman, L.W., 2005. Social Research Methods: Qualitative and Quantitative Approaches. Allyn and Bacon, London.

Newton, A.C., 2010. Use of a Bayesian network for Red Listing under uncertainty. Environ. Model. Softw. 25 (1), 15-23.

Newton, A.C., Oldfield, S., 2008. Red Listing the world's tree species: a review of recent progress. Endanger. Species Res. 6 (2), 137-147.

Nourani, E., Kaboli, M., Farhoodinia, M., Collen, B., 2017. National assessment of threatened species using sparse data: IUCN Red List classification of Anatidae in Iran. Anim. Conserv. 20 (1), 42-50.

Pe'er, G., Mihoub, J.B., Dislich, C., Matsinos, Y., 2014. Towards a different attitude to uncertainty. Nat. Conserv. 8, 95.

Pimenta, B.V., Haddad, C.F., Nascimento, L.B., Cruz, C.A.G., Pombal, J.P., 2005. Comment on "Status and trends of amphibian declines and extinctions worldwide". Science 309 (5743), 1999.

Possingham, H.P., Andelman, S.J., Burgman, M.A., Medellín, R.A., Master, L.L., Keith, D.A., 2002. Limits to the use of threatened species lists. Trends Ecol. Evol. 17 (11), 503-507.

Pregernig, M., Böcher, M., 2012. Normative and analytical perspectives on the role of science and expertise in environmental governance. In: Hogl, K., Kvarda, E., Nordbeck, R., Pregernig, M. (Eds.), Environmental Governance: The Challenge of Legitimacy and Effectiveness. Edward Elgar, UK, pp. 199-219.

Regan, T.J., Master, L.L., Hammerson, G.A., 2004. Capturing expert knowledge for threatened species assessments: a case study using NatureServe conservation status ranks. Acta Oecol. 26 (2), 95-107.

Renn, O., 2003. Sozialwissenschaftliche Politikberatung: Gesellschaftliche Anforderungen und gelebte Praxis. TA-Informationen (1), 4-13.

Richards, G.W., Den Hoed, R.C., 2018. Seven strategies of climate change science communication for policy change: combining academic theory with practical evidence from science-policy partnerships in Canada. In: Leal Filho, W., Manolas, E., Azul, A.M., Azeiteiro, U.M., McGhie, H. (Eds.), Handbook of Climate Change Communication: Vol. 2: Practice of Climate Change Communication. Springer, Cham, pp. 147-160.

Rodrigues, A.S., Pilgrim, J.D., Lamoreux, J.F., Hoffmann, M., Brooks, T.M., 2006. The value of the IUCN Red List for conservation. Trends Ecol. Evol. 21 (2), 71-76.

Rossi, G., Orsenigo, S., Montagnani, C., Fenu, G., Gargano, D., Peruzzi, L., Conti, F., 2016 Is legal protection sufficient to ensure plant conservation? The Italian Red List of policy species as a case study. Oryx 50 (3), 431-436.

Selin, H., Keane, S.E., Wang, S., Selin, N.E., Davis, K., Bally, D., 2018. Linking science and policy to support the implementation of the Minamata Convention on Mercury. Ambio 47 (2), 198-215.

Smith, Z.A., 2017. The Environmental Policy Paradox. Routledge, New York.

Spierenburg, M., 2012. Getting the message across biodiversity science and policy interfaces-a review. GAIA 21 (2), 125-134.

Sterling, E.J., Hurley, M.M., 2005. Conserving biodiversity in Vietnam: applying biogeography to conservation research. Proc. Calif. Acad. Sci. 56, 98.

Stevanov, M., Böcher, M., Krott, M., Krajter, S., Vuletic, D., Orlovic, S., 2013. The research, integration and utilization (RIU) model as an analytical framework for the professionalization of departmental research organizations: case studies of publicly funded forest research institutes in Serbia and Croatia. Forest Policy Econ. 37, 20-28.

Ugolini, F., Massetti, L., Sanesi, G., Pearlmutter, D., 2015. Knowledge transfer between stakeholders in the field of urban forestry and green infrastructure: results of a European survey. Land Use Policy 49, 365-381.

VAST (Vietnam Academy of Science and Technology), 2003. Revising Vietnam Red Data Book Following IUCN Criteria 1994. Research Project Report. Hanoi. Vietnam.

Vignoli, L., Macale, D., Luiselli, L., Lecis, R., Casula, P., 2017. Are conservation assessments of threatened species reliable? Updated distribution of the endangered Sardinian newt Euproctus platycephalus and implications for Red List assessments of Italian amphibians. Oryx 51 (3), 482-488.

Webb, G.J., 2008. The dilemma of accuracy in IUCN Red List categories, as exemplified by hawksbill turtles Eretmochelys imbricata. Endanger. Species Res. 6 (2), 161-172.

Young, J.C., Waylen, K.A., Sarkki, S., Albon, S., Bainbridge, I., Balian, E., McCracken, D. 2014. Improving the science-policy dialogue to meet the challenges of biodiversity conservation: having conversations rather than talking at one-another. Biodivers. Conserv. 23 (2), 387-404.

Zamin, T.J., Baillie, J.E., Miller, R.M., Rodríguez, J.P., Ardid, A.N.A., Collen, B.E.N., 2010. National red listing beyond the 2010 target. Conserv. Biol. 24 (4), 1012-1020. 
Biological Conservation

\section{Electronic Supplementary Material}

Title: Red lists in conservation science - policy interfaces: A case study from Vietnam

Appendix 1: List of interviewees

\begin{tabular}{lll}
\hline Interview & Affiliation & Date \\
\hline 1 & Botanist - Forest Inventory and Planning Institute & $11 / 05 / 2017$ \\
2 & Botanist - National University of Hanoi & $12 / 05 / 2017$ \\
3 & Zoologist - Institute of Ecology and Biological Resources & $20 / 05 / 2017$ \\
4 & Zoologist - Institute of Ecology and Biological Resources & $22 / 05 / 2017$ \\
5 & Government officer - Vietnam Administration of Forestry, & $23 / 05 / 2017$ \\
& MARD & \\
6 & Government officer - Forest Protection Department, MARD & $25 / 05 / 2017$ \\
7 & Zoologist - Institute of Ecology and Biological Resources & $31 / 05 / 2017$ \\
8 & Government officer - CITES Vietnam & $01 / 06 / 2017$ \\
9 & Zoologist - Institute of Ecology and Biological Resources & $02 / 06 / 2017$ \\
10 & Botanist - Institute of Ecology and Biological Resources & $22 / 06 / 2017$ \\
11 & Zoologist - Institute of Ecology and Biological Resources & $23 / 06 / 2017$ \\
12 & Zoologist - Institute of Ecology and Biological Resources & $24 / 06 / 2017$ \\
13 & Government officer - Biodiversity conservation agency, & $25 / 06 / 2017$ \\
& MONRE & \\
14 & Government officer - Department of Nature Conservation, & $28 / 06 / 2017$ \\
15 & MARD & \\
\multirow{2}{*}{16} & Zoologist - Institute of Ecology and Biological Resources & $04 / 07 / 2017$ \\
& Government officer - CITES Vietnam & $05 / 07 / 2017$ \\
& Botanist - Center for Plant Conservation (by email) & $06 / 07 / 2017$ \\
\hline & & \\
\hline & &
\end{tabular}


18 Biodiversity program officer - IUCN Vietnam 10/07/2017

19 Zoologist - Vietnam National University of Forestry 12/07/2017

20 Botanist - Vietnam National University of Forestry 15/07/2017

21 Botanist - National Institute of Medicinal Materials 20/07/2017

22 Zoologist - independent consultant (by email) 2/08/2017

23 Government officer - Biodiversity conservation agency, 5/08/2017 MONRE (by email)

24 Government officer - Biodiversity conservation agency, $\quad$ 10/8/2017 MONRE

25 Primate expert, Vietnam primate conservation program 22/8/2017

IUCN/SSC Primate Specialist Group (by email) 
Appendix 2: Results of the analysis using the RIU model

\begin{tabular}{|c|c|c|c|}
\hline \multirow{2}{*}{$\begin{array}{l}\text { Activities } \\
\text { of the RIU } \\
\text { model }\end{array}$} & \multirow{2}{*}{ Criteria } & \multicolumn{2}{|r|}{ Vietnamese Red Data Book 2007} \\
\hline & & Occ* & Description \\
\hline \multirow[t]{4}{*}{ Research } & $\begin{array}{l}\text { Assessing current } \\
\text { scientific } \\
\text { information }\end{array}$ & + & National and international scientific sources were well-assessed \\
\hline & $\begin{array}{l}\text { Compliance with } \\
\text { the procedures of } \\
\text { sound scientific } \\
\text { practice }\end{array}$ & - & $\begin{array}{l}\text { - Lack of sound and recent empirical monitoring data of species } \\
\text { - Listing methods include: personal knowledge of experts and literature } \\
\text { review } \\
\text { - Research results have not been peer-reviewed } \\
\text { - However, red listing process has been clearly documented }\end{array}$ \\
\hline & $\begin{array}{l}\text { Cooperation with } \\
\text { external scientific } \\
\text { projects and } \\
\text { institutions }\end{array}$ & + & $\begin{array}{l}\text { - Maximize cooperation between Vietnamese researchers from } \\
\text { Vietnamese research institutions such as the Institute of Ecology and } \\
\text { Biological Resources, Vietnam National University, Institute of Tropical } \\
\text { Biology, Institute of Marine Research ( } 73 \text { Vietnamese researchers) }\end{array}$ \\
\hline & $\begin{array}{l}\text { Independent } \\
\text { meaningfulness of } \\
\text { scientific findings }\end{array}$ & - & $\begin{array}{l}\text { Research results of the red listing are dependent on other studies, such as } \\
\text { land use planning, farming and climate change }\end{array}$ \\
\hline
\end{tabular}




\begin{tabular}{|c|c|c|c|}
\hline \multirow[t]{4}{*}{ Integration } & $\begin{array}{l}\text { Orientation } \\
\text { towards public } \\
\text { goals }\end{array}$ & + & $\begin{array}{l}2 \text { public goals: } \\
\text { - Conservation of threatened species in Vietnam } \\
\text { - Compliance with international conventions on biodiversity that Vietnam } \\
\text { signed (i.e. CBD) }\end{array}$ \\
\hline & $\begin{array}{l}\text { Relevance in } \\
\text { regard to political } \\
\text { processes }\end{array}$ & + & $\begin{array}{l}\text { Some scientific recommendations of the red data book have been used in } \\
\text { five laws on protected species that are legally binding for Vietnamese } \\
\text { authorities and people. }\end{array}$ \\
\hline & $\begin{array}{l}\text { Relevance with } \\
\text { regard to allies }\end{array}$ & +- & $\begin{array}{l}\text { - Partial involvement of IUCN ( through workshops, training courses) } \\
\text { - National allies: MARD and MONRE }\end{array}$ \\
\hline & $\begin{array}{l}\text { Target group- } \\
\text { oriented } \\
\text { intermediation for } \\
\text { the right media }\end{array}$ & +- & $\begin{array}{l}\text { Many communication activities, but only good for political actors (elites) } \\
\text { Not applicable for local people since they could not recognize the red } \\
\text { listed species }\end{array}$ \\
\hline \multirow[t]{2}{*}{ Utilization } & $\begin{array}{l}\text { Contribution to } \\
\text { democracy }\end{array}$ & - & $\begin{array}{l}\text { - Do not contribute to democracy due to the establishment of the red list is } \\
\text { only for elites (government, nature reserves) } \\
\text { - Local people do not recognized threatened species in the red list and } \\
\text { Decrees } 32 \text { and } 160 . \\
\text { - No participation of hunters and local people }\end{array}$ \\
\hline & $\begin{array}{l}\text { Contribution to the } \\
\text { rule of law }\end{array}$ & + & $\begin{array}{l}\text { - Scientific basis for making the list of threatened species in Decree } 32 \text { and } \\
\text { Decree } 160\end{array}$ \\
\hline
\end{tabular}


- 19\% (164/856) of the species found in the Vietnamese Red Data Book made it into Decree 32, and $11 \%$ (94/856) of the species made it into Decree 160.

\begin{tabular}{lll}
\hline $\begin{array}{l}\text { Contribution to } \\
\text { good governance }\end{array}$ & +- & $\begin{array}{l}\text { - No participation of local people } \\
\text { - However, scientific recommendation has been used by political actors }\end{array}$ \\
\hline $\begin{array}{l}\text { Appropriate } \\
\text { solutions to } \\
\text { problems }\end{array}$ & $?$ & $\begin{array}{l}\text { - Need further research on the effectiveness of the established wildlife } \\
\text { protection policies }\end{array}$ \\
\hline $\begin{array}{l}\text { Participation in the } \\
\text { scientific } \\
\text { discourse }\end{array}$ & + & $\begin{array}{l}\text { Many scientific publications both at the national and international level } \\
\text { (good topic for scientists) }\end{array}$
\end{tabular}

Note: $*$ Occ. $=$ Occurrence $(-$ not given $; \pm$ partly given; + given; $?$ No information $)$.

Source: adapted from Böcher and $\operatorname{Krott}(2014,2016)$ 
Appendix 3: Current wildlife protection laws in Vietnam

\begin{tabular}{|c|c|c|c|c|}
\hline No & Name of laws & $\begin{array}{c}\text { Issued } \\
\text { year }\end{array}$ & $\begin{array}{c}\text { Promulgated } \\
\text { by }\end{array}$ & Contents \\
\hline 1 & $\begin{array}{l}\text { Decree } 32 / 2006 \text { on } \\
\text { management of rare } \\
\text { and endangered forest } \\
\text { plants and animals }\end{array}$ & 2006 & $\begin{array}{l}\text { Prime Minister } \\
\text { of Vietnam }\end{array}$ & $\begin{array}{l}\text { - Included } 203 \text { rare and threatened species under the two levels } \\
\text { of protection: } \\
\text { + Group I (IA: Plant; IB: Animal): Species listed under the } \\
\text { highest level of protection cannot be extracted from the wild and } \\
\text { the use of all products derived from these species is forbidden } \\
\text { Group IA: } 13 \text { species + } 2 \text { genera } \\
\text { Group IB: } 62 \text { species } \\
\text { + Group II (IIA: Plant; IIB: Animal): The extraction of the } \\
\text { species listed under this lower level of protection are allowed } \\
\text { for breeding, research, or other scientifically compelling } \\
\text { purpose with a permission issued by MARD. } \\
\text { Group IIA (Plants): } 33 \text { species }+4 \text { genera } \\
\text { Group IIB (Animals): } 89 \text { species }\end{array}$ \\
\hline 2 & $\begin{array}{l}\text { Decree } 160 / 2013 \text { on } \\
\text { criteria to determine } \\
\text { species and the } \\
\text { regime of managing } \\
\text { species under the list } \\
\text { of endangered, } \\
\text { precious and rare } \\
\text { species prioritized } \\
\text { protection }\end{array}$ & 2013 & $\begin{array}{l}\text { Prime Minister } \\
\text { of Vietnam }\end{array}$ & $\begin{array}{l}\text { - All forms of commercial trade of the listed endangered species } \\
\text { are prohibited. } \\
\text { + Animals: } 83 \text { species } \\
\text { + Plants: } 17 \text { species }\end{array}$ \\
\hline
\end{tabular}




\begin{tabular}{|c|c|c|c|c|}
\hline 3 & $\begin{array}{l}\text { Circular } 02 / 2006 \text { on } \\
\text { list of aquatic species } \\
\text { banned from } \\
\text { exploitation and } \\
\text { exploitation for a } \\
\text { definite period in the } \\
\text { year (amended by } \\
\text { Circular } 62 / 2008 \text { and } \\
\text { Circular } 02 / 2018 \text { ) }\end{array}$ & 2006 & $\begin{array}{l}\text { Ministry of } \\
\text { Fisheries } \\
\text { (presently } \\
\text { MARD) }\end{array}$ & $\begin{array}{l}\text { - Listed aquatic species banned from exploitation: } \\
21 \text { species (amended to } 25 \text { species in Circular } 62 \text { and to } 32 \\
\text { species in Circular 02/2018). } \\
\text { - Included aquatic species banned from exploitation for a } \\
\text { definite period in the year: } 27 \text { species (amended to } 29 \text { species in } \\
\text { Circular 62) }\end{array}$ \\
\hline 4 & $\begin{array}{l}\text { Decision } 82 / 2008 \text { on } \\
\text { list of endangered } \\
\text { aquatic species that } \\
\text { need to be protected, } \\
\text { rehabilitated, and } \\
\text { developed (amended } \\
\text { by Circular 01/2011) }\end{array}$ & 2008 & MARD & $\begin{array}{l}\text { - Listed } 236 \text { endangered aquatic species which need protection, } \\
\text { reproduction and development: } \\
\text { + Species extinct in the Wild (EW): } 4 \\
\text { + Critically endangered species (CR): } 18 \\
\text { + Endangered species (EN): } 56 \\
\text { + Vulnerable species (VU): } 158\end{array}$ \\
\hline 5 & $\begin{array}{l}\text { Decision } 140 / 2000 \text { on } \\
\text { list of protected } \\
\text { species which are } \\
\text { predators of rats }\end{array}$ & 2000 & MARD & $\begin{array}{l}\text { - Listed protected species which are predators of rats: } \\
18 \text { species } \\
2 \text { Genera } \\
1 \text { Family }\end{array}$ \\
\hline
\end{tabular}


Appendix 4: Actors involved in the establishment and use of the Vietnamese Red Data Book 2007

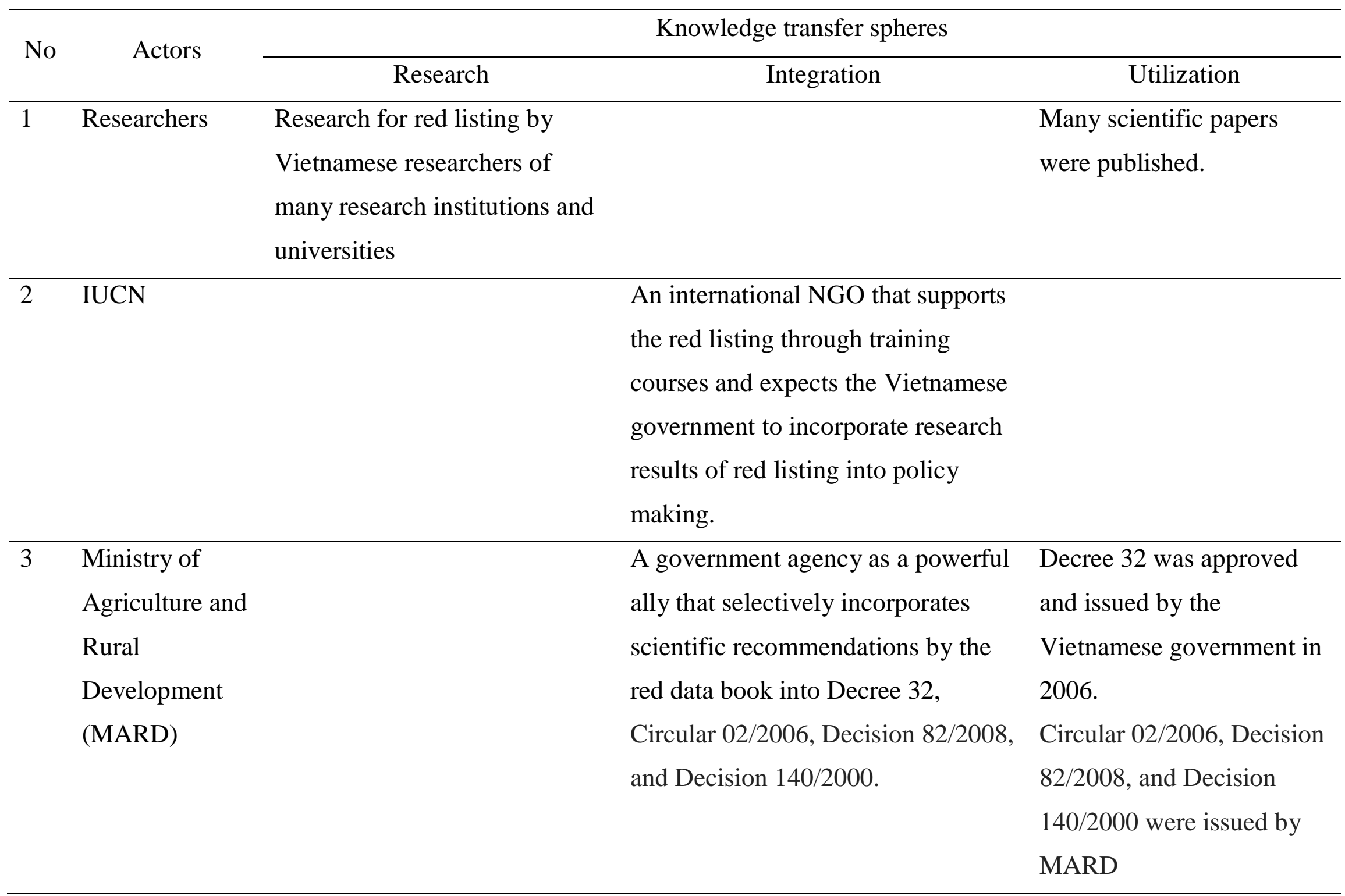




\begin{tabular}{|c|c|c|c|}
\hline 4 & $\begin{array}{l}\text { Ministry of } \\
\text { Natural } \\
\text { Resource and } \\
\text { Environment } \\
\text { (MONRE) }\end{array}$ & $\begin{array}{l}\text { A government agency as a powerful } \\
\text { ally that selectively incorporates } \\
\text { scientific recommendations by the } \\
\text { red data book into Decree } 160 .\end{array}$ & $\begin{array}{l}\text { Decree } 160 \text { was approved } \\
\text { and issued by the } \\
\text { Vietnamese government in } \\
2013 .\end{array}$ \\
\hline 5 & Local People & & $\begin{array}{l}\text { Difficult to recognize } \\
\text { endangered species in the } \\
\text { red data book and the five } \\
\text { laws on protected species. }\end{array}$ \\
\hline
\end{tabular}




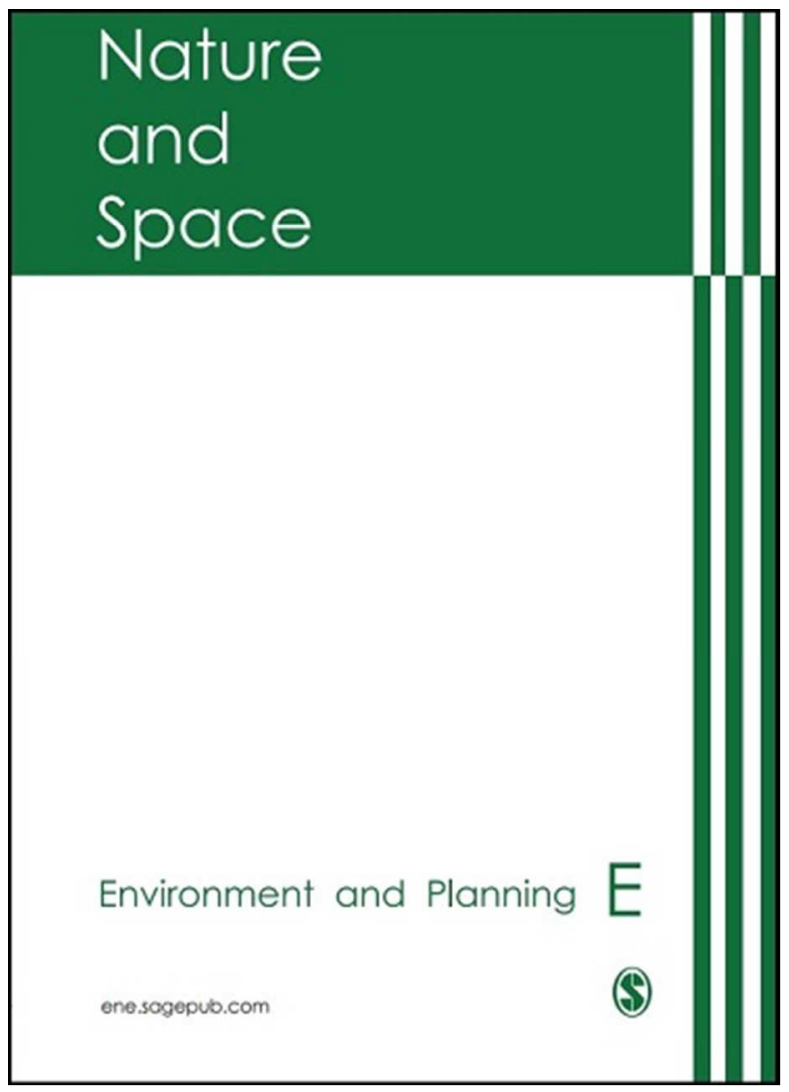

\section{Can landscape planning solve scale mismatches in environmental governance? A case study from Vietnam}

\begin{tabular}{|r|l|}
\hline Journal: & Environment and Planning E: Nature and Space \\
\hline Manuscript ID & EPE-17-011.R1 \\
\hline Manuscript Type: & Article \\
\hline Keywords: & $\begin{array}{l}\text { Fit; Landscape Planning; Nature Conservation; Research-Integration- } \\
\text { Utilization model; Scale; Scientific Knowledge Transfer. }\end{array}$ \\
\hline Abstract: & $\begin{array}{l}\text { Landscape planning has been advocated by many researchers and } \\
\text { conservationists because of its potential to support nature conservation at } \\
\text { a landscape scale. We examined an internationally funded project in } \\
\text { Vietnam (the ECOLIME project) that failed in its endeavor to establish } \\
\text { landscape planning at the scale of an ecologically valuable karst landscape. } \\
\text { We applied the Research-Integration-Utilization (RIU) model of scientific } \\
\text { knowledge transfer to analyze why the ECOLIME project failed in adapting } \\
\text { the scale of the political-administrative planning system to the ecological } \\
\text { scale of the karst ecosystem landscape. Our study shows that the } \\
\text { implementation of landscape planning in the Pu-Luong Cuc Phuong area }\end{array}$ \\
\hline
\end{tabular}




\section{SCHOLARONE"' \\ Manuscripts}

was not successful to solve scale mismatches in environmental governance because of weak integration resulting from a lack of both a link to the Vietnamese political process and support from powerful Vietnamese actors. The establishment of a landscape planning group with the support of an (1) the need for a link to the existing political process and (2) the need to gain the sustainable support of powerful allies. 
Can landscape planning solve scale

\section{2 mismatches in environmental governance?}

3 A case study from Vietnam

4$$
5
$$$$
6
$$

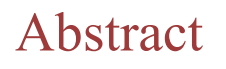

Keywords: Fit; Landscape Planning; Nature Conservation; Research-Integration-Utilization model; Scale; Scientific Knowledge Transfer. 


\section{Introduction}

There has been an increasing concern in recent years about the promotion of nature conservation at a landscape scale (Bennett, 2003; Frost et al., 2006; Reed et al., 2017; Tang et al., 2011). Since the conservation of native flora and fauna and the maintenance of natural ecological processes cannot be assured by depending solely on areas dedicated to nature conservation, the focus of conservation planning and management must extend beyond the boundaries of nature reserves to encompass the whole landscape (Bennett, 2003; Tang et al., 2011). Landscape planning is essential for reconciling the needs of competing land uses and incorporating them into a landscape (Bennett, 2003). Landscape planning has been defined as "a continuing process that strives to make the best use for mankind of a limited area of the earth's surface, while conserving its productivity and beauty" (Vaníček, 1974: 105). From the ecological perspective, landscape planning seeks to integrate human activity with the conservation of environmental resources and contribute to the implementation of sustainable development (von Haaren et al., 2008). Although landscape planning is considered to be important in regulating the relationship between humans and their environment, the practical implementation of landscape planning has been facing various concrete problems (Lütz and Bastian, 2002; von Haaren, 2002).

Like in other developing countries, landscape planning is a new area for planners and policymakers in Vietnam. Although there have been certain changes in the Vietnamese planning system since the introduction of Doi Moi (Renovation) in 1986, still many challenges remain for implementing landscape planning in Vietnam. The development plans of Vietnam still lay a considerable stress on economic growth and infrastructure development and lack the integration of environmental issues into these plans (MPI, 2000; Sekhar, 2005; Vater, 2001). Landscape planning is considered an important planning instrument to bring together different land uses and environmental matters (von Haaren et al., 2008). Therefore, there is an increasing need to investigate the potential for the incorporation of landscape planning into the Vietnamese planning system, especially in the context of the new planning law of Vietnam issued in 2017. In effort to better understand integrated planning in Vietnam, we have examined the implementation of landscape planning activities in $\mathrm{Pu}$ Luong Cuc Phuong landscape funded by the Pu Luong Cuc Phuong limestone landscape conservation project (ECOLIME project). The $\mathrm{Pu}$ Luong Cuc Phuong landscape is recognized as a globally important example of a karst ecosystem that supports the largest remaining area of lowland limestone forest in northern Vietnam (FFI, 2002). Since karst landscape has porous structure, which means that surface actions can easily translate impacts underground or downstream, it requires total landscape management more than any other type of landscape (Furey and Infield, 2007; Vermeulen and Whitten, 1999). In order to promote a regional approach to planning process and support integrated conservation in $\mathrm{Pu}$ Luong Cuc Phuong conservation area, the ECOLIME project was conducted between 2002 and 2009 (FFI, 2002).

One of considerable efforts under the ECOLIME project was put into the establishment of an inter-provincial landscape planning group for three provinces in $\mathrm{Pu}$ Luong Cuc Phuong area. The initiative to establish an inter-provincial landscape planning group was based on the scientific

41 concepts of fit and scale that emphasize the need for compatibility between ecosystem properties 42 and institutional arrangements created to manage human activities affecting these systems 43 (Cleveland et al., 1996; Moss, 2012; Young, 2002). It is widely accepted that scale is a value 44 dimension in environmental governance (Albert et al., 2017; Green 2016; Moss and Newig 45 2010). Since scale is claimed to be socially produced and negotiated between interests in 
political processes (Engel-Di Mauro 2009; Rangan and Kull 2009; Sayre 2009), taking political processes into account and defining appropriate scales in decision-making are essential for the development of working planning strategies (Padt and Westerink 2012). In fact, the mismatches between the geographical extent of a resource or ecosystem and the territorial scope of relevant institutional arrangements can lead to the ineffectiveness, spatial externalities and spillover (Moss and Newig 2010; Moss, 2012). To respond to problems of mismatch, the establishment of new task-specific governance levels (e.g. an inter-provincial landscape planning group) has been advocated to enhance fit with environmental scales (Hooghe and Marks, 2003; Moss and Newig, 2010; Young, 2002). Although the ECOLIME project aims to solve scale mismatches in environmental governance in $\mathrm{Pu}$ Luong Cuc Phuong landscape through landscape planning activities, its target is not easy to obtain in the end. In this study, we employed the ResearchIntegration-Utilization (RIU) model of scientific knowledge transfer (Böcher and Krott, 2014, 2016) to analyze the implementation of landscape planning activities and examine the reasons for the lack of success in establishing landscape planning at the scale of the karst ecosystem in the Pu Luong Cuc Phuong landscape. Thus, our guiding research question is this: How can the failure of landscape planning to solve scale mismatches be explained from the perspective of the RIU model of scientific knowledge transfer?

18 In the following sections, we present an overview of the theoretical background of our study and the RIU model. Next, we present an overview of the Pu Luong Cuc Phuong case study and the planning system in Vietnam. This is followed by a description of our empirical research methods. We then show that the ECOLIME project failed to build links to the political process and win the powerful allies needed to establish landscape planning in Vietnam. Finally, we provide suggestions for how landscape planning could be achieved more successfully in developing countries like Vietnam.

\subsection{Scale and Politics of Scale in Political Ecology}

The concept of scale has been used in many different disciplines. In ecology and geography,

28 scale is usually defined in terms of spatial and temporal dimensions (Gibson et al., 2000;

29 Schneider 2001). In contrast, in sociology, scale refers to the representative nature of social

30 structures from individuals to organizations, as well as the social institutions that govern the spatial and temporal extent of resource access rights and management responsibilities (Bodin and Norberg 2005; Chidumayo, 2002; Ziker 2003). Scale has long been a concept of central concern in political-ecological analyses (Bryant, 2015; Neumann, 2009). In the early efforts to shape political ecology, Blaikie and Brookfield (1987) have emphasized that the complexity of humanenvironment interactions demands an approach that contains the contribution of different geographical scales and hierarchies of socioeconomic organizations. In addition, Zimmerer and Bassett (2003) have asserted the centrality of geographical scale to political-ecological analysis.

38 Political ecology, in the sense of understanding political as well as biogeophysical processes

39 behind people - environment relations (Robbins, 2011; Watts, 2000; Zimmerer and Bassett

40 2003), offers more context-situated approaches of scale and greater sensitivity with respect to 41 micro-scale society-environment relations, which help to improve spatio-temporal resolution and 42 reduce analytical losses of detail of explanatory importance (Engel-Di Mauro, 2009). Moreover, 
Brown and Purcell (2005) have shown that research in political ecology would benefit from more explicit and careful attention to the question of scale and scalar politics.

One of central arguments of scale literature is that scale is socially constructed and its focus is on the roles of diverse actors in struggles that produce scale (Engel-Di Mauro, 2009; Leitner and Miller, 2007; Marston, 2000; Rangan and Kull, 2009; Sayre 2009). It is believed that the social and ecological outcomes of a given scale or any particular scalar arrangement are the result of the political strategies of particular actors, and not the inherent qualities of particular scales (Brown and Purcell, 2005; Marston, 2000). Since there has been an emphasis on social construction of scales through political struggle and a research shift toward examining the political genesis of scale, the phrase "the politics of scale" has become the catchphrase of the literature (Brown and Purcell, 2005; Swyngedouw, 1997a). In addition, the scale has been described as both fluid and fixed (Brenner, 2001; Swyngedouw, 1997b). This is because scales are socially produced through political struggle that is an ongoing process. Thus, scale and scalar arrangements are constantly being made and remade (Brown and Purcell, 2005). The literature of scale has also emphasized that scale is fundamentally a relational concept that necessarily implies a set of relationships in which scales are embedded within other scales (Brenner, 2001; Brown and Purcell, 2005; Kelly, 1999). Therefore, it is suggested that the focus should be put on the analysis of relationships among scales (Brown and Purcell, 2005). In landscape planning, the politics of scale approach has been considered a promising approach to study dynamic interplay between biophysical, social, policy and political processes within landscapes (Padt and Westerink, 2012).

\subsection{Scale Mismatches and Fit}

Scale mismatches between social and ecological systems may be spatial, temporal, or functional (Cumming et al., 2006; Lee, 1993). Spatial mismatches will occur when the spatial scales of management and the spatial scales of ecosystem processes do not align appropriately (Cumming et al., 2006). Scale mismatches arise through changes in the relationships between the spatial, temporal, or functional scales at which the environment varies, the scales at which human social organization occurs, and the demands of people and other organisms for resources (Cumming et al., 2006; Moss 2012). When scale mismatches between social and ecological systems happen, problems inevitably arise either in social institutions responsible for management or in ecological systems managed (Cumming et al., 2006; Young, 2002).

Environmental problems of scale are those problems that arise due to mismatching spatial relations among biophysical processes, administrative structures and procedures, or individual preference (Gibbs et al., 2002; Meadowcroft, 2002; Young, 2002). If administrative responsibility does not match the spatial, temporal, or functional scale of natural phenomena, unsustainable resource use can be expected (Lee, 1993). Scale is a fundamental attribute in adopting a landscape-based approach to planning (Selman, 2006). In terms of achieving more sustainable landscape, there is a strong argument that we should manage our own land using activities within spatial units that resonate with the self-organizing properties of nature (Selman, 2006).

The concept of fit refers to the compatibility between ecosystems and institutional arrangements created to manage human activities affecting these systems (Young, 2002). There are three

44 categories of fit: functional, temporal, and spatial (Folke, 2007; Galaz, 2008). The premise of fit 
is that the closer the fit is between ecosystems and institutional systems, the better the relevant institutions will perform, at least in terms of sustainability (Young, 2002). However, achieving perfect fit has proven to be an elusive task in practice (Galaz, 2008; Young, 2002; 2005). The mismatch of scales is central to the problem of fit within institutions and between ecosystems and institutions (Folke, 2007). When responding to the problem of mismatch, researchers and policy makers have striven to improve fit in the design of institutions aimed at formulating institutional arrangements that fit ecosystems (Moss, 2012). Endeavors to create environmental or resource regimes should begin with an assessment of the principal properties of the relevant ecosystems and proceed to the designing and building of institutional arrangements that fit the bio-geophysical contours of the problem (Young, 2002).

\section{2.3. Concept of Landscape Planning}

12 Over the last decade, landscape planning as a discipline and as a necessary part of the planning process has attracted considerable attention from planners and scholars (Linehan and Gross, 1998; von Haaren, 2002). The task of landscape planning is achieved through the interaction of plans at different scale levels (von Haaren et al., 2008). Landscape planning has to consider all relevant factors associated with natural and human elements within the landscape. Thus, landscape planning involves many relevant stakeholders with different interests in the existing problems within the landscape. Ecologists, economists, planners, and others need to work together and also communicate with one another in mutually comprehensible terms to communicate their ideas in ways that engage non-experts (Selman, 2006). In addition, landscape planning encompasses a variety of skills and tools, such as landscape architecture, nature conservation, and knowledge of plants, ecosystems, soil science, hydrology, and cultural landscapes (Rega, 2014).

In terms of nature conservation, landscape planning is one of the most important planning instruments in landscape management (von Haaren et al., 2008). Through landscape planning, ideas for sustainable landscape development can be presented and fed into other sectoral planning efforts (von Haaren et al., 2008). To conserve the Pu Luong Cuc Phuong landscape as a whole, landscape planning was initiated under the ECOLIME project as a central issue in nature conservation in this landscape. The key project objective addressed the question of how to

30

31 achieve planning for the entire limestone mountain range and how to promote inter-agency cooperation for planning throughout the mountain range (FFI, 2002).

\subsection{Science and Technology Studies and the RIU model}

The merits of Science and Technology Studies (STS) are that these studies identify the strong connection between science, society and politics and that the function of science within political processes is much more complex than just "speaking truth to power", as it is argued by many traditional linear models of the science-policy interface. STS highlights that especially in highcomplex fields like environmental policy, political decisions are the result of co-production between science, politics and society and a clear separation between (scientific) facts and (political) norms is not possible in situations of high uncertainties and unclear scientific prognoses about certain issues and their consequences (Sismondo, 2010). STS are a very important contribution to this field since they argue that knowledge transfer is (if ever) only possible through common interactions between science and practice (Sismondo, 2010; Lidskog 
and Sundqvist, 2015). In the so-called processes of boundary work special actors or institutions act as boundary spanners in processes "through which the distinctions between science and nonscience, science and politics, and experts and lay people are constructed and maintained" (Braun and Kropp, 2010: 771). Landscape planning is a good example of such actions since planning professionals here often act as boundary spanners between science (science-based theories and methods of landscape planning) and practice (practical planning actors, e.g. planning administration).

Our RIU model shares the general co-production is the idea of STS that political and practical decisions are the result of interactions between science, politics and society (Sismondo, 2010). Knowledge transfer from science into practice and vice versa is only possible by bi-directional actions from science and practice. RIU helps to describe and analyze these boundary-spanning activities as they are identified by STS studies, while they are here re-interpreted as the so-called "integration" activities, consisting of permanent switching of roles between research and practical demands, a combination of different activities that are crucial for scientific knowledge transfer. These roles are different since they always have to reflect the main differences in the rationality of science compared to those of political practice. However, in contrast to STS, RIU highlights that political or practical actors follow their own power-driven rationalities and do not necessarily have to follow or even understand scientific reasoning. In situations in which scientific arguments can be linked to powerful actors playing the role of "allies of science", knowledge transfer can be realized, even without a deep consensus or mutual understanding between science and practice (Böcher and Krott 2014, 2016). In RIU model, "allies of science" are powerful actors that support the use of scientific concepts in practice (Böcher and Krott, 2016). The RIU model serves as an analytical model that helps to gain deeper understanding of what happens in co-production surroundings: analytically, different roles between science and practice can be distinguished, in order to theoretically describe their functions for the whole process of scientific knowledge transfer.

27 The RIU model was first developed by Böcher and Krott (2014) in various research projects that addressed scientific knowledge transfer in environmental and forest policy in Germany (Böcher 2016; Böcher and Krott, 2014, 2016; Heim and Böcher, 2016) and in Eastern Europe (Stevanov et al., 2013). Since then, it has been applied to analyze the science-based activities of state forest research institutes in Japan and Sweden (Nagasaka et al., 2016a, 2016b), science-based win-win solutions for fishery management in Indonesia (Dharmawan et al., 2016, 2017) and sciencebased policy advice for nature conservation in Vietnam (Do Thi et al, 2017a, 2017b). In the RIU model, scientific knowledge transfer is defined as a process consisting of the connection of three phases: research (R), integration (I), and utilization (U), each following an individual logic (Böcher and Krott, 2014; 2016) (Figure 1). The RIU model is a useful tool in analyzing three important interconnected steps for science-based policy advice: research, integration, and utilization (Böcher, 2016). Based on the analytical RIU model, criteria can be derived to assess these three activities in actual scientific knowledge transfer processes (Böcher and Krott, 2016). In the RIU model, integration is very important because it can selectively link the spheres of 41 science and politics with the aim of finding science-based solutions for policy and practical 42 problems (Böcher and Krott, 2016). 

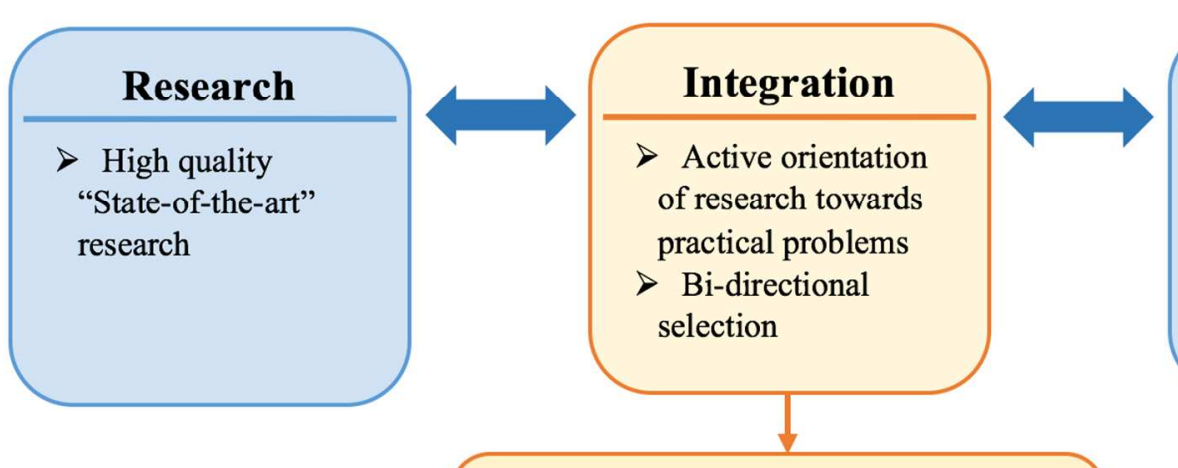

- Orientation toward public goals

- Relevance to political process

- Relevance to allies

- Target group oriented intermediation

\section{Figure 1: Research-Integration--Utilization (RIU) model of scientific knowledge transfer} (adapted from Böcher and Krott, 2016; Böcher, 2016)

In the integration phase, stakeholders select research results that are relevant to solving practical problems based on practical demands (Böcher and Krott, 2014; 2016). Integration connects scientific concepts with the expectations and interests of political and practical stakeholders, but it does not alter the results of scientific research (Böcher and Krott, 2014). Successful integration leads to the utilization of scientific results in practice. The RIU model defines the criteria for assessing integration activities as the orientation of research toward public goals, the applicability of scientific solutions to practical problems, the relevance to stakeholders (allies) and the political process, and appropriate target group-oriented intermediation by means of the right media. It assumes that a deficit of one or more of these criteria might lead to unsuccessful integration, which may result in unexpected failures in transferring scientific concepts into practice. However, few empirical studies have been conducted to examine how a lack of integration according to the RIU model may influence the process of transferring scientific concepts into practice. In this research, we focused on two out of four important criteria for a successful transfer of scientific knowledge as stated in the RIU model with the main assumption that scientific concepts need to have relevance to the political process and stakeholders (allies) to be successfully transferred into practice. Based on the RIU model, we derived two hypotheses that might explain the failure of permanent implementation of landscape planning in our case study:

Hypothesis 1: Landscape planning needs a link to the existing planning system to be successfully transferred into practice.

Hypothesis 2: Landscape planning needs powerful allies to be successfully transferred into practice. 


\subsection{The Case of the Pu Luong Cuc Phuong Landscape}

The Pu Luong Cuc Phuong range is a globally important karst landscape in Northern Vietnam (FFI, 2002) (Figure 2). The landscape covers approximately 170,000 ha and stretches across three provinces (Ninh Binh, Hoa Binh, Thanh Hoa). The ecological importance of the area is based on its high biodiversity level, the endemism of fauna and flora species, the sensitivity of the karst ecosystem, and traditional cultural values (FFI, 2002). To protect this ecosystem, three protected areas were approved by the Vietnamese government. Cuc Phuong is the oldest national park in Vietnam, established in 1962, in the eastern part of the landscape. The Pu Luong Nature Reserve was established in 1999 in the western part of the landscape. Ngoc Son Ngo Luong, in the central part, was approved as a nature reserve in 2004 , forming a biodiversity corridor between the other two.

A key feature of the Pu Luong Cuc Phuong landscape is the influence of the local people on the landscape. Culture and traditional values, such as traditional costumes, architecture, farming techniques, and markets, have a crucial visual impact on this landscape (Overjero, 2005). In 2002, an input research of the ECOLIME project showed that there were many threats to the conservation of the limestone landscape, including the expansion of commercial-scale timber harvesting, illegal hunting, expansion of new roads, and uncontrolled quarrying (FFI, 2002). The ECOLIME project is labeled as an Integrated Conservation and Development Project that aimed to protect biodiversity values and cultural characters of the Pu Luong Cuc Phuong limestone range by addressing conservation issues and the building capacity for ecosystem management (FFI, 2002). The project was divided into two phases. Phase 1, which lasted from 2002 to 2006, was funded by the Global Environment Facility and the Spanish Agency for International Cooperation and was focused on biodiversity research, law enforcement, and protection. Phase 2 was carried out from 2007 to 2009 and was focused on community livelihood development initiatives and raising awareness. Phase 2 was funded by the Japan Social Development Fund. Both phases of the project were implemented by the Fauna \& Flora International (FFI) Vietnam Conservation Support Program, in partnership with the Forest Protection Department of the Vietnamese Ministry of Agriculture and Rural Development, with technical assistance from the German Development Service (DED). Establishing a landscapelevel plan covering the whole ecological scale of the karst ecosystem was at the heart of the ECOLIME project's objectives, which should ultimately build local capacity in ecosystem management and introduce this into the regional policy and planning process of Vietnam (FFI, 2002).

34 Initially, the ECOLIME project claimed to formulate a formal institution for the Pu Luong Cuc 35 Phuong landscape, according to the argument that the separate institutions of the three provinces 36 were not suited to managing the landscape, crossing the boundaries of three provinces. This idea 37 refers to the concept of spatial fit, which reflects the need for compatibility between the 38 geographical extent of a biophysical system and the management area of an institution (Moss, 2012; Young, 2002). The establishment of an inter-provincial institution was intended to enhance the fit between the scale of the limestone ecosystem (the Pu Luong Cuc Phuong landscape) and the scale of the institutional arrangement (the proposed inter-province institution). The ECOLIME project made a lot of effort to establish a landscape planning group with the participation of all three provinces. It was expected that the establishment of such a group would improve cooperation between the leading departments of the three provinces and allow for the 
1 gradual evolution of a locally appropriate institution that would meet the needs of the landscape and its stakeholders (Infield, 2004; Overjero, 2005).

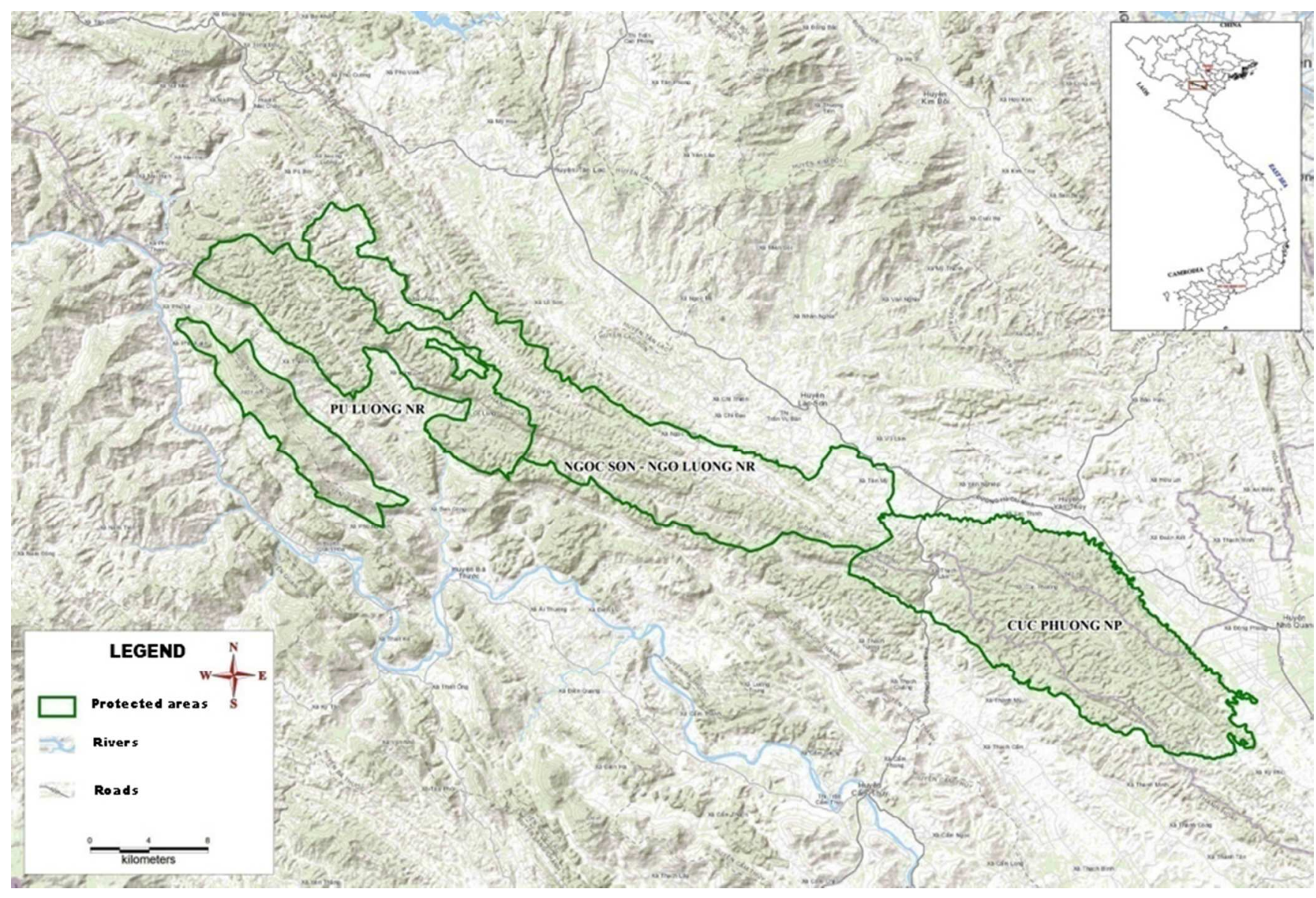

$6 \quad$ Figure 2: Pu Luong Cuc Phuong Landscape (Map by Dinh Vu Xuan, 2017)

\section{3.2. Vietnamese Planning System: Structure and Main Actors}

8 Originally, Vietnam followed a command planning model adopted from the U.S.S.R, according

9 to which resources were allocated directly by the central authorities to what were considered to

10 be the high-priority tasks of national development (Quang 2002; Quang and Kammeier, 2002;

$11 \mathrm{Vu}, 2008)$. However, this planning system led to economic inefficiency and a low quality of life 12 in Vietnam during the period from 1954 to 1985 (Vu and McIntyre-Mills, 2008). In 1986, the 13 Vietnamese government adopted a policy of economic reform (Renovation or Doi Moi in 14 Vietnamese) that marked a crucial change from a centrally planned economy to a multi-sector 15 market economy. As a result, reformative approaches were applied to the national planning 16 system (Quang and Kammeier, 2002; Vu and McIntyre-Mills, 2008). In 2004, the Vietnamese 17 government established a legal framework for the reform of the planning process. Recently, the 18 new law on planning was issued in 2017. Despite these declared innovations, planning 19 mechanisms in Vietnam still resemble the centralized model, according to which the central 20 government controls all resources (Vu, 2008; Vu and McIntyre-Mills, 2008) of the local 
governments, such as mandatory powers, financial resources, political resources, and information resources. All planning is viewed as a process of implementing the planned investment of state resources, rather than as a means of guiding and controlling private development and investment into the public interest (Lawrie, 2000; Quang 2003). The planning methodology is essentially a top-down (target-setting) approach that does not start with concrete issues to be addressed (Poppe, 2004; Quang, 2003).

In Vietnam, all planning efforts are considered to fall into one of these three categories:

(1) socioeconomic development planning (policy and strategy), (2) sector development planning, or (3) physical planning (giving spatial orientation to investment decisions) (Quang and Kammeier, 2002; Quang, 2003) (Figure 3). Different relevant actors are involved in the socioeconomic, sector, and physical plans at the planning levels (Figure 4).

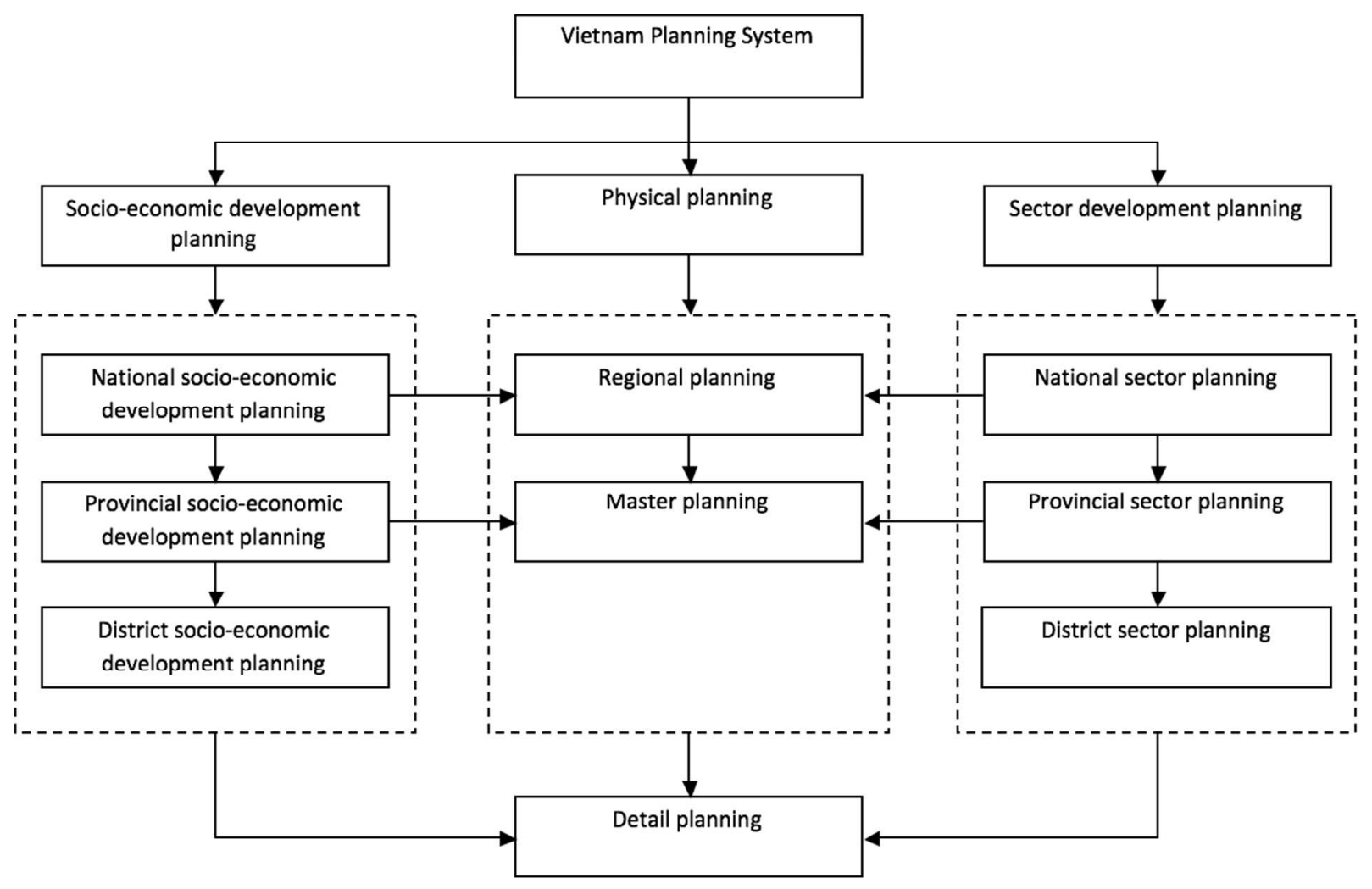

14 Figure 3: The Structure of the Vietnamese Planning System

15 (adapted from Quang Nguyen, 2003)

\section{3.2.1. Socioeconomic Development Planning}

17 At the national level, socioeconomic development plan is formulated and synthesized based on

18 the sectoral, regional and provincial plans in line with the priority and orientation of national

19 socioeconomic goals and objectives promulgated by the National Assembly (following the

20 Party's resolutions). Socioeconomic development planning has taken a dominant position in the

21 Vietnamese planning system since the public sector represents the dominant investment sources

22 (Quang 2002; Quang and Kammeier, 2002; Vu 2008). It also plays a strategic planning role since 
its recommendations can be regarded as strategies. National socioeconomic planning has been prepared and coordinated at the central level by the Ministry of Planning and Investment (MPI) and submitted to the National Assembly for approval. At the provincial and district levels, the process of preparing and approving socioeconomic plans is similar to that followed at the national level. In principle, the provincial or district socioeconomic development plan must include plans of institutions and enterprises located in the province or district but under the direct management of central government (Quang, 2003; Vater, 2001). The provincial Department of Planning and Investment (DPI) is responsible for formulating socioeconomic plans based on sectoral master plans at the provincial level. Then, provincial socioeconomic plan is submitted to Provincial People's Committee (PPC) for approval. The district DPI is responsible for formulating and implementing socio-economic plan at the district level.

\subsubsection{Sector development planning}

Sector development plans are prepared by the line ministries and/or subordinated agencies to guide particular sectors' development (i.e. forestry, mining industry) at the national and local levels. Ministries and subordinated agencies are designated to establish their professional sector plans based on the directions, strategies and targets provided by the central government (Quang 2002; Vater, 2001). At sub-national levels, the preparation of sector plans is proceeded in a similar way to that followed at the national level, but the contents of plans are more limited within a certain province or district (MPI, 2000; Quang 2003; Vater, 2001). Provincial line departments under ministries and provincial DPI are responsible for preparing and implementing the provincial sector plans. At the district level, sector plans are formulated and implemented by district line departments.

\subsubsection{Physical planning}

Physical planning is an essential tool for the spatial arrangement of land uses in a region or city (Quang, 2002; 2003). It is important to understand that a region may consist of many provinces, many districts or of one province or district (Quang, 2002). In Vietnam, physical planning is not seen as a means of addressing urban social or physical problems, but is rather a process of allocation of state resources to meet specified targets (Quang, 2002; 2003; Quang and Kammeier, 2002). Thus, physical planning is claimed to be rigid and dependent on socioeconomic planning. Physical planning is classified into three linked categories: regional planning; general (master) physical planning, and detailed physical planning (Matsumura et al., 2017; Quang, 2003). Physical planning is applicable to a given region or urban area for a period of 10-15 years and updated every five years. The Ministry of Construction (MOC) has the coordinating responsibility for preparing and conducting master physical plans for the class I and II urban areas and submitting them to the Prime Minister for approval. For the remaining urban areas, local Construction Departments (CDs) are designated to establish master physical plans and submit them to the PPC for approval. The main actors in detailed urban planning include the PPC and local CDs.

In conclusion, despite the positive transition toward multi-sector market economy, the Vietnamese planning system still resembles the past centralized model in which all decisions are made by the central government. The main strength of the planning system is that all types of planning (socioeconomic, sector and physical) are prepared, at least theoretically, in a strong orientation toward the defined national goals and objectives (Quang, 2002; 2003; Vu and McIntyre-Mills, 2008). The requests for funding are submitted from the local to the central level.

46 The central level (MPI) then coordinates and takes decisions which are communicated to the 
1 local level in the form of targets with an approved list of investment plans or projects (i.e. in 2 socioeconomic and sector plans) (Quang 2002; 2003; Interview 14, 23, 27).

3 However, under the condition of a market economy, this planning system is inappropriate and 4 can cause serious risks to the credibility of planning and to the environment (Pierre, 2000). There 5 is an ineffective coordination among the socioeconomic plans, sectoral plans and urban plans due to the absence of spatial concept in socioeconomic plans and lack of strategic orientations and priority settings in physical plans (Quang, 2002; 2003; Interview 14, 27, 28). Given that planning and investment are mainly decided by the state, there is limited participation of non-state (foreign, domestic private and community) sectors in the preparation of socioeconomic and 10 urban plans which, consequently, has limited the feasibility and effectiveness of this planning 11 tool under the conditions of the market economy (Quang 2002; 2003; Interview 14, 27). In 12 addition, this hierarchical planning system has created less interest in cooperation between 13 administrative units (e.g. provinces) since each province has its land use plan and funding 14 resources allocated by the central government (Interview 14, 24, 27). This is a considerable 15 16 17 obstacle to the implementation of inter-provincial planning or landscape planning in Vietnam.

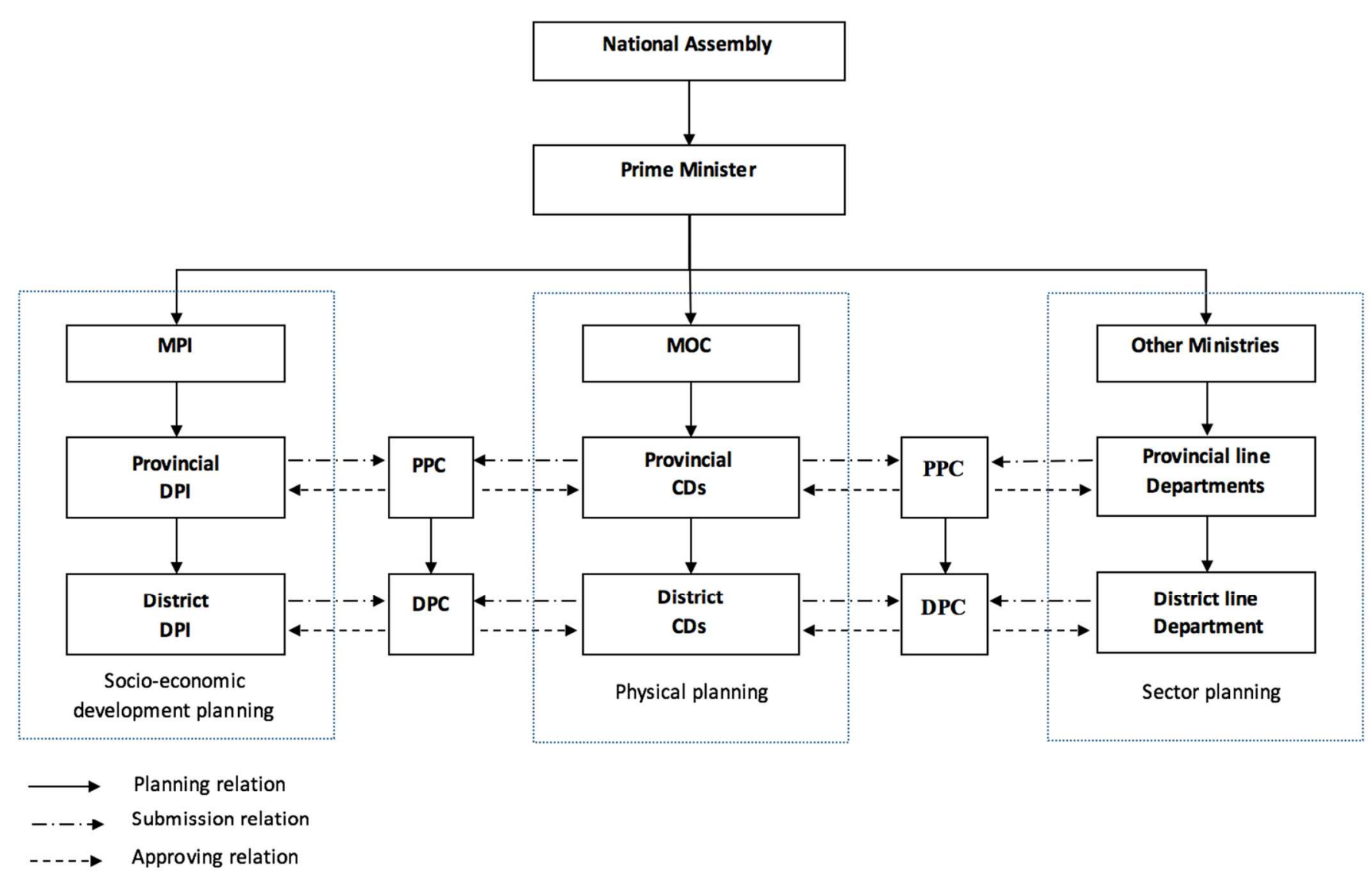

Note:

- MPI: Ministry of Planning and Investment

- DPI: Department of Planning and Investment

- PPC: Provincial People's Committee 
- MOC: Ministry of Construction

- CDs: Construction Departments

- DPC: District People's Committee

Figure 4: Main actors in the Vietnamese Planning System

(adapted from Quang Nguyen 2003)

\subsection{Data Collection and Analysis}

This study is based on expert interviews and document analysis. First, we searched all published papers and project documents related to the Vietnamese planning system. The information on characteristics of the Vietnamese planning system was compiled from eight previous studies. The concept of landscape planning was investigated from textbooks and international published papers. Second, we collected project documents of the ECOLIME project from many sources, including the FFI library, the central Forest Protection Department, and the Cuc Phuong National Park, Pu Luong Nature Reserve, and Ngoc Son Ngo Luong Nature Reserve libraries. In total, 30 documents of the ECOLIME project were collected, including project proposals, project completion reports, technical reports, progress reports, publications, unpublished reports, scientific articles, books, and informative documents. The extensive analysis of documents was conducted to better understand the purpose and motivation for the implementation of landscape planning activities in the $\mathrm{Pu}$ Luong Cuc Phuong landscape by the ECOLIME project. Third, we conducted 22 semi-structured interviews between November 2015 and February 2016, and six additional interviews (by email) between January and February 2018 (Appendix 1). Interviewees included various stakeholders involved in the ECOLIME project, such as researchers, governmental staffs, project staffs, and forest rangers of the nature reserves. In particular, we interviewed governmental staff members working for formal planning departments (MPI/DPI) to explore structure and functions of the Vietnamese planning system. In addition, planning researchers have been involved into our interviews to clarify the characteristics of the Vietnamese planning system. The selection of interviewees was based on their roles, knowledge and experience regarding the Vietnamese planning system and their participation in landscape planning activities in Pu Luong Cuc Phuong area. The interview questions focused on structure and functions of the Vietnamese planning system and the establishment of a landscape planning group in the study area. The interviews, lasting between 1 and 2 hours, were conducted in Vietnamese by a native researcher. All the collected data was triangulated to ensure the reliability of data. Subsequently, a qualitative content analysis was conducted to analyze all of the documents and interviews (Neuman, 2005) for the purpose of testing our two hypotheses. We used stakeholder analysis, as described by Schmeer (1999), to identify the main stakeholders in the Vietnamese planning system and investigate their potential links and interests in landscape planning. The stakeholder analysis helped to identify the actors that should be involved and to shed light on the possible roles of different actors, as well as some of the opportunities and risks associated with involving these actors (Hermans, 2008). In this study, we used the collected data to assess the power of the stakeholders within the political system in Vietnam as being either high $(+)$ or low (-), based on an analysis of power that considered three aspects: (1) legal decision-making right, (2) informal decision power, and (3) the main budget. 


\section{Results}

\subsection{Lack of a link between the concept of landscape planning and the Vietnamese planning system}

Because the Vietnamese planning system is separated into three categories (socioeconomic, sector, and physical plans), many differences exist between its characteristics and the concept of landscape planning (Table 1). Landscape planning is considered to be a means to reconcile the needs of the competing land uses and incorporate them into a landscape (Vanicek, 1974). Basically, landscape planning is created for the whole area, including the populated and unpopulated areas (von Haaren et al., 2008). Since landscape planning aims to reconcile different demands on land use, conservation and natural resource management, it is essential that the ecological, socio-cultural and economic values of the landscape are fully taken into account in planning and decision-making (De Groot, 2006). While landscape planning requires an integration of all plans and values within a specific landscape, there is a separation between the three planning types in the Vietnamese planning system. The Vietnamese socioeconomic development planning process is a dual and fragmented central process that concentrates decision-making at the central level (Poppe, 2004; Quang, 2002; 2003). The planning responsibilities between the different ministries (sector plans) are fragmented, and coordination by the MPI is difficult because the sectors compete against each other for financial resources (Poppe, 2004; Quang, 2003). In addition, the integration of sector plans into development plans is carried out superficially through consultation between ministries or line agencies at various levels, without the involvement of non-governmental stakeholders (Poppe, 2004; Vater, 2001). Priority setting (in socioeconomic plans) and the implementation of physical planning are separated and are therefore difficult to coordinate (Quang and Kammeier, 2002). Furthermore, because of the vertical structure of Vietnamese government and the top-down planning system, the implementation of coordination across and among sectors is a very difficult task (Vu 2008; Vu and McIntyre-Mills, 2008). Each agency is under a certain administration of its own sector and works independently of other agencies at the same horizontal level. Although planning and investment departments consult sector agencies when making overall development plans, such consultations are aimed at making plans rather than coordinating them $(\mathrm{Vu}$ and McIntyre-Mills, 2008). Little decision-making authority is delegated to lower governmental levels, since they have little independence in addressing issues without interference from the central government ( $\mathrm{Vu}$ and McIntyre-Mills, 2008). As a result, local governments take a passive approach to capital resources, leading to a lack of linkage between budgeting and planning (Quang 2002; Vu and McIntyre-Mills, 2008).

\section{Table 1: Differences between the concept of landscape planning} and the Vietnamese planning system

\begin{tabular}{|l|l|l|}
\hline Categories & $\begin{array}{l}\text { Characteristics of the Vietnamese } \\
\text { planning system }\end{array}$ & Concept of landscape planning \\
\hline
\end{tabular}




\begin{tabular}{|c|c|c|}
\hline Composition & $\begin{array}{l}\text { Planning system is separated into } \\
\text { three types of planning } \\
\text { (socioeconomic, sector, and physical) }\end{array}$ & $\begin{array}{l}\text { Landscape planning reconciles the needs } \\
\text { of the competing land uses and } \\
\text { incorporates them into a landscape } \\
\text { (Vanicek, 1974) }\end{array}$ \\
\hline $\begin{array}{l}\text { Planning } \\
\text { approach }\end{array}$ & $\begin{array}{l}\text { Follows a top-down approach, } \\
\text { according to which resource } \\
\text { allocation is determined by the } \\
\text { central authorities (Quang, 2003; Vu } \\
\text { 2008). }\end{array}$ & $\begin{array}{l}\text { Landscape planning is an activity } \\
\text { requiring the cooperative effort of relevant } \\
\text { stakeholders (Selman, 2006; Valencia- } \\
\text { Sandoval et al., 2010; Vroom, 1976). }\end{array}$ \\
\hline Participation & $\begin{array}{l}\text { Power is in the hands of a small } \\
\text { group of the highest authorities of } \\
\text { PPC and DPI (Vu and McIntyre- } \\
\text { Mills, 2008). }\end{array}$ & $\begin{array}{l}\text { The involvement of stakeholders and the } \\
\text { public is essential for the acceptance and } \\
\text { the success of a landscape plan (von } \\
\text { Haaren, 2002). }\end{array}$ \\
\hline $\begin{array}{l}\text { Integration of } \\
\text { environmental } \\
\text { issues }\end{array}$ & $\begin{array}{l}\text { Focus on developing infrastructure } \\
\text { (Huong, 2006) and lack of } \\
\text { incorporation of environmental issues } \\
\text { into socioeconomic development } \\
\text { plans in Vietnam (Sekhar, 2005, } \\
\text { Vater, 2001). }\end{array}$ & $\begin{array}{l}\text { Landscape planning needs to be developed } \\
\text { within the context of environmental } \\
\text { planning (von Haaren, 2002). }\end{array}$ \\
\hline $\begin{array}{l}\text { Role of } \\
\text { planner }\end{array}$ & $\begin{array}{l}\text { Because the Vietnamese planning } \\
\text { mechanism still resembles a } \\
\text { centralized model, different planners } \\
\text { do not need to work together and } \\
\text { have low capacity on integrating the } \\
\text { environment and development in } \\
\text { Vietnam (Bass, 2009). }\end{array}$ & $\begin{array}{l}\text { Planners are familiar with implementation } \\
\text { instruments and the instruments of } \\
\text { cooperation, persuasion, and negotiation } \\
\text { (von Haaren, 2002). }\end{array}$ \\
\hline
\end{tabular}

1

Landscape planning is considered a participatory activity that requires many cooperative efforts by relevant stakeholders (Selman, 2006; Valencia-Sandoval et al., 2010; Vroom, 1976). The communities and stakeholders should be involved in key planning processes, both actively (e.g. in participatory design or site management) and passively (e.g. by receiving information) (Selman, 2006). It has been shown that community engagement through the use of participatory landscape planning has become an effective tool to inform and impact local policy related to sustainable community development in rural Mexico (Valencia-Sandoval et al., 2010). In contrast to this approach, the planning system in Vietnam follows a top-down approach. The five-year socioeconomic development planning process reflects single-party top-down governance. Decisions concerning what to do and how are made by the central government. Local authorities (councilors and officers) do not make decisions about policies for their local areas alone; rather, they often look to the national government for guidance about what standard of service to provide, for ideas to imitate or to avoid, for ways to tackle common problems, and 
for justifications or philosophies in particular strategies (Vu and McIntyre-Mills, 2008). When a plan has been issued by a higher governmental level, local governments have to strictly follow the plan. If there is any action outside the plan that relates to the higher-level decision-making authority, the local government needs to propose action to and wait for decisions from the higher governmental level (Vu and McIntyre-Mills, 2008). These factors pose a considerable challenge to linking the concept of landscape planning to the Vietnamese planning system.

Despite the existence of an internal platform (among sectors and authority levels), the contribution of sector agencies and local authorities to the investment plans or projects which are formulated from the master socioeconomic development plans, is limited to providing opinions. Decisions on project identification and approval are made mainly by a small group of the highest-level authorities of the PPC and DPI (Quang 2002; Vu and McIntyre-Mills, 2008). The DPI does not share the power and responsibility for project identification and assessment with other departments (Vater 2001; Vu and McIntyre-Mills, 2008). Thus, while decision-making in the Vietnamese planning system rests in the hands of a small group of powerful stakeholders, landscape planning boosts the participation of all stakeholders. Research on landscape planning has demonstrated that the involvement of stakeholders and the public is essential for the acceptance and success of landscape planning projects (Luz, 2000; von Haaren, 2002). Moreover, improving communication skills of all participants in landscape planning is considered to be the core of guidelines for the implementation of landscape plans (Luz, 2000). However, this study has shown that the potential for the establishment of stakeholder participation in the Vietnamese planning system is very limited.

The concept of landscape planning should be developed within environmental planning (von Haaren, 2002), whereas development plans in Vietnam emphasize the importance of economic growth and infrastructure development (MPI, 2000; Vater, 2001). Environmental considerations are not a priority in the Vietnamese planning system (Huong, 2006). Furthermore, there is a lack of incorporation of environmental issues into socioeconomic development plans in Vietnam (Sekhar, 2005). The competence of planners is also an important issue. In landscape planning, planners have to be familiar with methods of cooperation, persuasion, and negotiation (von Haaren, 2002). However, in Vietnam, because of the centralized planning approach, different planners do not need to work together and have low capacity on environment-development and poverty-environment issues, especially at the provincial level (Bass, 2009). Because of these significant differences, many obstacles for the integration of landscape planning into the Vietnamese planning system are inevitable.

At the beginning of the project, the ECOLIME project recognized many existing challenges derived from the significant differences between the concept of landscape planning and the Vietnamese planning system (Interview 1, 2). In addition, since there was not a legal framework for regional or inter-provincial planning in Vietnam in the project time, the formulation of a formal authority for the Pu Luong Cuc Phuong region was far from an easy task (Overjero, 2005). In order to tackle these challenges, a landscape planning group was established in 2005 as an important effort of the ECOLIME project to improve the stakeholders' awareness and strengthen inter-provincial cooperation within Pu Luong Cuc Phuong landscape (Interview 1, 2, 8). The task of landscape planning group was to help harmonizing the multiple interests and perspectives of the landscape as well as promoting cooperation between the different stakeholders and the authorities responsible for the management of the karst ecosystem landscape. 
processes, including different sectors. The second was to establish the concept of the landscape within the institutions of the three provinces and to establish recognition of the need for the provinces to plan for the landscape together. The third was to establish an institution that could achieve coordinated planning at the landscape level (Interviews 1,3).

Initially, the landscape planning group was successful in contributing to the development of some new cooperative agreements among different actors in the three provinces (Interviews 17, 18, 20). Although, the management boards of the Pu Luong and Ngoc Son Ngo Luong nature reserves still cooperate in certain forest protection and management activities (Interviews 11, 13), we observed that after the funding of the ECOLIME project expired, the implementation of these signed agreements largely vanished. With the support of the ECOLIME project, the landscape planning group has conducted five annual inter-provincial and many inter-district meetings to discuss and find solutions for general problems within the landscape, such as watershed management, biodiversity conservation, irrigation and environment pollution (FPD, 2006; 2007; Interview 1, 2). However, the group only identified these problems in the landscape; it did not achieve in arriving at solutions for these problems in practice (Interviews 1, 2, 19). In the discussions of the landscape planning group, several ideas were developed for the future development of the area (e.g. establishing a national park covering the whole landscape or creating a Man-and-Biosphere Reserve). Nevertheless, none of these ideas were implemented in practice due to weak commitment of the stakeholders and a lack of funding (Interview 1, 11, 12). Furthermore, the landscape planning group had no mandate or force to produce legally binding advice to the provincial governments. In fact, the recommendations of the group were not successfully integrated into the socioeconomic and sector plans of the three provinces. Thus, our analysis showed that although the cooperation between some actors in the three provinces was improved by the activities of the landscape planning group, landscape planning could not be permanently implemented in the case study. Thus, the ECOLIME project failed in transforming the concept of landscape planning into practice because of the huge differences between the concept of landscape planning and the Vietnamese planning system. These huge differences could not be overcome by the creation of a landscape planning group. Thus, hypothesis 1 was supported.

4.2. Landscape planning lacks support from powerful allies

In the Vietnamese planning system, the National Assembly and the Central Government (headed by the Prime Minister) are the most powerful actors in approving socioeconomic and sector plans. While the MPI is responsible for coordinating and preparing socioeconomic and sector plans, the preparation of general urban plans is the responsibility of the MOC. At the provincial level, the PPC makes decisions concerning the approval of provincial socioeconomic and sector plans. The DPI is tasked with assisting the PPC in formulating the provincial socioeconomic plans. The remaining actors (i.e. line ministries or line departments) assist by providing specialized knowledge and by implementing the approved plans.

39 Because landscape planning is not integrated into the three types of planning in Vietnam, the 40 issue of landscape planning does not meet the interests of the powerful actors in the country. At 41 all levels, landscape planning is believed to make an important long-term contribution to the 42 conservation of natural resources (von Haaren et al., 2008). Landscape planning not only 43 addresses the narrower areas of particularly valuable protected sites, but also devises strategies 44 for full coverage, sustainable conservation, and long-term development of nature and landscapes 
(BfN, 2002). Nevertheless, in the Vietnamese planning system, the function of socioeconomic planning in MPI could be confused with the interest to promote investment and the task of physical planning by MOC would be prepared with the interest to optimize public investment projects (Lawrie, 2000). Since the powerful stakeholders in the Vietnamese planning system put economic development as the main priority, environmental considerations have not received the attention of Vietnamese planners (Table 2). We discovered that the actors in line ministries (i.e. the Ministry of Agriculture and Rural Development and the Ministry of Natural Resource and Environment) have interests in integrating environmental issues (including landscape planning) into their plans. However, they are not powerful actors in the Vietnamese planning system. As a result, the integration of landscape planning into the Vietnamese planning system is not of sufficiently strong interest to be implemented in practice.

With the establishment of the landscape planning group in 2005, the ECOLIME project was expected to attract the support of powerful actors. However, under a centralized planning system, with all decisions made by the central government, powerful actors have no interest in cooperating within such a group (Interview 6,12). This is because each province of Vietnam has its own land use plan and its allocated funds from central government. Moreover, powerful actors of a province could not influence decision-making of the neighboring provinces. This causes significant obstacles for maintaining the landscape planning group and its activities. The core members of this landscape planning group were the representatives of some leading institutions and departments of the three provinces and three protected areas of the mountain range, such as the PPC, the Forest Protection Department (FPD), the DPI, the Department of Natural Resource and Environment (DONRE), the Department of Agriculture and Rural Development (DARD), the Pu Luong Nature Reserve, the Ngoc Son Ngo Luong Nature Reserve, and the Cuc Phuong National Park.

Furthermore, the different organizations working in Pu Luong Cuc Phuong have very different roles and responsibilities, and consequently, they do not share the same perspectives on the problems that exist in Pu Luong Cuc Phuong area (Huong, 2006). Different members of the group have different interests motivating their participation in the group. In the Pu Luong Cuc Phuong area, the PPCs and DPIs of the three provinces (Hoa Binh, Ninh Binh, and Thanh Hoa) are the most powerful actors in preparing and approving socioeconomic and sector plans. However, these actors prioritize economic development; they have little interest in landscape planning (Interviews 2, 3, 6). Moreover, each province has its own plan, which is approved by the PPCs. Thus, establishing a landscape plan that encompasses the plans of the three provinces did not receive the great interest from their powerful actors. The DARD and the DONRE of each of the three provinces had significant concerns about environmental issues and implementation of Agenda 21 in the Pu Luong Cuc Phuong area [Agenda 21 is an environmental agenda of the United Nations, which emanated from the Rio Earth Summit in 1992, and aims to establish a policy context for achieving sustainable development]. As an attachment to the mission of sustainable development and climate change, Vietnam's government signed Agenda 21 at the Earth Summit in 1992 and Paris climate agreement at the $21^{\text {st }}$ Conference of the Parties of the UNFCCC in Paris in 2015.

42 The idea of landscape planning received considerable attention from representatives of DARD 43 and DONRE of the three provinces. However, because the DARD and the DONRE are not 44 powerful actors in the provincial planning system, they cannot incorporate landscape planning 45 into the plans of the three provinces. Without a strong legal framework for landscape planning, 46 the establishment of the landscape planning group was not successful in achieving the support of 
1 the powerful actors and making them allies in the endeavor of permanently establishing 2 landscape planning. This led to the limited implementation of landscape planning in the $\mathrm{Pu}$ 3 Luong Cuc Phuong landscape. Thus, although the establishment of the landscape planning group 4 was supposed to obtain the support of powerful allies, it proved to be inapplicable in practice. 5 This result clearly supports our hypothesis 2 , which states that a lack of support by powerful 6 allies led to the unsuccessful implementation of landscape planning in the Pu Luong Cuc Phuong 107 area. 
1 Table 2: Actors, their interests, and their potential link to landscape planning 2

\begin{tabular}{|c|c|c|c|c|c|}
\hline Level & Actors & $\begin{array}{l}\text { Level } \\
\text { of } \\
\text { Power }\end{array}$ & Responsibility & $\begin{array}{l}\text { Potential link to landscape } \\
\text { planning }\end{array}$ & $\begin{array}{l}\text { Interest in landscape } \\
\text { planning }\end{array}$ \\
\hline \multirow[t]{5}{*}{$\begin{array}{l}\text { National } \\
\text { level }\end{array}$} & National Assembly & + & $\begin{array}{l}\text { - Approve socioeconomic } \\
\text { development plans at the } \\
\text { national level }\end{array}$ & $\begin{array}{l}\text { - Prioritize economic } \\
\text { growth and infrastructure } \\
\text { development }\end{array}$ & No \\
\hline & $\begin{array}{l}\text { Central Government } \\
\text { (Prime Minister) }\end{array}$ & + & $\begin{array}{l}\text { - Prepare socioeconomic } \\
\text { plans and submit them to } \\
\text { National Assembly for } \\
\text { approval } \\
\text { - Ensure sector plans by line } \\
\text { ministries and PPCs are } \\
\text { consistent with national } \\
\text { policy } \\
\text { - Approve general urban } \\
\text { plans }\end{array}$ & $\begin{array}{l}\text { - Prioritize economic } \\
\text { growth and infrastructure } \\
\text { development }\end{array}$ & No \\
\hline & $\begin{array}{l}\text { Ministry of } \\
\text { Planning and } \\
\text { Investment }\end{array}$ & + & $\begin{array}{l}\text { - Coordinate and assist } \\
\text { government in preparing } \\
\text { socioeconomic and sector } \\
\text { development plans }\end{array}$ & $\begin{array}{l}\text { - Promote investment } \\
\text { resources and economic } \\
\text { development }\end{array}$ & No \\
\hline & $\begin{array}{l}\text { Ministry of } \\
\text { Construction }\end{array}$ & + & $\begin{array}{l}\text { - Prepare general urban } \\
\text { plans and submit them to the } \\
\text { government for approval }\end{array}$ & $\begin{array}{l}\text { - Optimize public } \\
\text { investment projects }\end{array}$ & No \\
\hline & $\begin{array}{l}\text { Line Ministries (i.e. } \\
\text { MARD, MONRE) }\end{array}$ & - & $\begin{array}{l}\text { - Prepare master sector } \\
\text { development plans for } \\
\text { separated sectors }\end{array}$ & $\begin{array}{l}\text { - MONRE and MARD have } \\
\text { interests in environmental } \\
\text { issues (including landscape }\end{array}$ & $\begin{array}{l}\text { Support for } \\
\text { environmental issues } \\
\text { and the landscape }\end{array}$ \\
\hline
\end{tabular}




\begin{tabular}{|c|c|c|c|c|c|}
\hline & & & & planning) & planning group \\
\hline \multirow[t]{4}{*}{$\begin{array}{l}\text { Provincial } \\
\text { level }\end{array}$} & $\begin{array}{l}\text { Provincial People's } \\
\text { Committee }\end{array}$ & + & $\begin{array}{l}\text { - Formulate provincial } \\
\text { socioeconomic development } \\
\text { plans }\end{array}$ & $\begin{array}{l}\text { - Prioritize economic and } \\
\text { infrastructure development } \\
\text { at the provincial level }\end{array}$ & No \\
\hline & $\begin{array}{l}\text { Department of } \\
\text { Planning and } \\
\text { Investment }\end{array}$ & - & $\begin{array}{l}\text { - Assist PPC in formulating } \\
\text { provincial socioeconomic } \\
\text { development plans }\end{array}$ & $\begin{array}{l}\text { - Focus on economic } \\
\text { development objectives }\end{array}$ & No \\
\hline & $\begin{array}{l}\text { Department of } \\
\text { Construction }\end{array}$ & - & $\begin{array}{l}\text { - Set up, assess, and submit } \\
\text { the urban plans for approval }\end{array}$ & $\begin{array}{l}\text { - Focus on investment plans } \\
\text { for urban areas }\end{array}$ & No \\
\hline & $\begin{array}{l}\text { Line provincial } \\
\text { Department } \\
\text { (DARD, DONRE) }\end{array}$ & - & $\begin{array}{l}\text { - Prepare provincial-sector } \\
\text { development plans }\end{array}$ & $\begin{array}{l}\text { - DONRE and DARD have } \\
\text { interests in environmental } \\
\text { issues at the provincial } \\
\text { level }\end{array}$ & $\begin{array}{l}\text { Interest in } \\
\text { environmental issues } \\
\text { and the landscape } \\
\text { planning group }\end{array}$ \\
\hline \multirow[t]{3}{*}{$\begin{array}{l}\text { District } \\
\text { level }\end{array}$} & $\begin{array}{l}\text { District People's } \\
\text { Committee }\end{array}$ & - & $\begin{array}{l}\text { - Formulate district } \\
\text { socioeconomic development } \\
\text { plans } \\
\text { - Implement socioeconomic } \\
\text { development plans at the } \\
\text { district level }\end{array}$ & $\begin{array}{l}\text { - Prioritize economic and } \\
\text { infrastructure development } \\
\text { at the district level }\end{array}$ & No \\
\hline & $\begin{array}{l}\text { District Department } \\
\text { of Planning and } \\
\text { Investment }\end{array}$ & - & $\begin{array}{l}\text { - Assist District People's } \\
\text { Committee in preparing } \\
\text { socioeconomic development } \\
\text { plans }\end{array}$ & $\begin{array}{l}\text { - Focus on economic } \\
\text { development objectives }\end{array}$ & No \\
\hline & $\begin{array}{l}\text { District line } \\
\text { departments }\end{array}$ & - & $\begin{array}{l}\text { - Prepare district sector } \\
\text { plans } \\
\text { - Implement district sector } \\
\text { plans at district level }\end{array}$ & $\begin{array}{l}\text { - District DONRE and } \\
\text { DARD have interests in } \\
\text { environmental issues at the } \\
\text { district level }\end{array}$ & $\begin{array}{l}\text { Interest in } \\
\text { environmental } \\
\text { protection and } \\
\text { landscape planning }\end{array}$ \\
\hline
\end{tabular}




\begin{tabular}{|l|l|l|l|l|l|}
\hline $\begin{array}{l}\text { Commune } \\
\text { level }\end{array}$ & $\begin{array}{l}\text { Commune People's } \\
\text { Committee and } \\
\text { subordinated } \\
\text { agencies }\end{array}$ & - & $\begin{array}{l}\text { Implement socioeconomic } \\
\text { plan at commune level }\end{array}$ & $\begin{array}{l}\text { - Focus on economic } \\
\text { development at the } \\
\text { commune level }\end{array}$ & No \\
\hline
\end{tabular}

$1 \quad$ Level of power: high (+); low (-) 


\section{Discussion}

Previous research has shown that although landscape planning is a potential tool for regulating the relationship between humans and their environment, there have been many challenges in conducting landscape planning in practice (Lütz and Bastian, 2002; von Haaren, 2002). In our study, we focused on the aspect of scientific knowledge transfer of landscape planning concept in a developing country by using a new model of scientific knowledge transfer (RIU model). What we share with previous studies is that landscape planning has a scientific basis, focusing on the multi-functionality of the landscape (von Haaren, 2002). Moreover, landscape planning has also been proven to be ecologically relevant (Linehan and Gross, 1998). In this study, we use the RIU model of scientific knowledge transfer to examine the importance of integration sphere in the transmission of landscape planning concept to practice. Particularly, we delve deeply into two important criteria to conduct a professional integration, according to the RIU model, which include the relevance of scientific results to political processes and the support of powerful allies. Our empirical analysis showed that the concept of landscape planning is neither linked to the Vietnamese planning system nor supported by powerful allies. The ECOLIME project failed in its strategy to create an inter-provincial landscape planning group to establish landscape planning in the case study area. This group had no links to the Vietnamese planning system and could not achieve alliances in landscape planning in the Pu Luong Cuc Phuong area. As a result, the landscape planning group as well as landscape planning activities do not persist in the Pu Luong Cuc Phuong area. Thus, the application of the RIU model contributed to our understanding of the reasons for the failure of the ECOLIME project to transfer the innovative concept of landscape planning to an important conservation area of Vietnam. Based on the results of our study, we confirm the idea of STS that scientific knowledge transfer is only possible through bi-directional actions from science and practice (Braun and Kropp, 2010; Lidskog and Sundqvist, 2015; Sismondo, 2010). With the application of RIU model, we take additional steps to analyze these boundary spanning activities identified by the STS studies, which are called "integration" in the RIU model. Our analysis has shown that an increased emphasis should be put on the relevance of scientific knowledge to political processes and the support of powerful allies to produce a successful knowledge transfer in practice.

From a perspective of fit and scale, we endorse the value of scale in finding solutions for environmental governance (Albert et al, 2017; Moss and Newig, 2010). Many works have suggested that adequate multi-level governance arrangements should be explored to improve the effectiveness of environmental policy through adapting the scale of governance to that of environmental problems (Albert et al., 2017; Newig and Fritsch, 2009). Our study reveals that the ECOLIME project did not succeed to solve the mismatch between the scale of the politicaladministrative planning system and the ecological scale in Pu Luong Cuc Phuong area. Based on our research results, we suggest rethinking the presumption that adapting the scale of the political-administrative system to the scale of the ecosystem will solve the problems of misfit. In terms of achieving the spatial fit, it is often difficult to define the territorial boundaries of a natural resource, because of its complex interdependence with broader ecosystems (Moss, 2012; Young, 2005). As Fitzsimmons (1999) indicates, there are no generally accepted rules for ascribing boundaries to ecosystems. In addition, there is controversy over what constitutes an 
appropriate size for a landscape planning unit (Selman, 2006). Some researchers have suggested that an area of several square kilometers is sufficient, while others have indicated that the region is the appropriate level (Selman, 2006). Furthermore, the understanding of an appropriate scale for the governance of environmental problems can differ among the different stakeholders involved (Juerges and Newig, 2015). Thus, opinions on the appropriate size of an ecosystem can differ and be context-dependent. This opens up decision space to choose between alternative ecosystem scales for landscape planning. Previous literature has also shown that giving the responsibility for solving cross-boundary problems to the higher level might be a common way of solving scale problems (Albert et al., 2017). However, there has been an extensive body of literature addressing the issue of scale under the banner of the 'politics of scale', indicating that scale is socially produced and negotiated between interests in political processes (Engel-Di Mauro, 2009; Rangan and Kull, 2009; Sayre, 2009). Thus, social construction of scale is very complex. Our research results have indicated that an increasing attention should be put into the understanding of political processes to find the compatible scale between ecosystem properties and institutional arrangements in particular countries. In the context of Vietnam, it is not easy to change the political process.

17 Thus, we suggest that the political process is analyzed first and that the ecosystem scale that fits

18 into the political process is then determined. In Vietnam, it is necessary to make small and incremental steps toward the desirable implementation of landscape planning. Future projects could consider implementing landscape planning within smaller ecological systems (e.g. ranging over only one province) because it might be easier to link landscape planning to the provincial planning system and achieve support from powerful provincial allies. If landscape planning elements are successfully implemented in one province, they may be expanded more successfully to other provinces. When the inter-province cooperation is improved, landscape planning may be integrated into the plans of various provinces or particular regions. This will require a sustainable funding resource within a long period (e.g. 10 years). However, it will be a significant challenge for conservation and development projects like the ECOLIME project. In addition, the formal concept of landscape planning goes beyond basic coordination. Thus, improvement in coordination is not sufficient to successfully implement the idea of landscape planning in developing countries like Vietnam. Instead of establishing independent landscape planning, we recommend that landscape planning elements should be integrated into a part of Vietnam's existing planning system (e.g. infrastructure planning). In addition, making use of the informal interests of powerful actors in promoting landscape planning elements could be an additional strategy. For example, in the context of Vietnam, the central government would welcome landscape planning if it would legitimize reducing budgets for specific provinces. This could help landscape planning to obtain the support of powerful actors. In the case of successful knowledge transfer, landscape planning may contribute to the improvement of fit in environmental governance.

The existing literature on politic of scale characterized scale as fluid and fixed (Brenner, 2001; Swyngedouw, 1997b) and being constantly defined and redefined in processes of re-scaling, which created a need for adaptation among the involved regions (Brown and Purcell, 2005; Green, 2016; Moss and Newig, 2010). This may be a window of opportunity opened in search of a compatible scale since political struggle is an ongoing process. In the case of Vietnam, the issue of a new planning law in 2017, entering into force in 2019, may provide a good opportunity to conduct landscape planning in the context of Vietnam. Further research on this issue is needed. Based on our research results, we suggest that scientists and planners should pay 
attention to both political processes and ecosystem properties to find appropriate solutions for solving scale mismatches in environmental governance.

\section{3}

4

5

\section{Conclusions}

The results of this study showed that the transmission of innovative scientific knowledge into practice is far from an easy task. Although the ECOLIME project involved many considerable efforts to transfer the idea of landscape planning to the conservation in the Pu Luong Cuc Phuong area, it ultimately did not succeed. Our analysis of the project, based on the RIU model as an analytical framework, showed that the reasons for the project's failure in landscape planning activities stemmed from weak integration which derives from a lack of both a link to the Vietnamese political process and support from powerful Vietnamese actors. The ECOLIME project failed to establish a link between the scientific concept of landscape planning and the existing political process, and lacked permanent support of the powerful allies. The establishment of a landscape planning group was not a sufficient strategy for establishing such links and winning powerful allies. From a perspective of scientific knowledge transfer, our study has shown that a better understanding should be put into integration of innovative concepts in the scientific knowledge transfer process, creating a link to political process and winning powerful allies. Therefore, improving awareness of the need to integrate scientific concepts into the political process could help internationally funded projects such as the ECOLIME project be more successful in practice.

In terms of scale and political ecology, the ECOLIME project did not succeed to solve the mismatch between an inter-provincial limestone ecosystem and the existing political system of Vietnam through the establishment of a landscape planning group among three provinces. Based on our results, we argue that the political process has to be taken as seriously as ecological properties in environmental governance. In general, it is not easy to change a political process to adapt the scale of relevant institutions to attributes of the ecosystem. This has been confirmed by Thus, our study suggests looking at the political process and at the properties

natural and social scientists in identifying various options for solving scale mismatches that are compatible with the political system and the interests of powerful actors. In addition, the interests and power relations of local actors have to be taken into account in internationally funded projects that seek to establish landscape planning in developing countries. While this study focused on a case of Vietnam, the lessons learned regarding the better understanding of political system and the effective strategies of winning powerful allies can be transferred to landscape planning practice in developing countries where it is facing mismatches between the scale of the ecosystem and the institutional system.

Taken together, our study emphasizes the importance of professional integration in achieving the successful transfer of scientific concepts into practice. Future research is needed to examine strategies for identifying governance scales that match the ecosystem and the political system. 
1 Appendix: List of interviewees

2

\begin{tabular}{|c|c|}
\hline Interview & Affiliation \\
\hline 1 & Manager of ECOLIME project \\
\hline 2 & Coordinator of landscape planning, FFI Vietnam \\
\hline 3 & Manager, FFI Vietnam (by email) \\
\hline 4 & Researcher, Institute of Geology and Mineral Resources \\
\hline 5 & Researcher, Institute of Geology and Mineral Resources \\
\hline 6 & Researcher, Ethnology Institute \\
\hline 7 & Researcher, Ethnology Institute \\
\hline 8 & Officer, FFI Vietnam \\
\hline 9 & Officer, FFI Vietnam \\
\hline 10 & Director, Hoa Binh FPD \\
\hline 11 & Director, PLNR \\
\hline 12 & Former Director, PLNR \\
\hline 13 & Director, NSNLNR \\
\hline 14 & Researcher, UN-Habitat Vietnam (by email) \\
\hline 15 & Director of Nature Conservation Department \\
\hline 16 & Forest ranger, PLNR \\
\hline 17 & Forest ranger, PLNR \\
\hline 18 & Forest ranger, PLNR \\
\hline 19 & Forest ranger, NSNLNR \\
\hline 20 & Forest ranger, NSNLNR \\
\hline 21 & Forest ranger, Cuc Phuong National Park \\
\hline 22 & Forest ranger, Cuc Phuong National Park \\
\hline
\end{tabular}




\begin{tabular}{|l|l|}
\hline 23 & Officer, Ministry of Planning and Investment \\
\hline 24 & Officer, Ministry of Planning and Investment \\
\hline 25 & Officer, Department of Planning and Investment \\
\hline 26 & Officer, Department of Planning and Investment \\
\hline 27 & $\begin{array}{l}\text { Researcher, Vietnam Institute for Development Strategies, } \\
\text { Ministry of Planning and Investment }\end{array}$ \\
\hline 28 & $\begin{array}{l}\text { Officer, Planning - Architecture Department, Ministry of } \\
\text { Construction }\end{array}$ \\
\hline
\end{tabular}

1

2

3 Notes:

$4 \quad$ FFI: Fauna and Flora International

5 UN-Habitat: United Nations Human Settlements Programme

6 PLNR: Pu Luong Nature Reserve

7 NSNLNR: Ngoc Son Ngo Luong Nature reserve

8 FPD: Forest Protection Department

\section{References}

12 Albert C, Von Haaren C, Othengrafen F, Krätzig S and Saathoff W (2017) Scaling policy 13 conflicts in ecosystem services governance: A Framework for Spatial Analysis. Journal of $14 \quad$ Environmental Policy \& Planning 19(5): 574-592.

15 Bass S, Annandale D, Van Binh P, Dong TP, Nam HA, Le Thi Kien Oanh MP and Van Phuc N 16 (2009) Integrating environment and development in Viet Nam. Achievements, challenges and next steps. Paper resulting from the Vietnam Environmental Mainstreaming "Lessons Learned Review" of March.

Bennett AF (2003) Linkages in the Landscape: The Role of Corridors and Connectivity in Wildlife Conservation. Gland, Switzerland, and Cambridge, UK: IUCN.

BfN (2002) Landscape Planning for Sustainable Municipal Development. German Federal Agency for Nature Conservation (Bundesamt für Naturschutz, BfN).

23 Blaikie P and Brookfield H (1987) Land degradation and society. New York: Methuen. 
Bodin Ö and Norberg J (2005) Information network topologies for enhanced local adaptive management. Environmental management 35(2): 175-193.

Böcher M and Krott M (2014) The RIU model as an analytical framework for scientific

Chidumayo EN (2002) Changes in miombo woodland structure under different land tenure and knowledge transfer: The case of the "decision support system forest and climate change." Biodiversity and Conservation 23(14): 3641-3656.

Böcher M (2016) How does science-based policy advice matter in policy making? The RIU model as a framework for analyzing and explaining processes of scientific knowledge transfer. Forest Policy Economics 68: 65-72.

Böcher M and Krott M (2016) Science Makes the World Go Round: Successful Scientific Knowledge Transfer for the Environment. Basel, Switzerland: Springer.

Braun K and Kropp C (2010) Beyond speaking truth? Institutional responses to uncertainty in scientific governance. Science, Technology, \& Human Values 35(6): 771 - 782.

Brenner N (2001) The limits to scale? Methodological reflections on scalar structuration. Progress in Human Geography 25(4): 591-614.

Brown JC and Purcell M (2005) There is nothing inherent about scale: political ecology, the local trap, and the politics of development in the Brazilian Amazon. Geoforum 36(5): 607624.

Bryant RL (2015) The international handbook of political ecology. UK: Edward Elgar Publishing.

Cleveland C, Costanza R, Eggertsson T, Fortmann L, Low B, McKean M and Young O (1996) A framework for modeling the linkages between ecosystems and human systems. Beijer Discussion Paper Series No. 76 Sweden: Beijer Institute of Ecological Economics.

Cumming GS, Cumming DH and Redman CL (2006) Scale mismatches in social-ecological systems: causes, consequences, and solutions. Ecology and society 11(1).

De Groot R (2006) Function-analysis and valuation as a tool to assess land use conflicts in planning for sustainable, multi-functional landscapes. Landscape and urban planning 75 (34): 175-186.

Dharmawan B, Böcher M and Krott M (2016) The failure of the mangrove conservation plan in Indonesia: Weak research and an ignorance of grassroots politics. Ocean Coastal Management 130: 250-259. 

1 Dharmawan B, Böcher M and Krott M (2017) Endangered Mangroves in Segara Anakan, Indonesia: Effective and Failed Problem-Solving Policy Advice. Environmental management, 60(3), 409-421.
4
Do Thi H, Krott M and Böcher M (2017) The success of scientific support for biodiversity conservation policy: The case of Ngoc Son Ngo Luong nature reserve in Vietnam. Journal for Nature Conservation, 38, 3-10.
Do Thi H, Krott M, Böcher M and Juerges N (2017) Toward successful implementation of conservation research: A case study from Vietnam. Ambio, 1-14.

Engel-Di Mauro S (2009) Seeing the local in the global: Political ecologies, world-systems, and the question of scale. Geoforum 40(1): 116-125.

FFI (Fauna and Flora International) (2002) Detailed Proposal for Development of the Pu LuongCuc Phuong Limestone Landscape Conservation Project. Vietnam Country Program, Hanoi.

Fitzsimmons AK (1999) Defending Illusions: Federal Protection of Ecosystems. Maryland, USA: Rowman \& Littlefield.

Folke C, Pritchard L Jr, Berkes F, Colding J and Svedin U (2007) The problem of fit between ecosystems and institutions: Ten years later. Ecology and Society $12(1-38)$.

FPD (Forest Protection Department) Thanh Hoa (2006) Report on activities of landscape planning group in 2006 and planning for 2007. Thanh Hoa, Vietnam.

FPD (Forest Protection Department) Hoa Binh (2007) Report on activities of landscape planning group in 2007 and planning for 2008. Hoa Binh, Vietnam.

Frost P, Campbell B, Medina G and Usongo L (2006) Landscape -scale approaches for integrated natural resource management in tropical forest landscapes. Ecology and Society, 11(2).

Furey N and Infield M (2007) Conservation of Karst Limestone Ecosystems in Vietnam: Challenges and Opportunities. Chinese Tropical Forestry 35(S1): 57-67.

Galaz V, Olsson P, Hahn T, Folke C and Svedin U (2008) The problem of fit among biophysical systems, environmental and resource regimes, and broader governance systems: Insights and emerging challenges. In: Institutions and Environmental Change: Principal Findings, Applications, and Research Frontiers. Cambridge, USA: The MIT Press, pp.147-182.

Gibbs D, Jonas A and While A (2002) Changing governance structures and the environment: Economy-environment relations at the local and regional scales. Journal of Environmental Policy and Planning 4(2): 123-138. 
Gibson CC, Ostrom E and Ahn TK (2000) The concept of scale and the human dimensions of global change: a survey. Ecological Economics 32(2): 217-239.

Green KE (2016) A political ecology of scaling: Struggles over power, land and authority.

Geoforum 74: 88-97.

Heim J and Böcher M (2016) CITES and science: Using the RIU model to analyze institutionalized scientific policy advice in Germany for the case of ivory trade. Journal of International Wildlife Law and Policy 19(2): 159-175.

Hooghe L and Marks G (2003) Unraveling the central state, but how? Types of multi-

Hermans L (2008) Exploring the promise of actor analysis for environmental policy analysis: lessons from four cases in water resources management. Ecology and Society 13(1).

Huong NH (2006) Landscape Perspective of Pu Luong Cuc Phuong Limestone Range, Vietnam. levgovernance. American Political Science Review 97(2): 233-243.

Infield M (2004) Options for Landscape Level Planning for the Pu Luong Cuc Phuong Journal of Vietnamese Social Sciences 4: 55-68.

\section{Landscape. Consultant paper. FFI Vietnam, Hanoi, Vietnam.}

Juerges N and Newig J (2015) What role for frames in scalar conflicts? Land Use Policy 49: $426-434$.

Kelly P (1999) The geographies and politics of globalization. Progress in Human Geography 23(3): 379-400.

Lawrie W (2000) An Overview of Urban Planning and Management in Vietnam. Report, Hansen Partnership International, Hanoi.

Lee KN (1993) Greed, scale mismatch, and learning. Ecological Applications 4: 560-564.

Leitner H and Miller B (2007) Scale and the limitations of ontological debate: a commentary on Marston, Jones and Woodward. Transactions of the Institute of British Geographers 32(1): 116-125.

Lidskog R and Sundqvist G (2015) When does science matter? International relations meets science and technology studies. Global Environmental Politics 15(1): 1-20.

Linehan JR and Gross M (1998) Back to the future, back to basics: The social ecology of landscapes and the future of landscape planning. Landscape and Urban Planning 42(2): $207-223$. 
1 Lütz M and Bastian O (2002) Implementation of landscape planning and nature conservation in the agricultural landscape - a case study from Saxony. Agriculture, ecosystems \& environment 92 (2-3): 159-170.

Luz F (2000) Participatory landscape ecology-a basis for acceptance and implementation.

Marston SA (2000) The social construction of scale. Progress in human geography 24(2): 219Landscape and urban planning 50(1-3): 157-166.

8 Matsumura S, Hoa NT and Kien TT (2017) New Approach and Issues for the Urban Planning

Meadowcroft J (2002) Politics and scale: Some implications for environmental System in Vietnam. Urban and Regional Planning Review 4: 58-70.

Moss T and Newig J (2010) Multilevel water governance and problems of scale: Setting the governance. Landscape and Urban Planning 61(2): 169-179.

Moss T (2012) Spatial fit, from panacea to practice: Implementing the EU Water Framework stage for a broader debate. Journal of Environmental Management 46(1): 1-6.

Nagasaka K, Böcher M and Krott M (2016a) Science-policy interaction: The case of the forest

MPI (2000) Description of the Present Planning System. Provincial Pilot Project. Internal Report for Project VIE/97/007 “Environmental Issues in Investment Planning”. Hanoi: Ministry of Investment and Planning (MPI).

Nagasaka K, Böcher M and Krott M (2016b) Are forest researchers only scientists? Case studies on the roles of researchers in Japanese and Swedish forest policy processes. Forest Policy and Economics 70: 147-154.

Neumann RP (2009) Political ecology: theorizing scale. Progress in Human Geography 33(3): 398-406.

Neuman WL (2005) Social Research Methods: Quantitative and Qualitative Approaches. 6th Ed. London: Allyn and Bacon.

28 Newig J and Fritsch O (2009) Environmental governance: participatory, multi-level-and

29 effective?. Environmental policy and governance 19(3): 197-214.

30 Overjero J (2005) Landscape Level Planning in Vietnam: A review Issue Presented by a Case Mountain Range. Consultation Report, FFI Vietnam. Hanoi, Vietnam. 
Padt FJ and Westerink J (2012) Addressing scale in open space preservation: learning from the Hague region in the Netherlands. Tijdschrift voor economische en sociale geografie 103(5): 601-614.

Pierre M (2000) Obstacles, Barriers and Opportunities for Reform. Discussion Paper for Project VIE/ 97/007 “Environmental Issues in Investment Planning”. Hanoi: Ministry of Planning and Investment (MPI), SDC and UNDP.

Poppe M (2004) Integrated Watershed Management Planning in the Lower Mekong Basin. MRC-GTZ Cooperation Program, MRC, Vientiane, Laos PDR.

9 Quang N and Kammeier HD (2002) Changes in the political economy of Vietnam and their 10 impacts on the built environment of Hanoi. Cities 19(6): 373-388.

Quang N (2002) Changes in the political Economy of Vietnam and their impact in the built environment: A study of Hanoi city. PhD Thesis, Asia Institute of Technology, Thailand.

Quang N (2003) Review of existing planning system: Obstacles and strategies moving toward innovative planning approaches. A case study of Ha Tinh Planning System. GTZ, PDPHaTinh.

Rangan H and Kull CA (2009) What makes ecologypolitical?: rethinking scale in political

Reed J, van Vianen J, Barlow J and Sunderland T (2017) Have integrated landscape approaches reconciled societal and environmental issues in the tropics? Land Use Policy 63: 481-492.

\section{Rega C (Ed.) (2014) Landscape Planning and Rural Development: Key Issues and Options} Towards Integration. New York and London: Springer.

Robbins P (2011). Political ecology: A critical introduction. UK: John Wiley \& Sons.

Sayre NF (2009) Scale. In: Castree N, Demeritt D, Liverman D and Rhoads B (eds) $A$ Companion to Environmental Geography. Chichester: Wiley-Blackwell, pp. 95-108.

25 Selman P (2006) Planning at the Landscape Scale. London and New York: Routledge.

Sekhar NU (2005) Integrated coastal zone management in Vietnam: Present potentials and future challenges. Ocean Coastal Management 48(9): 813-827.

Schmeer K (1999) Stakeholder analysis guidelines. Policy Toolkit for Strengthening Health

30 Schneider DC (2001) The Rise of the Concept of Scale in Ecology: The concept of scale is 31 evolving from verbal expression to quantitative expression. AIBS Bulletin 51(7): 545-553. 
Sismondo S (2010) An introduction to science and technology studies. Chichester: WileyBlackwell.

3 Stevanov M, Böcher M, Krott M, Krajter S, Vuletic D and Orlovic S (2013). The research, 4 integration, and utilization (RIU) model as an analytical framework for the professionalization of departmental research organizations: Case studies of publicly funded forest research institutes in Serbia and Croatia. Forest Policy and Economics 37: 20-28.

Swyngedouw E (1997a) Power, nature, and the city. The conquest of water and the political ecology of urbanization in Guayaquil, Ecuador: 1880-1990. Environment and planning A 29(2): 311-332.

Swyngedouw E (1997b) Neither global nor local: glocalization and the politics of scale. In: Cox

Tang L, Li A and Shao G (2011) Landscape-level forest ecosystem conservation on Changbai Mountain, China and North Korea (DPRK). Mountain Research and Development 31(2): $169-175$.

Valencia-Sandoval C, Flanders DN and Kozak RA (2010) Participatory landscape planning and sustainable community development: Methodological observations from a case study in rural Mexico. Landscape and Urban Planning 94(1): 63-70.

Vaníček V (1974) Definition of landscape planning. Landscape Planning 1: 105.

Vater EU (2001) Structure of the Vietnamese Planning System. Internal Report, PDP Ha Tinh, Ha Tinh.

Vermeulen J and Whitten T (1999) Biodiversity and cultural property in the management of limestone resources. World Bank, Washington, DC, pp.120.

von Haaren C (2002) Landscape planning facing the challenge of the development of cultural landscapes. Landscape and Urban Planning 60(2): 73-80.

von Haaren C, Galler C and Ott S (2008) Landscape Planning: The Basis of Sustainable Landscape Development. BFN Federal Agency for Nature Conservation.

Vroom MJ (1976) Landscape Planning: A Cooperative Effort; A Professional Activity. Landscape Planning (Netherlands).

Vu MTT (2008) Comprehensive planning: Does it work? Experiences from Vietnam. Journal of Administration and Governance 3(2):17-24.

Vu MTT and McIntyre-Mills JJ (2008) Towards local government strategic planning in Vietnam: Systemic governance interventions for sustainability. Asian Journal of Social Science 4(2): 91-105. 
1 Watts M (2000) Political ecology. In: Barnes T and Sheppard E (eds) A Companion to Economic 2 Geography. Oxford: Blackwell Publishing, pp. 257-275.

3 Young OR (2002) The Institutional Dimensions of Environmental Change: Fit, Interplay, and $4 \quad$ Scale. Cambridge, MA: MIT Press.

5 Young OR (2005) Science Plan. Institutional Dimensions of Global environmental Change.

6 IHDP Report No. 16. International Human Dimensions Programme. Bonn, Germany.

7 Ziker JP (2003) Assigned territories, family/clan/communal holdings, and common-pool

8 resources in the Taimyr autonomous region, northern Russia. Human Ecology 31(3): 3319368.

10 Zimmerer KS and Bassett TJ (2003) Political ecology: an integrative approach to geography 11 and environment-development studies. New York: Guilford Press 


\section{CURRICULUM VITAE}

1. NAME Do, Thi Huong SEX: Female

2. DATE OF BIRTH 19 February 1984

3. PLACE OF BIRTH Dien Bien, Vietnam

4. NATIONALITY Vietnamese

5. OCCUPATION Lecturer, researcher

6. PERSONAL Xuan Mai Town, Chuong My District, Hanoi, Vietnam ADDRESS

7. TELEPHONE NO. (+49) 15905325275 (Germany) (+84)989190284 (Vietnam)

8. E-MAIL ADDRESS dohuongnlkh@gmail.com or tdo1@gwdg.de

9. EDUCATION

2014 - 2018: Ph.D. candidate in Chair Group of Forest and Nature Conservation Policy, George-August University of Göttingen, Germany.

2008 - 2010: MSC in Forestry Department, Vietnam National University of Forestry, Viet Nam.

2002 - 2006: BSC in Social Forestry Department, Vietnam National University of Forestry, Vietnam.

1990 - 2001: Pupil in Primary, secondary and high school, Dien Bien, Vietnam.

10. SCIENTIFIC INTERESTS: Biodiversity conservation policy, forest policy, scientific knowledge transfer, community forestry, natural resource management.

11 EMPLOYMENT

2007 - 2016: Lecturer at Department of Agroforestry, Silviculture Faculty, Vietnam National University of Vietnam

2016 - present: Lecturer at College of Land Management and Rural Development, Vietnam National University of Vietnam

\section{PUBLICATIONS}

Do, T. H., Krott, M., Juerges N. \& Böcher, M. (2018). Red lists in conservation science - policy interfaces: A case study from Vietnam. Biological Conservation 226, 101-110. Do Thi, H., Krott, M., Böcher, M., \& Juerges, N. (2018). Toward successful implementation of conservation research: A case study from Vietnam. Ambio, 47(5), 608-621. 
Do, T. H., Krott, M., \& Böcher, M. (2017). The success of scientific support for biodiversity conservation policy: The case of Ngoc Son Ngo Luong nature reserve in Vietnam. Journal for Nature Conservation, 38, 3-10.

Do Thi, H., Juerges N., Krott, M. \& Böcher, M. (2018) Can Landscape planning solve scale mismatches in environmental governance? Under revision in Environment and Planning E.

Do Thi, H., Krott, M., Böcher, M., \& Juerges, N. (2018). Combining biodiversity conservation with poverty alleviation: Scientific strategies and options for integration. $6^{\text {th }}$ international conference on sustainable development, September $12-13,2018$. Rome, Italy.

Do, T. H., Böcher, M. \& Krott, M. (2016). Science - based support for Biodiversity Conservation Policy of Vietnam: A case study of Ngoc Son Ngo Luong Nature Reserve. Tropentag, September 18-21, 2016 Vienna, Austria.

Do, T. H., Ngai Ba Nguyen, Duc Le. 2013. The contribution of Forest Resources to rural livelihood of local community in Protected Areas of Vietnam - Case of Thuong Tien Nature Reserve, Kim Boi District, Hoa Binh Province. Tropentag 2013, September 17-19, 2013, Stuttgart-Hohenheim, Germany.

Dang Tung Hoa, Do, T. H, 2012. Research on the dependence of local community on forest resources at Thuong Tien Nature Reserve in Kim Boi District - Hoa Binh Province. Journal of Agriculture and Rural Development, Hanoi.

Vu Van Can, Do, T. H., Vu Quoc Phong, Pham Thi Tam. 2012. Report on the indigenous knowledge in the management, protection, development, and use of nontimber forest products of five ethnic groups: Muong, Tay, Dao, Thai, Hmong in the mountains of northern Vietnam. Program CASI III sponsored by CARE Vietnam. 